\title{
Microcredit to women and its contribution to production and household food security
}




\section{Thesis committee}

\section{Promotor}

Prof. Dr G. Antonides

Professor of Economics of Consumers and Households

Wageningen University \& Research

\section{Co-promotor}

Dr J.A.C. van Ophem

Associate professor, Economics of Consumers and Households Group

Wageningen University \& Research

\section{Other members}

Prof. Dr A. Niehof, Wageningen University \& Research

Prof. Dr E.H. Bulte, Wageningen University \& Research

Prof. Dr W.J.M. Heijman, Wageningen University \& Research

Prof. Dr C. de Graaf, Wageningen University \& Research

This research was conducted under the auspices of the Wageningen School of Social Sciences (WASS) 


\section{Microcredit to women and its contribution to production and household food security}

Namayengo Mayanja Muyonga Faith

\section{Thesis}

submitted in fulfilment of the requirements for the degree of doctor at Wageningen University

by the authority of the Rector Magnificus, Prof. Dr A.P.J. Mol, in the presence of the Thesis Committee appointed by the Academic Board to be defended in public on Monday 8 May 2017 at 11 a.m. in the Aula. 
Namayengo Mayanja Muyonga Faith

Microcredit to women and its contribution to production and household food security 235 pages.

$\mathrm{PhD}$ thesis, Wageningen University, Wageningen, the Netherlands (2017)

With references, with summary in English

ISBN: 978-94-6343-110-1

DOI: $10.18174 / 407189$ 


\section{Table of Contents}

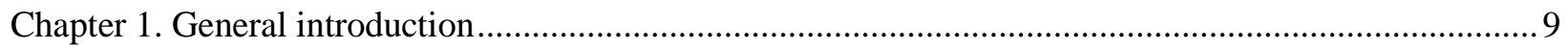

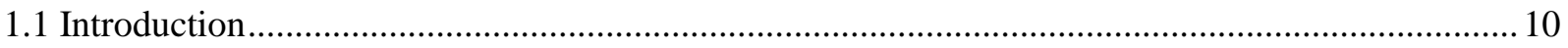

1.2 Prevalence, causes and manifestations of food insecurity ....................................................... 13

1.3 Poverty, food insecurity and agricultural production............................................................... 15

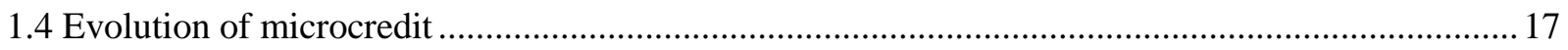

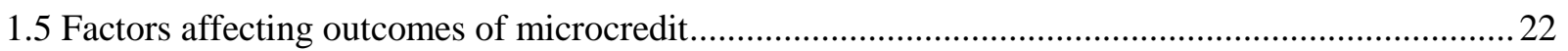

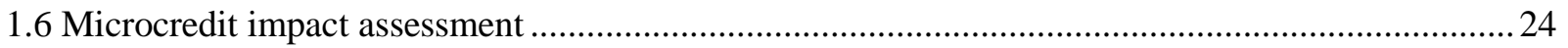

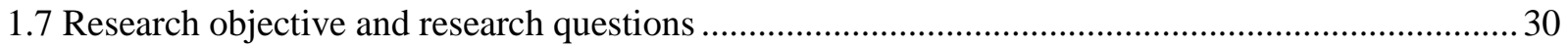

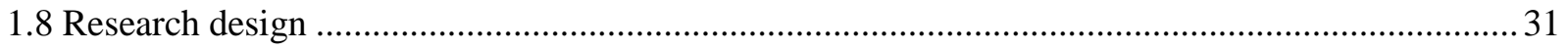

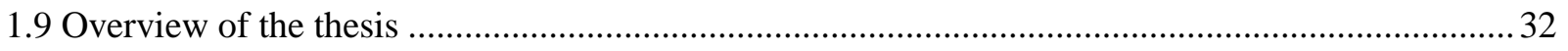

Chapter 2. Women and microcredit in rural agrarian households of Uganda: Match or mismatch between

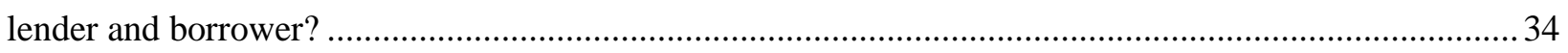

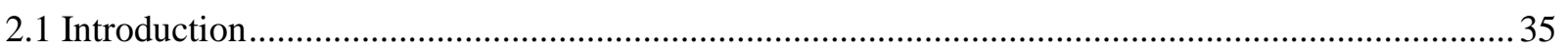

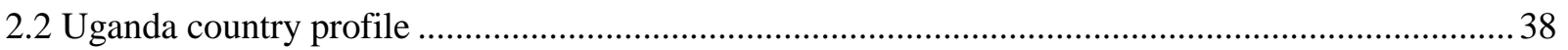

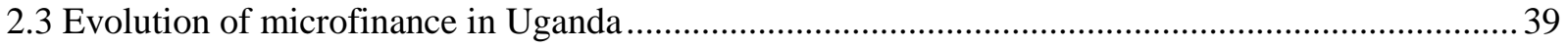

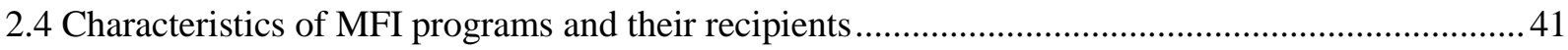

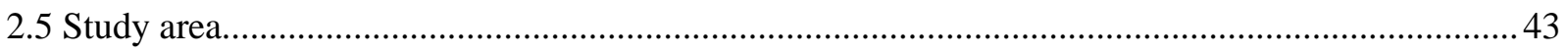

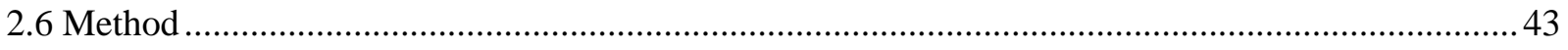

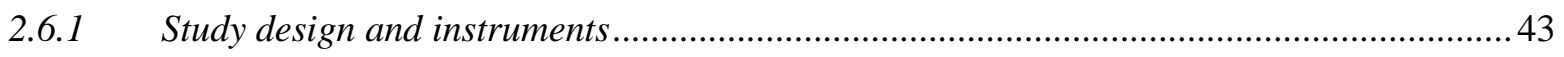

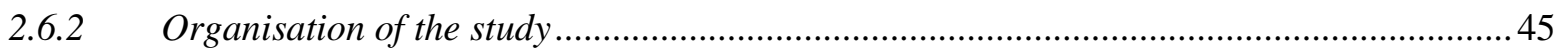

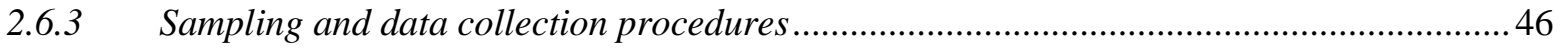

2.6.4 Data operationalisation, processing and analysis ....................................................... 48

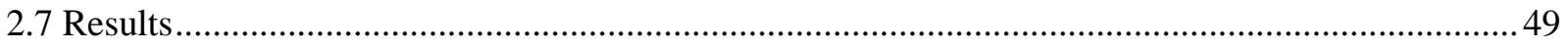

2.7.1 Borrowing information and characteristics of the BRAC microfinance program .............. 49

2.7.2 Socio-demographic and personality characteristics of current $(O B)$ and in-coming $(N B)$

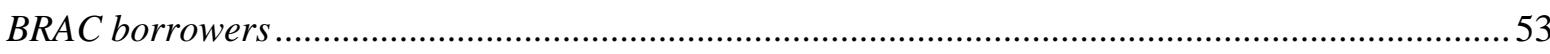




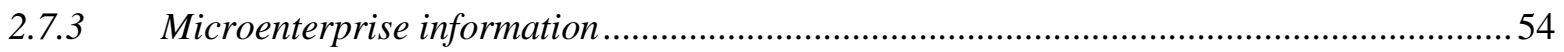

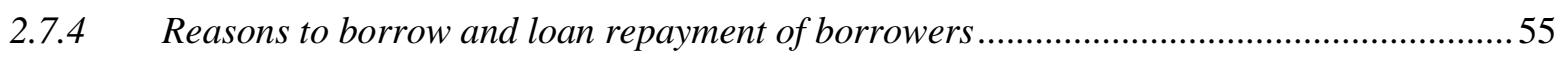

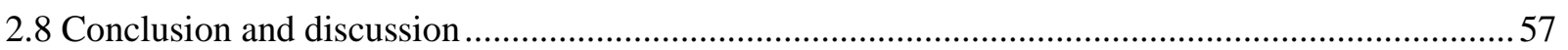

Chapter 3. Does microcredit improve performance of women-run non-farm microenterprises? ...............63

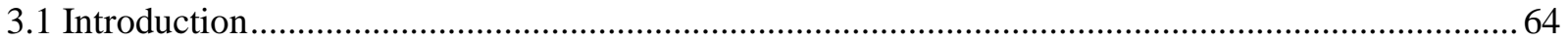

3.2 Theoretical framework for relation between microcredit and microenterprise development ...........69

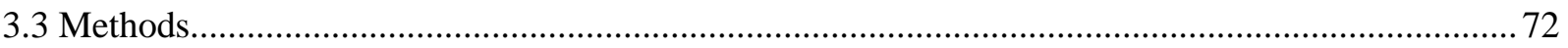

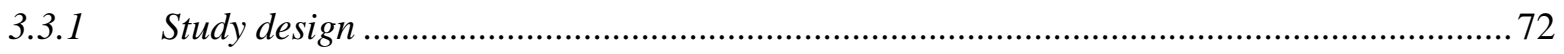

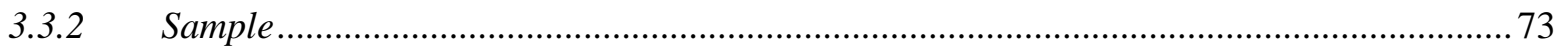

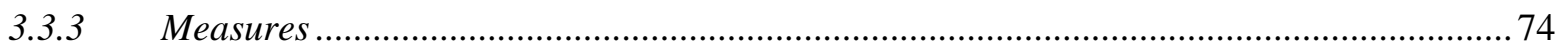

3.3.4 Residual heterogeneity in the data in cross-sectional sample and in the panel study ........ 76

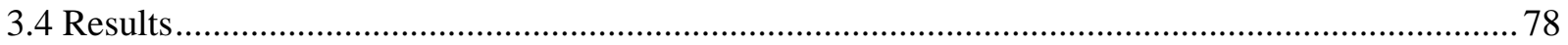

3.4.1 Cross-sectional OB/NB comparison results................................................................... 79

3.4.2 FGD results about borrowing and non-farm ME performance …................................... 84

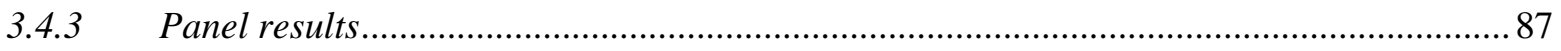

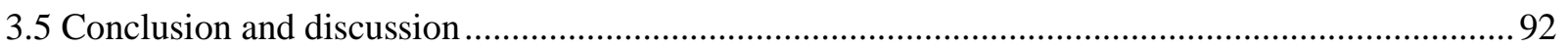

Chapter 4. Microcredit and agricultural production among resource-poor rural women (Quasiexperimental comparison of current and in-coming borrowers in Uganda) ...........................................98

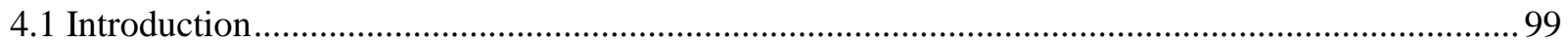

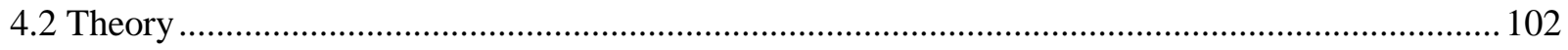

4.2.1 Women and peasant agricultural production ….......................................................... 102

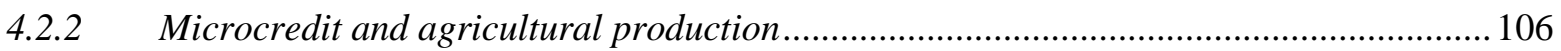

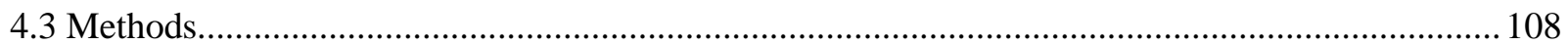

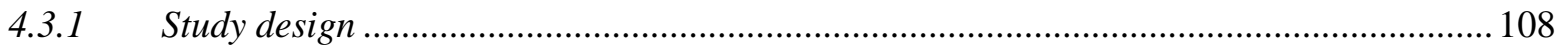

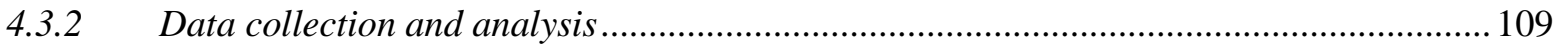

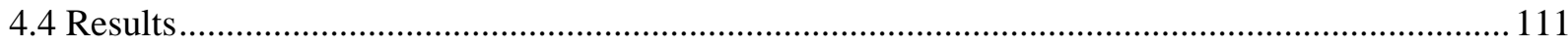

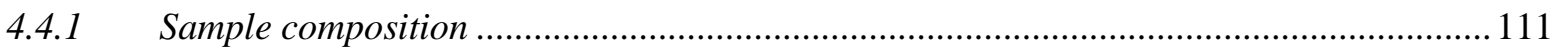


4.4.2 Characteristics of respondents with agriculture-related MEs ...................................... 111

4.4.3 Crop production information for current and in-coming borrowers ................................ 112

4.4.4 Effects of microcredit on expenditure and output for crop production............................. 113

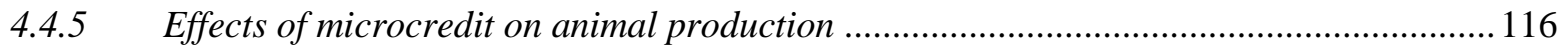

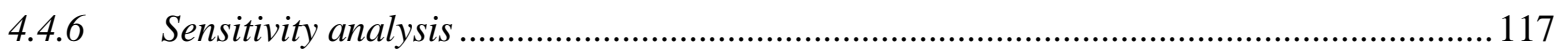

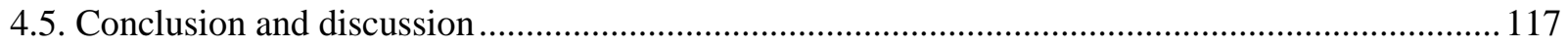

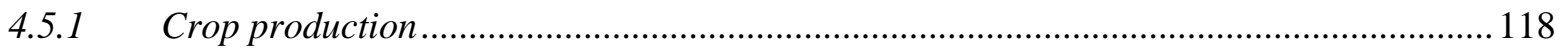

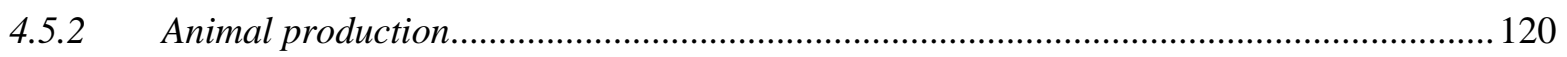

Chapter 5. Microcredit and food security: Evidence from peasant communities in Uganda................... 124

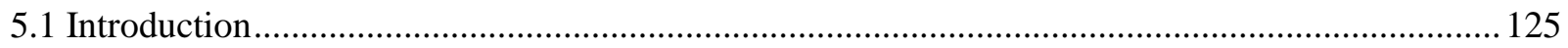

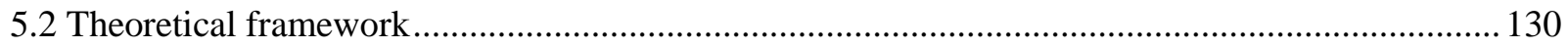

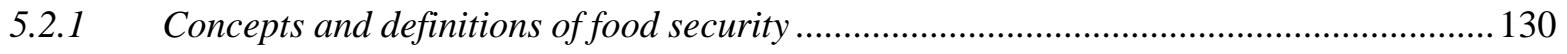

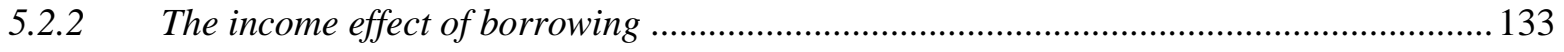

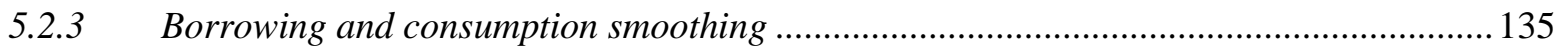

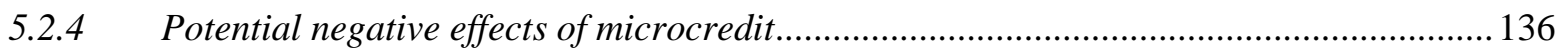

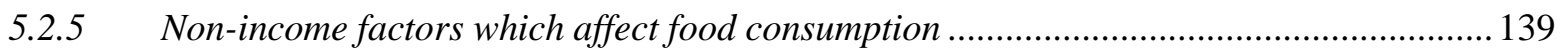

5.2.6 Available evidence on microcredit and food security .................................................. 140

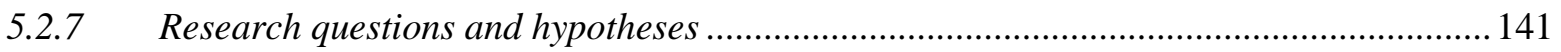

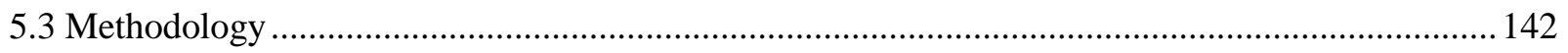

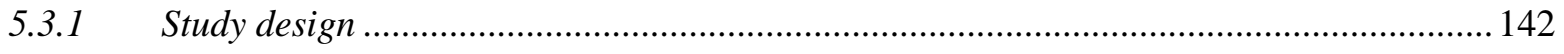

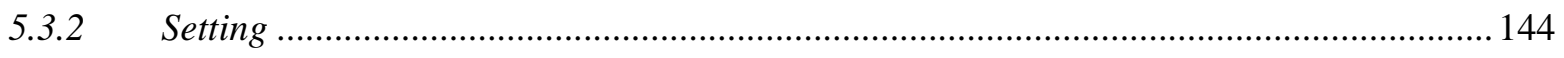

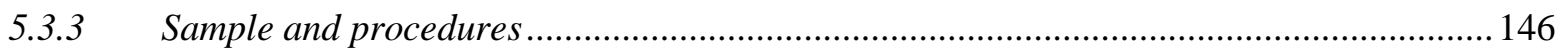

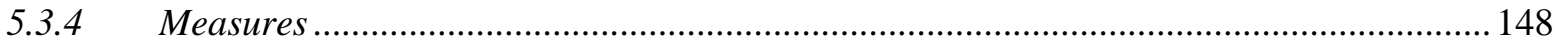

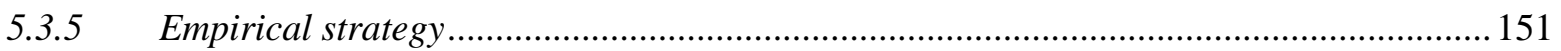

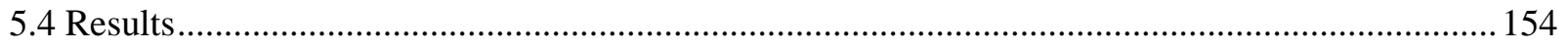

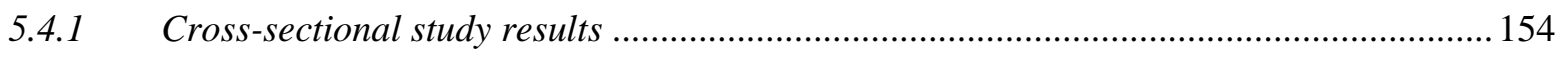

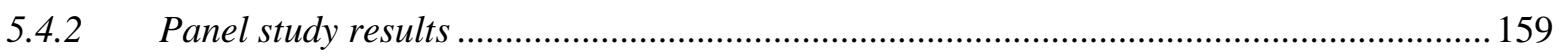




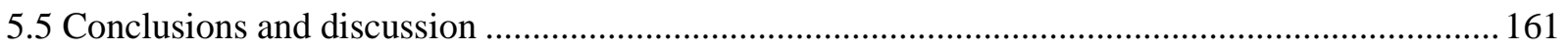

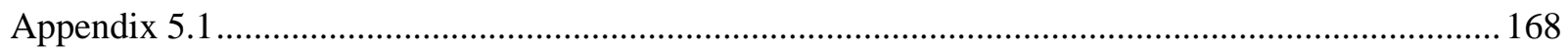

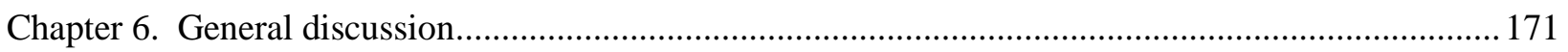

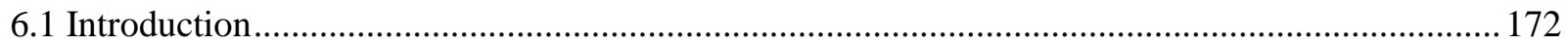

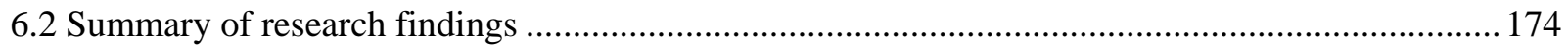

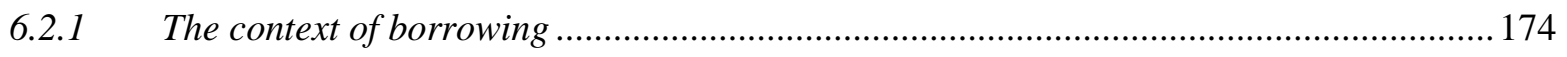

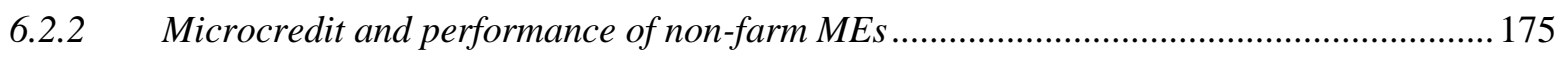

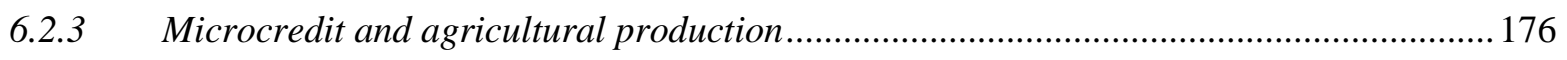

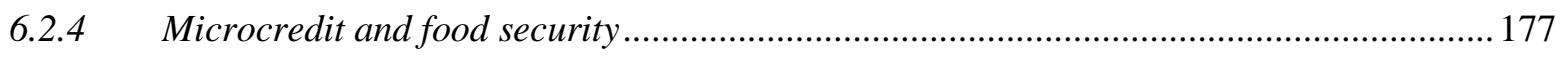

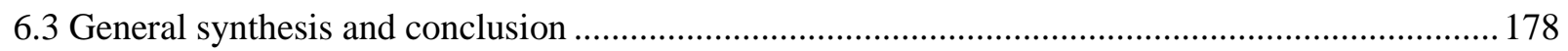

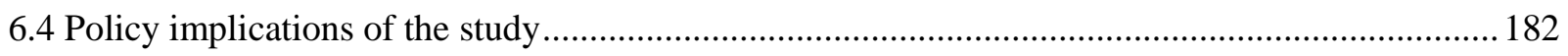

6.5 Limitations of the study and suggestions for future research ............................................... 184

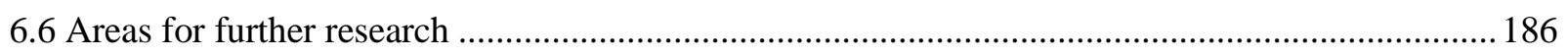

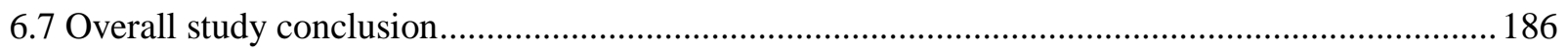

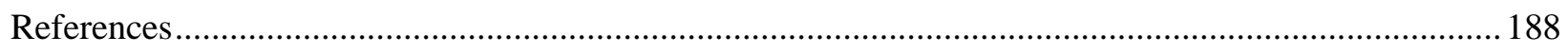

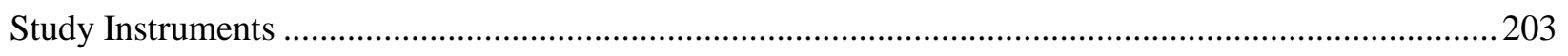

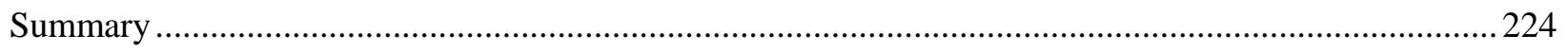

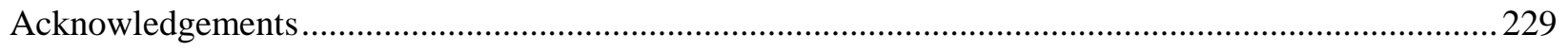

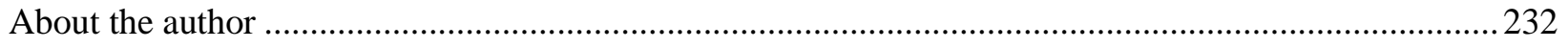

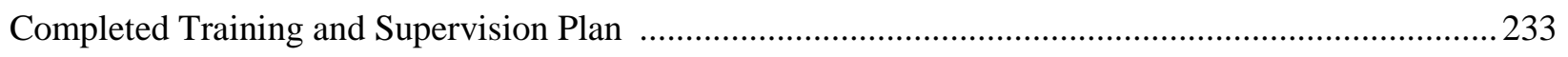




\section{Chapter 1}

General introduction 


\subsection{Introduction}

Food security has many definitions. The 1996 World Food Summit defined food security as a situation that exists when all people, at all times, have physical, social and economic access to sufficient safe and nutritious food that meets their dietary needs and food preferences for an active and healthy life (FAO, 1996).

The definition of food security reflects its three pillars, which are food availability, access to and utilisation of food. Attaining food security implies availability of nutritionally adequate and safe food, individual households accessing socially acceptable food to meet their needs, and ability of the body to utilise essential dietary nutrients (Barrett, 2010; Maxwell \& Frankenberger, 1995; Smith, El Obeid, \& Jensen, 2000). Food availability is usually in reference to national food supplies from agricultural production, import or food aid, while access refers to individual households having physical and or economic access to food. Utilisation on the other hand reflects concerns about the quality of household food choices, hygienic and sanitary conditions of food preparation, and finally a state of health that is needed for the body to metabolise essential dietary nutrients (Mahadevan \& Hoang, 2016; Smith et al., 2000).

Food security attainment is a prerequisite for economic development (World Bank, 2007) and many development practitioners and national governments continue to place food security attainment at the centre of their development goals and objectives. Yet the Food and Agricultural Organisation, estimated that more than 800 million people worldwide were undernourished in terms of dietary energy intake, while micronutrient malnutrition affected 2 million people (FAO, IFAD, \& WFP, 2015). The UNDP Human Development Report (1994) placed food insecurity on the list of threats to human security, and mentioned food as one of the basic determinants of well-being. It also identified improvement in income of people as a prerequisite for food security 
attainment (UNDP, 1994). The 1996 World Food Summit set a goal of halving the number of the hungry or undernourished by 2015 (FAO, 1996). This goal was not met in some of the agriculture-based countries of sub-Saharan Africa and promoting agriculture remains a prerequisite for reduction of hunger and poverty (FAO et al., 2015). The recent world food price surges put food insecurity in the limelight, with more efforts being sought to address the food insecurity question (Mittal, 2009). This thesis deals with the problem of food insecurity, especially about the way it might be alleviated by improving agricultural production and trade through access to microfinance.

Food insecurity arising from inadequate access to quality food manifests itself differently in different households depending on the entitlements available to them. Nobel Prize winner Amartya Sen introduced the concept of entitlement, the endowment of a household that can be transformed into food, via production, trade or commodity exchange (Maxwell \& Frankenberger, 1995). For rural agrarian communities relying on subsistence agriculture, food security is mainly attained via the production entitlement. The trade entitlement, though not as common, is enhanced when peasants pursue rural non-farm activities as a method of enhancing their livelihoods.

This thesis studies how the provision of microfinance may influence production and trade entitlements, in order to improve household food security in rural areas in Uganda. For long microfinance was believed to be a panacea in poverty alleviation and welfare improvement (Bornstein, 1997; Morduch, 1999; Morduch; 2000). The tide changed when accounts of numerous negative effects of borrowing including high interest rates, over-indebtedness and repayment stress (Brett, 2006; Copestake, Bhalotra, \& Johnson, 2001; Field, Pande, Papp, \& Park, 2012; Ganle, Afriyie, \& Segbefia, 2015; Rahman, 1999a), lack of control over loans (Goetz 
\& Gupta, 1996), increased group-related violence and domestic violence (Rahman, 1999a) came to light. In the recent past six randomised evaluations of the effect of microfinance were commissioned in six countries drawn from four continents (Bosnia, Ethiopia, India, Mexico, Morocco and Mongolia). These studies utilised different experimental designs and econometric methods to assess the effectiveness of microfinance as a development tool. Results of these studies were summarised by Banerjee, Karlan, and Zinman (2015). The six studies concluded that the effects of microfinance are not as large as once thought. In addition they did not find conclusive evidence of negative effects of borrowing. This left the microfinance debate open and revealed the need for further research on the outcomes of microfinance to poor borrowers (Banerjee, 2013). In this study we sought to contribute to this debate, by assessing the effect of borrowing on agricultural production of female farmers, which is one of the major activities rural women do. In the food security debate, increased production would have a positive implication for food security even if monetised income did not increase. We thus measured both the monetised and the non-monetised (hidden) income of women, from both crop and animal production.

However, since the need for women to participate in non-farm activities for income needed for food security improvement cannot be over-emphasised, we also looked at the effect of microcredit on non-farm microenterprise (ME) performance. In addition to ME profits, we assessed the effect of borrowing on the monetary worth of the MEs, and on recurrent business expenditures. Finally, we assessed the effect of microcredit on household food security, using various measures of food insecurity, as well as its effect on non-food consumption.

This introduction chapter will first consider the food security situation and its relation with poverty and agricultural production. We continue with the development of microcredit and how 
it may contribute to food security. We then consider the problems associated with measuring the impact of microcredit. We present our research objective, and research questions, and briefly present the research design. We finish with an overview of the next chapters of the thesis.

\subsection{Prevalence, causes and manifestations of food insecurity}

Rahman, Matsui, and Ikemoto (2013) defined food insecurity as lack of access to sufficient quality food. Food insecurity may be short term and transitory, experienced for example when an agrarian community misses a rainy season. It may become chronic due to persistent drought, political conflict, and persistent lack of access to productive land and to food markets (Ashley, 2016; Maxwell \& Frankenberger, 1995; Rahman et al., 2013).

Measurements of food security includes those related with foods and nutrients consumed, measures of nutritional status as well as measures of access to food. One common measure of food security is measurement of per capita caloric and nutrient intake. These can be used to identify undernourishment, an indicator of people failing to attain intake of calories or of one or more essential nutrients required for good health (FAO et al., 2015; Mahadevan \& Hoang, 2016). Dietary diversity scores (DDS) (Hoddinott \& Yohannes, 2002; Arimond \& Ruel, 2004) and the qualitative Household Food Insecurity Access Scale (HFIAS) (Coates, Swindale, \& Bilinsky, 2007; Swindale \& Bilinsky, 2006b) are common measures of food security (access).

While many parts of the world made good progress in the reduction of hunger and malnourishment in the last decades, many countries in sub-Saharan Africa made dismal progress, with 1 in 5 people still being hungry (FAO et al., 2015; Stevens et al., 2012). The slow progress is attributed to, among others, failure to attain levels of agricultural production and productivity increase commensurate with the rate of population growth. In addition, unstable incomes, poor 
markets and marketing infrastructure, and high postharvest losses put subsistence farmers who rely on agriculture as a source of income at a disadvantage, and yet they also are net buyers of food (FAO et al., 2015). Food insecurity is also caused by poverty, natural or human induced disasters and political instability (FAO, 2016; FAO et al., 2015). Environmental degradation, climate change and unpredictable weather patterns are also major causes of food insecurity in poor communities (Ashley, 2016; FAO, 2016).

The prevalence of undernourishment in Uganda is estimated at 25.5\% (FAO et al., 2015). By 2014 about 4-5 million of the population in Uganda remained at risk of becoming food insecure (MoFPED, 2014).

The country has recorded improvement in some anthropometric indicators for young children. For example, stunting defined as low height for age (a measure of chronic malnutrition), dropped from $45 \%$ in 1995 to $33 \%$ in 2011 . The level of underweight reduced from $25 \%$ in 1995 to $14 \%$ in 2011 (World Bank, 2016b).

Food insecurity in Uganda is mainly caused by lack of access to diversified diet and low nutrient content of commonly eaten foods. Instability in food supplies due to seasonality in food production, high food prices, and unreliable earning patterns all aggravate the food insecurity problem (GOU, 2011). Progress in reduction of under-nourishment has been hampered by slow progress in growth of agriculture (FAO et al., 2015). Although causes of food insecurity in the world are many and diverse, including conflict and climate change, low agricultural productivity and poverty have been implicated most in the causation of food insecurity in developing countries (Misselhorn, 2005; Smith et al., 2000). 


\subsection{Poverty, food insecurity and agricultural production}

Poverty is a major cause of food insecurity (Ashley, 2016; FAO, 1996; Rahman et al., 2013; Smith et al., 2000). Poor people may have difficulty obtaining adequate food, spend a greater proportion of their income on food, buy poorer quality food, and may eat less frequently than the non-poor (Ashley, 2016; Mellor, 1983; Rahman et al., 2013; Von Braun, De Haen, \& Blanken, 1991). By 2012 close to 900 million people in the world lived below the extreme poverty level of less than USD 1.9 per day. The global figure of poverty prevalence is $12.7 \%$ (World Bank, 2016a).

Poverty is prevalent in sub-Saharan Africa where the majority of people rely on subsistence farming as the main source of food and income (Ashley, 2016). According to the World Bank (2016a), Uganda has made significant progress in poverty reduction in the past two decades. The poverty rates, based on the national poverty line (USD 0.88-1.04) depending on the region of the country), have reduced from 33.8\% in 2000 to $19.7 \%$ in 2016 (World Bank, 2016b). The proportion of households living below the international poverty rate in Uganda fell by 2.7 percentage points per year since 2003, the second highest in sub-Saharan Africa for the time period. The annual reduction rate, based on the national poverty, was 1.6 percentage points.

The country also recorded reduction in levels of non-monetary poverty. For example, infant mortality rate (probability of dying between birth and exactly 1 year of age per 1,000 live births) dropped from 88 in 2001 to 54 in 2011, while the under-five mortality (probability of dying between birth and exactly 5 years of age per 1,000 live births), stood at 90 in 2011, having dropped from 152 in 2001 (UBOS \& ICF, 2012; World Bank, 2016a).

However despite all improvements the country is still among the poorest in the world. In 2013, more than a third of the citizens lived below the international poverty line. Even with 
improvement in non-monetary poverty, the country still faces widespread deprivation. Human development indicators like child and maternal malnutrition, and mortality are still among the worst in the world.

Since agricultural production is one of the pillars of food security (Quisumbing, Brown, Feldstein, Haddad, \& Peña, 1995), low levels of agricultural productivity are also implicated in the food insecurity problem. Underlying causes of food insecurity include limited off-farm work opportunities, limited capital to set up businesses, poor access to land, limited information and inputs for farm production, inefficient farm support services, and low adoption of tools for efficient production (GOU, 2011; UNICEF, 1990).

As the discourse for reduction of food insecurity continues, interventions are needed to address the problem. These include among others rural economic development interventions geared towards agricultural production, and rural income diversification (Barrett, Reardon, \& Webb, 2001; Ellis, 1993; World Bank, 2007).

Rural income diversification involves promotion of non-farm earnings which have been estimated to contribute about $42 \%$ of income for rural communities in developing countries (Haggblade, Hazell, \& Reardon, 2002). These promotions are important to address poverty which is prevalent in agrarian societies.

Improvement in agricultural production of small-holder farmers, including women, has the potential to contribute to improvement in food security since many poor people rely on agriculture as a form of livelihood and a source of food (FAO et al., 2015; Ruel \& Alderman, 2013; Sibhatu, Krishna, \& Qaim, 2015). Growth may be attained by promotion and adoption of modern inputs such as fertilisers and seeds (Abate, Rashid, Borzaga, \& Getnet, 2016). Agricultural growth should be nutrition sensitive, with focus on improved dietary diversity, 
nutritional education and nutrition awareness, and women's empowerment, among others (FAO et al., 2015; Ruel \& Alderman, 2013). In addition to production improvements, gender-sensitive interventions are needed to reduce women's time constraints, and strengthen their control over income (FAO, 2011). Indeed according to the National Planning Authority (NPA) and the Ministry of Finance Planning and Economic Development (MoFPED), the government of Uganda recognises the need for sustained agricultural production and has placed agricultural improvement at the core of its development plans (MoFPED, 2014; NPA, 2010).

\subsection{Evolution of microcredit}

According to Karlan and Goldberg (2011) microfinance refers to very small loans given to lowincome clients with the aim of self-employment. Microfinance has been associated with dispersion of small collateral-free loans (microcredit) to jointly liable groups (usually consisting of poor women) in order to foster income generation and poverty reduction through enhancing self-employment. Microfinance for loans is referred to as microcredit. The origin of the microcredit or microfinance movement can be traced to Muhammad Yunus, an economics professor and founder of the Grameen Bank in Bangladesh. Yunus in 1976 observed that lack of capital was an obstacle to productive self-employment among the poor (Bornstein, 1997). The poor lacked collateral to access funds from formal banking institutions. He observed that the poor could utilise small loans to recapitalise their business, and also make regular small repayments. This worked well when loan repayments were frequent and small, and when the borrowing and repayment process was conducted openly in the village. It also worked well when the borrowing arrangement was in groups, where individuals guaranteed each other's repayment. The peer groups offered support and exerted pressure for loan payment, as future access to credit 
for all members would depend on all members fully paying up their loans (Bornstein, 1997). This loan procedure was the birth of the 'Grameen-style' solidarity group lending model. In this model, borrowers use information available on others in their social circle to screen those to work with (Armendáriz \& Morduch, 2010; Morduch, 1999). Group lending has been found to support loan repayment from poor borrowers who usually lack collateral needed by formal financial institutions (Ghatak, 1999; Ghatak \& Guinnane, 1999). With the assumption that poor people need credit (Ledgerwood, 1999), Yunus and others believe that providing loans to the poor ultimately leads to improvement in their welfare, and in the long run may contribute to the economic development of their communities (Bornstein, 1997; Todd, Schultz, \& John, 2007).

Based on the above highlighted development potential, the microfinance industry has become a global movement for combating rural poverty. It is considered a tool that can enable the poor, who are otherwise excluded from formal financial facilities, to unlock their productive potential by growing small businesses through access to microfinance (Armendáriz \& Morduch, 2010). Substantial amount of development aid has been allocated to microfinance institutions (MFIs) to improve poor people’s access to microcredit (Armendáriz \& Morduch, 2010). By 1995, about $\$ 7$ million in outstanding loans had been given to more than 13 million individuals and groups (Ledgerwood, 1999). According to Microcredit Summit Campaign (2015) by the end of 2013, the microfinance community had reached 211 million clients, 114 million of which were women. Microcredit as a form of financial development strategy brings access to financial resources closer to resource-constrained communities. However, lack of collateral, information asymmetry, and high transaction costs make formal lending institutions shy away from the poor (Morduch, 2000). Unable to access formal financial markets, the poor instead rely on informal support, which may be expensive and yet not always assured (Ghatak \& Guinnane, 1999; Morduch, 
2000). With microcredit, would-be entrepreneurs pursue potentially profitable business opportunities they would otherwise not be able to pursue (Guiso, Sapienza, \& Zingales, 2004; Sen, 1999).

Because of different reasons, including focus on the poor, financial sustainability of participating institutions, the many success stories, and the innovative financial products, the microfinance movement grew and thrived in many countries (Ledgerwood, 1999). The government of Uganda embraced it as a key strategy for poverty reduction and livelihood improvement (NPA, 2010). BRAC (Bangladesh Rural Advancement Committee) is one of the largest MFIs in Uganda that target women with microcredit to recapitalise microenterprises. BRAC uses Village Organisations (VOs), under the 'Grameen-style' group lending model which relies on joint liability of members for loan repayments at weekly group meetings (Armendáriz \& Labie, 2011; Armendáriz \& Morduch, 2010; Eijkel, Hermes, \& Lensink, 2011; Morduch, 1999). Small individual loan amounts (microcredit) are advanced to women who must belong to VOs consisting of 15-20 person (Berger, 1989; BRAC, 2008; Morduch, 1999).

Women are targeted because they lack access to credit (De Mel, McKenzie, \& Woodruff, 2009) and yet when they access credit have good record for loan repayment (Kabeer, 2005; Karlan and Goldberg, 2011). In addition, they play a key role in household welfare maintenance, by allocating to households a large proportion of their resources (Agarwal, 1997; Barnes, Morris, \& Gaile, 1999; Cheston \& Kuhn, 2002; Kabeer, 2005). For example, Pitt \& Khandker (1998) and Pitt et al (2003) found that credit to women led to greater improvement in the nutrition status of children, than that given to men. Women are household food producers (Fletschner \& Kenney, 2014; Quisumbing et al., 1995), managers of nutrition provision to families (Ashley, 2016), and general care givers (Niehof, 2015). Microcredit to women is thus expected to lead to household 
food security improvement especially if it translates into expansion of the entrepreneurial activities with concomitant increase in income (Barnes et al., 1999; Berger, 1989; Kabeer, 2005). Figure 1.1 summarises the channels through which microcredit is expected to affect food security of borrowers and their households. Expansion of women-owned non-farm microenterprise may yield more income, and contribute to food security through improved economic access to food (FAO, WFP, \& IFAD, 2012). Since women are major food producers, investment of microloans into agricultural production will be a positive step towards improving household food availability from own production (NEPAD, 2006). Credit access is expected to spur agricultural output and household income, as a result of adoption of technologies that enhance productivity (Feder, Lau, Lin, \& Luo, 1990; Zeller \& Sharma, 2000). Agricultural production is expected to become more commercialised, leading to improved agricultural investment and output. However, the extent to which this happens is subject to debate.

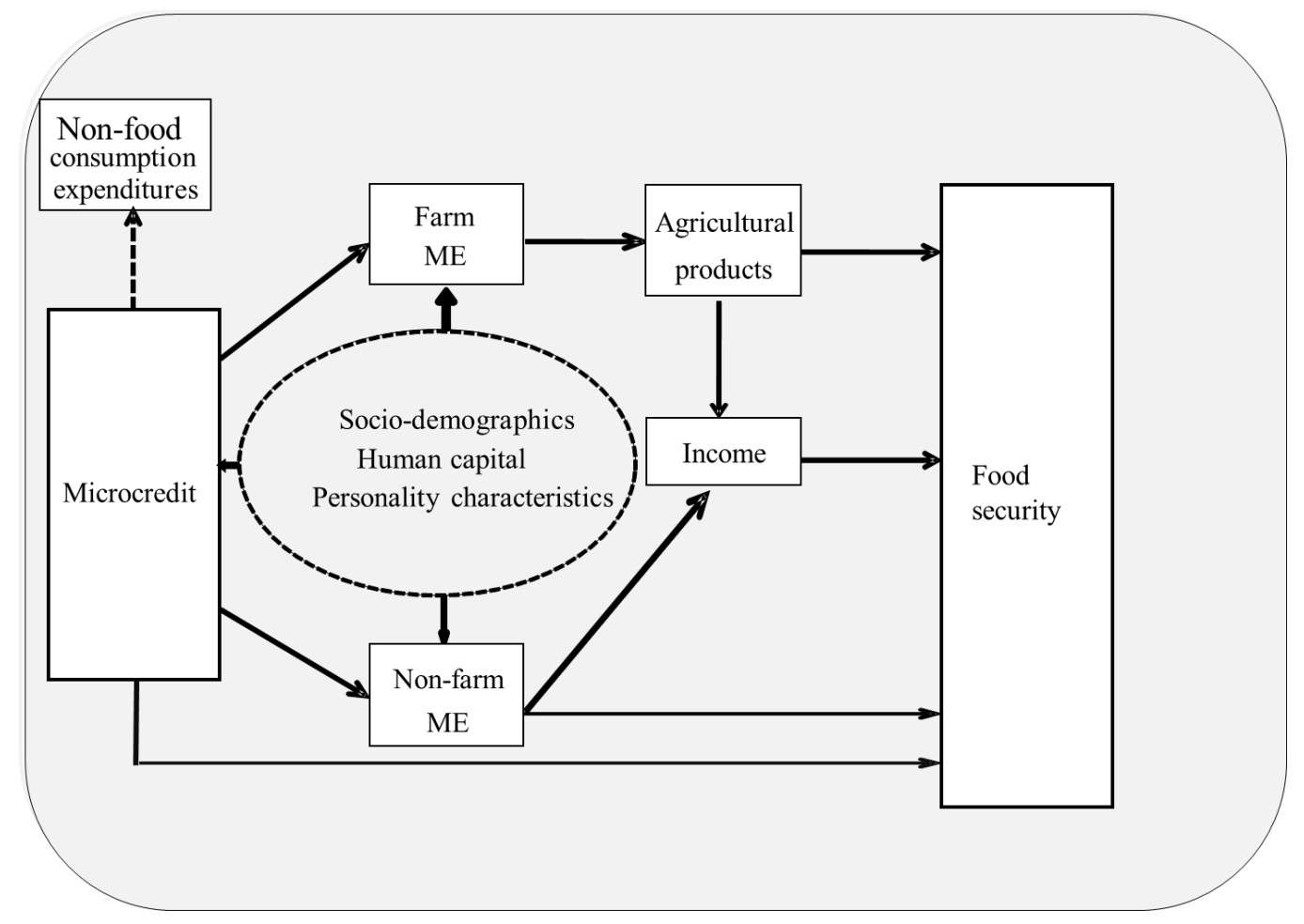

Figure 1.1. Theoretical framework relating microcredit to production and food security 
Introduction of MFI activities enables communities that were previously excluded from financial markets to get immediate access to credit (Kaboski \& Townsend, 2012). Credit access will then lead to changes in production and consumption decisions (Crépon, Devoto, Duflo, \& Pariente, 2015).

Loans provide financial capital for production activities, either on-farm or non-farm microenterprises (MEs) (Matin, Hulme, \& Rutherford, 2002). Recipients may invest in a new business, expand an existing business or increase their labour supply (Banerjee, Duflo, Glennerster, \& Kinnan, 2015; Crépon et al., 2015). After borrowing, household members may devote more time to activities of the microenterprise (Banerjee, 2013; Crépon et al., 2015; McKernan, 2002). In the long run businesses owned by recipients of microcredit are expected to record higher profits than their non-credit counterparts (McKernan, 2002). Farm households may adopt labour-saving technologies that they were otherwise unable to afford (Matin et al., 2002). The extra investment is expected to lead to, among others, improved productivity (Matin et al., 2002), ME expansion, increased business outputs, profits and income, and asset accumulation (Gobezie, 2004; Karlan \& Goldberg, 2011; McKernan, 2002; Sebstad, Neill, Barnes, \& Chen, 1995). In addition, the human capital improvement from non-credit MFI services, including training, business sharing and group support, may improve business and self-employment skills (McKernan, 2002), and increase output further.

Microcredit may also impact households through change in consumption decisions. Households accessing microcredit may sacrifice short-term consumption of non-asset goods and leisure in order to acquire durable goods (Banerjee et al., 2015; Crépon et al., 2015). Such households will manage their assets and liabilities more efficiently. For example, they may reduce levels of assets for precautionary savings and increase assets for production purposes 
(Matin et al., 2002). Participation in microcredit programs may lead to consumption smoothing (Banerjee et al., 2015; Crépon et al., 2015; Kaboski \& Townsend, 2012; Kempson, Crame, \& Finney, 2007). This is achieved through use of microcredit to procure food for consumption or diversion of food stock from business to consumption. Such diversion is more likely in communities with production problems, for example, due to seasonality (Develtere \& Huybrechts, 2002). In addition, the possibility of future credit access may alter the need for savings as protection against future shocks, and clients may then rely on credit to cover current consumption (Kaboski \& Townsend, 2011; Matin et al., 2002).

\subsection{Factors affecting outcomes of microcredit}

Outcomes of borrowing depend on many factors including the context and characteristics of the lending program, the socio-demographic and personality characteristics of the borrower, and the type of activities engaged in (Kabeer, 2005; Snodgrass \& Sebstad, 2002).

Characteristics of the microcredit program, such as loan cycle (Copestake et al., 2001), loan amount (Panjaitan-Drioadisuryo \& Cloud, 1999), interest rate, repayment requirements (Snodgrass \& Sebstad, 2002; Kabeer, 2005) and length of borrowing time (Hulme, 2000a), may all influence outcomes. Loan allocation and loan use may also influence attained outcomes. Investment of funds into targeted MEs should lead to business expansion, increase in profits and employment (Panjaitan-Drioadisuryo \& Cloud, 1999; van Rooyen, Stewart, \& de Wet, 2012). Business expansion will lead to improvement in household income (Karlan \& Goldberg, 2011) and household assets (Gobezie, 2004). On the other hand diversion of funds to household consumption deprives MEs of much-needed capital, and no change in profitability may be 
attained (Gifford, 2004; Rutherford, 2011; van Rooyen et al., 2010), although short-time consumption smoothing may be achieved.

The type of microenterprise may also determine the probability of successful outcomes. Different types of microenterprises have varying levels of profitability with some failing to yield any profits (van Rooyen et al., 2012). Also, poor micro-entrepreneurs may remain food insecure if the microcredit-supported activities are not productive enough (Balatibat, 2004). In addition, investment in agricultural-related microenterprises augments the traditional roles of women in food production (MacGuire \& Popkin, 1990), which is the first pillar of food security (Quisumbing et al., 1995).

Livelihood assets and resources of the recipients and their households may moderate levels of outcome. Individual characteristics, skills and abilities may influence outcomes of microcredit participation (Cheston \& Kuhn, 2002; Gifford, 2004). For example, the owner's level of formal education is a key predictor of survival for small businesses (Bates, 1990). Human-capital characteristics such as level of schooling (Bates, 1990; Berger, 1989; Crook, Todd, Combs, Woehr, \& Ketchen, 2011; Rakodi, 1999), age and marital status (van Rooyen et al., 2012) may influence the success of women-owned microenterprises. Time preference, risk preference, and the desire for achievement may further explain success or failure of microenterprises (Rauch \& Frese, 2000). In addition, group commitment to microcredit repayment may be related to time preference of the recipients (Bauer et al., 2012).

Household structure and composition may define levels of burden on recipients, decision making on time and resource allocation, and the support structure and mechanisms for recipients (Berger, 1989; Feroze, Chauhan, \& Chakravarty, 2011; Gifford, 2004; Hulme, 2000a; Nelson et al., 2004; Rakodi, 1999). Social networks of the family may also influence microenterprise 
survival and productivity (Gifford, 2004; Rakodi, 1999). Other borrowing contextual issues such as location of the program, rural versus urban, markets and infrastructure may all affect borrowing programs.

Food security improvement from microcredit participation is mediated by improvement in income and savings, self-esteem, and empowerment to participate in household decision making on household resource use and allocation (Gobezie, 2004; Kabeer, 2005). Female control over income from microenterprise expansion is needed to realise increments in expenditures on food (Grown \& Sebstad, 1989; Jiggins, 1989) and dietary diversity (Carletto, Zezza, \& Banerjee, 2013; Hoddinott \& Yohannes, 2002).

Potentially negative outcomes of microfinance program participation, e.g. child labour, increase in recipient work load and sale of household assets for loan repayments, have been reported (Karlan \& Goldberg, 2011). Exogenous factors such as spouse's and other people's contributions to meeting household food needs and non-loan related food production may affect household food security changes among microcredit recipients (MacGuire \& Popkin, 1990).

\subsection{Microcredit impact assessment}

The need to ensure that microcredit leads to the intended developmental outcomes necessitates the careful consideration of methodologies in impact assessments. Studies must strive for rigour, while keeping in mind the objectives, context, and financial and human resource availability (Hulme, 2000a).

Sebstad (1998) defined impact assessments (IAs) as 'inquiries that estimate the value, degree or pattern of change that can be plausibly associated with an intervention' (p. 3). In consideration of the opportunity cost of investment in some activities and not others (Armendáriz \& Morduch, 
2010), evidence is needed from IAs to justify the huge expenditures on development programs such as microfinance (Hulme, 2000a).

Microfinance impact assessments compare individuals who have accessed credit (treatments) to otherwise similar individuals who have not yet got credit (controls). Changes may be assessed based on differences in outcomes between the treated and controls. Impact assessment studies may be done at either enterprise or household level (Hulme, 2000b). Examples of household level indicators in microfinance impact assessments include changes in household income, expenditure, assets and consumption. Social indicators include food security and women empowerment such as measures of decision making (Hulme, 2000a). Sebstad et al. (1995) provided examples of outcome variables in microfinance impact assessment. Assessment of the ME resource base may include assessment of levels and sources of the enterprise capital. After receiving microcredit borrowers are expected to transition away from use of personal savings and family resources to using credit.

Development interventions work on the assumption of a change in human behaviour and practice after the intervention, leading to desired intervention outcomes. In IAs, comparisons are made of key program outcomes on 'agents' who have experienced an intervention, to what would have existed without the program. Hulme (2000a) provides two alternative schools of thought in choosing the path of analysis. The beneficiary school of thought focuses analysis on who benefits and how, while the intermediary school of thought focuses on effectiveness and efficiency of MFI operations and procedures. In this study we focus on the beneficiary school of thought, since it emphasises the social benefits of microfinance.

Another consideration in any analysis concerns the level of analysis which may be done at the individual, household or enterprise level. Analysis at different levels balances out potential limits 
and benefits of assessments at any of the levels (Hulme, 2000a). In the current study analysis was done at the household, individual and microenterprise levels for different variables.

The primary challenge of impact evaluations is estimation of the counterfactual, the level of outcome among participants without the program. However, since people cannot be both participants and non-participants in an intervention at the same time, estimation gives rise to methodological problems of attribution of observed effects to the intervention (Armendáriz \& Morduch, 2010; Glennerster \& Takavarasha, 2013; Hulme, 2000a; Khandker, Koolwal, \& Samad, 2010). Different methods have been developed for estimation of this counterfactual.

While randomised control trials are promoted as the best alternative in impact assessments, because treatment and control groups are randomly allocated (Glennerster \& Takavarasha, 2013; Karlan \& Goldberg, 2011), they are expensive and time consuming (Hulme, 2000a), and not always feasible if interventions have already started (Karlan \& Goldberg, 2011). Some methods estimate the counterfactual by comparing treated and untreated groups when both are eligible to be treated (with and without treatment comparisons). Commonly, middle-range IAs are being promoted with tools developed by USAID-funded Assessing the Impact of Microenterprises Services (AIMS) project, using with/without credit group comparisons (Sebstad, 1998). To overcome selection bias, comparison groups may be obtained by use of prospective borrowers who have self-selected to participate in a program before they access loans (Barnes \& Sebstad, 2000; Gaile \& Foster, 1996; Karlan \& Goldberg, 2011; Nelson et al., 2004). In this quasiexperimental methodology, impact is obtained as the difference between outcome variables for in-coming borrowers and actual borrowers (Karlan \& Goldberg, 2011; Tedeschi, 2008). One shortfall that has been suggested for this method by Karlan (2001), is the potential bias from drop-outs, as well as unobservable reasons why incoming clients may differ from those who 
joined earlier. This may be overcome by tracing and inclusion of the drop-outs who can be traced, and also by use of propensity score matching (Khandker et al., 2010).

Another challenge of IAs is that external and internal factors, other than the intervention, may lead to changes in outcome variables of interest (Armendáriz \& Morduch, 2010; Glennerster \& Takavarasha, 2013).

Finally, selection of participants into a program may influence levels of observed outcomes. Individuals with unique characteristics may self-select into a program. In addition, program implementers may non-randomly select individuals and locations for the implementation of the program (Armendáriz \& Morduch, 2010; Glennerster \& Takavarasha, 2013). If self-selection and non-random program placement are not taken care of, selection bias may occur, which may lead to over- or under-estimation of program impact (Armendáriz \& Morduch, 2010). Selection bias may also lead to erroneous attribution of observed differences to a program, when in fact changes may be due to pre-existing differences (Armendáriz \& Morduch, 2010; Coleman, 1999; Glennerster \& Takavarasha, 2013; Tedeschi, 2008).

Another available method is the Difference-in-Difference (DID) method that involves comparisons of treated and untreated groups before and after the intervention. In this method, unobserved characteristics which are assumed to be time-invariant, and are differenced out in assessing differences between treated and controls (Armendáriz \& Morduch, 2010; Glennerster \& Takavarasha, 2013; Hulme, 2000a). Alternatively, quasi-experimental methodologies such as propensity score matching may be used to construct comparable groups through statistical design (Khandker et al., 2010). The propensity score matching (PSM) methodology has been described by many authors (Chemin, 2008; Khandker et al., 2010; Luellen, Shadish, \& Clark, 2005; Rosenbaum \& Rubin, 1983). It is a quasi-experimental statistical analysis tool used to create 
treatment and control groups which are similar on a set of observable covariates. It is applied in the assessment of impact of interventions in which random allocation of participants into treatment or control groups is impractical or unethical, and in programs where it is impossible because an intervention has already taken place and participants naturally selected themselves into different groups. To ensure comparability, selected covariates (factors which may influence the probability of belonging to either category and which may also influence the outcome of an intervention) are used in a probit or logit regression procedure which assigns a propensity score to each individual. The score represents the probability of the respondent being in either group. In the matching step, treatments and controls with similar scores are paired for inclusion in the impact effect analysis. Individuals with no matches are eliminated from further analysis. The key result of PSM is a reduction of selection bias due to the observed covariates. After matching, the effect of the intervention is determined as the average difference in outcome between the groups. Different types of matching methods are available. In nearest-neighbour (NN) matching, each treatment unit is matched to the one in the control group with the nearest propensity score. Calliper or radius matching involves utilisation of a threshold on the acceptable propensity score for the matching process. Another alternative is weighted Kernel matching which is based on giving more weight to more similar cases in the two groups, and less weight to more dissimilar cases. One limitation of PSM is the assumption that only the measured covariates influence selection into treatment and control groups. In the event that there are unmeasured covariates, there may be some residual bias. One of the ways for checking the influence of unobservables to the comparisons is by use of sensitivity analysis (DiPrete \& Gangl, 2004; Rosenbaum, 2010).

Another way of measuring impact is by use of the instrumental variable method. This involves using an instrument that influences participation in microcredit programs but does not 
influence the outcome of participation. However, finding a suitable instrument is sometimes not feasible (DiPrete \& Gangl, 2004).

Qualitative approaches using open-ended interview questions in focus group discussions may also be used in impact assessments. They are useful in the pooling of information, knowledge and experiences of participants of the program. They have the advantage of providing rich information and details on the mechanism through which the program works (Duflo, Glennerster, Kremer, Schultz, \& John, 2007). Various authors recommend the use of a combination of qualitative and quantitative methods in IAs to aid in the interpretation of findings and identifying impacts that have high plausibility (Barnes \& Sebstad, 2000; Hulme, 2000a; Khandker et al., 2010). The current study uses a combination of a quantitative survey and qualitative focus group discussions to assess the effect of participation in a program on ME performance.

Given the influence of context on the outcomes of microcredit (Chliova, Brinckmann, \& Rosenbusch, 2015; Coleman, 1999; Kabeer, 2005), there is a need to evaluate microcredit programs in different communities. To the best of our knowledge, no rigorous assessment of the food security outcomes of microcredit has been undertaken in Uganda.

Microcredit has greatly expanded in Uganda in the past decades and is lauded as a livelihood improvement strategy for promoting food production, income and food security improvement in the country through farm and non-farm activities. However, it is not clear if food security improvement influences decisions by microcredit beneficiaries to take credit and to what extent microfinance support leads to food security improvement of borrowers' households. There is limited evidence to show if microloans are invested into agricultural and non-farm MEs, and if this leads to improved agricultural output and improved profits from the MEs, respectively. It is not clear to what extent and how microcredit to women affects income, food production and food 
security of resource-constrained agrarian households in Uganda, and which factors enhance or limit observed outcomes. Many factors (see Section 1.5 above) influence borrowing outcomes, hence the need for impact assessments in different contexts.

There is need to establish if proceeds from microcredit investment into non-farm MEs adequately compensate for any foregone opportunities to engage in food production, especially in communities which traditionally rely on own food production for food. There is also need to establish if female borrowers are able to transform subsistence food and non-farm MEs into commercial ones, which is one of the key goals of lending programs.

\subsection{Research objective and research questions}

This study aims to assess the contribution of microcredit to women in Uganda to household production activities and food security status and to evaluate factors that enhance or limit food security outcomes. This objective is accomplished by assessing the effect of borrowing on the performance of non-farm microenterprises, on input expenditures and output from agriculturalrelated activities and by assessing the effect of borrowing on food and non-food consumption.

The main research question is whether microfinance access by women influences production activities and the food security situation of their households and the underlying factors. This research question comprises several specific research questions listed below.

1. To what extent do the objectives and design of the BRAC microfinance program match the expectations, context and characteristics of female borrowers in a rural agrarian setting in Uganda?

2. How does borrowing influence investments in non-farm MEs, the operation of MEs, their monetary worth and profits and, what factors affect the observed changes? 
3. To what extent does borrowing affect investment and input expenditures, and output from agriculture?

4. How does microcredit participation affect food consumption of households?

\subsection{Research design}

The overall study was a panel design in which we collected data on three categories of respondents. The first category was the old borrower (OB) group who had a running loan with BRAC. The second category consisted of in-coming new borrowers (NB) into BRAC, before they received their first loan. The third group of respondents (the control group, CG) consisted of a group of women from the same villages as NBs, with a non-farm ME, but who never borrowed from BRAC or any other MFI.

During the baseline study we collected data on the three study groups. We used a quasiexperimental cross-sectional design to compare farm and non-farm ME performance parameters for OB and NB borrowers based on the USAID/AIMS comparative cross-sectional analysis design that was described by Nelson et al. (2004). We compared parameters of a treatment group of existing borrowers (OB) and a group of incoming borrowers (NB), before they received their first loan. The basis of this methodology in the assessment of the effect of microcredit is that, since both groups have already self-selected to participate in microcredit, and one has just not received the loan, the difference between outcome measures for the two may be taken as the effect of borrowing. In this approach, baseline data from the OB was compared with NB data. Differences between $\mathrm{OB}$ and NB parameters were obtained using propensity score matching (PSM), which ensures comparability of groups based on observable characteristics, which may determine participation into the borrowing program. 
Furthermore, we carried out two waves of data collection for the NB and the CG groups, respectively (Gaile \& Foster, 1996). We used the collected data to obtain an alternative measure of the effect of microcredit using difference-in-difference (DID) analysis. With the consent of the participants and after assurance of confidentiality, structured questionnaires were used to collect quantitative data for the study. The questionnaire elicited information on socio-demographic characteristics of respondents and their households, household agricultural production information, information about non-farm enterprises and household food and non-food consumption as well as several personality variables.

Qualitative data were collected using the focus group method, following a focus group discussion (FGD) guide. FGDs were used to explore respondents' reasons for borrowing, loan allocation and use, and perceived benefits of borrowing to MEs and households, among others.

\subsection{Overview of the thesis}

In Chapter 2 we investigate the extent to which the objectives and design of the BRAC microfinance program match the expectations, context and characteristics of female borrowers.

Chapter 3 provides results of our investigation of the effects of microcredit on the performance of non-farm microenterprises (MEs) run by small-holder female farmers. This was conducted on a sub-category of respondents with non-farm MEs. We compared parameters for new borrowers (NB), before and after they received their first loan, and a control group (CG) of women who never received credit. Difference-in-difference (DID) analysis of the data revealed marginally significant improvement of ME monetary value. In an alternative approach, baseline data from current borrowers (OB) was compared with NB data using propensity score matching (PSM). 
In Chapter 4 we assess the microcredit-attributable changes in agricultural production input expenditure and outputs among women with farm MEs. We used a quasi-experimental crosssectional design with both quantitative and qualitative survey methods to obtain sociodemographic, personality and microenterprise (ME) characteristics of existing borrowers $(\mathrm{OB})$ and incoming borrowers (NB) before they received their first loan. To assess the effect of microcredit, we measured production input expenditures for crop and animal production, crop harvests in the season before the study, and the animal wealth for the respondents. We used propensity score matching to assess differences between OB and NB groups.

In Chapter 5 we investigate the effects of participation of women in a microcredit program on household food security parameters of female borrowers' households. We explore the modes of food acquisition, dietary diversity, calorie and protein intake, and qualitative food insecurity measures for different categories of respondents.

In Chapter 6 we discuss the implications of the major study findings. Overall, we find that taking microcredit did not lead to improved farm and non-farm ME income or food security among the rural women borrowers studied. This may be because of extreme poverty among borrowers and the loan conditions which are not conducive for investment in agriculture. 


\title{
Chapter 2
}

\section{Women and microcredit in rural agrarian households of Uganda: Match or mismatch between lender and borrower?}

\begin{abstract}
The alignment of microfinance programs with the context and expectations of recipients is critical to ensuring clients' satisfaction and desired program outcomes. This study sought to investigate the extent to which the objectives and design of the BRAC microfinance program match the expectations, context and characteristics of female borrowers in a rural agrarian setting in Uganda. Quantitative and qualitative survey methods were used to obtain socio-demographic, personality and microenterprise (ME) characteristics of existing and incoming borrowers and to obtain information about the microcredit program. We found that BRAC uses a modified Grameen-like group lending model to provide small, high interest rate production loans and follows a rigorous loan processing and recovery procedure. BRAC clients are mainly impoverished subsistence farmers who derive income from diverse farming and non-farm activities. The major reason to borrow is to meet lump-sum monetary needs usually school fees and for investment in informal small non-farm business activities. Many borrowers use diverse sources of funds to meet repayment obligations. Defaulting on loans is quite low. The stress caused by weekly loan repayment and resolution of lump sum cash needs were identified as reasons for women to stop borrowing. The limited loan amounts, the diversions of loans to nonproduction activities, the stages of the businesses and the weekly recovery program without grace period may limit the contribution of these loans to ME expansion and increase in income.
\end{abstract}

Key words: Uganda, BRAC, rural microcredit, women.

Publication status: Published as Namayengo, F.M.M., van Ophem, J.A.C., and Antonides, G. 2016. Women and microcredit in rural agrarian households of Uganda: Match or mismatch between lender and borrower? Applied Studies in Agribusiness and Commerce-APSTRACT 10 (2-3), 77-88. 


\subsection{Introduction}

Microfinance has been promoted by many national and international developmental agencies as a tool for poverty alleviation and development of poor communities (Armendáriz \& Labie, 2011; Armendáriz \& Morduch, 2010; Matin et al., 2002). The core objective of microfinance institution (MFIs) programs is to bring financial services to such resource-constrained communities. Formal institutions usually shy away from the poor because they lack collateral and because of information asymmetry and high transaction costs (Armendáriz \& Labie, 2011; Armendáriz \& Morduch, 2010; Hulme \& Mosley, 1996; Matin et al., 2002; Morduch, 2000).

Women constitute a large percentage of the poor in many communities (Fletschner, 2009; UNDP, 1996). This is because financial, social and economic inequalities limit their participation in formal markets (Meyer, 2013). Yet women make significant contributions to the welfare of their families and households. They play significant roles in economic production, social reproduction, care and community activities (Buvinić, 1997; Momsen, 2004; Niehof, 2004a, 2015b; Østergaard, 1992). They enhance their agency to seek for opportunities for personal and family welfare improvement. To diversify their livelihoods, they set up microenterprises with limited financial outlay and often low returns (Jiggins, 1989; Schreiner \& Woller, 2003). Women in Uganda are no exception. They reportedly suffer from the burden of poverty and financial and social deprivation (Lakwo, 2006; Wakoko, 2004). Poverty, hunger and food deprivation are common in rural areas which rely on agricultural production as a source of livelihood (MoFPED, 2014).

Poverty alleviation is a core objective of many MFIs. Under their microcredit component, MFIs target poor micro-entrepreneurs for financing. The financing is in the form of microloans for productive purposes, to be repaid with interest. The premise is that the loans are invested in 
poorly-financed microenterprises and enable borrowers to make strategic decisions for business growth and survival (Guiso et al., 2004; Matin et al., 2002; Sen, 1999). These loans are expected to increase the income from self-employment and in the long-run should lead to poverty reduction (Matin et al., 2002).

The performance of MFIs and benefits to the recipient depend on the characteristics of the lending program, the recipients and the general context (Cohen \& Snodgrass, 1997). Program characteristics like collateral requirements and lending model (Armendáriz \& Morduch, 2010; Attanasio et al., 2015; Morduch, 1999), borrower characteristics like gender and education (Barrett et al., 2001; Nanayakkara \& Stewart, 2015), and purpose of borrowing may influence the outcomes from borrowing.

MFIs have different ways of selecting program recipients, but many target poor women, for different reasons. Firstly, women have generally been underserved by MFIs because of different socio-cultural barriers (Meyer, 2013). Secondly, women play a key role in maintenance of household welfare and allocate a large proportion of their resources to this (Barnes et al., 1999; Cheston \& Kuhn, 2002; Kabeer, 2005). Loans to women are expected to benefit entire households. Studies have reported significant effects of borrowing on household consumption and child nutrition for female but not male clients (Pitt, Khandker, Chowdhury, \& Millimet, 2003).

MFI activity in Uganda commenced and greatly expanded in the 1990s. By the end of 2009, the country had over 350,000 active MFI clients (UBOS \& MoFPED, 2014). The Association of Microfinance Institutions of Uganda (AMFIU) reported 84 MFI members in 2011 (AMFIU, 2011). BRAC Uganda Microfinance Limited, commonly referred to as BRAC, is one of the largest micro-lenders in rural areas in Uganda (UBOS, 2010a). Its operations in Uganda started 
in 2006. In 2011, it was reported to have a loan portfolio of UGX 31 billion (about $€ 11$ million) and 107,000 active borrowers, predominantly $(98.4 \%)$ women. BRAC thus works with women in rural Uganda, who play a key role in agriculture, a major sector of employment in Uganda (UBOS, 2016). Like other MFIs that work with underserved rural agrarian recipients, BRAC has enormous potential to contribute to agricultural production, reduction of food insecurity and rural poverty, and improvement of the lives of poor women (Meyer, 2013).

A lot has been written about the operations and contributions to poverty reduction of BRAC and other MFIs in Bangladesh (Chemin, 2008; Chemin, 2012; Develtere \& Huybrechts, 2002; Montgomery, Bhattacharya, \& Hulme, 1996; Pitt \& Khandker, 1998). However, not much work has been done on MFIs in Uganda. We conducted a study to assess the contribution of microcredit to production and household food security as overall objective. We aim to add to the body of literature the potential of microcredit to contribute to food security improvements in resource-constrained agrarian communities. In this paper we present findings on the context and characteristics of the BRAC microfinance program in Uganda. We evaluate the characteristics of the borrowers, their reasons for borrowing, the process of loan application, loan allocation, use and repayment. The question we address is whether the BRAC program is well aligned with the characteristics and needs of the borrowers.

The remainder of the paper is organised as follows: Sections $2.2-2.5$ provide background information, including a description of the BRAC microfinance program. Section 2.6 provides the study design and data collection methods. Section 2.7 presents our findings including the characteristics of the BRAC microfinance program as well as comparisons of the sociodemographic and personality and microenterprise characteristics of current and in-coming borrowers. We also present focus group discussion (FGD) results on the reasons for borrowing, 
loan allocation and use as well as the dynamics of loan repayments. In Section 2.8 we present the discussion and conclusion.

\subsection{Uganda country profile}

Uganda is a tropical country in East Africa with an estimated population of about 35 million people according to the recently concluded Uganda population and housing census (UBOS, 2016). The country is divided administratively into 121 districts. In 1962 Uganda obtained its independence from Great Britain. The post-independence economic growth was short-lived when between 1970 and the early 1980s, the country plunged into years of political and financial stagnation under despotic leadership (UBOS \& ICF, 2012). In 1986, the National Resistance Movement took over leadership of the country and embarked on what was envisaged to be a period of growth for the country. In the late 1980s, the new government implemented the structural adjustments programmes (SAPs) promoted by the IMF and World Bank. This included restructuring of the public sector, reduction of public spending, and privatisation of poorly performing government parastatals. Many government workers were retrenched and the role of the private sector in the development of the country gained prominence. Unfortunately one of the undesirable outcomes of the SAP was the government giving up provision of services that previously supported poor women. At the same time there was a widening gap between men and women for the control of productive resources (Makokha, 2001). The need for women to join the informal sector by setting up microenterprises also increased.

The government committed itself to macroeconomic stability with a resultant period of economic growth. The 1990s saw Uganda ranked among the fastest growing economies in subSaharan Africa, in terms of GDP. The high inflation rate of the 1980s was brought down to less 
than $10 \%$ in the 1990s. By the year 2000 the country lost a substantial part of its reproductive labour force to HIV and AIDS (Karuhanga, 2008), but progress has been made in the fight against HIV, with recent data putting prevalence at 7.4\% (Republic of Uganda, 2014b).

Between 1995 and today, the country has continued to make economic progress, albeit at a slow rate. There has been some progress in the reduction of poverty to the current level of 19.7\%. Poverty levels remain higher in rural areas, where agriculture is the mainstay of rural livelihoods (MoFPED, 2014). The country still ranks as one of the poorest in the world, with a GDP per capita of 423 in 2014 and GDP growth rate of $4.9 \%$ in 2014. Agriculture remains the major form of employment with $57 \%$ of women and $55 \%$ of men engaged in agriculture, forestry and fisheries (UBOS, 2016). The country has poor human development indices, with total fertility rate at 6.5 per woman, maternal mortality rate at 438 , infant mortality rate at 54 and under-five mortality rate at 90, per 1000 live births (UBOS \& ICF, 2012)

\subsection{Evolution of microfinance in Uganda}

After the SAPs of the late 1980s, the government of Uganda shifted focus to the private sector, particularly the financial sector, as an engine of development of the country. The financial sector was poorly performing due to poor regulation and lack of control. The government launched the financial sector reform strategy to improve efficiency in the sector. This included among others licensing of private financial institutions and liberalisation of borrowing rates and the foreign exchange market (Bategeka \& Okummu, 2010).

During 1997-1999 poorly performing banks were closed. Some of these had a wide national coverage, including rural areas. The result was a sector vacuum in many parts of the country. The remaining banks struggled with defaults and remained reluctant to lend to the rural poor 
(Bategeka \& Okummu, 2010; Carlton et al., 2001). The government then implemented the financial institutions act to strengthen supervision of the financial sector, including MFIs. With the sector being more stable and streamlined, the first MFIs in Uganda began operations in 1990 and thrived. Rapid expansion of the sector took place in the mid-1990s. From 1997 onwards, the collaborative effort of Bank of Uganda, donors, NGOs and capacity building partners resulted in strengthening the MFI sector. The Association of Microenterprise Finance Institutions of Uganda (AMFIU), launched in 1997, aims at providing a platform for sharing experiences, technologies and also to work as a lobby group for MFIs. In 2000, the different stakeholders came together to synchronise operations and develop a framework of regulation and control for the sector. Coupled with the closure of two major banks, this created opportunities for MFIs to expand (Bategeka \& Okummu, 2010; Carlton et al., 2001). In 2003, the government passed the microfinance deposit-taking act which allowed pioneer MFIs in Uganda to take deposits under regulation of the Bank of Uganda. This act enhanced collaboration among MFIs and between traditional MFIs (e.g. FAULU, PRIDE and the Uganda Microfinance Union) and formal banks that also offered microfinance services. Providers who originally offered group loans shifted to individual loans as clients complained about the rigours of weekly loan repayment meetings. Those who maintained group borrowing reduced the required minimum group size to as low as three borrowers. Individual loan requirements were also changed to more realistic forms of collateral, such as salaries, vehicle log-books, guarantors, unregistered land ownership documents, post-dated cheques, and other valuable assets (Mutesasira \& Kaffu, 2003; Wright \& Rippey, 2003). New products were designed to target the poorer segments of the population.

Despite the aforementioned adjustments, several challenges remained. Wright et al. (1998) reported high drop-out rates among MFI borrowers in Uganda. They observed that because of 
the concentration of MFIs in urban areas many did not reach poor clients, but instead reached rich and not-so-poor clients. The not-so-poor dropped out after the $3^{\text {rd }}$ and $4^{\text {th }}$ cycles when larger loan sizes translated into unmanageable repayment instalments. The poor clients in rural areas dropped out or rested because of seasonal variations in incomes and expenditures or family emergencies that depleted the borrowed funds and led to repayment failure. The rich dropped out because of frustration with the obligatory weekly meetings or because they found the loans too small for their needs (Wright et al., 1998). Another problem was multiple-borrowing prompted by the need for patch-up loans for the small amounts offered by some MFIs and the need for emergency loans to fund health and education expenditures (Wright \& Rippey, 2003).

\subsection{Characteristics of MFI programs and their recipients}

To enable them reach their target groups efficiently and achieve good loan repayment levels, MFIs need to specify the target group characteristics (usually age and sex) and have to decide on matters like group lending versus individual lending, loan amounts, interest rates and fixed periods of loan repayments. Some MFIs lend to individuals, others only to members of borrowing groups. The group lending model is widely associated with the Grameen Bank in Bangladesh. Groups of 5-20 women decide to form a borrowing group but are given individual loans. The group is responsible for repayment of the loans. When a member fails to repay, all members may then be denied subsequent loans (Armendáriz \& Morduch, 2010; Morduch, 1999). Group loan programs have been found to reach more women than individual loan programs. Advantages to the MFI include peer screening and monitoring, which diminishes problems of moral hazard and information asymmetry (Morduch, 1999; Niels \& Lensink, 2007). This supports high repayment levels even in the absence of collateral (Ghatak, 1999; Ghatak \& 
Guinnane, 1999). Group meetings may also function as venues for social marketing on health, nutrition, agriculture or family planning. In addition social networks are built and utilised in group sessions (McKernan, 2002; Pitt, Khandker, McKernan, \& Latif, 1999). However, the obligatory weekly meetings and the social pressure may be a burden to the borrowers (Wright et al., 1998). Hence, some MFIs have now moved away from group lending to individual lending (Meyer, 2013).

Most MFIs provide production credit, some consumption credit. Mahajan and Ramola (1996) observed that the poor usually have relatively high demand for consumption credit. However, since this is rarely offered, production loans are used for consumption purposes. MFIs target borrowers of different characteristics regarding age, sex, and education, which may influence the outcomes of the programs. Whereas Pitt and Khandker (1998) reported positive outcomes for female borrowers, Kaboski and Townsend (2012) found no positive outcomes. The level of education influences outcomes positively (Attanasio et al., 2015). MFIs also have different policies regarding maximum and minimum loan size (AMFIU, 2011). Loan size may influence the willingness of clients to join a program and also the outcomes of the programs. Some loans may be too small to make contributions to poverty reduction. The success of microfinance also depends on the context in which a program is implemented (Chliova, Brinckmann, \& Rosenbusch, 2015; Coleman, 1999; Kabeer, 2005). Some programs target the urban poor, others the rural poor, and some have no specific categories as long as borrowers can pay (AMFIU, 2011). 


\subsection{Study area}

Our study was conducted in the districts of Mukono and Buikwe, both located in the central region of Uganda, within the Lake Victoria basin. The districts were selected based on two criteria. The first one was the presence of BRAC microfinance activities among rural agrarian clients. The second was the MFI having expansion plans which was necessary for the identification of new borrowers for the study (see Table 2.1). Mukono district shares borders with Buikwe in the East. The relief, climate and fertile soils make the area suitable for agricultural production (Mukono District Local Government, 2010).

With a population of about 599,817 people Mukono ranks seventh out of the 121 districts of Uganda, whereas Buikwe has a population of about 436,406. Most people in Mukono (73\%) and Buikwe (67\%) live in rural areas (UBOS, 2016). Over $80 \%$ of the population in rural parts of both districts rely on agricultural production. Subsistence agriculture is characterised by low acreage due to increasing family sizes and land fragmentation, and by low productivity per unit area because of deteriorating soil fertility. Because of the proximity to the lake and the presence of rivers and many fish landing sites, fishing is an important economic activity in the two districts. Most fish is taken by big fish processing companies for the export market (Mukono District Local Government, 2010). Buikwe district is located 62 kilometres by road east of Kampala. It became a separate district in 2009 (UBOS, 2016).

\subsection{Method}

\subsubsection{Study design and instruments}

Employing a methodology sometimes referred to as the USAID/AIMS comparative crosssectional analysis design (Gaile \& Foster, 1996; Nelson et al., 2004), we compared the 
characteristics of existing borrowers or Old Borrowers (OB) and incoming clients or New Borrowers (NB). The latter were in their mandatory orientation period of one month and had not yet received their first loan. We expected these women to have comparable characteristics as women in the OB category (cf.Armendáriz \& Morduch, 2010). The selection criteria are summarised in Table 2.1. Tables $2.2 \mathrm{a}$ and $2.2 \mathrm{~b}$ provide details of the data collected by the different data collection methods.

Table 2.1. Study group criteria of selection

\begin{tabular}{lcl}
\hline Groups & Accessed microcredit & Criteria \\
\hline Old Borrowers (OB) & Yes & $\begin{array}{l}\text { Had a microenterprise (ME). Had a running loan with } \\
\text { BRAC. Had not borrowed from other MFI before BRAC. }\end{array}$ \\
New Borrowers (NB) & No & $\begin{array}{l}\text { Had ME. Had joined a village organisation (VO), but } \\
\text { were in the mandatory period of one month of orientation } \\
\text { before getting a loan. }\end{array}$ \\
\hline
\end{tabular}


Table 2.2a. Summary of data collected in the quantitative survey

\begin{tabular}{|c|c|}
\hline Data category & Variables of interest \\
\hline $\begin{array}{l}\text { Respondent socio- } \\
\text { demographic characteristics }\end{array}$ & Respondent age, marital status, education and religion and savings. \\
\hline Household information & Numbers, age, and sex composition of household members \\
\hline $\begin{array}{l}\text { Microcredit-related } \\
\text { information }\end{array}$ & Loan amount, loan cycles, loan allocation and expenditure and loan-repayment \\
\hline Non-farm ME data & Type and monetary value of MEs \\
\hline Crop ME data & Types of crops. \\
\hline Animal ME data & Types of animals \\
\hline $\begin{array}{l}\text { Time preference items }{ }^{1} \\
\text { (Adapted from Petrocelli, } \\
\text { 2003) }\end{array}$ & $\begin{array}{l}\text { (1) I only focus on the short term; (2) I live more for the present than for the } \\
\text { future; (3) The future will take care of itself. }\end{array}$ \\
\hline $\begin{array}{l}\text { Achievement motivation } \\
\text { items }{ }^{1} \text { (Adapted from } \\
\text { Keinan and Kivetz, 2011, } \\
\text { and Ray, 1980) }\end{array}$ & $\begin{array}{l}\text { (1) I get restless and annoyed when I feel I am wasting time; (2) I have always } \\
\text { worked hard to be among the best; (3) I am an ambitious person; (4) Improving } \\
\text { my life is important to me }\end{array}$ \\
\hline $\begin{array}{l}\text { Risk Preference items }{ }^{1} \\
\text { (Adapted from Blais and } \\
\text { Weber, 2006) }\end{array}$ & $\begin{array}{l}\text { (1) I enjoy taking part in decisions with un-known outcomes; (2) I avoid } \\
\text { activities whose outcomes are uncertain (reverse scored); (3) to gain high profits } \\
\text { in business one should take decisions even when uncertain of the outcomes; (4) I } \\
\text { would invest all my monthly profit in a new business venture. }\end{array}$ \\
\hline \multicolumn{2}{|c|}{$\begin{array}{l}{ }^{2} \text { Personality characteristics scale (1=agree strongly; } 2=\text { agree to some extent; } 3=\text { disagree to some extent; } 4=\text { disagre } \\
\text { strongly) }\end{array}$} \\
\hline \multicolumn{2}{|c|}{ Table 2.2b. Summary of data collected by qualitative methods } \\
\hline Data category & Discussion themes \\
\hline $\begin{array}{l}\text { Focus group } \\
\text { discussion data }\end{array}$ & $\begin{array}{l}\text { Reasons for borrowing, loan repayment, group dynamics in loan repayment, benefits of } \\
\text { borrowing, types of loan-funded MEs. }\end{array}$ \\
\hline $\begin{array}{l}\text { Key informant } \\
\text { interview }\end{array}$ & Characteristics of the BRAC microcredit program \\
\hline
\end{tabular}

\subsubsection{Organisation of the study}

The original questionnaire was designed in English. To reduce inter-interviewer variation in administering the questions and for easy communication with the respondents, it was translated into Luganda (local language) by the Institute of Languages of Makerere University. Seven Luganda-speaking enumerators with experience in conducting surveys were selected, 
interviewed and trained. During the training, enumerators also translated and back-translated the questionnaire and the result complemented the translation by the professional translators.

Initial enumerator training lasted one week. During this time, the interviewers were oriented about the study questions, objectives and data collection methods. Role-plays were used to practice how to approach and address respondents and how to introduce the study and ensure compliance. Points of emphasis during the training included respondent categorisation, themes and objectives of different sections of the questionnaire, self-introduction and introduction of the study to respondents, proceeding through the questionnaire, and the importance of getting complete data. After the training a pilot study was conducted by collecting data from 25 respondents. The data collected was then analysed to ensure its usefulness for meaningful results and analysis, especially for the open parts of the questionnaire. A few modifications were made to the questionnaire after this activity. Given that it was not easy to obtain alternative respondents especially in the NB category, these respondents were re-interviewed to obtain data that was originally missed.

\subsubsection{Sampling and data collection procedures}

All BRAC branches in Mukono and Buikwe districts were eligible for inclusion into the study. We purposively included BRAC branches that had expansion plans, a pre-requisite for recruitment of new borrowers (NB). In order to balance out the effect of loan period and loan cycles, we also sampled and included Village Organisations (VOs) that had existed for more than two years. BRAC branch managers and loan officers used loan sheets to aid in the selection of VOs, with typically agrarian borrowers. VOs for NBs were newly-formed VOs or had new borrowers. All women in a selected VO were eligible as respondents, except those who 
previously borrowed from other MFIs. NBs were enrolled in the study during the mandatory one-month orientation period into BRAC. OBs were women with a running loan with BRAC and were selected from VOs in the same or neighbouring village as selected NBs. Drop-outs from OB groups were traced and interviewed to reduce drop-out bias. Karlan (2001) proposed inclusion of drop-outs in borrowing group analyses if possible, in case they would possess unique characteristics that could lead to biased outcomes. Information about the BRAC microcredit program was obtained from FGDs with the borrowers and from key-informant interviews with BRAC loan officers, branch managers and the area manager. We got some information from BRAC loan-borrower documents, that we were able to access and also attended some VO meetings to understand more about the program operations.

With the consent of the participants and after assurance of confidentiality baseline data collection was undertaken between September 2013 and March 2014. Six FGD sessions were held for OB groups and two for NBs. Each focus group comprised 8-15 participants who had not been respondents in the survey and from groups not included in the survey. Detailed notes and audio recordings were used to record the interviews. A FGD guide was used to elicit information from participants about their opinions and experiences with borrowing.

The following problems were encountered:

- Interviews were sometimes interrupted when conducted at the women's work place because they had to attend to their business clients.

- Sometimes we had to deal with husbands who had to be convinced to give room for the interview to take place and sometimes curious people who tried to listen in on the interviews. 
- Respondents became uncomfortable when asked questions about their wealth and expenditures.

- Interviews lasted about two hours, which tried the patience of the respondents.

However, these problems did not affect the realisation of the study objectives. Each time we carefully explained to the respondents the objectives of some of the intrusive questions to ensure compliance and ease in response and requested non-respondents to excuse us as we conducted the study. Working together with the chairperson of the village council also helped to get support for the study.

\subsubsection{Data operationalisation, processing and analysis}

Data processing was an intensive activity of cleaning, coding, data entry and analysis. Data from the open-ended parts of the questionnaire were processed into variables that could be used in further analysis. All data were entered into IBM SPSS Statistics 22. Analysis was done using Stata 10. In order to assess the characteristics of women BRAC reaches, we analysed base-line data of 533 respondents. Of these 312 were current borrowers (OB) and 221 were in-coming borrowers (NBs). They were from 138 VOs, from seven BRAC branches in Buikwe and Mukono districts.

We compared OB and NB groups on socio-demographic and personality variables, including religion, marital status, age, and years of education, time preference, risk preference, and achievement motivation. Focus group discussion data were analysed using ATLAS.ti software, to obtain the most commonly occurring issues during discussions. Principal components analysis was used to check the dimensionality of the personality characteristics. We also constructed an asset index and a housing facilities index, as a proxy for wealth using principal component 
analysis of data on household wealth and asset ownership. We obtained two components from our analysis. The household assets index included seven variables: numbers of tables, chairs, beds, mattresses, cell phones, hoes and radios. The housing facilities index comprised the variables of house ownership, TV ownership, presence of electricity, type of walls and the material for the floor of the houses.

\subsection{Results}

\subsubsection{Borrowing information and characteristics of the BRAC microfinance program}

In this section we present our findings on the objectives and design of the BRAC microfinance program, as obtained from our direct observations and interactions with borrowers, from focus group discussions and in-depth interviews with different BRAC personnel.

The BRAC microfinance program targets poor women (aged 20-50 years) with stable businesses to enhance the performance of their self-employment activities (agricultural or nonfarm microenterprises). BRAC uses the group lending model, to provide individual loans to women who must belong to a village organisation (VO). The VOs in the study had on average 20 women. We were informed that groups above this are split. Indeed, we found groups with similar names in the same village and sometimes holding meetings at the same place, which were previously part of a bigger group.

BRAC's policy is to mainly employ women in its programs. Although we observed males at higher staffing ranks, all area managers, branch managers and credit officers were found to be female. When starting in a new area, a survey is done to determine the potential for new borrowers. The BRAC branch and area managers as well as credit officers (COs) are in charge of 
expansion of BRAC activities in new areas by fostering $\mathrm{VO}$ formation and registration and admission of women into the program. When a new area is deemed viable, a new branch is established. Then COs move door-to-door to inform women about the microfinance program and encourage them to form groups. New groups select their leaders (a chairperson, secretary and cashier), chose a name for the group and decide where they will hold the weekly group meetings. At the weekly meetings the $\mathrm{CO}$ assigned to the group explains BRAC policies and processes. After a VO is established, old members bring in new ones. For all new members there is a mandatory one-month period of orientation before receiving the first loan. A new member is introduced by a seconder into the VO and has to present herself and her motivation to join the group. Members will accept the new member based on how they judge the risk of default. On acceptance into the $\mathrm{VO}$, the new member will receive three independent inspections of her home and business by the VO credit officer, the branch manager and the area manager. The inspections are meant to confirm the physical existence and location of the woman's residence and business and to assess stability and viability of the business and the woman's ability to pay the weekly instalments. When the team is satisfied the group members may sign a group resolution of admission into the group and the $\mathrm{CO}$ will sign the BRAC admission form. Upon admission, the new member has to produce an introduction letter from the chairperson of her village, provide three passport photographs and physically present to the group a guarantor (usually the husband) who will repay the loan in case loan recovery fails. The final step of admission occurs at the branch office, where the woman and her guarantor present themselves at a session chaired by the area manager and the new VO members pay their annual registration fee.

Loan applications are guaranteed by every member of the group. Loan amounts must also be agreed upon unanimously. Authorized microloans are disbursed in cash to individual women, at 
the branch. At the time of the study the borrowers in the OB group had received credit on average three times. The mean amount of the first loan was UGX $358,414(\$ 138)$, while the average amount of running loans was UGX 725,000 (\$278). The average number of weeks since receiving the last loan for the respondents was 20 and since receiving the first loan 97 weeks.

Loans were repayable in either 20 or 40 equal weekly instalments, at flat interest rates of $12 \%$ and $25 \%$, respectively. The instalments are paid at weekly meetings with repayments commencing one week following the receipt of the loan. Repayments are received from individual members by the $\mathrm{VO}$ chairperson who passes the money over to the $\mathrm{CO}$ for checking and bagging. At the end of the day's rounds the $\mathrm{CO}$ hands over all payments received to the branch cashier for banking. Women who are unable to make the week's repayment before the meeting day may request support from VO members. In case of a member's payment failure the group chairperson and credit officer urge members to cover the payment together by pooling funds. A VO meeting may not disperse until all funds have been collected, counted and verified in front of all women. When members fail or refuse to raise the funds for a defaulting member, the loan guarantor will be contacted. If this fails as well, usually after a period of haggling and arguing, the CO may reluctantly allow the meeting to disperse and visit the defaulting member's home or continue to seek the guarantor. If all fails, the branch cashier can deduct the deficit from the CO's salary. When all points to a woman's inability to continue making her weekly repayments, her loan guarantor is heavily leaned on to repay the loan in one instalment or weekly payments until the full amount is paid up. In extreme cases, property of the woman (usually some business asset) or of the guarantor may be confiscated.

We observed that credit officers were very vigilant in attending the VO meetings and hardly ever failed to turn up, even in adverse weather conditions. Borrowers also regularly attended VO 
meetings but resented the duration of the meetings. On days with special events, for example on market days they would get impatient. COs and branch managers reported very good repayment performance for initial loans and repayment difficulties with larger loans for successive loans cycles when weekly repayment amounts commensurately increase. They identified two categories of BRAC participants: the borrower category, consisting of women with a running loan with BRAC, and the member category. The latter includes the borrower category plus women who are new and did not yet borrow, and those who are 'resting'. A woman was said to be to be resting if she once belonged to a $\mathrm{VO}$ and had a BRAC loan, but decided not to apply for another loan (yet). Resting borrowers were eligible to borrow again. Drop-outs are women who stopped borrowing and even withdrew the security deposit (10\% of the loan) that was retained for all loans as insurance against defaults. Outstanding loans of defaulters could be recovered from this deposit. BRAC has the lowest portfolio at risk (PAR) of MFIs in Uganda (Mohammad Dulham Hussain Chowdhury, 2016, personal communication). At the time of the study the dropout rate was estimated at $15-20 \%$. BRAC records we saw indicated presence of resting and dropout members in different groups, especially the older VOs. We could not establish actual dropout rates for it was hard for us to access borrowing sheets for most of the VOs we visited.

BRAC has no mandatory members' savings program. However the women indicated belonging to self-help Rotating Saving and Credit Associations (ROSCAs) in which they mobilised savings for loan repayment and other lump-sum payments. 


\subsubsection{Socio-demographic and personality characteristics of current $(\mathrm{OB})$ and in-coming}

(NB) BRAC borrowers

This section presents survey data on the socio-demographic and personality characteristics of the two groups of borrowers, OB and NB.

Table 2.3. Socio-demographic and personality characteristics of current and in-coming borrowers

\begin{tabular}{lccc}
\hline Respondent Characteristic & \multicolumn{3}{c}{ Sample Means } \\
\cline { 2 - 4 } & OB & NB & \multicolumn{1}{c}{0.92} \\
\hline Dependency ratio & 1.58 & 1.46 & $2.31^{*}$ \\
Age at first loan & 35.23 & 33.03 & 0.39 \\
Education (Years) & 7.35 & 7.22 & 1.46 \\
Time preference score & 3.48 & 3.36 & 1.01 \\
Achievement motivation score & 1.23 & 1.20 & 1.34 \\
Risk preference & 2.25 & 2.16 & 1.11 \\
Anglican (\%) & 0.32 & 0.27 & -0.81 \\
Pentecostal (\%) & 0.14 & 0.16 & 0.64 \\
Muslim (\%) & 0.21 & 0.19 & -0.35 \\
Marital status (\%) & 0.70 & 0.71 & 1.55 \\
Household asset index & 2.23 & 2.11 & 0.73 \\
Housing facilities index & 0.47 & 0.45 & \\
\hline
\end{tabular}

$* p<0.05$

The only characteristic the current and in-coming borrowers differed on was age (see Table 2.3). The average age for the $\mathrm{OB}$ group was significantly higher than that for the NB group. Overall the majority of respondents had completed seven years of primary education. The average time preference, achievement motivation and risk preference scores indicate that both groups had a high future bias, a high need for achievement and are mostly risk neutral. The majority were married and came from households with low household asset and housing facilities indexes. 


\subsubsection{Microenterprise information}

Table 2.4 shows the types of microenterprises for current borrowers $(\mathrm{OB})$ and in-coming borrowers (NB).

Table 2.4. Types of microenterprise for current $(\mathrm{OB})$ and in-coming (NB) BRAC borrowers

\begin{tabular}{lcccc}
\hline Type of microenterprise (ME) & Respondent Category & N & \% (Yes) & Chi-square \\
& & & & \\
\hline Non-farm ME only & OB & 318 & 41.67 & 0.91 \\
\multirow{2}{*}{ Agricultural ME only } & NB & 221 & 37.56 & \\
\multirow{2}{*}{ Agricultural and non-farm ME } & OB & 312 & 13.14 & $6.48^{*}$ \\
& NB & 221 & 6.33 & \\
Animal production ME & OB & 312 & 43.27 & $6.30^{*}$ \\
& NB & 221 & 54.30 & \\
& OB & 312 & 14.10 & 0.89 \\
& NB & 221 & 11.31 & \\
\hline
\end{tabular}

$* p<0.05$

Almost a quarter of current borrowers (OB) indicated that they exclusively practiced agriculture as a business. Of current borrowers (OB) and in-coming borrowers (NB), a considerable proportion (43\% and 54\%, respectively) indicated running both an agricultural and non-farm ME. The NB group had a significantly higher number of respondents who indicated owning both agricultural and non-farm MEs.

For both $\mathrm{OB}$ and NB we found that the majority of respondents ( $85 \%$ and $92 \%$, respectively) owned some kind of non-farm ME. The self-reported monetary values of the non-farm MEs, for OB and NB groups were on average about USD 300 and USD 200, respectively. Four respondents reported ME values of less than USD 5. The majority of respondents in the OB group (65\%) were small-shop and market retailers of farm produce from their own gardens and 
from other farmers. Some also sold common household consumer goods. Few women (about $11 \%$ ) offered semi-professional services of hair dressing and small-restaurant catering. Fifteen percent of the combined sub-sample of $\mathrm{NB}$ and $\mathrm{OB}$ were involved in production-related activities, such as crafts and liquid soap and bread making. Ten percent was involved in natural resource extraction, like brick-making, stone-quarrying, and charcoal-burning. The majority of the respondents was self-employed and did not employ others.

For both OB and NB about two-thirds of respondents with agricultural microenterprises were food crop farmers. Maize and beans were the main crops produced for sale. The numbers of women involved in traditional cash crop production were negligible. Few respondents (14\% and $11 \%$, respectively) reported practicing animal husbandry as a microenterprise. Respondents who kept animals on the homestead considered these as a form of storage of wealth. Goats, chicken, and pigs were the most commonly kept animals.

\subsubsection{Reasons to borrow and loan repayment of borrowers}

In the focus group discussions (FGD) women expressed their appreciation for BRAC enabling them to access credit, because they lacked alternative sources of credit and could not meet their lump-sum needs from their meager incomes. However, contrary to the expectation that loans would be invested in productive activities, qualitative results revealed that many borrowers invested only a fraction of the loan in their ME and used the rest for non-business purposes such as school fees and building expenses. In the FGDs the following reasons for borrowing, in order of frequency of occurrence, were mentioned: (1) pay children's school fees; (2) recapitalise nonfarm microenterprises; (3) personal development; (4) household welfare and improvement; (6) crop farming; (7) animal husbandry; (8) start a new business. This shows that non-business 
expenses were among the motives for acquiring credit. We asked the women whether improving food security improvement was a reason for borrowing, but they indicated it was not. They claimed to have adequate food from their gardens most of the time, except during the planting season. But they denied spending loan money on food purchases even then, which is reflected in the following comments:

'I cannot spend BRAC money on food purchase. But on the day I get the funds, I may buy a kilogram of meat for my children, to encourage them to support my efforts at loan repayment'.

'Whenever I get a loan, I purchase a personal item for myself; could be a bag or a dress. Sometimes after a while, it is all you have to show for the money you borrowed'.

Education came out as an important reason for borrowing, which shows in the following comment: 'Our children can now go to school without being sent back home for fees'.

The borrowers indicated that they worked harder than before borrowing and harder than women who did not borrow in order to be able to repay their loans. They found the BRAC policy of loan repayment starting in the week after borrowing too tight. To comply with repayment requirements, some borrowers kept a portion of the received loans to make repayments in the weeks just after borrowing. The majority indicated to have more than one source of income, to ensure funds for loan repayment. From the FGDs it transpired that indeed most women practiced some kind of trade. We got comments like:

'Everyone has something to sell. Some of us sell agricultural produce from our gardens, others prepare and sell ready-to-eat snacks or have small retail shops or market stalls'. 
'You cannot have only one source of income and manage loan repayment. If you have borrowed, your brain does not rest like the women who did not borrow. If all else fails, you put aside funds from what the husband has given you to take care of the home and use if for loan repayment'.

For stopping to borrow the following reasons were given: (1) achieved the objective of borrowing, usually business stabilisation; (2) the business collapsed; (3) ordered to abandon borrowing by the husband; (4) sickness or death in the family leading to failure to repay loans; (5) to get relief from the pressure of loan repayments; (6) high interest rates. Women indicated that they found the interest rates rather high and also consider the security deposit an extra cost. Some said they would have preferred larger amounts, but usually, this is not possible especially with the first loan. Women could accept the loan application requirements and procedures the first time but expressed discomfort with the same procedures for subsequent loans.

\subsection{Conclusion and discussion}

In this chapter, we sought to describe the characteristics of the BRAC microfinance program and to assess the degree of matching between lender and borrower conditions and aspirations. We determined the borrower characteristics, type of their business, and the reasons for borrowing and dropping out. These were compared to BRAC procedures, goals, and objectives.

The BRAC modified Grameen lending model seems to fit the Uganda women quite well. Women in Uganda are generally not faced with restrictions on their mobility and can venture out of their homes, unlike in rural areas in South Asia where there is a tradition of purdah (Papanek, 1973). This makes it possible for the women to attend the weekly VO meetings. Additionally, the fact that most credit officers are female reduces distrust among husbands. 
In our case, we found evidence of the advantages of group lending with joint liability to loan recovery, as has been reported in literature (Armendáriz \& Morduch, 2010; Postelnicu, Hermes, \& Szafarz, 2014). Because women only admit women they know well into their group, they are able to use their social ties to screen new members, monitor the process, and ensure loan repayment by group members. Social capital is utilised to coordinate repayment decisions, cooperate for mutual benefit and reduce loan defaults. The additional requirement of presenting a loan guarantor also helps to ensure loan recovery.

The age and educational profile of the borrowers (both current and new) matched BRAC program requirements. For women with only seven years of education it is difficult to participate in the formal sector. With just basic literacy and numeracy skills such women face personal and institutional barriers to formal credit access, leaving them poor and deprived. The BRAC microfinance program with its reach into rural areas offers these women financial services they otherwise would have no access to, different from some MFIs that shy away from rural areas and from funding agricultural activities (UBOS, 2010a; Word Bank, 2007). Many BRAC borrowers were engaged in subsistence food crop production with some relying exclusively on agriculture. Women's limited involvement in animal and cash crop production is probably due to societal perceptions of women as household food providers (Gladwin et al., 2001; Schroeder, 1996) and cash crop production as a male activity (Gladwin et al., 2001). Unfortunately, this limits women borrowers' earning capacity since food production has a time lag between investment and returns. Agricultural incomes are also unreliable because of erratic climatic conditions and depleted soils (Morvant-Roux, 2011).

Possibly to cope with the risks associated with agriculture, we found many respondents owning both agricultural and non-farm microenterprises. Income diversification is a common 
strategy in resource-constrained communities (Banerjee \& Duflo, 2007; Barrett et al., 2001; Ellis, 1998; Niehof, 2004b) and a prerequisite for the development of rural communities (Word Bank, 2007). Livelihood diversification has been observed to increase with borrowing (Khandker \& Koolwal, 2016) and is practiced as an insurance against income shocks (Buckley, 1997). Women engage in agricultural production using resources that are available to them (notably own labour) and complement this with non-farm self-employment activities (Banerjee \& Duflo, 2007). As observed by Smith, Gordon, Meadows, and Zwick (2001) and Buckley (1997) about non-farm activities in Uganda, women get the start-up capital for such activities from the sale of farm produce and sometimes husbands and children. Unfortunately, women usually start lowreturn activities that have little potential to lift them out of poverty (Gladwin et al., 2001). In our case, the non-farm microenterprises the women engaged in were small with low monetary value. They had few business assets and were not employing others. The businesses seemed geared towards survival rather than expansion and self-reliance, and reflect little innovativeness and ambition. This may have to do with the context in which these women operate. Rural and agrarian Uganda has no history of family business or artisanship to build on.

BRAC borrowers indicated that they work harder than before they received their loans. However, rather than their hard work resulting in innovativeness and business expansion it amounts to scurrying around between different activities in an effort to diversify income sources to raise money for loan repayment. BRAC and other MFIs have a vision of financing the entrepreneurial poor to facilitate improvement in their socio-economic status. It is questionable whether this description applies to the borrowers in our study. Some of them seem to fit better in the category of the ultra-poor of the BRAC Bangladesh Targeting the Ultra Poor (TUP) program described by Hulme, Moore, and Seraj (2011). And perhaps they would benefit more from such a 
program. As Viswanathan (2002) observed on the informal sector in West Africa, apart from lack of credit women's informal businesses are constrained by lack of entrepreneurial skills and poor product differentiation. Women deal in almost the same type of products and services, leading to undue competition. Similarly, Adams and Von Pischke (1992) noted that credit may not be the biggest problem for agricultural small holders, who face price and other production risks as well as transportation and other infrastructural challenges.

Some of the characteristics of the BRAC borrowers and their business do not seem to match with BRAC program specifications. First, the requirement of repayment commencing in the week following loan access is a notable problem for loans invested in farming, which require time between investment and outputs. To avoid defaulting, women employ drastic measures like selling off any kind of saleable agricultural produce, using part of the received loans to make loan repayments, or shifting the burden to relatives, children and husbands. Secondly, BRAC loans are rather small and some women indicated they would have preferred larger loan amounts for more meaningful investments. However, in-depth interviews with BRAC credit officers revealed increasing repayment problems when women graduate to larger loans that come with larger weekly instalments. This shows that, contrary to the desire for larger loans expressed by borrowers, the small loans provided in early loan cycles may be the most sustainable. Interest rates are rather high and the loan processing procedure is rigorous. Montgomery et al. (1996) observed that women in Bangladesh had problems with the BRAC security deposit requirement because of the strict rules surrounding the deposit without borrowers having a say on its size and when they may access it.

We pitted the reasons for borrowing against the objectives of the lender and found a potential mismatch. Whereas potential BRAC borrowers must stipulate a productive use for loans, our 
findings indicate that women borrow to obtain lump-sum amounts for use on school fees and other expenditures. Montgomery et al. (1996), reported respondents to be reticent about such loan diversions, but in our study respondents openly shared information about their use of loans for non-productive purposes, revealing payment of school fees as a major motive for borrowing. The strong aspirations for the education of their children that Dowla (2011) reported about women in Bangladesh were also found among the women in our sample. Indeed, because education removes barriers to engagement in better-paying non-farm employment (Barrett et al., 2001; Word Bank, 2007). Although Uganda has a policy of universal primary and secondary education, many state-sponsored schools face challenges of absentee teachers and poor quality instruction (Deininger, 2003). This results in parents trying to find money to send their children to private schools. But even though this might be a desirable investment, use of production loans to finance education brings no immediate returns for loan repayment. As Dowla (2011) argued, unlike land and other movable assets, expected future income from education cannot be used as collateral against loans. Such an investment may lead to repayment burden. In line with our results, UBOS (2010b) reported that in Uganda the three most frequent motives for borrowing are: to get working capital for small businesses (25.9\%), to buy consumption goods (15.9\%) and, third, to pay school fees (14.8\%). Matin et al. (2002) conclude that loans enable the poor to make lump-sum expenditures against small future savings and income which they use to make repayment instalments. BRAC and/or the Uganda government could consider making loans available to support children's education. BRAC currently does have a scholarship scheme, which could be modified to cater for the current need of women for their children's education.

BRAC runs a strict procedure of assessment and review of loan applications, aimed at assessing the borrower's ability to make weekly loan repayments. But after loan disbursement 
there is no supportive follow-up on the performance of the loan-funded enterprises. BRAC already has programs that could support the women, but these probably have limited coverage since the borrowers in the study were unaware of these programs. We found a few cases of women borrowers who gave the loan to husbands and children to invest and provide funds to enable the women to pay the instalments. Follow-up support might discourage the use of loans for consumption which leaves women with the burden of repayment without a meaningful investment. Follow-up with supportive services could contribute to realising both borrower and lender objectives. Alternatively, as proposed by Mosley and Hulme (1998), BRAC could come up with an alternative lending model with focus on consumption, with flexible repayment periods and with a saving facility.

We can conclude that the BRAC microfinance program indeed reaches poor women who otherwise would be unable to access funds to meet lump-sum needs. However, when these women decide to get a loan, they do so against their future meagre earnings and pay back at a frequency and cost which they eventually realise is rather high. They stop borrowing, as soon as the immediate need for borrowing is met. To a certain extent, there is a match between the lender and the borrower; women are able to meet their needs for borrowing and the lender is able to attain good repayment levels. For long-term benefit of the borrowing program, however, there is a need for the lender to reassess loan-term related issues, such as the interest rate, commencement of loan repayment, and the loan processing requirements and procedures. 


\title{
Chapter 3
}

\section{Does microcredit improve performance of women-run non-farm microenterprises?}

\begin{abstract}
We investigated the effects of microcredit on the performance of non-farm microenterprises run by small-holder female farmers in Uganda. We compared baseline data from a group of current borrowers with new borrower data. Propensity score matching revealed positive effects of microcredit on funds used to restock businesses, and on the monetary value of the microenterprises.

In an alternative approach, we compared parameters for new borrowers, before and after they received their first loan, and a control group of women who never received credit. Difference-in-difference analysis of the baseline data and follow up after one year revealed marginally significant improvement of microenterprise monetary value.

Concluding, borrowers invested reasonable fractions of received loans. However, the borrowing context, loan repayment terms, type and size of microenterprises did not seem to favour higher profits.
\end{abstract}

Publication status: Namayengo, M.M.F., van Ophem, J.A.C., and Antonides, G. 2016.

Does microcredit improve performance of women-run non-farm microenterprises? Under review at International Small Business Journal. 


\subsection{Introduction}

Self-employment by means of running a microenterprise (ME) is a widespread livelihood coping strategy among poor people in developing economies (Banerjee \& Duflo, 2007; Barrett et al., 2001; Ellis, 1998; Margolis, 2014; Niehof, 2004b). Pursuit of non-farm income sources enables households to mitigate risks associated with agricultural production. For example, erratic weather patterns and depleted soils make agricultural-related income unreliable (Morvant-Roux, 2011). Enterprise diversification by adoption of non-farm MEs helps resource constrained farmers to improve their livelihood sources and survive the failures in agriculture. In case of failure in agricultural production, non-farm income sources then become key pre-requisites to realisation of income and food security (FAO, 2016). Fortunately, if well managed, these sources have potential to contribute to the well-being and development of communities (Word Bank, 2007). Operating in the informal sector, both in rural and urban areas, MEs in developing economies contribute significantly to the owners' livelihoods (Asian Development Bank, 1997; Schreiner \& Woller, 2003).

In the case of Uganda, self-employment and income diversification strategies in rural areas gained prominence after the structural adjustment program (SAP) of the 1990s. One of the key outcomes of the SAPs was growth of the informal ME sector, as retrenched government workers joined the informal sector. At the same time, urban-to-rural financial remittances diminished, at a time the government also reduced provision of services, like free medical care, that previously benefitted the rural poor. Many rural dwellers, especially women, sought opportunities to pursue non-farm employment usually in the form of MEs (Makokha, 2001). Government statistics show that a larger proportion of the rural $(61 \%)$ than the urban workforce $(54 \%)$ was active in the informal sector (UBOS, 2010b). 
To support initiatives aimed at creating self-employment government implemented different socio-economic interventions. These include, among others, support for youth and non-youth with vocational and financial training, provision of start-up capital for ME establishment, and sometimes direct income support (MoFPED, 2014). Government-supported savings and credit associations (SACCOs) were also established to spur growth of household MEs.

As has been reported for other developing countries (Asian Development Bank, 1997; Margolis, 2014; Schreiner \& Woller, 2003) microenterprises in Uganda usually conduct lowinvestment, low-income, low-productivity activities, including traditional crop farming, and small scale retailing (Smith et al., 2001; World Bank, 2016b). ME activities are usually mixed with the household economy and use little or no fixed assets. Many MEs in Uganda lack start-up and working capital (UBOS, 2010b).

Microfinance is a popular global strategy for the supply of microcredit and other financial services to poor people to promote ME development (Hulme, 2000a). Microfinance is a major form of financing for the poor since they are usually excluded from financial markets (Armendáriz \& Morduch, 2010; Bornstein, 1997; Fletschner, 2009). It offers opportunities for financial investments in MEs leading to business expansion and increased profitability of MEs (Hulme, 2000a). Access to credit is expected to foster improvement or creation of livelihoods, when credit is used to finance self-employment activities (Hulme, 1990). Many microfinance institutions (MFIs) target poor women (Angelucci, Karlan, \& Zinman, 2013; Banerjee et al., 2015; Morris \& Barnes, 2005). Women generally lack capital and access to credit is necessary to expand or improve their productivity and income from MEs (Fletschner, 2009). Women have been reported to perform better as MFI clients than men and microcredit granted to them has 
been observed to lead to better household outcomes than that to men (Pitt \& Khandker, 1998;

Pitt, Khandker, Chowdhury, \& Millimet, 2003).

Microenterprise finance through provision of microcredit is enthusiastically regarded by donors and non-governmental organisations as a tool for poverty alleviation in low-income communities (Armendáriz \& Labie, 2011; Armendáriz \& Morduch, 2010; Hulme, 2000b). However, these claims are still the subject of debate and much scrutiny (Crépon et al., 2015; Mosley \& Hulme, 1998). There is need to obtain more evidence on credit-attributable changes in various contexts (Armendáriz \& Morduch, 2010; Banerjee, 2013; Chliova et al., 2015).

Available studies on the impact of microcredit on households and MEs show mixed results. Some studies found positive effects of microfinance participation on business income and profits (Copestake et al., 2001; Crépon et al., 2015; Fofana, Antonides, Niehof, \& van Ophem, 2015; McKernan, 2002; Pitt \& Khandker, 1998; Tedeschi, 2008) and on the general well-being of families (Barnes, Keogh, \& Nemarundwe, 2001; Panjaitan-Drioadisuryo \& Cloud, 1999). Other studies found no improvement in business income (Angelucci et al., 2013; Barnes et al., 2001) and general wealth (Angelucci et al., 2013; Banerjee et al., 2015). Banerjee et al. (2015) and Crépon et al. (2015) observed extra investments in businesses by microcredit recipients but found no impact of microcredit on business profits or general development outcomes such as education and health. Coleman (1999) observed insignificant effects of microcredit on savings, production, sales, productive expenses, and expenditures on health and education.

We also reviewed studies of the impact of borrowing in Uganda and found one study by Morris and Barnes (2005), who used a repeated cross-sectional design of borrowers and nonborrowers of three MFIs in Uganda and obtained generally positive descriptive accounts of effects of borrowing on recipients, their MEs and their households. Many impact assessment 
studies have been conducted in Bangladesh where the microfinance movement started. Some studies have alluded to some borrowers becoming worse off after borrowing (Barman, Mathur, \& Kalra, 2009; Copestake et al., 2001; Field et al., 2012; Goetz \& Gupta, 1996; Rahman, 1999a), on account of high interest rates, over-indebtedness and repayment stress, lack of control over loans and increased domestic and group-related violence. Recent randomised evaluations of the effects of microfinance in countries in four continents, as described by Banerjee, Karlan, and Zinman (2015) did not provide conclusive evidence on the effect of borrowing on entrepreneurship, business size and women empowerment, and concluded that borrowing is not as effective as once envisaged. However, they failed to confirm the negative effects of borrowing on households.

Since the success of microfinance depends considerably on the context within which a program is implemented (Coleman, 1999; Kabeer, 2005) as well as the socio-economic conditions and personality characteristics of recipients (Snodgrass \& Sebstad, 2002), we analysed the impact of microcredit on different business outcomes (ME worth, recurrent business expenditures, and profits), for resource-constrained rural agrarian clients in Uganda. Over the past few decades, the microfinance industry in Uganda has experienced rapid growth in the number of active borrowers, mainly consisting of women, estimated at 350,000 by the end of 2009 (UBOS, 2010a). While the government of Uganda supports MFIs as important partners in national development NPA (2010), there is limited information regarding their impact on targeted communities. Poverty continues to be a big problem (World Bank, 2016b) and women resort to set up poorly financed microenterprises (Ishengoma \& Kappel, 2008; Rooks, Szirmai, \& Sserwanga, 2009) as a source of income and livelihood. Many MFIs provide financial support to women with the objective of improving the outcomes and profitability of the MEs. However it is 
not clear whether the women actually invest their received credit in the MEs, and whether the MEs improve in performance.

Provision of microcredit is expected to spur ME growth and expansion since lack of financing is considered a limiting factor to ME expansion. We thus make the assumption in this study that provision of microcredit to women will lead to improvement in the performance of the MEs of poor women, for various reasons. First, microloans may be invested in factors, inputs and practices that promote higher ME outcomes and profits, leading to higher business turnover and profits. In addition, borrowers may take up more risky but more profitable investments. On the other hand, ME performance may deteriorate or remain unchanged after borrowing for various reasons. First, loan fractionation between MEs and other household needs may leave only a fraction of the received loan for ME investment. MEs may thus not become more profitable. In addition, loan repayment may continuously drain the MEs, affecting profitability and growth. Lastly, ME improvement may not be a core objective of borrowing.

In this paper, we aim at assessing differences between ME performance parameters of borrowers and non-borrowers using different performance indicators. We seek to assess whether borrowing induces changes in investments in non-farm MEs, the operation of MEs, and their monetary worth and profits. We also explore factors that may explain these effects for a subsample of respondents who run non-farm MEs.

Our main research question is whether access to microcredit leads to improvement in the performance of non-farm microenterprises. To answer the research question, we employ two study approaches. The first is a quasi-experimental approach that uses cross-sectional data from a treatment group of old borrowers (OB), in the BRAC Uganda microcredit program (see Section 3.2), and a control group of new borrowers (NB), who self-selected to participate in the BRAC 
microcredit program, before they received their first loan. We use propensity score matching to further ensure comparability of the groups and to assess differences between treatment and control groups.

In the second approach, we use one-year panel data from the NB category and control group (CG), who never got a loan from BRAC or other MFI. We employ a difference-in-difference (DID) estimation with Kernel matching to assess differences between ME performance parameters and profits for borrowers and control households. Next, we describe our theoretical framework, study methods, and results. We conclude with a discussion of our results.

\subsection{Theoretical framework for relation between microcredit and microenterprise}

\section{development}

This section is a summary of the theory of change in households and enterprises, resulting from microcredit. It provides the theoretical basis of the key variables of the study.

Women constitute a large percentage of the world's poor (Fletschner, 2009). By 1995, about 70 per cent of the 1.3 billion people living on less than $\$ 1$ per day, were women (UNDP, 1996). Hampered by low levels of education and skills, female participation in formal employment is limited. They thus resort to self-employment by setting up small survival and maintenance microenterprises. These poorly-financed microenterprises have low financial and human capital provisions, and low returns, and yet they constitute a major source of livelihood for women and their households (Jiggins, 1989; Schreiner \& Woller, 2003).

Proponents of microfinance argue that women lack access to credit and that credit access will lead to increase in the income of households by increasing investment in income-generating activities, diversification of income sources (Khandker \& Koolwal, 2016), and smoothing of 
consumption (Armendáriz \& Labie, 2011; Armendáriz \& Morduch, 2010; Khandker \& Koolwal, 2016), hence contributing to food security. Generally, access to credit is expected to improve the social and economic status of women in society (Fletschner, 2009; Hermes \& Lensink, 2011). There are many paths through which borrowing may affect individuals and households. Introduction of MFI activities in an area improves access to financial service, including microcredit (Guiso et al., 2004; Kaboski \& Townsend, 2012). Borrowers after credit access may then change their production and consumption decisions (Crépon et al., 2015). They may invest in a new business, expand an existing one or increase their labour supply (Banerjee et al., 2015; Crépon et al., 2015). The extra investment is expected to lead to, among others, improved productivity (Matin et al., 2002), ME expansion, increased business outputs, profits and income, and asset accumulation (Gobezie, 2004; Karlan \& Goldberg, 2011; McKernan, 2002; Sebstad et al., 1995). The human capital of borrowers may improve also from non-credit MFI services, like training, business sharing and group support, which may improve business and self-employment skills (McKernan, 2002), and ME output. However, diversion of microloans to non-ME expenditures may deprive MEs of capital and negatively affect ME profitability or expansion (Gifford, 2004; Rutherford, 2011).

Microenterprises in rural communities are intertwined with other household economic activities. Decisions about these activities are made in due consideration of the trade-offs and options within the overall household economy (Sebstad et al., 1995). Income from selfemployment microenterprise activities is complemented with farm income from the sale of crops and animals (Ellis, 1998). Microenterprises depend to varying degrees on the household for capital, labour and inputs. The reverse is also true, since households depend on the MEs as sources of cash (Sebstad et al., 1995) and income in kind. The income and cash flow within 
households is fungible with allocation and reallocation of funds between different livelihood activities. Because MEs are firmly embedded in the household among poor families, searching for the impact of microcredit may take care of fungibility issues, due to loan diversion, by looking for impact on household consumption, in addition to production (MkNelly \& Lippold, 1998).

Generally, microcredit is expected to lead to development and poverty reduction by stimulating creation or expansion of microcredit, resulting in improvement in household income, asset accumulation, and economic security (Sebstad et al., 1995). The nature and state of the business (Crépon et al., 2015; De Mel et al., 2009; van Rooyen et al., 2012), socio-demographic attributes, such as level of schooling (Bates, 1990; Berger, 1989; Crook et al., 2011; De Mel, McKenzie, \& Woodruff, 2009; Fletschner, 2009; Rakodi, 1999), gender (De Mel et al., 2009), age and marital status (Copestake et al., 2001; Feroze et al., 2011; van Rooyen et al., 2012), may affect the impact of microcredit on enterprise performance. Furthermore, time preference, risk preference, and the need for achievement may explain the decision to borrow (Bauer, Chytilová, \& Morduch, 2012), and the success or failure of the microenterprise (Begley \& Boyd, 1987; Rauch \& Frese, 2000). Time preference negatively influences the willingness to invest (Frederick, Loewenstein, \& O'donoghue, 2002), whereas risk preference and need for achievement positively influence entrepreneurial decisions (Wärneryd, 1988). Household structure and household composition may influence support available to recipients, and decision making on time and resource allocation (Berger, 1989; Cheston \& Kuhn, 2002; Fletschner, 2009; Gifford, 2004; Hulme, 2000a; Nelson et al., 2004; Rakodi, 1999). Finally, social networks may influence microenterprise survival and productivity (Attanasio et al., 2015; Gifford, 2004; 
McKernan, 2002; Rakodi, 1999). It appears that microcredit may lead to business improvement, depending on a number of personal and social factors influencing the way of spending the loan.

In this study, we tested the following hypothesis: Participation in the microcredit program leads to improvement in performance of women run-MEs. The ME performance indicators assessed were restocking amounts, primary ME value, number of employees, and ME profits. In addition, we explored the effect of different socio-demographic and personality characteristics on level of profits for non-farm MEs.

\subsection{Methods}

\subsubsection{Study design}

The design of the current study is presented in Table 3.1. The overall study was a panel design in which we collected data on three categories of respondents. The first category was the old borrowers (OB) group who had running loans with BRAC. The second category consisted of incoming new borrowers into BRAC (NB), before they received their first loan. The third group of respondents consisted of a group of women from the same villages as NBs, with a non-farm ME, but who never borrowed from BRAC or other MFI (CG).

Table 3.1. Study design

\begin{tabular}{|c|c|c|c|c|}
\hline Groups & $\begin{array}{l}\text { Microcredit } \\
\text { intervention } \\
\text { before } t_{1}\end{array}$ & Measure ( $\left.t_{1}\right)$ & $\begin{array}{l}\text { Microcredit } \\
\text { intervention } \\
\text { after } t_{1}\end{array}$ & Measure $\left(t_{2}\right)$ \\
\hline Old Borrowers (OB) & Yes & $\begin{array}{l}\text { Outcome } \\
\text { variables }\left(\mathrm{O}_{1}\right)\end{array}$ & - & - \\
\hline New Borrowers (NB) & No & $\begin{array}{l}\text { Outcome } \\
\text { variables }\left(\mathrm{O}_{2}\right)\end{array}$ & Yes & $\begin{array}{l}\text { Outcome } \\
\text { variables }\left(\mathrm{O}_{4}\right)\end{array}$ \\
\hline Comparison group (CG) & No & $\begin{array}{l}\text { Outcome } \\
\text { variables }\left(\mathrm{O}_{3}\right)\end{array}$ & No & $\begin{array}{l}\text { Outcome } \\
\text { variables }\left(\mathrm{O}_{5}\right)\end{array}$ \\
\hline
\end{tabular}


During the baseline study we collected data on the three study groups. We used a quasiexperimental cross-sectional design in which we compared non-farm ME performance parameters for $\mathrm{OB}$ and NB borrowers based on the methodology sometimes referred to as the USAID/AIMS comparative cross-sectional analysis design as described by Nelson et al. (2004). We compared non-farm ME performance parameters of a treatment group of existing borrowers (OB) and a group of incoming borrowers (NB), before they received their first loan. The basis of this methodology in the assessment of the effect of microcredit is that, since both groups had already self-selected to participate in microcredit, and one had just not received the loan, the difference between outcome measures for the two may be taken as the effect the intervention.

Furthermore, we carried out two waves of data collection for the NB and the CG groups, respectively, and these were used to obtain an alternative measure of the effect of microcredit on non-farm ME performance using the difference-in-difference (DID) method.

\subsubsection{Sample}

We use clients of BRAC, which is one of the largest micro-lenders in the world and in Uganda. Details of the BRAC microfinance program as well as Buikwe and Mukono districts where we conducted the study are given in Chapter 2 of this thesis. The results in this chapter are based on a comparison of OBs and NBs, with non-farm MEs. It also contains results for comparison of new borrowers (NB) with non-farm MEs, to a control group (CG), with non-farm MEs. Details of data collection are provided in Chapter 2 of this thesis. 


\subsubsection{Measures}

Data collection was undertaken between September 2013 and March 2014. It entailed both a questionnaire-based survey and qualitative focus group discussions (FGDs). FGDs were used to explore respondents' reasons for borrowing, loan allocation and use, and perceived benefits of borrowing to MEs and households, among others. Six FGD sessions were held for OB groups and two sessions for NBs. The focus groups each comprised 8-10 participants, and included groups which had not been included in the quantitative study. Information about the BRAC microcredit program was obtained from loan officers.

The questionnaire elicited information on sociodemographic characteristics of respondents and their households, household expenditure, enterprise-related expenditure and income, as well as several personality variables. Details of the variables we obtained from the questionnaire and those which we derived are given in Tables 3.2 and 3.3.

Socio-demographic and personality measures were assumed to reflect stable personality characteristics that might explain residual heterogeneity in the samples of new and old borrowers. 


\section{Table 3.2. List of questionnaire-based variables}

\begin{tabular}{|c|c|}
\hline Data category & Variables of interest \\
\hline $\begin{array}{l}\text { Socio-demographic } \\
\text { characteristics }\end{array}$ & Respondent age, marital status, education and religion \\
\hline Household information & Numbers and ages of household members \\
\hline $\begin{array}{l}\text { Time preference items }{ }^{1} \\
\text { (Adapted from Petrocelli, } \\
\text { 2003) }\end{array}$ & $\begin{array}{l}\text { (1) I only focus on the short term; (2) I live more for the present than for the } \\
\text { future; (3) The future will take care of itself. }\end{array}$ \\
\hline $\begin{array}{l}\text { Achievement motivation } \\
\text { items }{ }^{1} \text { (Adapted from } \\
\text { Keinan and Kivetz, 2011, } \\
\text { and Ray, 1980) }\end{array}$ & $\begin{array}{l}\text { (1) I get restless and annoyed when I feel I am wasting time; (2) I have always } \\
\text { worked hard to be among the best; (3) I am an ambitious person; (4) Improving } \\
\text { my life is important to me }\end{array}$ \\
\hline $\begin{array}{l}\text { Risk Preference items } s^{1} \\
\text { (Adapted from Blais and } \\
\text { Weber, 2006) }\end{array}$ & $\begin{array}{l}\text { (1) I enjoy taking part in decisions with un-known outcomes; (2) I avoid } \\
\text { activities whose outcomes are uncertain (reverse scored); (3) to gain high profits } \\
\text { in business one should take decisions even when uncertain of the outcomes; (4) I } \\
\text { would invest all my monthly profit in a new business venture }\end{array}$ \\
\hline $\begin{array}{l}\text { Microcredit-related } \\
\text { information }\end{array}$ & Loan amount, loan cycles, loan allocation and expenditure and loan-repayment \\
\hline Non-farm ME data & Type and monetary value of ME \\
\hline Recurrent ME & $\begin{array}{l}\text { Summation of expenditures for paid labour, rent transport, electricity, tax and } \\
\text { licences, loan repayment, telephone costs and repairs }\end{array}$ \\
\hline
\end{tabular}


Table 3.3. Glossary of calculated /derived study variables

\begin{tabular}{|c|c|}
\hline Variable & Derivation method \\
\hline ME profit calculation & $\begin{array}{l}\text { We used a profit proxy described by Daniels (2001); It involved summation of } \\
\text { the total value of products consumed by the household, money from the ME used } \\
\text { by the household and any money left over after restocking the ME }\end{array}$ \\
\hline $\begin{array}{l}\text { Loan-taking initiative score } \\
\text { based on question (Qn. 207) }\end{array}$ & $\begin{array}{l}\text { A loan-taking initiative score was a measure of borrower initiative to take a loan. } \\
\text { It was based on responses to the question inquiring whose initiative it was to take } \\
\text { the loan }(0=\text { Spouse and others, } 1=\text { Self and spouse, } 2=\text { Self })\end{array}$ \\
\hline $\begin{array}{l}\text { Repayment dependency } \\
\text { ratio (Qn. 208a) }\end{array}$ & $\begin{array}{l}\text { Repayment dependency score was a measure of borrower autonomy in loan } \\
\text { repayment. It was based on responses to the question about who was/would be } \\
\text { responsible for the repayment of the loan }(0=\text { Others/Spouse, } 1=\text { Self and spouse, } \\
2=\text { Self) }\end{array}$ \\
\hline $\begin{array}{l}\text { ME loan-repayment score } \\
\text { (Qn. } 210 \text { and 210a) }\end{array}$ & $\begin{array}{l}\text { The ME loan-repayment score was a measure of ME importance in loan } \\
\text { repayment. It was based on responses to the question identifying source of funds } \\
\text { for the last loan repayment }(0=\text { Spouse and others, e.g. VO members and family, } \\
1=\text { Sale of agriculture produce, } 2=\text { Proceeds from loan funded MEs })\end{array}$ \\
\hline Assets index (Qn. 412) & $\begin{array}{l}\text { The first component of principle components analysis (PCA) of respondent } \\
\text { household asset ownership included seven count variables (number of tables, } \\
\text { chairs, beds, mattresses, cell phones, hoes, and radios) used to calculate the assets } \\
\text { index }\end{array}$ \\
\hline $\begin{array}{l}\text { Housing facilities index } \\
\text { (Based on Qn. 412) }\end{array}$ & $\begin{array}{l}\text { The second component of PCA included variables related to housing and housing } \\
\text { facilities (house ownership, TV ownership, electricity presence, type of walls of } \\
\text { the house, and the material for the floor) used to calculate the housing facilities } \\
\text { index }\end{array}$ \\
\hline
\end{tabular}

${ }^{1}$ Personality characteristics scale (1=agree strongly; $2=$ agree to some extent; $3=$ disagree to some extent; 4=disagree strongly). Question numbers refer to the questionnaire in the Appendix.

\subsubsection{Residual heterogeneity in the data in cross-sectional sample and in the panel study}

To ensure comparability of the OB and NB groups further we used Probability Score Matching

(PSM). Factors which could influence self-selection into microcredit and those which could influence microcredit outcomes were used as control variables in the PSM procedures, including nearest neighbour, weighted Kernel and radius matching (Luellen et al., 2005). These factors comprised respondent background characteristics including age, religion, years of education, dependency ratio, time preference, risk preference, and achievement motivation. In order to compare with the NBs, all age-related variables of OBs were converted to the age basis at the time of their first loan, indicated as 'corrected age', 'corrected family size', and 'corrected 
dependency ratio' hereafter. The control variables were used to construct propensity scores estimating the probability of being in the control or treatment group.

The PSM procedure was also used to estimate the effect of receiving microcredit. The rationale of PSM is to match the participants in the treatment group to those in the control group based on propensity scores. Therefore any remaining differences observed can be attributed to the treatment. The average treatment effect on the treated $\left(\tau_{A T T}\right)$ was defined as:

$$
\tau_{A T T}=E(\tau \mid D=1)=E[Y(1) \mid D=1]-E[Y(0) \mid D=1]
$$

where $D=1$ if a participant received microcredit and $D=0$ otherwise. $Y(D)$ is the outcome variable of each participant while $[Y(0) \mid D=1]$ is counterfactual and unobservable. According to Rosenbaum and Rubin (1983) $\tau_{\text {ATT }}$ can be expressed as:

$$
\tau_{A T T}=E_{P(X) \mid D=1}[E[Y(1) \mid D=1, P(X)]-E[Y(0) \mid D=0, P(X)]]
$$

where $P(X)$ is the propensity score, that is, the probability of an individual to participate in the microcredit program given the observed characteristics $X$.

\section{DID-PSM analysis of panel data.}

Panel data analysis involved comparison of data for NBs and CG respondents using the DID approach in combination with PSM. DID measures the impact of microcredit on borrowers by comparing treatment and control groups on changes in outcomes of interest over time relative to the outcomes observed in the baseline survey (Armendáriz \& Labie, 2011). The method recognises that unobserved heterogeneity in participation is present, but assumes that such factors are time invariant (Khandker et al., 2010). We obtained the difference between outcome variables between the two time periods $\left(T_{1}-T_{2}\right)$ and netted out roles of measured and unmeasured individual attributes that do not change over time. Since this difference may be a 
reflection of differences in the broader social and economic environment, we use the control group baseline and follow-up control measures to obtain $\mathrm{C}_{1}$ and $\mathrm{C}_{2}$ differences.

That is, given the two-period setting, where $t=0$ before borrowing and $t=1$ after borrowing, letting $Y_{t}^{T}$ and $Y_{t}^{C}$ be respective outcomes of treatment and control units in time $t$, the DID method was used to estimate the average microcredit impact as follows:

$$
\mathrm{DID}=\mathrm{E}\left(\left(\mathrm{Y}_{\mathrm{t}}^{\mathrm{T}}-\mathrm{Y}_{0}^{\mathrm{T}} \mid \mathrm{T}_{1}=1\right)-\mathrm{E}\left(\mathrm{Y}_{1}^{\mathrm{C}}-\mathrm{Y}_{0}^{\mathrm{C}} \mid \mathrm{T}_{\mathrm{i}}=0\right)\right)
$$

$T_{1}=1$ denotes respondents accessing credit at $t=1$, whereas $T_{1}=0$ denotes the control group that never received or applied for microcredit. The DID estimator has the advantage of allowing for unobserved heterogeneity (the unobserved difference in mean counterfactual outcomes between treated and untreated units) that could lead to selection bias.

We improved the DID methodology by combining it with Kernel matching (Khandker et al., 2010). We used propensity scores based on factors (socio-demographic and personality characteristics of $\mathrm{NB}$ and $\mathrm{CG}$ ) which could influence participation in the microcredit program to match controls and borrowers on pre-program characteristics, in the baseline year. We then obtained differences between NB and CG groups within the common support region, on different food security parameters.

\subsection{Results}

In this section, we present empirical results of our assessment of cross-sectional and panel analysis of differences in non-farm ME performance for borrowers and those without credit. In the cross-sectional analysis, we compare baseline ME parameters for OB and NB groups. We then present longitudinal 2-year panel data comparison for CGs and NBs. Finally, we discuss the study findings and conclude. 


\subsubsection{Cross-sectional $\mathrm{OB} / \mathrm{NB}$ comparison results}

In this section, we present quasi-experimental analysis results for 467 respondents who had nonfarm MEs. These were used in the cross-sectional comparison of old borrowers ( $\mathrm{OB}, \mathrm{n}=264)$ and new borrowers (NB, $n=203)$. As mentioned before, PSM was used to ensure comparability of the two groups. It was also used to determine the average treatment effect on the treated (ATT), a measure of differences between treatment and controls, after controlling for variables that could influence taking credit.

\section{Probability score matching}

Descriptive characteristics of the respondents in the cross-sectional study before and after matching on factors that would influence microcredit participation are shown in Table 3.4.

Table 3.4. T-tests for equality of means for different variables before and after matching (NB/OB)

\begin{tabular}{|c|c|c|c|c|c|c|c|c|}
\hline \multirow{2}{*}{ Characteristic } & \multicolumn{3}{|c|}{ Unmatched sample means } & \multicolumn{3}{|c|}{ Matched sample means } & \multirow[t]{2}{*}{$\%$ Bias } & \multirow{2}{*}{$\begin{array}{l}\% \text { Bias } \\
\text { reduction }\end{array}$} \\
\hline & OB & NB & $t$ & OB & NB & $t$ & & \\
\hline Dependency ratio & 1.56 & 1.44 & 1.03 & 1.56 & 1.59 & 0.26 & -2.60 & 74.50 \\
\hline $\begin{array}{l}\text { Age at first loan } \\
\text { (years) }\end{array}$ & 34.76 & 32.82 & $2.00 *$ & 34.76 & 34.56 & 0.21 & 2.10 & 89.70 \\
\hline Education (years) & 7.24 & 7.42 & 0.57 & 7.24 & 7.27 & 0.10 & -0.10 & 83.70 \\
\hline Time preference & 3.45 & 3.42 & 0.38 & 3.45 & 3.44 & 0.14 & 1.30 & 65.00 \\
\hline $\begin{array}{l}\text { Achievement } \\
\text { motivation }\end{array}$ & 1.07 & 1.05 & 0.93 & 1.07 & 1.06 & 0.45 & 4.50 & 51.60 \\
\hline Risk preference & 2.27 & 2.26 & 0.14 & 2.27 & 2.25 & 0.28 & 2.70 & -96.00 \\
\hline Anglican (\%) & 0.31 & 0.25 & 1.39 & 0.31 & 0.29 & 0.51 & 5.00 & 64.00 \\
\hline Pentecostal (\%) & 0.12 & 0.16 & 1.23 & 0.12 & 0.13 & 0.34 & -3.20 & 74.10 \\
\hline Muslim (\%) & 0.26 & 0.19 & 1.55 & 0.19 & 0.26 & 0.05 & 0.50 & 97.00 \\
\hline Marital status (\%) & 0.69 & 0.71 & 0.44 & 0.69 & 0.71 & 0.50 & -4.80 & -10.20 \\
\hline $\begin{array}{l}\text { Household asset } \\
\text { index }\end{array}$ & 2.13 & 2.07 & 0.81 & 2.13 & 2.15 & 0.15 & -1.40 & 82.30 \\
\hline $\begin{array}{l}\text { Housing facilities } \\
\text { index }\end{array}$ & 0.44 & 0.45 & 0.39 & 0.44 & 0.45 & 0.49 & -4.60 & -20.60 \\
\hline
\end{tabular}


The probit regression analysis of treatment and control group membership, before matching, indicated no differences in education level, dependency ratio (defined as the ratio of dependents, aged 0-14 years, and those over 65 years, to the household productive members, 15-64 years), time preference, achievement motivation, and religion, between the treatment and control groups. Older women were more likely to be part of the OB group. Respondents in both groups had limited formal education, regardless of the group to which they belonged (OB or NB). The average length of schooling was 7.2 years for both groups. The dependency ratio was similar for both groups (1.44 for NB and 1.56 for $\mathrm{OB})$. The majority of women in both groups were married. Both groups had respondents with a moderate future time preference (average score $=$ 3.4) on the 4-point time preference scale. After matching, the two groups became about equal for all control variables in the study (Table 3.4).

\section{Borrowing information for respondents in the cross-section comparison}

Table 3.5 shows borrowing information including loan taking initiative, loan amount and the loan investment ratio defined as the proportion of loan invested in productive activities for $\mathrm{OB}$ and NB respondents

Table 3.5. Borrowing information for $\mathrm{OB}$ and NB respondents

\begin{tabular}{lllllllll}
\hline \multirow{2}{*}{ Variables } & \multicolumn{1}{c}{ NB } & \multicolumn{7}{c}{ OB } \\
\cline { 2 - 9 } & Max & Min & Mean & SD & Max & Min & Mean & SD \\
\hline Loan-taking initiative index $^{\mathrm{a}}$ & 2 & 0 & 1.02 & 0.92 & 2 & 0 & 1.24 & 0.91 \\
Repayment dependency score $^{\mathrm{b}}$ & 2 & 0 & 1.46 & 0.89 & 2 & 0 & 1.54 & 0.83 \\
Fraction of loan to be and/or & 1 & 0 & 0.87 & 0.30 & 1 & 0 & 0.73 & 0.32 \\
actually invested into ME $^{\mathrm{c}}$ & & & & & & & & \\
ME-repayment score $^{\mathrm{d}}$ & 2 & 0 & 1.90 & 0.38 & 2 & 0 & 1.82 & 0.55 \\
Financial burden score $^{\mathrm{f}}$ & 1 & 0 & 0.60 & 0.49 & 1 & 0 & 0.60 & 0.49 \\
\hline
\end{tabular}

Notes: ${ }^{a}$ level of initiative to take last loan; ${ }^{b}$ autonomy of borrower during loan repayment; ${ }^{\mathrm{c}}$ anticipated or actual percentage of loan invested in ME; ${ }^{\mathrm{d}}$ score of $\mathrm{ME}$ as source of funds to repay the loan; ${ }^{\mathrm{e}}$ level of burden on woman for household financial expenditures. 
The average scores of loan-taking initiative for the NB and OB respondents were 1.02 and 1.24, respectively. This means that the decisions to take loans were mainly taken by women together with others, who may have included other women, loan officers or husbands.

About loan repayment, one-third of the respondents hoped others would be in charge of paying back the received loans. The calculated loan repayment dependency score (our measure of how much women were in charge of loan repayment) was between 1 and 2 (1.46 and 1.54 for $\mathrm{NB}$ and $\mathrm{OB}$, respectively). This implied that a few borrowers expected others rather than themselves to be in charge of loan repayment.

In a similar way, we asked OBs to indicate the source of funds for last loan repayment. For the NBs we asked them what would be the source of funds for the first loan repayment. Results were used to calculate the ME repayment score, a measure of degree of reliance on the ME as source of ME repayment funds. For both NBs and OBs, we obtained ME-loan repayment scores close to 2, the maximum possible score for the ME as a source of funds for loan repayment (see Table 3.5). This implied that MEs were considered the major source of funds for loan repayment for both OBs and NBs.

Contrary to the expectation that microloans would be invested entirely in productive activities, both qualitative and quantitative results revealed that loan recipients invested fractions of the microloans between non-farm MEs, and lump-sum non-business expenditures (usually school fees and building expenses). Quantitative results revealed that even before accessing loans, NBs anticipated allocating most of the received funds (87\%) into MEs, with the remaining percentage being allocated to other household expenditures. The OB category reported investing $73 \%$ of the loans into MEs. On average NBs anticipated investing $10 \%$ of received loans into the education of children. The OBs reported a similar percentage. From the FGD results we found 
that payment of school fees was the most frequently given reason for borrowing. Investment in non-farm ME was number two in the order of occurrence of the codes we used in the qualitative analysis of the reasons for borrowing (see Chapter 2).

The NBs had not received loans by the time of the study but the average amount of running loans for OBs was UGX 725,000 (\$278) and the average number of loan cycles was 3. The average self-reported monetary worth of the primary MEs for the $\mathrm{OB}$ and NB categories were about $\$ 280$ and $\$ 184$, respectively.

\section{Microenterprise information for current borrowers $(\mathrm{OB})$ and in-coming borrowers $(\mathrm{NB})$}

Table 3.6 provides the distribution of respondents in the cross-sectional comparison of OB and NB by ME category and by type of main non-farm ME.

Table 3.6. Numbers of respondents with different ME categories and activities (\%)

\begin{tabular}{lcc}
\hline Type of microenterprise (ME) & OB $(\mathbf{n = 2 6 4})$ & NB $(\mathbf{n = 2 0 3})$ \\
\hline ME category & & \\
Non-farm ME only & 48.86 & 40.89 \\
Both agricultural and non-farm ME & 51.14 & 59.11 \\
Total & 100.00 & 100.00 \\
Type of main non-farm ME activity & & \\
Petty trade (small shop and market retailers) & 60.84 & 72.28 \\
Services & 15.97 & 10.40 \\
Natural resource extraction & 9.51 & 3.47 \\
Production & 12.17 & 11.39 \\
Other & 1.51 & 2.46 \\
Total & 100.00 & 100.00 \\
\hline
\end{tabular}

For both OBs and NBs more than half of respondents with non-farm microenterprises had both farm and non-farm MEs. The majority of respondents (resp. 72.28\% and 60.84\%) were small-shop and market retailers of farm produce from their gardens and from other farmers. They also dealt in basic household consumer goods like sugar, salt and paraffin. About one-tenth of 
both NBs and OBs were involved in production-related activities, including making crafts, liquid soap and bread. Common natural resource extraction activities included brick making, charcoal burning as well as hand-splitting of stones in stone quarries. Average monetary worth of MEs was UGX 730,000 (\$300), with 50\% of the current borrowers (OB) having MEs worth about UGX 450,000 (\$ 173), and a quarter with MEs worth about UGX 200,000 (\$ 77).

\section{Effect of microcredit on performance of women-run non-farm MEs}

The respondents used in the assessment of effect size were not significantly different across control and treatment groups on all weighted control variables of the study after matching. Also, the balancing condition was met, indicating similar distributions of the control variables independent of treatment status. Since the PSM procedure indicated that potential bias between the treatment and control groups was removed, differences in outcomes could then be attributed to the effect of microcredit.

Table 3.7. Effects of microcredit on non-farm ME performance (PSM with Kernel matching) for all respondents in the study

\begin{tabular}{lcccccc}
\hline Outcome variable & $N$ & \multicolumn{1}{c}{$\begin{array}{c}A T T \\
(\mathrm{OB})\end{array}$} & $N$ & $\begin{array}{l}\text { ATT } \\
\text { (NB) }\end{array}$ & Difference & $t$ \\
\hline Ln (profit) & 217 & 11.95 & 185 & 11.79 & 0.16 & 1.31 \\
Ln (monthly expenses for trade) & 217 & 11.37 & 185 & 11.04 & 0.33 & $2.68^{*}$ \\
Ln (total ME value) & 217 & 12.96 & 191 & 12.49 & 0.47 & $4.24^{*}$ \\
Ln (restocking amount) & 213 & 11.78 & 193 & 11.54 & 0.24 & $2.32^{*}$ \\
Number of employees & 148 & 0.15 & 193 & 0.14 & 0.00 & 0.11 \\
\hline
\end{tabular}

$* p<0.05$

Results of the PSM analysis (Table 3.7) of baseline OB and NB data for all respondents with non-farm MEs revealed positive effects of microcredit on recurrent business input expenditures 
(expenditures other than restocking), the self-reported monetary worth of the MEs, and the funds used for restocking the businesses, transformed into logarithms. The OBs spent on average 33\% more than NBs on recurrent business expenditures (other than business stock). We also found a $24 \%$ difference in investments in stock acquisition on ME restocking days between OBs and NBs. In the same line, self-reported monetary worth of non-farm MEs for OBs was $47 \%$ larger than for NBs. However, we found no difference between OBs and NBs on profits from the MEs, although we note a positive trend.

Table 3.8. Effect of microcredit on non-farm ME performance (PSM with Kernel matching result) (Comparison of NBs to OBs with 2 loan cycles only)

\begin{tabular}{lcccccc}
\hline Outcome variable & $\boldsymbol{N}$ & $\begin{array}{l}\boldsymbol{A T T} \\
(\mathbf{O B})\end{array}$ & $\boldsymbol{N}$ & $\begin{array}{c}\boldsymbol{A T T} \\
(\mathbf{N B})\end{array}$ & Difference & $\boldsymbol{t}$ \\
\hline Ln (profit) & 114 & 11.89 & 178 & 11.80 & 0.09 & 0.65 \\
Ln (monthly trade expenses) & 124 & 11.27 & 185 & 11.04 & 0.23 & 1.44 \\
Ln (ME value) & 122 & 12.80 & 128 & 12.43 & 0.4 & $3.03 *$ \\
Ln (restocking amount) & 122 & 11.74 & 129 & 11.55 & 0.18 & 1.50 \\
Number of employees & 122 & 0.13 & 193 & 0.14 & -0.01 & -0.17 \\
\hline
\end{tabular}

$* p<0.05$

A comparison of NB respondents to OBs with two loan cycles only (Table 3.8) was done to imitate the loan cycles of the NBs in the CG/NB comparison of the panel data (see Section 4.2). Typically, the one-year period in the panel data included two loan cycles. We still found the monetary value of OB to be higher than NB in this comparison.

\subsubsection{FGD results about borrowing and non-farm ME performance}

In the FGDs we asked the respondents about the status of their MES after borrowing and if they got loan repayment funds from their loan funded MEs. FGDs participants indicated investing 
some loan funds in their non-farm MEs. Expansion of non-farm MEs was an important reason for borrowing as seen from the comment below:

'We borrowed money because we didn't have enough money to do what we wanted to do. For example me I had a business but with little capital so I came to BRAC to borrow money so that I could add some more capital into my business'.

As discussed in Chapter 2, women indicated working harder than before borrowing, on their farm and non-farm MEs with the aim of getting funds for loan repayment and for other needs.

About the status of ME performance after borrowing, a number of borrowers observed that their MEs had expanded after borrowing, and were doing much better. The non-farm MEs were important sources of funds for loan repayment. In addition, proceeds from non-farm MEs were used to ensure household welfare. The women were happy to have funds for meeting basic needs they did not have before, as indicated in the following comments.

'Funds from non-farm MEs are used for school fees payment, and to buy basics for the home because most husbands stop helping us when they see that we have borrowed money'.

On the contrary, some felt that the MEs had not grown as indicated in the following comments.

'Businesses grow but not to a level where one can always get money out of it'.

And from another respondent:

'Sometimes the business stagnates due to seasonal changes in demand, in that case women use past savings to repay loans. Sometimes women do casual jobs to get loan repayment money'. 


\section{Regression results for the predictors of ME profits}

In order to check the robustness of our results, and to determine the predictors of profits from the MEs, we conducted an Ordinary Least Squares (OLS) regression analysis including the same control variables as in the PSM. The treatment effects from OLS (Table 3.9) were of the same order of magnitude as the PSM results (Table 3.7). OLS was done for the baseline data for OBs and NBs with all OBs in the study, regardless of the number of loan cycles.

Results of the regression analysis of control variables on the profits from the non-farm MEs revealed that age, risk preference and marital status were negative predictors of levels of profits from MEs. Older, risk averse and married respondents were found to register lower profits from their MEs. However the study wealth index positively predicted profit levels from the MEs.

Table 3.9. Socio-economic and socio-demographic predictors of ME profits

\begin{tabular}{lc}
\hline Parameters & Coefficients \\
\hline Treatment & $0.15(0.12)$ \\
Dependency ratio & $0.04(0.05)$ \\
Respondent age & $-0.01(0.01)^{* *}$ \\
Respondent education & $0.03(0.02)$ \\
Time preference & $-0.06(0.08)$ \\
Achievement motivation score & $-0.45(0.33)$ \\
Risk preference & $-0.10(0.06)^{*}$ \\
Assets index & $0.09(0.08)$ \\
Housing index & $0.31(0.17)^{*}$ \\
Anglican & $0.01(0.15)$ \\
Pentecostal & $0.04(0.18)$ \\
Moslem & $0.08(0.16)$ \\
Marital status & $-0.22(0.13)^{*}$ \\
$\mathrm{R}^{2}$ & 0.07 \\
\hline$* * p<0.05, * p<0.10 ;$ figures in brackets are standard errors &
\end{tabular}

\section{Sensitivity analysis}

We conducted a sensitivity analysis of our matching procedure to obtain information about possible hidden bias or bias from unobserved respondent characteristics with potential to 
influence self-selection into microcredit program. Such unobserved variables could bias our conclusions about the effects of microcredit and we tested this by conducting a sensitivity analysis (DiPrete \& Gangl, 2004; Rosenbaum, 2010). We obtained $p$-values for the Wilcoxon signed rank tests for different levels of gamma $(\Gamma)$, the odds ratio of differential treatment assignment due to unobservable attributes. Each $\Gamma$ was evaluated at the critical $p$-value $(0.05)$, the limit of significance level of the treatment effect due to endogenous selection into treatment. We obtained results for up to $\Gamma=3$, for monetary value of MEs, and funds used on restocking days. Results indicate that unobservable covariates would need to change the odds of treatment assignment by factors beyond 3 (we obtained results to as high as 56 and the significance did not change) to conclude that the observed treatment effects from propensity score matching were due to non-random assignment.

\subsubsection{Panel results}

The panel data analysis was conducted on a total of 327 respondents, who had non-farm MEs. The treatment group in the panel study were 211 new borrowers (NB) who at baseline were just about to get their first loan. The control group (CG) were 116 women from the same villages as NB but who never got a loan from BRAC or other MFI.

\section{Probability score matching}

Table 3.10 shows that there were differences in risk preferences between the treatment and the control groups. Respondents in the control group were more poor in housing facilities and more risk averse than the NB category. We used propensity score matching (PSM) with Kernel matching of CG and NB groups, during the DID analysis, to reduce the self-selection bias and 
equalise groups based on the control variables which could influence a woman's decision to take credit or not. Matching thus reduced the bias between the two groups and matched groups had respondents of similar socio-demographic characteristics. This was useful in the assessment of potential contributions of microcredit to food security, results of which will be presented elsewhere.

Table 3.10. T-tests for equality of means for characteristics of NB and CG respondents at baseline

\begin{tabular}{lrrrrrrr}
\hline Sample & \multicolumn{9}{c}{ Unmatched sample means } & \multicolumn{3}{c}{ Matched sample means } \\
\hline Characteristic & NB & CG & $\boldsymbol{t}$ & NB & CG & \multicolumn{1}{c}{} & $\begin{array}{r}\text { \% Bias } \\
\text { reduction }\end{array}$ \\
& & & & & & & -6.10 \\
Dependency ratio & 1.44 & 1.56 & -0.83 & 1.40 & 1.53 & 1.26 & 76.70 \\
Respondent age (years) & 32.82 & 34.09 & -1.0 & 32.78 & 32.48 & 0.31 & 87.50 \\
Resp. education (years) & 7.42 & 7.12 & 0.69 & 7.44 & 7.48 & -0.91 & 62.40 \\
Time preference & 3.42 & 3.54 & -1.19 & 3.42 & 3.46 & -0.56 & 3.30 \\
Achievement score & 1.05 & 1.05 & 0.70 & 1.05 & 1.04 & 0.70 & 72.70 \\
Risk preference & 2.27 & 1.97 & $2.35^{* *}$ & 2.27 & 2.35 & 0.51 & 22.80 \\
Anglican (\%) & 0.25 & 0.23 & 0.21 & 0.25 & 0.24 & 0.43 & -58.60 \\
Pentecostal (\%) & 0.16 & 0.17 & -0.21 & 0.16 & 0.17 & -0.43 & 41.50 \\
Muslim (\%) & 0.19 & 0.19 & 0.16 & 0.19 & 0.20 & -0.12 & 66.50 \\
Marital status (\%) & 0.71 & 0.62 & 1.45 & 0.71 & 0.68 & 0.63 & 76.20 \\
Household asset index & 2.07 & 2.11 & -0.39 & 2.07 & 2.08 & -0.52 & 69.00 \\
Housing facilities index & 0.45 & 0.36 & $1.87 *$ & 0.45 & 0.43 & 0.31 & \\
\hline
\end{tabular}

$* * p<0.05, * p<0.10$

\section{Borrowing information for $N B$ respondents in the follow-up study}

During the follow-up, most NBs had borrowed on average two times, with average loan amounts of UGX 666,814 (about $\$ 256$ ) at the time of the study. The mean amount of the current loan for the NBs was UGX 714,000 (approximately \$271). The mean amount of the first loan for the NBs was UGX 414,000 (approximately \$159). The majority of the treatment group (60\%) had received credit on average two times by the time of the follow-up study. 


\section{Microenterprise information for controls $(\mathrm{CG})$ and in-coming borrowers $(\mathrm{NB})$}

Table 3.11 provides summary information for categories and types of microenterprises for incoming borrowers (NB) and controls (CG). During baseline a larger proportion of CG (56.90\%), had non-farm MEs only compared to NB (39.80\%). On the other hand more NB (56.87\%) than CG (30.17\%) had both farm and non-farm MEs, respectively.

At the baseline, a total of $101 \mathrm{CG}$ respondents had some form of non-farm ME, the majority (61.39\%) being small-shop and market retailers. The number for the NB category was 203 respondents, the majority $(72.41 \%)$ being small-shop and market retailers. Fifty percent of respondents for both NB and CG sub-categories had MEs worth about UGX 200,000 (\$77), while a quarter had MEs worth about UGX 100,000 (\$ 38).

At follow-up a larger proportion of CG (55.68\%) had non-farm MEs only compared to NB (39.86\%). On the other hand more NBs (55.41\%) than CGs (38.64\%) had both farm and nonfarm MEs, respectively.

At the follow-up $84 \mathrm{CG}$ respondents had some form of non-farm ME, with the majority (55.95\%) being small-shop and market retailers. The corresponding number for the NB category was 136 respondents, with the majority $(72.71 \%)$ being small-shop and market retailers. 
Table 3.11. Types of microenterprise for control group (CG) and in-coming (NB) BRAC borrowers (\%) at baseline and follow-up

\begin{tabular}{lrrrr}
\hline & \multicolumn{3}{c}{ Baseline } & \multicolumn{3}{c}{ Follow-up } \\
\cline { 2 - 5 } Aspect of microenterprise & CG & NB & CG & NB \\
\hline ME Category & & & & \\
Agriculture (\%) & 8.62 & 2.37 & 5.68 & 4.05 \\
Non-farm ME only(\%) & 56.90 & 39.80 & 55.68 & 39.86 \\
None (\%) & 4.31 & 0.95 & 0.00 & 0.68 \\
Both agricultural and non-farm (\%) & 30.17 & 56.87 & 38.64 & 55.41 \\
Total (\%) & 100 & 100 & 100 & 100 \\
N & 116 & 211 & 88 & 148 \\
ME Type & & & & \\
Retail trade (\%) & 61.39 & 72.41 & 55.95 & 72.79 \\
Services (\%) & 20.79 & 10.34 & 22.62 & 5.88 \\
Natural resource extraction (\%) & 0.99 & 3.45 & 0 & 4.41 \\
Production (\%) & 13.86 & 11.33 & 16.67 & 15.44 \\
Other (\%) & 2.97 & 1.64 & 4.76 & 1.47 \\
Total (\%) & 100 & 100 & 100 & 100 \\
N & 101 & 203 & 84 & 136 \\
\hline
\end{tabular}

\section{Effects of microcredit on performance of women-run non-farm MEs}

DID analysis of non-farm ME performance showed a slightly larger increase in self-reported monetary value of the MEs for the NB than CG $(p<0.10)$. However, the number of employees (however small) showed a larger decrease for NB than CG. DID analysis did not reveal different changes in profits, trade expenses, and restocking amounts between NB and CG.

In order to compare the results from the DID analysis, which is based on 2-year panel data, with one year in between measurement periods, with the cross-section results for the subcategory of respondents with only two loan cycles, we compare Table 3.11 with Table 3.8. It appears that the positive effects of borrowing on the self-reported monetary value of the MEs in the cross-section analysis was maintained in the DID analysis. Apparently, the ME value increased because the women make extra investments in the business. However, some profit is invested in the ME and some is used for loan repayment. This may explain why ME profit does not increase. 
Table 3.12. DID with Kernel matching result for different performance parameters for trade MEs of NB and CG group

\begin{tabular}{|c|c|c|c|c|c|c|c|c|c|}
\hline Variable & Cat & $\mathbf{N}$ & $\begin{array}{l}\text { T1 } \\
\text { Means }\end{array}$ & $\begin{array}{l}\text { T1 } \\
\text { Diff. }\end{array}$ & $\mathbf{N}$ & $\begin{array}{l}\text { T2 } \\
\text { Means }\end{array}$ & $\begin{array}{l}\text { T2 } \\
\text { Diff. }\end{array}$ & $\begin{array}{l}\text { Diff-in- } \\
\text { Diff }\end{array}$ & $\mathbf{T}$ \\
\hline \multirow[t]{2}{*}{$\begin{array}{l}\text { Ln (restocking } \\
\text { amount) }\end{array}$} & CG & 77 & 10.99 & \multirow[t]{2}{*}{$\begin{array}{l}0.61 \\
(0.13)^{* *}\end{array}$} & 54 & 11.20 & \multirow[t]{2}{*}{$\begin{array}{l}0.45 \\
(0.16)^{* *}\end{array}$} & \multirow[t]{2}{*}{$\begin{array}{l}-0.16 \\
(0.21)\end{array}$} & \multirow[t]{2}{*}{-0.79} \\
\hline & NB & 193 & 11.60 & & 114 & 11.64 & & & \\
\hline \multirow[t]{2}{*}{$\begin{array}{l}\text { Ln (monthly } \\
\text { trade expenses) }\end{array}$} & $\mathrm{CG}$ & 74 & 10.61 & \multirow[t]{2}{*}{$\begin{array}{l}0.43 \\
(0.15)^{* *}\end{array}$} & 48 & 11.01 & \multirow[t]{2}{*}{$\begin{array}{l}0.37 \\
(0.19)^{* *}\end{array}$} & \multirow[t]{2}{*}{$\begin{array}{l}-0.06 \\
(0.24)\end{array}$} & \multirow[t]{2}{*}{-0.27} \\
\hline & NB & 48 & 11.04 & & 117 & 11.38 & & & \\
\hline \multirow[t]{2}{*}{$\begin{array}{l}\text { Number } \\
\text { employees }\end{array}$} & $\mathrm{CG}$ & 97 & 0.01 & \multirow[t]{2}{*}{$\begin{array}{l}0.10 \\
(0.03)^{* *}\end{array}$} & 95 & 0.05 & \multirow[t]{2}{*}{$\begin{array}{l}0.01 \\
(0.03)\end{array}$} & \multirow[t]{2}{*}{$\begin{array}{l}-0.08 \\
(0.04)\end{array}$} & \multirow[t]{2}{*}{$-\overline{2.07 *}$} \\
\hline & NB & 199 & 0.13 & & 196 & 0.05 & & & \\
\hline \multirow[t]{2}{*}{ Ln (ME profits) } & CG & 73 & 11.67 & \multirow[t]{2}{*}{$\begin{array}{l}0.14 \\
(0.15)\end{array}$} & 49 & 11.80 & \multirow[t]{2}{*}{$\begin{array}{l}-0.06 \\
(0.191)\end{array}$} & \multirow[t]{2}{*}{$\begin{array}{l}-0.20 \\
(0.24)\end{array}$} & \multirow[t]{2}{*}{-0.87} \\
\hline & NB & 177 & 11.81 & & 108 & 11.73 & & & \\
\hline \multirow[t]{2}{*}{$\begin{array}{l}\text { Ln (primary } \\
\text { ME value) }\end{array}$} & CG & 81 & 11.91 & \multirow[t]{2}{*}{$\begin{array}{l}0.68 \\
(0.15)^{* *}\end{array}$} & 56 & 11.96 & \multirow[t]{2}{*}{$\begin{array}{l}1.01 \\
(0.18)^{* *}\end{array}$} & \multirow[t]{2}{*}{$\begin{array}{l}0.39 \\
(0.24)\end{array}$} & \multirow[t]{2}{*}{$1.65^{*}$} \\
\hline & NB & 190 & 12.54 & & 120 & 12.97 & & & \\
\hline
\end{tabular}

Hypothesis 1 of Section 3.2.2 is partly confirmed and partly rejected for both PSM and DID, because the profit variable is not significant in either method. In addition the number of employees is not significant from the PSM analysis, but is significantly negative in DID calculation, contrary to expectation. This means that microcredit does not lead to increase in number of employees for non-farm MEs. The monthly recurrent business expenditures as well as funds for restocking MEs are significant in PSM but not DID analysis. Microcredit has a positive effect on primary ME value for both PSM and DID albeit at different levels of significance. The implications of the results of the hypothesis testing will be presented in the next section. 


\subsection{Conclusion and discussion}

We conducted this study to assess the effect of borrowing on the performance of women-run non-farm microenterprises and to also explore the factors associated with improvement in profits from the MEs. Hypothesis 1 of Section 3.2.2 was partly confirmed and partially rejected for different ME performance indicators, as outcomes differed between PSM and DID analysis.

Borrowing was associated with higher ME monetary worth in both PSM and DID analysis. For other variables the results were mixed. However, for both comparisons, we did not find evidence of improvement in the level of profit from the MEs among borrowers, within the time frame of the study. Given the increase in ME monetary worth, it is possible that the profits of MEs in which loans were invested would increase over time. It is therefore not prudent to conclude that microcredit does not have potential to improve ME profitability, even though a positive effect on profit was not recorded in the current study. The factor that was found to be positively associated with ME profit was household wealth, while those negatively associated included higher respondents' age, being married, and being risk averse. Next we provide explanations and implications of our findings.

One of the major advantages of borrowing is the provision of physical capital to MEs (Feder et al., 1990). We did find evidence of borrowing providing capital for MEs, as evidenced by increment in the monetary worth and restocking amount of the borrower MEs. The positive contribution of borrowing on ME monetary worth seems a direct result of investment of borrowed funds in MEs. We found an average loan-investment ratio of about $73 \%$ for borrowers in the study. This observed loan investment ratio seemed adequate to bring up the monetary worth of the MEs. ME worth improvement is a positive indicator of future ME performance and food security improvement. The ME stock may serve as a store of wealth, which can be used for 
food and non-food consumption smoothing. ME stock may be consumed by the household or cash from sale of stock may be used for future consumption. The use of part of the loan for other household needs, usually education and building also has positive implications for non-food consumption smoothing. In addition investment in education is a human capital investment.

Loan diversion and loan fragmentation between different household consumption expenditures was reported by Attanasio et al. (2015) who observed loan usage levels similar to ours from a study on borrowers in Mongolia. Fractionation and diversion of the already small loans reduces funds available for ME expansion, and may impair profitability. However fractionation may not be avoidable as the poor usually have relatively high demand for consumption credit. Since consumption credit is rarely offered, the poor go for production loans and use them for consumption (Mahajan \& Ramola, 1996). Because money is fungible within poor households, recipients inevitably allocate part of the loans to other household needs and funds from other household sources to the business. This reduces the amount available for investment. The diversion of loan funds by poor borrowers from business to competing household needs has been discussed by Matin et al. (2002), and Rutherford (2011). UBOS (2010b) reported the three most important motives for people to borrow in Uganda were to get working capital for small businesses (25.9\%), to buy consumption goods (15.9\%), and to pay school fees $(14.8 \%)$.

Another factor that may reduce funds for ME and productive activities that impedes $\mathrm{ME}$ profits are the high borrowing costs. At the time of the study BRAC charged flat interest rates of $12 \%$ and $25 \%$, for 20 weeks and 40 weeks, respectively. This translates into annual interest rates of $32.5 \%$ and $32.0 \%$, respectively. Women in our study decried these interest rates as being rather high. They engaged in a variety of activities to meet the demands of loan repayment, to the 
extent that defaulting was very low. Many lenders justify the high rates with arguments that it is expensive to lend to the poor because they live in hard-to-reach areas and demand only small loan amounts (Hudon, 2011). High interest rates enable lenders to attain financial sustainability, though it may compromise the much-acclaimed social objectives of lending. Recipients may be unable to benefit from the loans or have very little money left after loan repayment (Copestake, 2007; Roxin \& Fiege, 2010). We found that the MEs were an important source of loan repayment funds for the borrowers in the study. Other borrowing program factors, including loan size and maturity, may also be important. The requirement for loan repayment to commence right away may discourage risk-taking and innovation (Banerjee, 2013).

The lack of improvement in profits from MEs has been reported elsewhere. Banerjee et al. (2015) observed no improvement in profits in an experimental study of small MEs of microcredit recipients in India. Copestake et al. (2001), using a combination of PSM and qualitative FGDs, found improvement in profits and household income for borrowers on the second loan cycle. Time is thus needed to translate funds that are injected into MEs after borrowing into profits. Borrowers on the first loan cycle seemed to become worse off due to rigid loan repayment protocols that neglected the risks and uncertainties in business (Mosley \& Hulme, 1998).

Borrowing is supposed to lead to improvement in input and output management of borrowers leading to improved performance (Sebstad et al., 1995). This may be a far outcry for rural agrarian borrowers given their small survival and maintenance MEs. Matin et al. (2002) also observed that poor borrowers did not hire more labour or utilize improved technology, after borrowing. Coleman (1999) in a quasi-experimental design study, with pipeline borrowers as comparison group, observed negligible impact of microcredit on productive expenses. Studies in 
Ghana by Fafchamps et al. (2011) found women-run MEs to yield lower returns even when they got the same financial support as men.

The size and type of the MEs the borrowers invest the loans in could also explain the lack of profit increase. Small survival and maintenance MEs are typical of MEs in developing countries (Asian Development Bank, 1997; De Mel et al., 2009; Gladwin et al., 2001; Schreiner \& Woller, 2003). These studies report that MEs in developing countries usually have limited potential for growth and may yield no returns. Sometimes such businesses are hindered by lack of diversification that leads to undue competition (Fafchamps et al., 2011; Viswanathan, 2002). The MEs in the study fit the description of different authors about MEs in Uganda (Bigsten \& Kayizzi-Mugerwa, 1995; Rooks et al., 2009; Smith et al., 2001; World Bank, 2016b). These studies reported that MEs in Uganda were conducting low monetary-worth activities, mainly small-scale retailing, and with only one person, being the owner. The MEs also operate in lowincome markets hindering growth. Poor people's MEs, in such economically fragile environments, may have no reason to expand, probably because they have already attained optimal levels for their business (Banerjee, 2013).

As we try to answer the question as to why ME income does not grow and yet borrowing is supposed to open up the women's entrepreneur potential (Bornstein, 1997), we have to contemplate whether women borrowers are always entrepreneurial. Although we found both NB and CG respondents with high achievement motivation scores, there was no difference between groups. Stewart et al. (2010) argue that the assumption that all poor women are entrepreneurial, and utilising resources available to them to create new economic activities, products and markets, may be flawed. Being on the margin of survival, may make the poor risk averse (Banerjee, 2013; FAO, 1998), not the other way round. We found respondents with a high need 
for achievement but as argued by Banerjee (2013) consumption rather than entrepreneurial tendencies may compel them to borrow, and self-employment may not be a reflection of entrepreneurial tendency, but rather a lack of choice and alternatives. Women sometimes borrow to meet un-met consumption needs (Banerjee, 2013; Mahajan \& Ramola, 1996) and invest only a little.

Various human capital attributes of borrowers are supposed to influence the performance of women-run MEs. For example, Banerjee (2013) and Ehlers and Main (1998) argue that the poor lack human capital and networks required for success in business. Participation in the group lending program should have improved the social capital of women and positively influenced ME performance. We did not observe this in the current study, pointing to a missed opportunity of borrowing. In addition, contrary to the general belief that education improves performance in life (Bates, 1990), we obtain findings similar to Bigsten and Kayizzi-Mugerwa (1995), in that education did not predict business success, while age and risk aversion negatively predicted profits. Bigsten and Kayizzi-Mugerwa (1995) state that young people have higher stamina needed for the success in business, thus explaining the effect of age on ME profits. Although the direction and degree of risk taking influencing business success is subject to debate, a certain degree of riskiness is needed to obtain small business success (Begley \& Boyd, 1987; Rauch \& Frese, 2000). Unfortunately, being on the margin of survival makes the poor risk averse, inhibiting investments even when they could be profitable (Banerjee, 2013).

Household wealth (invested in housing) also positively predicted profits, probably because more wealthy families could raise higher start-up capital, needed for more meaningful investments (Bigsten \& Kayizzi-Mugerwa, 1995). 
On the whole we partially confirmed the expected positive effect of borrowing on ME performance. In line with the objective of borrowing to improve livelihoods through investment in MEs, borrowers invested reasonable fractions of received loans in MEs, leading to higher monetary worth of the MEs. However, the context, type and size of the MEs may not favour ME expansion or higher profits. Under the burden of loan repayment, especially older borrowers may cease borrowing quickly. For younger borrowers or those with more stable MEs, borrowing may maintain or stabilize MEs, and lead to more secure livelihoods after longer periods of borrowing. Since improvement in food security requires improvement in income, borrowers whose MEs do not expand may experience further food insecurity challenges, especially if they record changes in agricultural production as result of participation in the borrowing programme.

From a policy perspective, it looks like loans should not be given to applicants with the assumption that self-employment is tantamount to being entrepreneurial. There may be need to screen loan applications on the basis of in-depth analysis of the potential of applicant MEs. After loan disbursement, in addition to follow-up on loan repayment, group meetings may be used to offer support for ME expansion. It is also important to access viability of enterprises proposed by borrowers to establish their viability, in line with the loan amount and repayment schedule. Further research is needed to establish types of MEs which are likely to undergo expansion, with microcredit. 


\title{
Chapter 4
}

\section{Microcredit and agricultural production among resource-poor rural women}

\section{(Quasi-experimental comparison of current and in-coming borrowers in Uganda)}

\begin{abstract}
In this study, we investigated changes in expenditure and outputs for agricultural production when women access microcredit in a rural agrarian setting in Uganda. A quasi-experimental design was used to compare socio-demographic, personality and farming microenterprise (ME) activities of existing borrowers and incoming borrowers before they received their first loan. To determine the effect of microcredit, production input expenditures for crop and animal production, crop harvests in the season before the study and the animal wealth for the respondents were measured. We used propensity score matching to assess differences between study groups. Results revealed that current borrowers had less recurrent crop-input expenditures, spent more time on garden work, and recorded lower crop-harvest value than incoming borrowers. Likewise, borrowing did not lead to improvement in animal-production input expenditure. Instead, we observed lower monetary worth of some types of animals among borrowers. The subsistence nature of agriculture practiced by the women, coupled with the high risk associated with agricultural production could be discouraging investment of microloans in agricultural production. In addition the need for weekly loan repayment may favour engagement into non-farm activities, at the expense of farm production, and the sale of household animals.
\end{abstract}

Key words: Uganda, BRAC, rural microcredit, women, agricultural production.

Publication status: Manuscript under preparation 


\subsection{Introduction}

According to the World Bank (2007), three out of every four people in developing countries live in rural areas and mostly depend on agriculture for their livelihood, contributing significantly to the national gross domestic product (GDP). Agriculture continues to be a fundamental instrument for sustainable development and poverty reduction. Despite the special position of agriculture, agrarian communities in the least-developed countries still suffer from temporary food shortages because of fluctuations in production and food prices (Morvant-Roux, 2011). The Food and Agricultural Organisation (FAO) reported that unfavourable climate conditions aggravate agricultural production problems in different parts of the world leading to persisting food insecurity challenges (FAO, 2016).

Given the importance of agriculture in poverty reduction and development, national and international organisations have established programs geared towards agricultural production improvement with focus on transformation from subsistence to fully commercial agriculture as prerequisites for economic development (Moti, Berhanu, \& Hoekstra, 2009; Von Braun et al., 1991; World Bank, 2007).

In the case of Uganda, the Uganda Bureau of Statistics (UBOS) reported that in 2014/15 about $70 \%$ of the working population in Uganda was engaged in agriculture, forestry and fishing, with a higher proportion of women (72\%) than males (67\%) (UBOS, 2016). The agricultural sector contributed $22.6 \%$ to the GDP and 53\% to the country's exports (UBOS, 2016). In 2014, $42 \%$ of the households mainly earned their income from subsistence agriculture (UBOS, 2014).

The strategic direction of the Ministry of Agriculture, Animal Industry and Fisheries (MAAIF), for the Government of Uganda, includes transformation of subsistence farmers into enterprise farmers. These programs entail, among others, activities aimed at improvement of 
agricultural production and productivity, increasing access to farm inputs, and improving agricultural markets. Rural infrastructure development, provision of extension services, dissemination of weather information and promotion of improved production practices and crop varieties are some of the activities undertaken by the government (UBOS, 2016).

It has long been argued that food security may be improved through increasing access to financial services (FAO, 1998; Meyer, 2013), because lack of financing and poorly functioning financial markets limit farmers' capacity to invest in new practices and improved technologies (FAO, 2011). Investment of microcredit in agriculture is expected to improve input expenditures and subsequent agricultural output (Morvant-Roux, 2011). However, MFIs offering loans for agriculture are few in number because of the riskiness of agricultural production, and the lag phase between investment and agricultural output that often does not favour MFI schedules of loan repayment. However, since reduction in food insecurity and rural poverty are key mandates of many microfinance institutions (MFIs), targeting rural agrarian populations with microcredit for agricultural production investments is a desirable MFI direction (Morvant-Roux, 2011).

There is, however, a dearth of literature about the extent to which female microcredit recipients invest microloans in agricultural production, and whether such investments in agriculture translate into production output increase. Currently the debate rages on about the effect of borrowing on households (Banerjee, 2013; Banerjee et al., 2015). For rural agrarian communities the focus on agriculrural production cannot be over-emphasized. Given the difficulty in establishing monetary income of such households, in the current study we focus on non-monetised income from agricultural production.

One would expect access to microcredit to increase production, since investment in improved technology is important in optimising the production process. On the other hand, agricultural 
output may not change for various reasons. First, loan repayment needs and schedules may not favour investment in agriculture. Second, agricultural production improvement may not be a core objective of borrowing. The current study seeks to explore these issues.

We conducted a quantitative and qualitative cross-sectional comparison of current borrowers and incoming borrowers, before they received their first loan. We used Propensity Score Matching (PSM) to make these groups comparable on a number of characteristics, then assessed differences between investment and output from both crop and animal production. Qualitative focus group discussions (FGDs) were used to obtain in-depth understanding of the relationship between microcredit and agricultural production. FGDs were used to find out whether food production increase was a core reason for borrowing, whether women invested their loans in agriculture, and to assess women's perceptions of investing their loans in agricultural production. Our main result was that access to credit did not lead to extra investment in crop and animal production. We also found borrowers having lower monetary value of harvested crops than incoming borrowers.

The rest of the chapter is organised as follows. Section 4.2 provides the theoretical framework and review of literature on microcredit and agricultural production, and the study questions. In Section 4.3 , we describe the study methods. Section 4.4 deals with the results of the study. Section 4.5 provides the discussion and conclusions. 


\subsection{Theory}

\subsubsection{Women and peasant agricultural production}

Peasant agricultural production has been explained in Ellis (1993). Agricultural production in peasant communities operates on a subsistence-like model, where family plots are tilled to obtain food and to generate income to meet non-food family needs. Women play a key role in agricultural production, and make significant contributions to agricultural production, both as farmers and as workers (Fletschner \& Kenney, 2014; Quisumbing et al., 1995). They provide about $43 \%$ of the agricultural labour force in developing countries and about $50 \%$ in parts of Africa (FAO, 2011), with social norms dictating the kind of roles they play. In some communities women have the gendered role of provision of food to households (Niehof, 2016), and thus play a key role in food security attainment. In such communities women are in charge of short-cropping-season food crop production, while men take charge of the more lucrative traditional cash crops which take longer to mature. In other communities, crop production activities are shared out between men and women. Women may be in charge of sowing, weeding, and simple food processing operations, while men's roles include land clearing, harvest and sale of crop and animal produce. In Africa males and females have been reported to cultivate different plots with different crops (Udry et al., 1995). In some instances different crops may be planted on the same plot, to ensure against external shocks to production and have stable harvests (Fafchamps, 2003). Plots managed by females are usually intensively cultivated, use less manure and have lower output than those managed by men. Men rarely allocate labour time to womencultivated plots, and sometimes even child labour may be allocated more to male-cultivated than to female-cultivated plots (Udry et al., 1995). Female-cultivated plots are usually allocated to 
food and vegetable crops for which they have more expertise. As far as animal production is concerned, female control of livestock varies from culture to culture. Usually men have control over purchase and sale of larger animals like cattle, while women have control over smaller animals like goats, chicken and pigs (Esenu et al., 2005). According to FAO (2011), the demand for animal products is likely to grow, thus improving the potential of animal production contributing to poverty reduction in poor communities. Livestock are an important source of supplementary income for the poor, a source of animal protein and fertilisers, and a store of wealth.

Agriculture in peasant communities is dogged with many challenges, some of which have been summarised in Figure 4.1. Lack of land is rampant sometimes because of traditional land inheritance customs that promote land decimation and slicing. These factors hinder large-scale agricultural production and mechanisation. The resultant small pieces of land are tilled repeatedly, leading to soil exhaustion and depletion. Reliance on depleted soils and unreliable weather patterns also prevent production improvements (FAO et al., 2015; Jiggins, 1989). In these communities where purchase and use of agricultural production inputs is limited, the situation poses a challenge to improvement in production (Ellis, 1993).

Recently, agriculture has come under pressure as climate change affects food production, food prices and income from agriculture. Dry spells, late onset of rains, and high temperature, work together against productivity, harvest value and food access (FAO, 2016). Uncertainty about food production leads to reduced investment in agricultural production and prevents farmers to profit from ensuing high food prices (FAO, 2016). Indeed greater risk has been observed to lead to reliance on low-risk, low-return crops, less use of purchased inputs such as fertilisers and new technologies, and a generally low level of investment in agriculture (Fafchamps, 2003). 
These challenges are magnified more for women than men. Women face gender-specific constraints that reduce their productivity and limit their contribution to agricultural production. These challenges have been discussed by many authors (Ali et al., 2015.; FAO, 2011; Jiggins, 1989). Women generally lack access to land and the land they control may be of poorer quality and of insecure tenure. Lack of land ownership rights makes women dependent on husbands and other male relatives to access land for production. As a result they often access small pieces of low-productivity land which they over-cultivate, lowering productivity even more. Women have fewer working animals and sometimes have no control over the income from sale of small animals they keep. They have limited access and are less likely to use improved agricultural technology and inputs. They have limited access to agricultural knowledge and information, perpetuated by their low levels of education, limited access and exposure to extension agents and extension information, and their inability to move away from household responsibilities. Because of all these factors, women register lower yields than males, not because they are less capable. If larger inputs would be used by women and if the gender gap could be reduced, then the quantity of food available to people in the world would be much higher (FAO, 2011).

Such engendered limitations are common in Uganda (Lakwo, 2006; Wakoko, 2004), one of the countries of the world where gender biases are still growing (FANTA-2, 2010). These biases have been found to hinder levels of agricultural productivity (Ali et al., 2015.). And yet women persist with their engagement in subsistence crop and animal production for income and household food provision.

Support for women-run agriculture is thus important for household food production, a key pillar of food security (Quisumbing et al., 1995). Such support includes enabling women to access credit. Limited access to credit has been cited as a main challenge women face in 
accomplishing their role in production. Women have been reported to use less credit than men and sometimes may not control the credit they get (Goetz \& Gupta, 1996). Factors that hinder women's access to credit have been discussed by many authors (Armendáriz \& Labie, 2011; Berger, 1989; FAO, 2011; Fletschner, 2009; Meyer, 2013). Legal barriers and cultural norms prevent them from holding bank accounts or entering into financial contracts. Many times they lack collateral needed by banks to advance loans to them. Women are sometimes not favoured by some MFIs, who prefer men who are able to get larger loans, and when they are given the opportunity to borrow, may be given smaller loans than men (Agier \& Szafarz, 2013; Fletschner, 2009). And yet studies have shown that granting credit to women has more positive implications for the nutrition of households than credit given to men (Pitt \& Khandker, 1998).

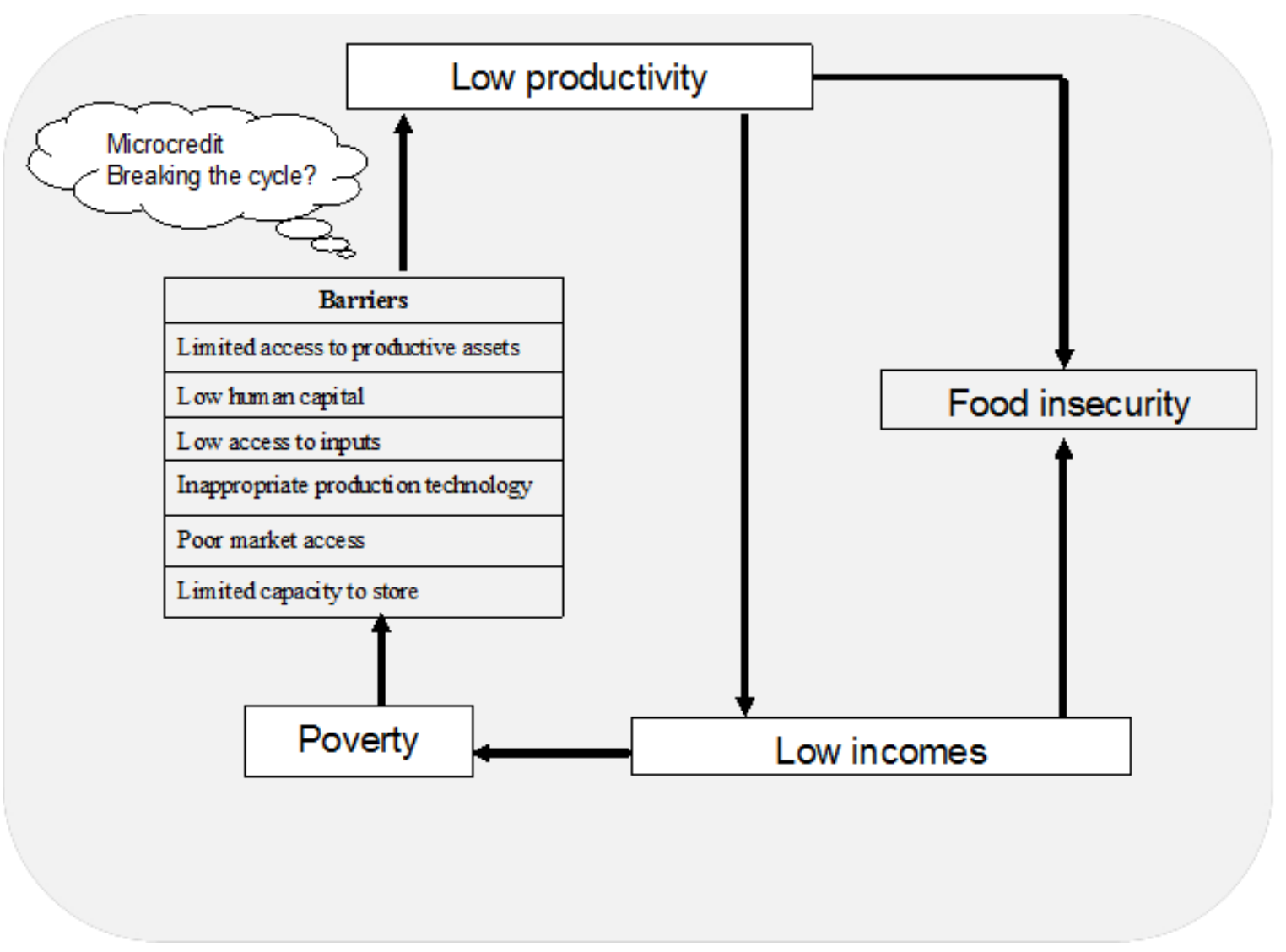

Figure 4.1. Microcredit and agricultural production in rural agrarian communities 


\subsubsection{Microcredit and agricultural production}

Agricultural productivity of the poor is hampered by limited use of inputs, low human capital use of rudimentary technology and general lack of productive resources (See Figure 4.1). Poor market access and post-harvest losses due to limited storage facilities further reduce the value poor farmers generate from their agricultural activities, and contribute to sustain the vicious cycle of poverty and food insecurity. By providing the poor with resources for investment in agricultural production, MFIs could help to break this cycle and enable the poor to expand their

production, thus contributing to commercialisation of subsistence agriculture. Commercialisation, manifested by an increase in use of external production inputs may lead to increase in both cash and in-kind transactions for otherwise peasant agriculture. In addition, the proportion of farm output for sale will increase (Von Braun et al., 1991).

Microcredit is one of the avenues to increase commercialisation. Since agricultural production is risky and unreliable, leading to unreliable income which is needed for loan repayments, many MFIs do not offer microloans for agricultural production. One of the exceptions is BRAC, one of the largest microcredit providers in Uganda, which offers such loans to women who show potential to make the weekly loan repayments (Wright \& Rippey, 2003). Also MFIs like Amanah Ikhtiar Malaysia (AIM) offer credit that may be invested in agricultural production (Chan \& Ghani, 2011). Provision of loans in Uganda has improved with the fraction of adults applying for a loan increasing from $17 \%$ in $2009 / 10$, to $22 \%$ in $2012 / 13$. Most borrowers apply for loans to get working capital for their microenterprises (UBOS, 2014).

Credit access may lead to changes in production decisions by farmers (Crépon et al., 2015), favouring more profitable investments of longer duration (Foltz, 2004; Matin et al., 2002). They may adopt labour-saving technologies and other technologies that enhance agricultural output, 
including use of improved crop varieties and fertilisers (Khandker \& Koolwal, 2016; Matin et al., 2002; Zeller \& Sharma, 2000). They may also use credit to increase animal stocking levels, and use improved animal rearing methods (Chan \& Ghani, 2011). Any extra investment in agricultural production will lead to improved agricultural productivity (Matin et al., 2002; Feder et al., 1990). One of the commonly cited positive outcomes of borrowing is women empowerment (Armendáriz \& Morduch, 2010; Swain \& Wallentin, 2009) and economic decision making (Pitt, Khandker, \& Cartwright, 2006), which may also have positive effects on agricultural production.

Since agriculture is a major source of food acquisition for peasant communities, improvement in production after credit access is expected to lead to increased household food availability as well as cash and non-cash income, both enabling better access to food.

On the other hand, borrowing may not lead to production improvement when demand for women's time increases after borrowing due to competing activities associated with agricultural production, non-farm MEs and domestic work (Basargekar, 2008; Kabeer, 2001). For example, Haile, Bock, and Folmer (2012) reported increment in work load of women after borrowing.

Considering the mixed results available from studies on the effects of microcredit, we attempted to answer the following research question. To what extent does borrowing affect expenditure and output from agricultural production?

The central null-hypothesis we tested for this study was: Borrowing has no effect on expenditure and output from agricultural production. We tested this against the two hypothesis below.

Hypothesis 1. Participation in the microcredit program leads to increment in crop and animal production input expenditure. 
Hypothesis 2. Participation in the microcredit program leads to increment in crop and animal output.

\subsection{Methods}

Section 4.3 provides the study design, describes the sample and measures, and deals with the data analysis techniques we employed.

\subsubsection{Study design}

The study employed a cross-sectional design involving 173 old borrowers (OB), and 71 incoming borrowers (NB) of BRAC microfinance, from Mukono and Buikwe districts, the latter group before they received their first loan. Study respondents were women who indicated in a preliminary question that they practiced agriculture as a business, i.e. invested in crop and animal production, with the aim of selling off the bigger percentage of their produce for income. Both districts have a large number of people who are involved in subsistence food production. Mukono is among the largest districts in Uganda and Buikwe is one of the districts that sometimes have food insecure households.

A quasi-experimental cross-sectional design with both quantitative and qualitative survey methods was used to obtain socio-demographic (age, dependency ratio, years of education, and marital status) and personality characteristics (risk preference, time preference, and achievement motivation) of borrowers. 


\subsubsection{Data collection and analysis}

We also calculated two wealth indices based on household asset ownership and housing facilities, respectively. Details of the study design, the criteria of selection of participants, study measure and different procedures of data collection, and information about the BRAC microcredit program are given in Chapter 2 of this thesis.

Data collection was done between September and December 2013 with the harvest season of April 2013 as the reference season for crop production data. The reference period for animal production was the period January-December, 2013.

FAO (2011) postulates that access to credit will lead to adoption of new technologies and practices as part of the agricultural commercialisation process. To assess the level of commercialisation of agricultural production, we constructed business-like scores for crop and animal production, respectively. These scores were based on their outlay of inputs of production in order to assess whether the crop and animal activities of the respondents qualified as 'business-like'. We based these on responses to questions eliciting use of cash in different crop and animal activities as follows. For crop production, a crop business-like score was computed as summation of positive responses to four questions eliciting information on (1) Having employees in crop production; (2) Payments for farm labourers in crop production; (3) Seed purchase; (4) Purchase of fertilisers and or pesticides. The maximum crop business-like score was thus 4 . The animal business-like score on the other hand was the summation of positive responses to the following questions: (1) Payment for veterinary support; (2) Animal feeds purchase; (3) Payments for hired farm labour. The maximum animal business-like score was thus 3 . This information was used to assess the degree of commercialisation of production activities. 
For crop producers, data on a self-reported measure of area under crop production, change in area under cultivation after accessing credit, and time allocation to garden work, both on days when the respondent conducted non-farm micro-enterprise (ME) activities and on days with no non-farm ME activity, were obtained.

To capture the effects of microcredit on output for crop-related agriculture, output of crop production was obtained and used to calculate monetary value of crop harvest, as the product of the quantity of different crops produced and the unit market price of respective crop items at the time of the study. For animal-related MEs an animal wealth variable was calculated as the product of the numbers of different types of animals and unit market price of the animal type at the time of the study. For crop and animal production, total crop production input expenditures and cost of animal production were computed, respectively. The propensity score matching methodology (PSM) was used to control for residual heterogeneity in selection into the borrowing program and to assess the effect of microcredit as the difference between parameters for $\mathrm{NB}$ and $\mathrm{OB}$ respondents. As explained in Chapter 1 of the thesis, control variables in the PSM matching procedure were factors that would influence the taking of credit including marital status, level of education, personality characteristics (time preference, risk preference and need for achievement motivation scores), age, marital status, religion and dependency ratio (defined as the ratio of dependents, aged 0-14 years, and those over 65 years, to the household productive members, 15-64 years).

From focus group discussions (FGDs) in the qualitative part of the study we obtained information on the reasons for borrowing, whether investment in agriculture and improvement in food security were among reasons for borrowing, the respondent's opinion on use of microloans in agricultural production, and loan repayment dynamics. 


\subsection{Results}

\subsubsection{Sample composition}

The total number of respondents with agriculture-related MEs for the baseline year was 244 $(\mathrm{OB}=173, \mathrm{NB}=71)$. The majority of $\mathrm{NBs}(66 \%)$ and $\mathrm{OBs}(53 \%)$ were involved in both crop and animal production.

\subsubsection{Characteristics of respondents with agriculture-related MES}

We found the socio-demographic and personality characteristics of the respondents with agricultural-related MEs in the study for both the NB and OB categories to be similar on the control variables, before and after propensity score matching. The similarity of the groups before matching seems to be an outcome of both $\mathrm{NB}$ and $\mathrm{OB}$ groups having self-selected to participate in the BRAC microcredit program. Respondents were on average 35 years of age, with 7 years of primary education. The dependency ratio was 1.4 , which is slightly higher than the national average of 1.2 . The majority (75\%) were married. Risk preference was 2.2 on average, indicating that most respondents were risk neutral and most had a high time preference score (3.3 on average), implying they possessed the ability to delay gratification to the future. The respondents had a high achievement motivation score (1.0 on average), implying they scored high on questions eliciting respondent aspirations to better themselves. The details for measurement of personality characteristics are provided in Chapter 2, Table 2a. 


\subsubsection{Crop production information for current and in-coming borrowers}

Assessment of the level of commercialisation of crop production based on crop business-like scores indicated that crop production was generally at a subsistence level. More than $50 \%$ of study respondents (both NB and OB together) had scores of less than 2 (the maximum score was 4) for crop business-like score. Average crop business-like scores for OB and NB were 2.0 and 2.2, respectively. About a quarter $(25 \%)$ of study respondents scored 0 on the business-likeness measure. The low score points to respondents who never hired labour, never purchased improved seeds nor used fertilisers in the season before the study. These respondents did not deploy any basic production inputs of crop production that would make production more profitable, after borrowing.

Respondents in the study planted an average of two different types of crops for commercial purposes, in the season before the study. Even after borrowing, borrowers mainly produced food crops, mainly maize and beans, which were planted by more than half of OBs. However, fewer OBs than NBs produced beans (see Table 4.1).

Table 4.1 Number of respondents with different types of crops in previous season

\begin{tabular}{lccl}
\hline Type of crops planted & NB $(\boldsymbol{\%})$ & OB $(\boldsymbol{\%})$ & Chi-square $(\mathbf{d f}=\mathbf{1})$ \\
\hline Maize & 56.34 & 48.28 & 1.31 \\
Beans & 59.15 & 39.10 & $8.21^{* *}$ \\
Potatoes & 28.17 & 29.31 & 0.03 \\
Tomatoes & 4.23 & 3.45 & 0.08 \\
Egg-plant & 0.00 & 5.12 & $3.81^{*}$ \\
Total N & 174 & 71 & - \\
\hline
\end{tabular}

$* p<0.05 ; * * p<0.01$

We observe a larger number of borrowers growing crops like egg-plants, which are mainly produced for sale and do not necessitate costly input use. We do not observe the same for crops like tomatoes and maize that require intensive use of inputs. 


\subsubsection{Effects of microcredit on expenditure and output for crop production}

Table 4.2 shows differences between NBs and OBs regarding basic crop and animal production parameters and practices, investments in crop production, and expected outcomes of borrowing on crop production. These differences can be considered as average treatment effects on the treated (ATT) based on probability score matching with Kernel matching.

Table 4.2 Differences between OB and NB agricultural production parameters

\begin{tabular}{lrrrr}
\hline Parameter & OB & NB & Diff. & $t$ \\
\hline Ln expenditure on crop production ${ }^{1}$ & 8.08 & 9.40 & -1.32 & $-1.68^{*}$ \\
Ln expenditure on crop production ${ }^{2}$ & 7.72 & 8.87 & -1.15 & -1.41 \\
Ln monetary value of harvest & 7.81 & 9.91 & -2.19 & $-2.28^{* *}$ \\
Ln total crop sales & 12.88 & 12.98 & -0.10 & -0.32 \\
Number who sold some crops (\%) & 0.56 & 0.61 & -0.11 & -1.54 \\
Types of crops planted & 2.02 & 2.46 & -0.45 & -1.62 \\
Crop business-like score & 1.95 & 2.26 & -0.31 & -1.27 \\
Garden hours (day with non-farm ME activities) & 3.47 & 2.72 & 0.74 & $2.01 * *$ \\
Garden hours (days with no non-farm ME activities) & 3.99 & 3.2 & 0.72 & 1.28 \\
Garden hours per week & 20.58 & 16.58 & 3.99 & $1.86^{*}$
\end{tabular}

$* p<.10, * * p<0.05$

${ }^{1}$ Including value of all planted seeds (purchased and from own production) for previous season

${ }^{2}$ Including value of purchased planted seeds in previous season only

Monetary values transformed into logarithms

We obtained no evidence of improvement in commercialisation of crop production after borrowing. This was revealed by the lack of differences between OBs and NBs on the number of planted crops, the business-like scores for crop production, number who sold some crop in the previous season, and on the monetary value of crop sales (see Table 4.2). 
We found that OBs spent less than NBs on crop input expenditures, (e.g., on planted seeds), with both groups spending less than $\$ 100$ equivalent on crop production inputs in the cropping season before the study. It was therefore not surprising that we found the monetary value of the whole crop harvest (the product quantity of respective crop harvest times the unit market price at the time of the study) for OBs to be less than for NBs. Although not significant, we observed a negative trend in number of borrowers who sold some crops from the previous season, the number of different types of crops planted, and the crop business-like score for the OBs compared to NBs. Comparison of the amount of time OBs and NBs spent on gardening, on days when they also conducted non-farm ME activities, revealed that OBs spent $74 \%$ more time than the NBs (see Table 4.2). However, responses to the inquiry about change in amount of time spent on garden-related activities after borrowing indicated that $43.8 \%$ of OBs spent the same amount of time, $33.3 \%$ spent less time, while $22.9 \%$ increased the amount of time.

The results of the quantitative survey were confirmed by the qualitative FGDs. Borrowing to purchase crop production inputs was ranked 6 out of 8 reasons to borrow (See Chapter 2 of this thesis). The FGDs provided insights into the reasons for limited investment in crop production. Some respondents, for example, argued that they had access to small pieces of land for crop growing, limiting the worth of investment in crop production. Respondents also argued that high risk associated with crop production made it unattractive for investment of loan funds. FGD participants also observed that investment in agriculture did not suit the BRAC weekly loan repayment requirements. One participant commented: 'You have to make weekly loan repayments from the very week you receive the loan. If you invest in agriculture and have no trade business, you will have difficulties'. 
Table 4.3 Differences in monetary values of individual crop harvests (in logarithms) between OBs and NBs

\begin{tabular}{lllcc}
\hline Crop type & OB & NB & Diff. & $\boldsymbol{t}$ \\
\hline Maize (68/143) & & & -2.04 & $-2.11^{* *}$ \\
Beans (68/143) & 4.55 & 6.59 & -2.87 & $-3.09^{* *}$ \\
Potatoes (68/144) & 4.09 & 6.96 & 0.69 & 0.87 \\
Cassava (67/140) & 2.81 & 2.12 & 0.02 & 0.03 \\
Egg-plant (69/143) & 1.61 & 1.58 & 0.45 & $2.48^{* *}$ \\
Tomatoes (67/142) & 0.45 & 0 & 0.36 & $2.02^{* *}$ \\
\hline
\end{tabular}

Figures in parentheses in column 1 are numbers of respondents in the common support region of PSM for NBs and OBs, respectively; $* * p<0.05$

The most important crops for the respondents based on monetary value of the harvest were maize, beans, potatoes, and cassava (see Table 4.3). The monetary values for maize and beans for OBs were $2 \%$ and almost $3 \%$, respectively, lower than that for NBs. On the other hand, the monetary value of harvested egg-plant and tomatoes for NBs were $0.45 \%$ and $0.36 \%$, respectively, higher than for OBs. Maize and beans may be the drivers of the negative shift in monetary harvest value. Evidently, borrowers may have reduced the production of some of their crops, possibly because of loan repayment challenges and other reasons discussed above. Another challenge respondents reported for their limited enthusiasm in investing borrowed funds in crop production was poor markets. Some observed that in times of good harvest, they failed to sell off crops like cassava and sweet potatoes, because of poor markets. They revealed that part of the harvested produce was consumed by the household and the excess used to feed pigs or left to rot in the gardens. This type of market failure may discourage additional investments in production of such crops.

Quantitative results revealed that one-third of the women with agricultural related MEs, had non-farm MEs, with self-reported net worth of less than \$50. Cash collections from these small businesses were pooled with the proceeds from sale of crops, and used to make weekly loan repayments. 


\subsubsection{Effects of microcredit on animal production}

In this section findings on effects of borrowing on animal production are given.

Table 4.4 Number of respondents with different types of animals

\begin{tabular}{lcll}
\hline Parameter & $\begin{array}{c}\text { NB (\%) } \\
\text { N=71 }\end{array}$ & $\begin{array}{l}\text { OB (\%) } \\
\text { N=174 }\end{array}$ & $\begin{array}{l}\text { Chi-square } \\
(\mathbf{d f}=\mathbf{1})\end{array}$ \\
\hline Number who owned an animal & 84.51 & 77.59 & 1.49 \\
Number with pigs & 42.25 & 48.85 & 0.88 \\
Number with local chicken & 38.03 & 27.01 & $2.90^{*}$ \\
Number with goats & 38.03 & 24.14 & $4.81^{* *}$ \\
Number with zero grazing cattle & 23.94 & 18.39 & 0.97 \\
Number with local cattle & 28.17 & 14.37 & $6.41^{* *}$ \\
Number with exotic chicken & 5.63 & 12.07 & $-2.28^{* *}$ \\
\hline
\end{tabular}

$* p<0.10, * * p<0.05$

Results indicate that pigs were the most commonly kept animal type. Fewer OBs than NBs owned goats, local cattle and local chicken (Table 4.4). Although we did not find quantitative evidence of the effect of borrowing on pig production, FGD participants indicated using loan funds to purchase pigs. They indicated that the preference for keeping pigs was due to their short lifecycle and the possibility of selling them readily to meet urgent household needs, and to provide capital for ailing MEs.

Table 4.5 Differences between OBs and NBs on monetary values of different animals (in logarithms)

\begin{tabular}{lrrrc}
\hline Parameter & OB & NB & Diff & \multicolumn{1}{c}{} \\
\hline Number of animals & 1.57 & 1.91 & -0.34 & $-1.69^{*}$ \\
Animal business-like score & 1.04 & 1.17 & -0.13 & -1.12 \\
Ln total animal wealth & 10.84 & 11.97 & -1.13 & -1.57 \\
Ln animal input expenditures & 8.85 & 8.92 & -0.07 & -0.09 \\
Ln value goats & 3.38 & 5.45 & -2.07 & $-1.96^{* *}$ \\
Ln value zero grazing & 2.07 & 2.89 & -0.82 & -0.94 \\
Ln value local cattle & 1.49 & 3.52 & -2.03 & $-2.28^{* *}$ \\
Ln value exotic chicken & 1.07 & 0.19 & 0.88 & $2.50^{* *}$ \\
Ln value pigs & 5.96 & 4.90 & 1.06 & 1.08 \\
Ln value local chicken & 3.40 & 4.71 & 4.71 & -1.49 \\
\hline
\end{tabular}

$* p<0.10, * * p<0.05$ 
We found that the majority of respondents kept at least one type of animal, with no difference between OBs and NBs. Borrowing seems to have a negative effect on animal production according to the probability score matching method, with Kernel matching (Table 4.5). Old borrowers did not spend more than new borrowers on animal production inputs. Instead we find them to keep marginally fewer types of animals, and the monetary value of some types (goats and local cattle) was lower. However the total animal wealth for OBs did not differ from NBs.

\subsubsection{Sensitivity analysis}

We conducted a sensitivity analysis as described by Rosenbaum (2010). We did this for the main finding of the study, monetary value of the harvest, and found that unobservable covariates would need to change the odds of treatment assignment by factors beyond 3 to conclude that the observed treatment effects from propensity score matching were due to non-random assignment. We concluded that our PSM results were unlikely to be influenced by unobservable attributes of the respondents.

\subsection{Conclusion and discussion}

Contrary to the common assertion that credit is the major limiting factor to improvement in agricultural production, and that borrowing will lead to improvement in investment in

agricultural production and output (Armendáriz \& Labie, 2011; FAO, 2016), we tested and rejected the hypothesis of improvement in agricultural input expenditures and in crop and animal output after borrowing. Unlike findings by Kaboski and Townsend (2012) of improvement in agricultural investment after borrowing, and Crépon et al. (2015), of expansion in the scale of non-livestock agriculture and livestock activities, our findings are more in line with Matin et al. 
(2002) who found that borrowers did not hire more labour nor did they increase their utilisation of improved technology after borrowing. This agrees with UBOS' observation UBOS (2010b) that only $6.8 \%$ and $3.2 \%$ of the people in Uganda borrow to buy farm inputs, that is seeds and livestock, respectively. Our findings are also in agreement with Grimpe (2002) who observed that FINCA Uganda recipients used loans to cater for short-term livelihood needs rather than development in agriculture.

\subsubsection{Crop production}

The major study finding for crop production is that borrowers did not increase their recurrent expenditures in crop production and animal production. We also found a reduction in non-cash income from crop production. This raises the question of why female borrowers did not increase recurrent expenditures in agricultural production or take up improved technologies.

The reasons why borrowers do not invest microloans in activities they purported to borrow to recapitalise may be found in the nature of their agricultural activities, the local market conditions for agricultural produce and the needs and requirements of the MFI for loan repayment.

First, we look at the characteristics of the women and the agricultural activities they were involved in. The respondents in this study seem to fit well the definition of peasants by Ellis (1993): 'Peasants are households that derive their livelihoods mainly from agriculture, utilize mainly farm ily labour in farm production, and are characterised by partial engagement in input and output markets which are often imperfect or incomplete' (p. 13). This definition appropriately characterises women-run agriculture in Uganda and sheds light on why women borrowers did not invest more in agricultural production. 
From the FGD results we presented in Chapter 2, borrowers indicated they were cautious while allocating loans to agricultural production. It is risky to invest in agriculture because of unpredictable weather patterns and thus unpredictable harvests. Crop failure may lead to loan repayment problems (See Chapter 2, this thesis). Agricultural production is risky and this, coupled with the lag phase between investment and harvest, may not favour investment of loans that have to be paid back with interest (Morvant-Roux, 2011).

Although we found women in our study to be risk neutral, women are generally regarded as being risk averse and unlikely to invest their loans when they perceive the possibility of failure in an activity (Fletschner, Anderson, \& Cullen, 2010).

Poor markets are a reality in many poor economies (Adams \& Von Pischke, 1992). For perishable agricultural products this factor may pose a risk to income and discourage agricultural investment. Adams and Von Pischke (1992) asserted that credit may not be as large a problem for agricultural smallholders as price and other production risks, and may be ineffective for helping most of the poor to enhance their economic condition.

The result of a smaller numbers of OBs planting beans and of OBs having smaller harvest values for maize and beans is surprising. Beans are widely grown by subsistence farmers in Uganda, with little deployment of production inputs. They play a special role in nutrition security as they are good sources of protein for peasant families. Maize too is widely grown by small scale farmers as a source of food and income security (GOU, 2016). There seems to be a missed opportunity for microcredit to contribute to food security improvement. Something seems to be limiting the women in this regard. One likely limitation is the scale of agricultural production, which is too small to warrant extra investment. This is evidenced by the observed average crop business-like scores for OBs and NBs with some respondents scoring zero. In addition, about 
$40 \%$ of $\mathrm{OB}$ and NB respondents did not sell any crop produce, meaning all harvest was used for own consumption.

Finally, another impediment to agricultural growth even after borrowing, is societal gender division of roles and social rigidities that define the roles women play (Schroeder, 1996). Uganda society still has widespread discriminatory behaviour towards women, which hinders agricultural production. Women have been found to record lower rates of agricultural production because of high child care needs, as well as difficulty in accessing markets and inputs. Differential uptake of cash crops and use of improved seeds and pesticides by women are also manifestation of these difficulties (Ali et al., 2015.). These factors may explain why women, even after borrowing, are mainly engaged in food provision for their households, and not in more lucrative cash crop production. It may also explain why they do not invest microloans in improved agricultural technologies.

\subsubsection{Animal production}

Our findings about microcredit and animal production echo the findings for crop production. We tested and rejected the hypothesis of improvement in investment in animal production inputs and of improvement in animal wealth after borrowing.

Borrowing does not translate into commercialisation of animal production among borrowers. This is evidenced by the similarity in the business-like score (animal production) between NBs and OBs. Apart from the increase in exotic chicken production among borrowers, borrowing seems to have a negative effect on animal wealth as per the result on reduction in monetary worth of some types of animals for borrowers and numbers of different types of animals owned 
by OBs. This could be attributable to a number of factors. OBs did take up, one of the inputintensive and yet commercially viable animal ventures in Uganda.

First it could be a result of sale of animals to get funds for weekly loan repayments. Animals being easily convertible into cash may be sold off to obtain funds for loan repayment. As observed in Chapter 2 of this thesis, women sell off whatever is saleable to get funds for loan repayment. On the other hand it may indicate a shift away from animal production when women borrow.

In addition the characteristics and requirements of the lending programme may explain some of these results (see Chapter 2). BRAC protocol requires weekly loan repayment that commences the week after loan disbursement. Such loans necessitate or require a regular flow of income and disfavour investment in agriculture. Borrowers may instead opt for non-farm activities, which have shorter gestation periods, at the expense of agricultural production.

Also investment in agricultural activities, especially crop production, is risky because of unpredictable weather patterns and reliance on depleted soils (Morvant-Roux, 2011). Being risk averse, poor households are unlikely to take up risky ventures (FAO, 1998), as would be the case if they had invested microloans in agriculture. This is one of the explanations offered by Banerjee (2013), as to why poor borrowers do not invest microloans in agricultural production.

The socio-economic condition of the women, including limited access to land, uncertain land tenure, high level of cash poverty, poor market conditions, as well as the persistently risky nature of agricultural production, may also not favour investment of borrowed funds in farming. This may therefore impede women to benefit from microcredit in their agricultural activities, thus failing to grasp any food security benefits of borrowing. 
Our results reiterate observations by Diagne and Zeller (2001) that resource-poor households lack the necessary infrastructure and socio-economic environment necessary for agricultural production to benefit from borrowing. They make the assertion that risks associated with drought and lack of irrigation, inadequate infrastructure and markets, low levels of education, malnutrition and disease, purge the potential benefits of borrowing. These factors need to be addressed if women are to benefit from borrowing.

Further research is needed on ways in which women may commercialise agricultural production and move away from subsistence agriculture, for food security improvement.

Concluding, borrowing did not lead to increment in recurrent agricultural production expenditures. Neither did it lead to increase in agricultural output, as usually expected. This was attributable to the subsistence mode of female agricultural production that has limited potential for commercialisation even after borrowing. The local context the women operate under, the MFI protocol for loan repayment and the risky nature of agricultural production also seem to discourage women from investing microloans in agricultural production. For a country that relies on agricultural production as a source of food and livelihoods, the food security improvement potential of microcredit may thus not be realised.

The main conclusion from this chapter was that borrowing did not lead to extra recurrent crop and animal production expenditures, Instead crop production expenditures, numbers of different types of animals kept by borrowers and monetary worth of some commonly kept animals went down. In addition non-cash income from crop production went down. From the results of FGD on loan repayment, it seems plausible that the downward trend in animal production was due to sale of animals for loan repayment, as discussed in Chapter 2 of this thesis. Food production, a 
main pillar of food security, was thus unlikely to improve on the account of these subsistence farmers accessing microcredit. 


\title{
Chapter 5
}

\section{Microcredit and food security: Evidence from peasant communities in}

\author{
Uganda
}

\begin{abstract}
In this study we investigate the effect of participation in a microcredit program on food security of female borrowers' households in a rural agrarian setting in Uganda. 'Modes of food acquisition, dietary diversity, caloric and protein intake, and qualitative food insecurity measures for different categories of respondents were investigated. A cross-sectional analysis was used for comparison of women that self-selected into borrowing. First time borrowers and non-borrowers were then compared using panel analysis to provide insights into changes of food security parameters. We use Kernel matching to control for potential bias in observables for the crosssectional comparison, and also perform a sensitivity analysis with respect to un-observables using Rosenbaum bounds. For panel analysis we use difference-in-difference with Kernel matching as well as an individual fixed effects panel analysis. Results show a decline in food security following the uptake of microcredit. In particular the analysis reveals robustly lower dietary diversity among long-time borrowers than new borrowers, and larger reductions in dietary diversity scores among new borrowers, after one year, compared to controls. The reduction in dietary diversity was traced to a reduction in animal-source food, fruit and sugar intake. We find indicative evidence that this may be partly explained by an apparent shift from own production to reliance on food purchase by households. Other household members relegating the burden of food provision to women after borrowing may also help explain the observed result.
\end{abstract}

Key words: Food security, microcredit, subsistence farming, microenterprises, women.

Publication status: Namayengo, F.M.M., Cecchi, F., \& Antonides, G. Microcredit and food security: Evidence from peasant communities in Uganda. Under review at Journal of African Economies. 


\subsection{Introduction}

Poverty is recognised as a major cause of food insecurity in many developing areas in the world (FAO, 1996), especially in rural areas where agriculture is key in the production of food and income (Ruel \& Alderman, 2013). In sub-Saharan Africa agricultural production is mainly undertaken by smallholders who provide over $80 \%$ of the food consumed, and women provide more than half of the agricultural labour force (Quisumbing et al., 1995). Smallholders contribute significantly to regional food security (IFAD \& UNEP, 2013), though their efforts remain insufficient, as the latest FAO report on the world status of food insecurity indicated that progress in reducing undernourishment in sub-Saharan Africa lags behind the rest of the world (FAO et al., 2015). Food insecurity manifested by problems of low dietary energy is rampant in virtually all developing countries. In Uganda, about $48 \%$ of the population is food-energy deficient, more than $40 \%$ of the rural population have low dietary diversity, and almost a third of the children are stunted (UBOS \& WFP, 2013; World Bank, 2016b). Food insecurity is prevalent in rural areas and has been associated with monetary poverty and reliance on bulky staple foods as a source of energy (UBOS \& WFP, 2013).

Given the association between poverty and food insecurity, interventions aimed at poverty reduction are expected to address the food insecurity question (FAO, 2000b). Diversification of livelihoods, especially in agricultural communities, is imperative for improved income and food security (Barrett et al., 2001; FAO, 2000a). Many such interventions target women in recognition of the special role they play in food security attainment. Women are involved in agricultural and non-agricultural activities, including subsistence crop production, and in informal trade and services, all of which contribute to household food access and availability (Buvinić, 1997; Momsen, 2004; Østergaard, 1992). Despite their key role, women constitute a large part of the 
world's poor (Fletschner, 2009). They lag behind men in labour market participation, and have lower human development indices (HDI) than men (UNDP, 2014). A combination of factors work together to limit female productivity and to entrap them in perpetual poverty. Financial, economic and social deprivation limits their market participation to low-return activities (Cheston \& Kuhn, 2002; Grown \& Sebstad, 1989; Jiggins, 1989; Lakwo, 2006; MacGuire \& Popkin, 1990). Other factors limiting their participation in formal employment include low levels of education and skills, limited land ownership rights, and lack of credit, among others (UNDP, 2003). They are also limited by unequal access to land, and other production inputs including improved seeds and fertilizers (Quisumbing et al., 1995).

The UNDP 2014 Human Development Report named Uganda as one of the countries in the world where gender disparity is increasing (UNDP, 2014). Although women make up 50\% of the Ugandan population, the majority are unpaid workers (UBOS, 2016). They contribute and have potential to contribute even more to the socio-economic development of the country and yet they are deprived and impoverished (Republic of Uganda, 2014b). According to the 2005/2006 Uganda National Household Survey (UNHS) women constitute 53\% of the work force in Uganda (UBOS, 2006). This pans out in a patriarchal system, with gender disparity in access to resources (Republic of Uganda, 2014b), with male dominance over productive resources and household decision making. There is wide-spread marginalisation of women in education, employment and property ownership (Karuhanga, 2008; Lakwo, 2006; Republic of Uganda, 2014a), and yet women are key players in the agricultural sector and household food provision (Republic of Uganda, 2014b). They continuously seek ways of enhancing their household management roles, by seeking opportunities for personal and family welfare improvement. An important way of doing this amounts to self-employment by setting up survival and maintenance 
microenterprises (MEs). These poorly financed low-return MEs, make significant contributions to the livelihood of the women and their households (Jiggins, 1989; Schreiner \& Woller, 2003; Smith et al., 2001) but are in need of financing. However, women usually lack access to credit, because of different factors including lack of information on available credit facilities, credit rationing which makes formal banking institutions prefer male clients who take larger loans, lack of collateral for loans, low levels of education, cultural constraints, and high transaction costs (Østergaard, 1992; Parpart \& Connelly, 2000).

Microcredit is one of the popular approaches to poverty eradication and subsequent food security improvement. With an underlying connection between finance, entrepreneurship, business growth and improvement in income, microfinance institutions target women with microcredit. They provide women with microloans for investment into their microenterprises which are expected to attain high return on investment (Kaboski \& Townsend, 2012). Women have been reported to have good loan repayment records (Kabeer, 2005; Karlan \& Goldberg, 2011), and are important in the maintenance of household welfare by allocating large proportions of their resources to household needs (Barnes et al., 1999; Cheston \& Kuhn, 2002; Kabeer, 2005). They devote a higher share of their income than men to everyday subsistence and nutrition (Blumberg, 1989; Carloni \& Goddard, 1987). Providers of microcredit thus believe that provision of microcredit to women will lead to improvement in food security of poor households. Food consumption is expected to increase for different reasons. First, borrowing is expected to have a positive income effect, hence is expected to lead to improved economic access to food through purchase. Second, investment of received credit in agricultural production is expected to lead to increased food availability at the household level. The third reason why food security is expected to improve is through the consumption smoothing effect of borrowing. Women may 
overcome income and non-income shocks by using acquired loans for household food consumption expenditures.

However, food security may remain unchanged or even deteriorate after borrowing, for various reasons. The first is loan repayment burden due to investment of loans in poorly performing MEs, and diversion of production loans to consumption, among other issues. In this case, borrowers may allocate meagre available resources away from essential needs like food provision to loan repayment and other household expenditure priorities. The second reason for food security deterioration may be the result of a shift from the established norm of reliance on own-food production to reliance on food purchase, with no commensurate improvement in income. Thirdly, women's burden of food provision may increase when they join the household's cash economy. Men usually meet cash needs of peasant families because of their higher involvement in cash crop production and in informal employment activities. When women borrow they join the cash economy and subsequently men may reduce their cash contributions with the supposition that women are now more financially empowered. Finally, food security may not improve after borrowing because of low prioritisation of food security improvement. Food security may not be an objective of borrowing; women may be comfortable with the current food security status and make no change in food consumption patterns after borrowing.

These and other food security dynamics are rarely explored in microfinance studies. Most studies focus on the influence of microcredit on usually minimalistic food security parameters, but rarely explore the underlying dynamics. In this study we utilised different food security indicators and two alternative study approaches to ensure consistency of our findings. In the first study approach, we utilised a quasi-experimental cross-sectional design and obtained the effect 
of borrowing on food security by comparing food security parameters for old borrowers (OB), in the BRAC Uganda microfinance program, and in-coming new borrowers (NB) into the same program, before they received their first loan. This design ensures that both groups are selfselected into borrowing. We utilised the propensity score matching (PSM) methodology to ensure comparability of the groups and to assess differences in food security outcomes of OB and NB groups. PSM results revealed significantly lower dietary diversity scores, and proportion of energy from own production, for OB than NB. OB also had smaller sugar-intake and fruitintake scores and proportion of energy consumption from fat than NB.

In the complementary approach, we used 2-year panel data for the NB category and a control group (CG), who never got a loan from BRAC or any other MFI. We employed a difference-indifference (DID) estimation with Kernel matching to assess changes in food security parameters of the NB and CG, within the study period. We again found a decline in the food security parameters of the households after borrowing. To the best of our knowledge previous studies has used neither the diversity of food security indicators that we employ, nor used two comparative approaches.

The remainder of the chapter is organised as follows. Section 5.2 presents the conceptual and theoretical framework of the study including the above-mentioned factors associated with food security improvement or lack of improvement. It also presents an overview of findings of previous studies on microcredit and food security. Section 5.3 describes the study area, the BRAC microcredit program and the study design and data collection methods. Section 5.4 shows the results of the cross-sectional and panel studies. Section 5 concludes. 


\subsection{Theoretical framework}

This section has three main objectives. In Section 5.2.1 we introduce and discuss the key food security concepts and indicators that we use in the study. In Section 5.2.2 we present a review of the theoretical background for potential effects of microcredit and food security, a brief review of available studies on microcredit and food security, and the hypotheses that were tested in the empirical part of the study.

\subsubsection{Concepts and definitions of food security}

There are various concepts at the core of our analysis. These include the definition of food security and its components, as well as indicators of food security used in the study. Food security has been defined in more than 200 different ways (Maxwell, 1996). We use the widely accepted World Food Summit definition, indicating that food security exists when all people at all times have physical and economic access to sufficient, safe and nutritious food, that meets their dietary needs and food preferences for an active and healthy life (FAO, 1996). Three broad concepts are encompassed in the definition of food security: food availability, food access and food utilisation. Sen (1981) postulates that food insecurity is not all about food availability, but rather that food access, especially economic access, is an important component of food security. Food access encompasses the ability of households to actually access available food, usually through having the economic means to do so (Ashley, 2016). Food availability denotes the physical availability of food of adequate quantity and quality in an area, while food utilisation refers to the body's ability to utilise ingested food usually affected by the state of health of the individual (FAO, 1996). Next, we discuss the indicators of food security that we use in the study including household dietary diversity (HDDS), qualitative measures of food insecurity based on 
the household food insecurity access scale (HFIAS), and measures of undernourishment based on caloric intake. Caloric intake of households can be used to classify households as food secure or food insecure (Ashley, 2016).

While modern food economies are characterised by availability of sufficient quantity and quality foods for consumers throughout the year, the majority of people in developing economies depend on own-produced monotonous diets. These are based on starchy staples, with minimal animal-source foods, and seasonal fruits and vegetables. Starchy staple foods constitute a large percentage of the food expenditures and caloric intake for poor households (Bouis \& NovenarioReese, 1997). However, reliance on these starchy staples translates into difficulties with meeting energy and nutrient needs especially because of these foods are high in dietary bulk (Ljungqvist, Mellander, \& Svanberg, 1981). This makes it difficult to consume enough quantities to meet nutritional needs. Meeting nutritional and energy needs requires use of diets consisting of a variety of foods. Dietary diversity is a key element of high quality diets (Torheim et al., 2004), and many nutritional guidelines recommend consumption of a variety of foods (Arimond \& Ruel, 2004). Dietary diversity is a widely used measure of food security, for interventions that focus on food security improvement. The Household Dietary Diversity Score (HDDS) is a simple count of the number of different food groups eaten by a household in a specified time period. A high HDDS is indicative of adequacy in caloric and nutrient supply from diets, especially in developing countries (Arimond \& Ruel, 2004; Hoddinott \& Yohannes, 2002). When incomes of poor communities improve, they shift away from monotonous diets to richer diets, with improved quantity, quality and diversity (Swindale \& Bilinsky, 2006b). Hoddinott and Yohannes (2002), found positive and strong relationship between HDDS and household per capita consumption expenditures and household per capita daily caloric availability from staples 
and non-staples. High HDDS is associated with caloric and protein adequacy (Chua et al., 2012; Swindale \& Bilinsky, 2006b), and higher household income (Swindale \& Bilinsky, 2006b). Interventions that empower women economically have been found to lead to improvement in the intake of animal source foods (Colecraft et al., 2006) and dietary diversity (Sraboni et al., 2014). DDS is easily affected by income and non-income shocks to which households usually respond by eating less or eating less preferred, poorer quality and less diverse foods (Ashley, 2016).

Another common measure of food access is the qualitative Household Food Insecurity Access Scale (HFIAS). HFIAS has been described and operationalised by Swindale and Bilinsky (2006a) and Coates, Swindale, and Bilinsky (2007). Based on work by the United States National Household Food Security Survey Measure (HFSSM), HFIAS comprises a series of questions that represent domains of household food insecurity (access) experiences that may be used to assign households on a continuum of severity from food secure to severely food insecure. HFIAS captures the respondents' feelings of uncertainty and/or anxiety over food, perceptions that food is of insufficient quality (for adults and children), and reported reductions in food intake (for adults and children). Many researchers have validated the use of HFIAS across different cultures and reported correlations between HFIAS and poverty, malnutrition and food insecurity (Coates, Webb, \& Houser, 2003; Frongillo, Nanama, \& Wolfe, 2004; Webb, Coates, \& Houser, 2002). Melgar-Quinonez et al. (2006) found a correlation between HFIAS and household expenditures on food. In addition, Coates et al. (2006) conducted a study to identify the commonalities in the experience and expression of food insecurity (access), across different cultures. They found that insufficient food quantity, inadequate food quality, uncertainty and worry about food, were a significant part of the food insecurity experience across different cultures. 
Interventions that empower women have been associated with improvement in caloric availability and DDS (Sraboni et al., 2014). Caloric intake of households can thus be used to classify households as food secure or food insecure (Ashley, 2016). Focus is placed on caloric needs because if these are not met, other dietary needs may not be met.

Income is another food security indicator, especially so when women are in charge of the income (Kennedy \& Peters, 1992). Adverse poverty prevents over a billion people in the world from accessing adequate food for productive living (FAO, 1996). People are said to suffer from severe or moderate forms of poverty if they live on less than $\$ 1$, resp. less than $\$ 2$ per day (Banerjee \& Duflo, 2007; Weisfeld-Adams \& Andrzejewski, 2008). Since measurements of income are usually difficult, household consumption expenditures are commonly used as an income proxy. Finally, expenditures on food may be another food security indicator because a large percentage of income of the poor goes to food (Mellor, 1983; Von Braun et al., 1991). Banerjee and Duflo (2007) found that food represented 56-78\% of the consumption expenditures of poor people in 13 countries.

\subsubsection{The income effect of borrowing}

Increased income is one of the major expected outcomes of borrowing, with direct bearing on food security of households. Any intervention that improves household income is expected to improve purchasing power and economic access to food. For rural agrarian communities depending on small-scale farming for income and food, improvement in agricultural productivity will lead to both improvements in cash income as well as income in kind, mainly in the form of food. Microcredit thus addresses food insecurity via two major pathways: increase in 
productivity from agricultural and non-farm MEs, and resultant improvement in income and use of credit for consumption smoothing.

It has long been argued that poor people are credit constrained and access to credit will enable them to transform their poorly performing investments with untapped potential into productive investments. Borrowers are expected to use the social and physical capital associated with borrowing to improve enterprise output (Feder et al., 1990) and thus generate more income (Zeller \& Sharma, 2000). Generally, investment of credit in existing business or new production activities is expected to lead to microenterprise expansion, increased business outputs, household and business assets, profits and income improvement (Banerjee et al., 2015; Crépon et al., 2015; Gobezie, 2004; Imai, Arun, \& Annim, 2010; Karlan \& Zinman, 2011; McKernan, 2002; Sebstad et al., 1995).

In the case of agricultural producers, access to credit is expected to lead to improved agricultural output (Feder et al., 1990). This may happen via different pathways. Firstly, credit enables farmers to access labour-saving technologies and have better access to agricultural inputs like fertilisers and improved seeds (Khandker \& Koolwal, 2016; Zeller \& Sharma, 2000). Recipients may also increase their labour supply (Banerjee et al., 2015; Crépon et al., 2015), leading to improved productivity and income (Matin et al., 2002). Some poor borrowers may utilise loans to rent land for agricultural production.

Secondly, households accessing credit may manage their assets and liabilities more efficiently; they may reduce levels of assets for precautionary savings and instead acquire production assets (Foltz, 2004; Matin et al., 2002). They may sacrifice short-term consumption of non-asset goods and leisure in order to acquire durable goods (Banerjee et al., 2015; Crépon et 
al., 2015). All these actions will improve their production potential. Indeed some studies have observed improvement in profits of MEs among borrowers (Copestake et al., 2001)

Since agriculture is a major source of food for peasant communities, improvement in production resulting from access to credit should lead to improved household food availability and improvement in cash income, which will lead to economic access to food, especially when credit is given to women. Investment in animal production is expected to lead to improvement in production of easy-to-sell animal products including milk and eggs.

\subsubsection{Borrowing and consumption smoothing}

Enhancement of consumption and consumption smoothing is another pathway through which microcredit can contribute to food security. The poor do not only face challenges of low income, their incomes are prone to shocks from risks like business failure, illness and death. Such shocks greatly influence household consumption and production decisions. Availability of credit helps the poor overcome such shocks without compromising consumption and production decisions (Morduch, 1995). Participation in microcredit programs has been observed to lead to consumption smoothing (Angelucci et al., 2013), especially for communities with production problems due to seasonality (Develtere \& Huybrechts, 2002; Morduch, 1995; Zeller \& Sharma, 2000). Farmers may use credit to invest in longer-duration and more profitable investments (Foltz, 2004; Matin et al., 2002), without worrying about current consumption. Availability of credit to address emerging shocks will enable the poor to survive without compromising food consumption. In addition, the possibility of future credit access may alter the need for savings as protection against future shocks, and clients may use acquired credit to cover current consumption (Kaboski \& Townsend, 2011; Matin et al., 2002). 
Furthermore, the poor have needs for lump-sum consumption expenditures including lifecycle expenditures of weddings and funerals, human capital investments in health, education, and food which may be covered by borrowing (Matin et al., 2002; Rutherford, 2000). Liquidity constrained borrowers may then use production loans to cover consumption expenditures they would otherwise be unable to make (Feder et al., 1990). Use of credit to cover consumption expenditures which are not related to production may be considered as loan diversion. Usually, borrowers conceal from lenders the fact that a loan will be used for consumption purposes, other than food (Attanasio et al., 2015), and improper expenditure of loans may lead to a reduction in food consumption (Angelucci et al., 2013).

\subsubsection{Potential negative effects of microcredit}

Recently, the discourse on microcredit and its effects on households has shifted to the potentially negative effects of borrowing. Some have argued that microcredit, especially for MFIs with both social and profit motivations in their operations, may not be a silver bullet to improve income and welfare of the poor, especially women (Buckley, 1997; Matin et al., 2002; Morduch, 2000). These MFIs focus on increasing their loan portfolio, profits and loan recovery, and may sometimes disregard social benefits of microcredit participation (Ghosh, 2013). Some levy high interest rates even when they have a range of prices to work within and still expand their operations (Angelucci et al., 2013). Borrowers, especially women, end up facing limitations in making good use of accessed loans and may not benefit from borrowing. For example, a study by FAO on MFIs in Uganda (FAO, 2000a) noted that many engendered practices are sometimes perpetrated even when women borrow; they are limited to crop and non-cash crop production, and for the case of non-farm MEs, they invest in less lucrative activities than men. 
Studies have been commissioned to assess potential negative effects of microcredit. Angelucci et al. (2013), studied potential negative effects of microcredit on welfare and business parameters, for borrowers of Compartamos Bancos (one of the largest micro-lenders in Bolivia) and concluded that negative effects were minimal. Goetz and Gupta (1996) pointed to potentially negative effects of microcredit and observed that one of the most widely acclaimed outcomes of microcredit (women empowerment) is not a universal outcome, as some women lack control over loans they secure. Other negative effects of borrowing reported among women have included over-indebtedness (Ganle et al., 2015; Rahman, 1999a) and domestic violence, loan repayment pressure and stress (Rahman, 1999a, 1999b), ME-running related stress (Ahmed, Chowdhury, \& Bhuiya, 2001), and solidarity group loan payment pressure (Mayoux, 2001; Rahman, 1999a, 1999b).

As such, access to credit may not lead to improvement in food security because of different factors, including: (1) no improvement in productivity of MEs leading to no improvement in cash and non-cash income and a resultant repayment burden; (2) food security may not be a priority for households; (3) there may be a reduction of contribution of others towards food purchase when women join the cash economy of households.

As Morduch (2000) and Buckley (1997) argue, there may be undue optimism among proponents of microcredit that the poor demand credit at whatever cost to transform their businesses. Some MFIs charge high interest rates to poor borrowers based on the fact that the borrowers are able to pay off loans and even come back for repeat loans. This positive picture of microcredit and automatic improvement in production ignores the many structural and societal constraints poor women face that limit their productive capacity as they try to make good of their small investments (Brett, 2006; Ehlers \& Main, 1998). Production improvement requires more 
than capital. It requires skills, information, connections, and transportation which many poor people lack (Buckley, 1997; Morduch, 2000). Women usually lack human, financial and social capital needed to transform their small businesses into profitable ventures (Ehlers \& Main, 1998). The type of MEs the women engage in also matters. Most women usually engage in lowproductivity, low-return activities, with limited potential to yield funds for loan repayment (Gladwin et al., 2001). It is no wonder that some researchers observed no improvement in ME profits among borrowers (Banerjee et al., 2015). Borrowers involved in agricultural-related MEs face production risks due to reliance on unpredictable weather patterns, which make incomes seasonal and unreliable. These risks come on top of the inevitable lag phase between investment and income (Morvant-Roux, 2011). And yet some MFIs require loan repayment to be effected within a year and for repayment to commence already in the week after loan receipt. This may not be feasible for many borrowers, for few businesses of the poor can attain the rates of return investment needed to meet such requirements (Rutherford, 2000).

Activities which the women engage in are usually those they can run within the confines of the households (Goetz \& Gupta, 1996). The embeddedness of such activities within the household economic portfolio may impair separation of funds from MEs for loan repayment (MkNelly \& Lippold, 1998).

The inevitable outcome of these factors is over-indebtedness and problems with loan repayment that may compromise the food security of households. Copestake et al. (2001) observed an increase in indebtedness of borrowers on the first loan cycle and envisaged it may have been due to rigorous loan repayment protocols that put no consideration on the risks and uncertainties of the businesses. Stuck with the burden of the repayment to save the social ties and relationships of women in group contracts, women do whatever it takes to ensure loan 
repayment, including compromising household consumption. They sell whatever is saleable, including household food items, sacrificing household expenditures to save funds for loan repayment. These may have a negative effect on household food security (Goetz \& Gupta, 1996). Women may never benefit from loans if issues like market access are not part of the interventions (Adams \& Von Pischke, 1992).

Some authors have explored negative effects of borrowing and found mixed results (Angelucci et al., 2013). Among the poor and less experienced borrowers some negative effects were observed.

\subsubsection{Non-income factors which affect food consumption}

Different factors have been observed that may influence food consumption even when people have physical and economic access to food. These include cultural and religious factors (den Hartog, van Staveren, \& Brouwer, 2006) as well as education (Burchi \& De Muro, 2016). Lack of nutrition knowledge may negatively impact on the food security outcomes of borrowing. Lack of nutrition knowledge is a common problem among the low-education women of poor communities and it has been associated with poor maternal and child nutrition. The UNICEF conceptual framework of the causes of malnutrition in deprived communities (UNICEF, 1990) identifies lack of nutrition knowledge as an underlying cause of child malnutrition.

One of the widely acclaimed effects of microcredit participation is the empowering effects of microcredit on women. Women who have accessed credit have been reported to have higher levels of decision making within their households (Rahman, 1986; Fofana et al., 2015), and improvement in societal and perceived self-worth (Angelucci et al., 2013; Hashemi, Schuler, \& Riley, 1996; Kabeer, 2001). These factors may all lead to food security improvement. Any 
intervention that enhances women's financial status and decision making will lead to higher social benefits including extra expenditure on food for households (Buvinić, 1997).

\subsubsection{Available evidence on microcredit and food security}

Studies on the relationship between microcredit and food security show mixed results. For example, whereas Attanasio et al. (2015) reported an increase in seven-day expenditure on food among borrowers in Mongolia, Augsburg et al. (2015) observed a reduction in weekly food expenditures among poor borrowers, who just started a new business, in order to supplement the loan. For borrowers who already had a business, their consumption remained unchanged. Barnes et al. (2001a) report a positive and significant relationship between microcredit participation and consumption of animal source food, and others report positive relationships between borrowing and the nutrition of children (Marquis et al., 2015; Moseson, Hamad, \& Fernald, 2014), women's nutritional status (Hamad \& Fernald, 2015), and food consumption for entire households (Doocy et al., 2005; Hamad \& Fernald, 2015; Imai \& Azam, 2012; Moseson et al., 2014). Other studies, however, have reported a negative relationship between borrowing and feeding among women. For example, borrowers under the Promujer lending program in Bolivia were reported to compromise their food intake as a result of the burden of loan repayment (Brett, 2006). Women reported reducing the quantity and quality of household meals and use of all available household resources to effect the payment. Crépon et al. (2015) reported a reduction in overall consumption and non-durable consumption for households with a pre-existing business, as they invested more in their businesses. However, they observe that borrowers who did not have pre-existing businesses increased their food consumption expenditures after borrowing. 
Microcredit participation has been associated with smoothening of consumption among women borrowers. Some studies have reported higher levels of household consumption among female borrowers (Khandker, 2005). Pitt and Khandker (1998) compared household consumption among female and male borrowers and found female borrower households with higher consumption expenditures than their male counterparts. Households that borrow are reported to smoothen their consumption expenditure in anticipation of borrowing or after borrowing. However, a number of studies found no changes in general consumption (Attanasio et al., 2015; Banerjee et al., 2015; Crépon et al., 2015) after borrowing. Coleman (1999) found no effect of borrowing on expenditure on health and education of children. Finally, overborrowing and bad investments may translate into consumption decreases to cover losses on these expenditures (Angelucci et al., 2013), including loan repayment.

\subsubsection{Research questions and hypotheses}

Against our theoretical review, and with focus on the food security aspects, we stated the following hypothesis to answer the question of whether borrowing leads to modification in food consumption among rural agrarian borrowers and the factors which may explain any observed differences. The central null-hypothesis we tested is: Borrowing has no effect on the food consumption of households. The following hypotheses were tested:

Hypothesis 1. Participation in the microcredit program leads to changes in mode of food acquisition and household expenditure.

Hypothesis 2. Participation in the microcredit program leads to increases in household food security parameters. 
Hypothesis 3. The contribution of others to household food needs decreases when women access loans.

\subsection{Methodology}

This section deals with the empirical survey among microcredit recipients and non-recipients in Uganda. Section 5.3.1 considers the study area and the BRAC microcredit organization. Section 5.3.2 explains the study design. Section 5.3.3 describes the measures. Section 5.3.4 deals with the analysis techniques.

\subsubsection{Study design}

Measurements of changes among program recipients brought about by a program involves estimating the counterfactual, i.e., what would have happened to program recipients, without the program. There are methodological challenges involved, since it is not possible to both be and not be in the program at the same time. In the case of microfinance programs, there is the challenge of selecting comparison groups, i.e., non-borrowers to compare with borrowers. This is not usually easy because program placement may be endogenous. The decision to join a credit program may also be endogenous, as those who decide to join the program, may be different from those who do not join the program (Armendáriz \& Morduch, 2010; Morduch, 2000) leading to self-selection bias. Different methods can be used to overcome these challenges including instrumental variable methods, double-difference methods, propensity score matching, randomised impact evaluation methods, and pipe-line methods (Coleman, 1999; Pitt \& Khandker, 1998). In this study, we employ some of these commonly used methods to assess the 
differences between borrowers and non-borrowers in selected outcome variables. The design of the current study is presented in Table 5.1.

Table 5.1. Study design

\begin{tabular}{lllll}
\hline Groups & $\begin{array}{l}\text { Microcredit } \\
\text { intervention }\end{array}$ & Measure $\left(\mathbf{t}_{\mathbf{1}}\right)$ & $\begin{array}{l}\text { Microcredit } \\
\text { intervention }\end{array}$ & Measure $\left(\mathbf{t}_{\mathbf{2}}\right)$ \\
\hline $\begin{array}{l}\text { Old borrowers } \\
(\mathrm{OB})\end{array}$ & Yes & $\begin{array}{l}\text { Measure on outcome } \\
\text { variables }\left(\mathrm{O}_{1}\right)\end{array}$ & - & - \\
$\begin{array}{l}\text { New borrowers } \\
(\mathrm{NB})\end{array}$ & No & $\begin{array}{l}\text { Measure on outcome } \\
\text { variables }\left(\mathrm{O}_{2}\right)\end{array}$ & Yes & $\begin{array}{l}\text { Measure on outcome } \\
\text { variables }\left(\mathrm{O}_{4}\right)\end{array}$ \\
$\begin{array}{l}\text { Comparison group } \\
(\mathrm{CG})\end{array}$ & No & $\begin{array}{l}\text { Measure on outcome } \\
\text { variables }\left(\mathrm{O}_{3}\right)\end{array}$ & No & $\begin{array}{l}\text { Measure on outcome } \\
\text { variables }\left(\mathrm{O}_{5}\right)\end{array}$ \\
\hline
\end{tabular}

The overall study was a panel design in which we collected data on three categories of respondents. The first category of respondents was the OB group who had a running loan with BRAC. The second category consisted of in-coming new borrowers (NB) into BRAC, before they received their first loan. The last group of respondents consisted of a group of women from the same villages as NB, with a microenterprise but who never borrowed from BRAC or other MFI.

During the baseline study we collected data on the three study groups. We used the baseline data to construct a quasi-experimental cross-sectional design in which food security parameters of the OB and NB borrowers were compared based on the methodology sometimes referred to as the USAID/AIMS comparative cross-sectional analysis design (Nelson et al., 2004). The basis of this methodology in the assessment of the effect of microcredit is that, since both groups have already self-selected to participate in microcredit and one has just not received the loan, the difference between outcome measures for the two may be taken as the effect the intervention. 
We also collected baseline data on women who never received a loan (Control group=CG). We carried out two waves of data collection for both the NB and the CG groups (Gaile \& Foster, 1996). After one year we conducted a follow-up study in which we collected data from the NB and CG groups only. This data were used to obtain an alternative measure of the effect of microcredit using the difference-in-difference method (DID).

\subsubsection{Setting}

We use clients of BRAC, which is considered to be the world's largest developmental organisation in terms of reach and staff scale (Economist, 2010). BRAC is one of the largest micro-lenders in Uganda with 110,000 active borrowers by the end of 2013. It operates in many rural agrarian districts of Uganda, and has an ongoing expansion plan (BRAC, 2008, 2013). The BRAC microfinance program targets poor women (20-50 years) with stable businesses to enhance the performance of their self-employment activities (agricultural or non-farm microenterprises). The BRAC microcredit program uses the Grameen-like group lending model (Armendáriz \& Morduch, 2010), relying on joint liability of members for loan repayments at weekly group meetings. Microloans (USD 50-700) are given in cash to individual women who are serviced in 15-20 person Village Organisations (VOs). Loans are repayable in either 20 or 40 equal weekly instalments, commencing in the week after loan access. A VO is served by a credit officer, who is in charge of explaining BRAC loan terms and processes, including 18 promises members recite in each meeting to promote desirable behavioural adaptations. The group members have to agree to joint liability for repayment of each other's loans. Joint liability helps overcome problems of information asymmetry before lending, and moral hazard after lending. In addition borrowers are required to present a loan guarantor who will pay the loan when all other 
forms of loan recovery have failed. Loan repayment is done weekly, starting in the week following loan access. If a member fails to make her payment, the group chairperson and credit officer urge members to cover the payment in the spirit of solidarity by pooling funds together. Loan guarantors are called in when a woman neither turns up for a VO meeting nor makes prior arrangement for a payment. Women who cannot attend a VO meeting send their repayment through fellow VO members. (More details and characteristics of BRAC are presented in Chapter 2 of this thesis. At the time of the study BRAC charged flat interest rates of $12 \%$ and $25 \%$ for the 20 and 40 -week repayment periods, respectively. Loan amounts were jointly agreed upon by members of the VOs and the BRAC credit officer, branch manager and area manager. The minimum loan size and usual amount of the first loan was at the time of the study UGX 250,000 (about \$ 100).

The study was conducted in the districts of Mukono and Buikwe, both located in the central region of Uganda, within the Lake Victoria basin. The districts were selected based on two criteria. The first one is presence of BRAC microfinance activities among rural agrarian clients. The second was the MFI having expansion plans which was necessary for the identification of new borrowers for the study (see Table 5.1 for study design). Mukono district shares borders with Buikwe in the East. The relief, climate and fertile soils makes the area suitable for crop production (Mukono District Local Government, 2010).

With a population of about 599,817 people Mukono ranks seventh out of the 121 districts of Uganda, whereas Buikwe has a population of about 436,406. Most people in Mukono (73\%) and Buikwe (67\%) live in rural areas (UBOS, 2016). Over $80 \%$ of the population in both districts rely on agricultural production. Subsistence agriculture is characterised by low acreage due to increasing family sizes and land fragmentation, and by low productivity per unit area because of 
deteriorating soil fertility. Because of the proximity to the lake and the presence of many fish landing sites and rivers, fishing is an important economic activity in the two districts. Most fish is taken by big fish processing companies for export (Mukono District Local Government, 2010). Buikwe district is located 62 kilometres by road east of Kampala. It became a separate district in 2009 (UBOS, 2016).

\subsubsection{Sample and procedures}

With the consent of the participants and after assurance of confidentiality baseline data collection was undertaken between September 2013 and March 2014. The follow-up study took place between September and April 2014, one year after the baseline survey. We collected data from 312 existing borrowers (Old Borrowers=OB) and 221 in-coming clients $(\mathrm{New}$ Borrowers $=\mathrm{NB})$ who had self-selected to join the microcredit program before they received their first loan. Because they had self-selected to participate in the microcredit program, the NB category was expected to have comparable characteristics to the OB category as described by Armendáriz and Morduch (2010). We also obtained data from 227 non-borrowers (control group=CG) following a method described by Karlan and Goldberg (2011). The LC1 (Local Council 1) chairman of the villages in which the NB groups resided helped to identify households engaged in the informal sector (a non-farm microenterprise or agriculture as a source of income). The follow-up study had a total of 373 respondents $(\mathrm{NB}=131$ and $\mathrm{CG}=203$, drop outs from the $\mathrm{NB}=30$, and Controls that borrowed $=9$ ). The overall recovery rate was thus $74 \%$ for the panel study.

The $\mathrm{OB}$ and NB categories were selected from $100 \mathrm{VOs}$, from 6 BRAC branches from Buikwe and Mukono districts (Buikwe, Nkokonjeru, Lugazi, Kasawo, and two from Mukono). At the start of the study, we purposively selected BRAC branches had expansion plans, a pre- 
requisite for recruitment of NBs into the study. By the time of the study BRAC had about 323 women organisations in the two districts that are served under 6 branches. All BRAC branches were eligible for inclusion into the study. We zeroed down on inclusion of VOs that had agrarian clients we defined as 'clients who practiced agricultural production for food or as ME'. In order to balance out the effect of loan periods and loan cycles, we sampled and included VOs that had existed for more than two years. BRAC branch managers and loan officers used loan sheets to aid in the selection of VOs, with typically agrarian borrowers. VOs for NBs were newly-formed or had new borrowers. All women in a selected VO were eligible as respondents, except NBs and OBs who previously borrowed from other MFIs. NBs were enrolled in the study during the mandatory one-month orientation period, before they accessed their first loan. OBs were selected from VOs in the same or neighbouring village as selected NBs. Drop-outs from OB groups were traced and interviewed to reduce drop-out bias as described by Karlan (2001).

Information about the BRAC microcredit program was obtained from focus group discussions (FDG) with the borrowers and from key-informant interviews with BRAC loan officers, branch managers and the area manager. We obtained some information from loan sheets that we were able to access and also attended some VO meetings to understand more about the program operations. Six FGD sessions were held for OB groups and two for NBs. Each focus group comprised 8-15 participants, and included persons who had not been included in the survey and from groups not included in the questionnaire survey. Detailed notes and audio recordings were used to record the interviews. A FGD guide was used to elicit information from participants about their opinions and experiences with borrowing (see Appendix 5.1). 


\subsubsection{Measures}

Food intake and dietary diversity were measured by asking the women to provide the number of days, amount, cost and source of food that was eaten by the households in the seven days before the study. Measurement of food availability was obtained from data on the types, quantities, cost and sources of food (purchase versus own-production), acquired or purchased by the household in the seven days before the study. Household measures with known weight equivalents were used to estimate the quantities of food eaten by the household. Information was obtained on household members who missed different meals in the reference time period, to account for missed meals. The energy, protein, caloric and fat intake of the households was calculated by using the respective values from $100 \mathrm{~g}$ of food as given by Ngulube (1989).

We calculated a household per capita caloric intake by dividing the total calories in the different foods acquired and or consumed by the household and dividing it with the total number of adult male equivalent (AME) units for the household. AMEs were obtained from information on the household size and age composition. All adults were assigned one AME and children 0.6 AME. The total AME units of the household were the sum total of the AME units of the household. In a separate procedure, the quantities of different types of food were converted into total calories using food composition data bases and the food composition by Ngulube (1989). To obtain per capita caloric intake for a household, the total caloric supply from the food was divided by the total household adult equivalence units (den Hartog et al., 2006; Smith \& Subandoro, 2007).

We calculated a household diet diversity score (HDDS) as the number of food groups consumed during the previous 24 hours of the study. In this study HDDS was based on 12 different food groups: cereals, white roots and tubers, legumes/pulses, vegetables, fish, fruits, 
meat, eggs, oil, sugar, and milk. This a slightly modified list from that used by Swindale and Bilinsky (2006b)

The household food insecurity access scale (HFIAS) was adapted from Swindale and Bilinsky (2006a), and Coates et al. (2007), to assess whether households experienced problems in access to food in the preceding 30 days. The HFIAS scale was used to obtain the following information: (1) feelings of uncertainty or anxiety over the food situation; (2) perception that food is insufficient of quantity for adults and children; (3) perceptions that food is insufficient in quality; (4) reported reductions in food intake for adults and children; (5) reported consequences of reduced food intake; (6) reported feelings of shame for resorting to socially unacceptable means to obtain food. Different questions related to the above were asked for a recall period of 4 weeks or 30 days. The respondent was first asked an occurrence question, as to whether the condition in the question happened at all in the past 4 weeks (Yes or No). If the respondent answered 'yes' to an occurrence question, a frequency of occurrence question was asked to determine whether the condition happened rarely (once or twice), sometimes (three to ten times) or often (more than ten times) in the past 4 weeks. We calculated a household food insecurity access score (HFIAS), for individual households, following the methods by Coates et al. (2007). The maximum score for a household was 27 and the minimum was zero. The higher the HFIAS score the more food insecurity the household experienced.

The quantitative survey questionnaire was also used to elicit information on sociodemographic characteristics of respondents and their households, household expenditure, as well as several personality variables. It also elicited data on the monthly household expenditure on non-durable goods/ non-food goods, frequently purchased services, and 7-day expenditure on 
food. We also used it to determine the level of monetary expenditure of other family members on food.

We used a 4-point Likert scale (1=agree strongly; $2=$ agree to some extent; $3=$ disagree to some extent; $4=$ disagree strongly) with different personality statements. Three time preference items were adapted from Petrocelli (2003): (1) I only focus on the short term; (2) I live more for the present than for the future; (3) The future will take care of itself. Four items for need for achievement were adapted from Keinan and Kivetz (2011), and Ray (1980), including: (1) I get restless and annoyed when I feel am wasting time; (2) I have always worked hard to be among the best; (3) I am an ambitious person; (4) Improving my life is important to me. Another four items for risk preference were adapted from Blais and Weber (2006): (1) I enjoy taking part in decisions with un-known outcomes; (2) I avoid activities whose outcomes are uncertain (reverse scored).; (3) to gain high profits in business one should take decisions even when uncertain of the outcomes; (4) I would invest all my monthly profit in a new business venture. Sociodemographic and personality measures were assumed to reflect stable personality characteristics that might explain residual heterogeneity in the samples of new and old borrowers.

We also constructed an asset index and a housing facilities index, as a proxy for wealth using principal component analysis of data on household wealth and asset ownership. We obtained two components from our analysis. Component 1 which we named the household assets index included seven count variables (number of tables, chairs, beds, mattresses, cell phones, hoes, and radios). Component 2 was composed of variables related to housing and housing facilities (house ownership, TV ownership, electricity presence, type of walls of the house, and the material for the floor of the houses). We used these variables to construct a household housing index. 
Qualitative data collection using focus group discussions was done for groups of up to 15 women, to obtain in-depth information on different aspects of the study: Reasons for borrowing; Female participation and responsibilities in the management of loans and loan-supported MEs; Decision making on loan acquisition; Control of loan funds and the running of the MEs; Changes in household welfare after borrowing (we probed for changes in lives of the respondents and their household after borrowing); Changes in community participation and respondent position in community after borrowing (we probed about loan repayment, sources of funds, difficulties, role of husbands etc.).

All study instruments were translated into Luganda, the commonly spoken language in the study area. They were pilot tested and improved before use in the study.

\subsubsection{Empirical strategy}

We analysed cross-sectional data for 533 respondents (312 OBs and $221 \mathrm{NBs)}$ from about 138 Village Organisations (VOs), from 7 BRAC branches in the Buikwe and Mukono districts. We cross-checked and ensured comparability of the OB and NB groups by use of the Probability Score Matching (PSM) methodology. Factors which could influence self-selection into microcredit and those which could influence microcredit outcomes were used as control variables in the PSM procedure, with weighted Kernel matching (Luellen et al., 2005). These factors included respondent background characteristics, that is religion, marital status, age, years of education, time preference, risk preference, and achievement motivation. In order to compare with the NBs, all age-related variables of OBs were converted to the age basis at the time of their first loan, indicated as 'corrected age', 'corrected family size', and 'corrected dependency ratio' hereafter. Principal components analysis was used to check the dimensionality of the personality 
characteristics. In this analysis, only the time preference items were found to have a single factor in common, hence the average item scores were used as a measure of time preference, or impatience. The need for achievement and risk preference items were not explained from common factors, so we used the individual item scores in the PSM procedure.

The control variables were used to construct propensity scores estimating the probability of being in the control or treatment group. The PSM procedure was also used to estimate the effect of receiving microcredit. The rationale of PSM is to match the participants in the treatment group to those in the control group based on propensity scores. Therefore any remaining differences observed can be attributed to the treatment. The average treatment effect on the treated ( $\tau$ ATT) was defined as:

$$
\tau_{\mathrm{ATT}}=\mathrm{E}(\tau \mid \mathrm{D}=1)=\mathrm{E}[\mathrm{Y}(1) \mid \mathrm{D}=1]-\mathrm{E}[\mathrm{Y}(0) \mid \mathrm{D}=1]
$$

where $\mathrm{D}=1$ if respondent had a running loan with $\mathrm{BRAC}$ and $\mathrm{D}=0$ when they belonged to the NB category. Y(D) is the outcome variable of each participant (for example dietary diversity score) while $[\mathrm{Y}(0) \mid \mathrm{D}=1]$ is counterfactual and unobservable. According to Rosenbaum and Rubin (1983) $\tau$ ATT can be expressed as:

$$
\tau_{\mathrm{ATT}}=\mathrm{E}_{\mathrm{P}(\mathrm{X}) \mid \mathrm{D}=1}[\mathrm{E}[\mathrm{Y}(1) \mid \mathrm{D}=1, \mathrm{P}(\mathrm{X})]-\mathrm{E}[\mathrm{Y}(0) \mid \mathrm{D}=0, \mathrm{P}(\mathrm{X})]]
$$

where $\mathrm{P}(\mathrm{X})$ is the propensity score, that is, the probability of an individual to participate in the microcredit program given the observed characteristics X.

Panel data analysis involved comparison of data for 222 NBs and 225 CGs respondents using: (1) the Difference-in-difference (DID) approach in combination with propensity score matching, 
and (2) a Generalized Least Squares (GLS) model with fixed effect to take advantage of the panel nature of the data. The first methodology was described by Armendáriz and Labie (2011). The DID measures the impact of microcredit on borrowers by comparing treatment and control groups on changes in outcomes of interest over time relative to the outcomes observed in the baseline survey. The method recognises that unobserved heterogeneity in participation is present, but assumes that such factors are time invariant (Khandker et al., 2010). We obtained the difference between outcome variables between the two time periods (T1-T2) and netted out roles of measured and unmeasured individual attributes that do not change over time. Since this difference may be a reflection of differences in the broader social and economic environment, we use the control group baseline and follow up control measures to obtain $\mathrm{C} 1$ and $\mathrm{C} 2$ differences. Given the two period setting, where $\mathrm{t}=0$ before borrowing and $\mathrm{t}=1$ after borrowing, letting $\mathrm{Y}_{\mathrm{t}}^{\mathrm{T}}$ and $\mathrm{Y}_{\mathrm{t}}^{\mathrm{C}}$ be the respective outcomes of treatment and control units in time $\mathrm{t}$, the DID method was used to estimate the average microcredit impact as follows:

$$
\text { Food Security }_{i t}=\mathrm{E}\left(\left(\mathrm{Y}_{\mathrm{t}}^{\mathrm{T}}-\mathrm{Y}_{0}^{\mathrm{T}} \mid \mathrm{T}_{1}=1\right)-\mathrm{E}\left(\mathrm{Y}_{1}^{\mathrm{C}}-\mathrm{Y}_{0}^{\mathrm{C}} \mid \mathrm{T}_{\mathrm{i}}=0\right)\right)
$$

where Food Security it $_{\text {is }}$ one of our seven measures of food security, $\mathrm{T}_{1}=1$ denotes respondent accessing credit, whereas $T_{1}=0$ denotes the control group that never received or applied for microcredit. The DID estimator has the advantage of allowing for unobserved heterogeneity (the unobserved difference in mean counterfactual outcomes between treated and untreated units that could lead to selection bias).

We improved the DID methodology by combining it with Kernel matching (Khandker et al., 2010). We used propensity scores of factors (socio-demographic and personality characteristics of NB and $\mathrm{CG}$ ) which could influence participation into the microcredit program to match controls and borrowers on pre-program characteristics, in the baseline year. We then obtained 
differences between NB and CG groups within the common support, on different food security parameters.

In addition to the DID with Kernel matching we use the data in the common support region to run a standard GLS model with fixed effects. In this case each woman in the sample is traced both in the baseline and follow up to form a panel of data. This way:

$$
\text { Food Security }_{i t}=\alpha_{i}+T_{i t}+\delta_{t}+\varepsilon_{i t}
$$

where Food Security $i t$ is again one of our seven measures of food security, $\alpha_{i}$ is the individual level fixed effect term, $T_{i t}$ is once more the microcredit treatment, $\delta_{t}$ represents a time dummy and $\varepsilon_{i t}$ the error term.

\subsection{Results}

In this section we present empirical results of our assessment of cross-sectional and panel analysis of differences in food security parameters of households of borrowers and those without credit. In the cross-sectional analysis, we compare baseline food security parameters for OB and NB groups. We then present longitudinal panel data comparison for CGs and NBs. Finally, we discuss and conclude based on the study findings.

\subsubsection{Cross-sectional study results}

In this section we present results for 533 respondents we used in the cross-sectional comparison of $\mathrm{OB}(\mathrm{n}=311)$ and NB $(\mathrm{n}=221)$. As mentioned before, propensity score matching was used to ensure comparability of the two groups. It was also used to determine the average treatment 
effect on the treated (ATT), a measure of differences between treatment and controls, after controlling for variables that could influence taking credit.

Descriptive characteristics of the respondents in the cross-sectional study before and after matching on factors that would influence microcredit participation are shown in Table 5.2. The dependency ratio defined as the ratio of dependents (aged 0-14 years and those over 65 years) to the household productive members (15-64 years), was about 1.48 for entire sample. This is lower than the national average. Respondents in the whole sample scored high on the time preference scale, indicating a moderately high future bias, and they scored around neutral on the risk measurement scale. The majority of the respondents $(70 \%)$ were married. The respondents in both groups typically had limited formal education, the majority having completed seven years of primary education. Older respondents were more likely to be in the OB group. 
Table 5.2. Socio-demographic characteristics of $O B$ and NB in unmatched cross-sectional samples

\begin{tabular}{|c|c|c|c|c|c|c|}
\hline Variables & $\begin{array}{l}\text { Pooled } \\
\text { Mean }\end{array}$ & Min & Max & $\begin{array}{c}\text { OB } \\
\text { Mean }\end{array}$ & $\begin{array}{c}\text { NB } \\
\text { Mean }\end{array}$ & $\begin{array}{c}t \\
(\text { OB-NB }\end{array}$ \\
\hline Age at borrowing & $\begin{array}{c}34.27 \\
(10.12)\end{array}$ & 19 & 72.05 & $\begin{array}{l}35.39 \\
(10.6)\end{array}$ & $\begin{array}{c}32.86 \\
(9.3)\end{array}$ & $-2.77 * *$ \\
\hline Education & $\begin{array}{c}7.31 \\
(3.30)\end{array}$ & 0 & 14 & $\begin{array}{c}7.27 \\
(3.34)\end{array}$ & $\begin{array}{c}7.31 \\
(3.39)\end{array}$ & 0.13 \\
\hline Dependency ratio & $\begin{array}{c}1.45 \\
(1.28)\end{array}$ & 0 & 9 & $\begin{array}{l}1.47 \\
(1.3)\end{array}$ & $\begin{array}{l}1.43 \\
(1.2)\end{array}$ & -0.38 \\
\hline Time preference scores & $\begin{array}{c}3.41 \\
(0.80)\end{array}$ & 1 & 4 & $\begin{array}{c}3.44 \\
(0.80)\end{array}$ & $\begin{array}{c}3.40 \\
(0.80)\end{array}$ & -0.57 \\
\hline Achievement motivation score & $\begin{array}{c}1.06 \\
(0.19)\end{array}$ & 0.33 & 2 & $\begin{array}{c}1.05 \\
(0.19)\end{array}$ & $\begin{array}{c}1.05 \\
(0.19)\end{array}$ & -0.10 \\
\hline Risk preference & $\begin{array}{c}2.30 \\
(1.00)\end{array}$ & 1 & 4.33 & $\begin{array}{c}2.32 \\
(1.05)\end{array}$ & $\begin{array}{c}2.27 \\
(0.96)\end{array}$ & -0.56 \\
\hline Anglican $(\%)$ & $\begin{array}{c}0.3 \\
(0.45)\end{array}$ & 0 & 1 & $\begin{array}{c}0.32 \\
(0.47)\end{array}$ & $\begin{array}{c}0.26 \\
(0.44)\end{array}$ & $(2.39)^{1}$ \\
\hline Pentecostal (\%) & $\begin{array}{c}0.14 \\
(0.35)\end{array}$ & 0 & 1 & $\begin{array}{c}0.12 \\
(0.33)\end{array}$ & $\begin{array}{c}0.16 \\
(0.37)\end{array}$ & $(1.78)^{1}$ \\
\hline Muslim (\%) & $\begin{array}{c}0.23 \\
(0.41)\end{array}$ & 0 & 1 & $\begin{array}{c}0.25 \\
(0.43)\end{array}$ & $\begin{array}{l}0.19 \\
(0.4)\end{array}$ & $(2.07)^{1}$ \\
\hline Marital status (\%) & $\begin{array}{c}0.70 \\
(0.46)\end{array}$ & 0 & 1 & $\begin{array}{c}0.70 \\
(0.46)\end{array}$ & $\begin{array}{c}0.71 \\
(0.46)\end{array}$ & $(0.01)^{1}$ \\
\hline Household asset index & $\begin{array}{c}2.16 \\
(0.83)\end{array}$ & 0.22 & 6.22 & $\begin{array}{c}2.23 \\
(0.82)\end{array}$ & $\begin{array}{c}2.07 \\
(0.83)\end{array}$ & $-2.06 * *$ \\
\hline Housing facilities index & $\begin{array}{c}0.46 \\
(0.35) \\
\end{array}$ & 0 & 1.25 & $\begin{array}{c}0.47 \\
(0.36) \\
\end{array}$ & $\begin{array}{c}0.46 \\
(0.34) \\
\end{array}$ & -0.44 \\
\hline
\end{tabular}

${ }^{\mathrm{I}}$ Pearsons Chi-square values. ${ }^{* *} p<0.05$.

The PSM method is useful to reduce differences in observable characteristics between borrowers and non-borrowers. Matching is expected to balance the distribution of explanatory variables across $\mathrm{OB}$ and NB groups. Table 5.3 contains covariate after-matching balancing test results for the two-sample t-test of mean differences between OB and NB women. The major observation from Table 5.3 is that all covariates are balanced since differences between the OB and NB samples are not significant after matching. Hence the matched groups can be considered similar with respect to matching variables. 
Table 5.3. T-tests for equality of means for matched samples (common support)

\begin{tabular}{lrrrc}
\hline Variables & OB & NB & \multicolumn{1}{c}{$\boldsymbol{t}$} & \% Bias \\
\hline Dependency ratio & 1.59 & 1.64 & -0.19 & -4.2 \\
Age at borrowing & 35.07 & 34.72 & 0.83 & 3.5 \\
Education & 7.36 & 7.23 & 0.44 & 4.0 \\
Time preference score & 3.46 & 3.43 & 0.39 & 3.4 \\
Achievement motivation score & 1.06 & 1.06 & 0.42 & 3.8 \\
Risk preference & 2.30 & 2.27 & 0.09 & 1.7 \\
Anglican (\%) & 0.32 & 0.31 & 0.20 & 1.9 \\
Pentecostal (\%) & 0.14 & 0.13 & -0.12 & -1.1 \\
Muslim (\%) & 0.22 & 0.23 & -0.38 & -0.3 \\
Marital status (\%) & 0.70 & 0.72 & -0.53 & -4.8 \\
Household asset index & 2.21 & 2.23 & 0.14 & 1.3 \\
Housing facilities index & 0.47 & 0.46 & 0.73 & -1.2 \\
\hline
\end{tabular}

Results of the PSM analysis (Table 5.4) found borrowers with running loans (OB), with significantly smaller dietary diversity scores and proportion of energy from own production, than in-coming borrowers (NB). OB dietary diversity scores were 0.64 points smaller than NB. They also took $2 \%$ smaller proportion of energy from fat and $8 \%$ smaller proportion of energy consumption from own production than NB. We disaggregated the household dietary diversity components further and found $\mathrm{OB}$ to have smaller fruit-intake and sugar-intake scores than NB. As a robustness check for our result we conducted the PSM procedure using Radius matching and nearest neighbour matching (see Table A5.1 in Appendix 5.1). Results are generally similar to those we obtain using Kernel matching.

Table 5.4 shows that food expenditures of OB households were significantly higher than for NB households. Also, the expenditures of others on food were significantly lower. For the other expenditure categories, no significant difference was found. We therefore do not reject hypothesis 1 and hypothesis 3 (Section 5.2.7). The results were quite consistent across other PSM matching methods (Table A5.1 in Appendix 5.1). 
Table 5.4. Differences between OB and NB food security parameters, Kernel matching

\begin{tabular}{|c|c|c|c|c|c|c|}
\hline & OB & & NB & & Difference & \\
\hline & $N$ & Mean & $N$ & Mean & $A T T$ & $t$ \\
\hline Caloric intake $^{1}$ & 250 & 2351.31 & 206 & 2393.40 & $\begin{array}{r}-42.07 \\
(104.56)\end{array}$ & -0.40 \\
\hline Dietary diversity score & 250 & 6.16 & 205 & 6.81 & $\begin{array}{l}-0.64 \\
(0.21)\end{array}$ & $-3.02 * *$ \\
\hline HFIAS score ${ }^{2}$ & 257 & 4.72 & 212 & 4.00 & $\begin{array}{r}0.72 \\
(0.44)\end{array}$ & $1.62 *$ \\
\hline Proportion of energy from fat & 246 & 0.14 & 210 & 0.16 & $\begin{array}{r}0.02 \\
(0.01)\end{array}$ & $-2.51 * *$ \\
\hline Proportion of own-food production ${ }^{3}$ & 228 & 0.47 & 195 & 0.55 & $\begin{array}{l}-0.08 \\
(0.03)\end{array}$ & $-3.05 * *$ \\
\hline $\begin{array}{l}\text { Log of seven-day per-capita expense on } \\
\text { food }\end{array}$ & 252 & 8.45 & 210 & 8.29 & $\begin{array}{r}0.16 \\
(0.08)\end{array}$ & $2.09 * *$ \\
\hline Log of monthly food expenditure by others & 250 & 6.90 & 209 & 8.14 & $\begin{array}{l}-1.2 \\
(0.5)\end{array}$ & $-2.49 * *$ \\
\hline
\end{tabular}

Figures in parentheses in the Difference column are standard errors. $* * p<0.05, * p<0.10 .{ }^{1}$ Adult Male Equivalent;

${ }^{2} 30$-Day Household Food Insecurity Access Scale score; ${ }^{3}$ Energy from own-food production proportion.

\section{Sensitivity analysis using R-Bounds}

We conducted a sensitivity analysis of our matching procedure to obtain information about possible hidden bias or bias from unobserved respondent characteristics with potential to influence self-selection into microcredit program. Such unobservable variables might bias our conclusions about the effects of microcredit and we tested this by conducting a Rosenbaum sensitivity analysis as described by Rosenbaum (2010) and DiPrete and Gangl (2004). Table A5.2 in Appendix 5.1 provides $p$-values for Wilcoxon signed rank tests for different levels of gamma $(\Gamma)$, the odds ratio of differential treatment assignment due to unobservable attributes. At each $\Gamma$ a critical $p$-value is shown, indicating the limit of significance level of the treatment effect due to endogenous selection into treatment. We present results for up to $\Gamma=3$, for weekly household food cost and for dietary diversity scores, some of the major outcomes of our study. Results indicate that unobservable covariates would need to change the odds of treatment assignment by factors beyond 3 (we obtained results to as high as 56 and the significance did not change) to conclude that the observed treatment effects from propensity score matching were due 
non-random assignment. Given the results of the sensitivity analysis for PSM, and the lack of suitable instruments explaining group membership, we refrained from conducting an instrumental variables regression on our data. To check if our result holds even across different analytical techniques, we conduct DID analysis on 2-year panel data, as described below.

\subsubsection{Panel study results}

The panel data analysis was conducted on a total of 448 respondents. The treatment group in the panel study were 222 new borrowers (NB) who at baseline were just about to get their first loan. The control group (CG), were 226 women from the same village as NB but who never got a loan from BRAC or other MFI.

Table 5.6 shows that the unmatched samples differed on age, family size, education level, achievement motivation score and risk preference. Respondents in the control group were older, less educated and more risk averse than the NB category. That the two groups were different is not surprising, since the NB category had self-selected to participate in the microcredit program and the CG had not. We incorporated Kernel matching, in our DID analysis, to ensure comparability of the two groups, based on observable variables including two wealth indices (housing index and asset index) and demographic and personality characteristics that would influence the decision to take credit. Once Kernel matching is performed, and data outside the common support region is excluded, the panel shows strongly balanced treatment and control groups with respect to the selected variables, none of them being significantly different across the two groups. 
Despite use of PSM matching, we may not rule out influence from unobserved characteristics, on our results. We thus make use of a panel setting and a GLS fixed effects to ensure that all time-invariant un-observables are taken care of by the individual constant term.

Table 5.6. T-tests for equality of means for unmatched and matched panel samples

\begin{tabular}{|c|c|c|c|c|c|c|c|}
\hline \multirow[t]{2}{*}{ Variables } & \multicolumn{3}{|c|}{ Unmatched sample } & \multicolumn{3}{|c|}{ Matched sample } & \multirow[t]{2}{*}{$\%$ Bias } \\
\hline & NB & CG & $t$ & NB & CG & $t$ & \\
\hline Dependency ratio & 1.43 & 1.49 & -0.53 & 1.43 & 1.51 & -0.71 & -6.80 \\
\hline Age at borrowing & 32.94 & 35.70 & $2.72 * *$ & 32.94 & 33.31 & -0.39 & -3.50 \\
\hline Education & 7.35 & 6.47 & $2.56 * *$ & 7.35 & 7.36 & -0.04 & -0.40 \\
\hline Time preference score & 3.38 & 3.30 & 0.99 & 3.38 & 3.40 & -0.23 & -2.10 \\
\hline Achievement motivation score & 1.06 & 1.13 & $2.51^{-}$ & 1.06 & 1.06 & 0.02 & 0.20 \\
\hline Risk preference & 2.28 & 2.05 & $2.52 * *$ & 2.28 & 2.32 & -0.42 & -4.30 \\
\hline Anglican $(\%)$ & 0.27 & 0.26 & 0.08 & 0.27 & 0.28 & -0.44 & -4.30 \\
\hline Pentecostal (\%) & 0.15 & 0.15 & -0.24 & 0.16 & 0.17 & -0.55 & -5.40 \\
\hline Muslim (\%) & 0.20 & 0.17 & 0.84 & 0.20 & 0.19 & 0.28 & 2.80 \\
\hline Marital status (\%) & 0.70 & 0.71 & -0.21 & 0.70 & 0.70 & 0.14 & 1.30 \\
\hline Household asset index & 2.09 & 2.09 & -0.10 & 2.09 & 2.10 & -0.13 & -1.20 \\
\hline Housing facilities index & 0.46 & 0.35 & $3.39 * *$ & 0.46 & 0.44 & 0.57 & 5.60 \\
\hline
\end{tabular}

** $p<0.05$. Matched sample on common support region only.

Table 5.7 shows the mean at time 0 and time 1 for the seven different food security parameters. The last two columns show respectively the outcomes of the difference-in-difference with Kernel matching and Generalised least squares with individual fixed effects models. In both cases there is strong evidence that microcredit uptake resulted in a robustly significant reduction in dietary diversity at the household level. Table A5.3 in Appendix 5.1 shows that this can be traced down to a reduction in the diversity of consumption of animal and sugar intake, and to a lesser extent of fruits, starchy staples and vegetables. While the result from the cross-sectional analysis regarding lower proportion of own food production over the total food consumed seems instead not to be confirmed by the panel analysis, we find that caloric intake is significantly 
lower at the $10 \%$ level, as is the reduction in food expenditures by other household members.

Based on this result we cannot confirm hypothesis 2 (Section 5.2.7).

Table 5.7. Panel differences: Diff-in-Diff with Kernel matching and GLS fixed effects

\begin{tabular}{|c|c|c|c|c|c|c|c|c|}
\hline \multirow{2}{*}{$\begin{array}{l}\text { Food Security } \\
\text { Parameters }\end{array}$} & \multirow[t]{2}{*}{ Category } & \multirow[t]{2}{*}{$\mathbf{N}$} & \multicolumn{2}{|c|}{$T_{0}$} & \multicolumn{2}{|c|}{$T_{1}$} & \multirow{2}{*}{$\begin{array}{l}\text { Diff-in- } \\
\text { Diff }\end{array}$} & \multirow{2}{*}{$\begin{array}{c}\text { GLS } \\
\text { (fe) }\end{array}$} \\
\hline & & & Mean & Diff & Mean & Diff & & \\
\hline \multirow[t]{2}{*}{ Caloric intake } & CG & 333 & 2119.3 & 256.38 & 2449.4 & 78.09 & -178.29 & $-278.96 *$ \\
\hline & NB & 324 & 2375.7 & (112.94) & 2527.4 & $(126.24)$ & $(169.38)$ & $(148.38)$ \\
\hline \multirow{4}{*}{$\begin{array}{l}\text { Dietary diversity } \\
\text { score } \\
\text { HFIAS score }\end{array}$} & CG & 364 & 5.22 & 0.22 & 4.81 & -0.64 & $-0.86^{* *}$ & $-1.03 * * *$ \\
\hline & NB & 398 & 5.44 & $(0.21)$ & (4.17) & $(0.21)$ & $(0.30)$ & $(0.28)$ \\
\hline & $\mathrm{CG}$ & 351 & 7.48 & -3.40 & 7.00 & -3.17 & 0.23 & 0.72 \\
\hline & NB & 350 & 4.08 & $(0.54)$ & 3.83 & $(0.59)$ & $(0.80)$ & $(0.59)$ \\
\hline \multirow{4}{*}{$\begin{array}{l}\text { Proportion of } \\
\text { energy from fat } \\
\text { Proportion of } \\
\text { own-food } \\
\text { consumption }\end{array}$} & CG & 329 & 0.15 & 0.01 & 0.14 & 0.01 & 0.01 & 0.01 \\
\hline & NB & 340 & 0.16 & $(0.01)$ & 0.15 & $(0.01)$ & $(0.01)$ & $(0.01)$ \\
\hline & CG & 304 & 0.51 & 0.03 & 0.59 & 0.00 & -0.03 & -0.01 \\
\hline & NB & 312 & 0.54 & $(0.03)$ & 0.60 & $(0.03)$ & $(0.04)$ & $(0.03)$ \\
\hline \multirow{2}{*}{$\begin{array}{l}\text { Log 7-day per- } \\
\text { capita food } \\
\text { expense }\end{array}$} & CG & 333 & 8.22 & \multirow{2}{*}{$\begin{array}{r}0.01 \\
(0.09)\end{array}$} & 8.06 & \multirow{2}{*}{$\begin{array}{c}0.11 \\
(0.10)\end{array}$} & \multirow{2}{*}{$\begin{array}{c}0.02 \\
(0.14)\end{array}$} & \multirow{2}{*}{$\begin{array}{c}0.05 \\
(0.10)\end{array}$} \\
\hline & NB & 337 & 8.31 & & 8.17 & & & \\
\hline Log of monthly & CG & 335 & 6.69 & 1.65 & 7.05 & 0.63 & -1.02 & $-0.99 *$ \\
\hline $\begin{array}{l}\text { food expenditure } \\
\text { by others }\end{array}$ & NB & 336 & 8.35 & $(0.62$ & 7.68 & $(0.58)$ & $(0.78)$ & $(0.57)$ \\
\hline
\end{tabular}

\subsection{Conclusions and discussion}

The objective of this study was to assess the effects of microcredit on the food security of households, using a variety of indicators and assessment methods. Unlike studies, which reported positive effects of microcredit on food security (Barnes et al., 2001; Doocy et al., 2005; Pitt et al., 2003), we tested and rejected the hypothesis of improvement in food security of households with microcredit. This is unfortunate since the Uganda Nutrition Action Plan (UNAP) has improvement in incomes and dietary scores as its core strategy for Uganda development (GOU, 2011). Indeed, for food security to be maintained, incomes of poor farmers have to be improved (FAO, 2000a). BRAC operations among the rural poor in Uganda (UBOS, 2010a) provide loans 
to women in the agricultural sector and thus have enormous potential to contribute to household food security (Meyer, 2013), which do not seem to be realised though.

The negative effect of microcredit on food security may be attributed to a number of factors. First, female borrowers seem to shift their mode of food acquisition from own food production to food purchase as evidenced by a lower proportion of energy from own production and commensurate increment in the weekly expenditures of households on food. However, their food purchases are not diversified enough, at the detriment of good maternal and child health, and nutrition (Muhoozi et al., 2016).

Unlike the study by Augsburg et al. (2015), which reported reduction in weekly food expenditures among borrowers we observe an increment. The increment in expenditure is, however, not reflected in the purchases of commonly purchased food items in Uganda (sugar, animal food, oil and seasonal fruits), since the intake frequencies of these items goes down after taking microcredit (see Table A5.3 in Appendix 5.1). In addition, variety in consumed starchy food also goes down, pointing to increased expenditure to maintain basic monotonous diets based on maize, supplemented with beans. The commonest types of crops, reported by women as income generating crops, were maize and beans (see Chapter 4), both of which are important staple foods in Uganda (FAO, 2000a). Women often sell off their produce to retailers, shortly after harvest to meet pressing cash demands. Maize and beans store better than other food crops and selling them all off leaves households food insecure. They, however, may have to buy the same type of food to meet household food needs during the lean season. When cash is limited, women are not able to provide variety in the diet. This may explain the reduction in HDDS. In the Bolivia study women borrowers also allude to reduction in quantity and quality of foods given to families, in order to meet the rigors of loan repayment (Augsburg et al., 2015). Some 
women in our focus groups indicated they would rather not eat, in order to have funds for loan repayment.

A shift from own production to food purchase for agrarian settings like in our study, requires a commensurate increase in incomes if household food security is to be maintained. This is because income is a major determinant of household food security (Kennedy \& Peters, 1992). However, unlike studies showing improvements in ME performance with microcredit (Copestake et al., 2001; Crépon et al., 2015; Kaboski \& Townsend, 2012; McKernan, 2002), we found no effect of microcredit on monthly business profits (see Chapter 3).

Other factors that may explain the observed negative effect on household food security among borrowers are loan payment burden, poverty, and low levels of education and food knowledge among the borrowers, to be considered next.

Burden of loan repayment. The rigors and burden of loan repayment may well be the single most important cause of the declining food security level among the borrowers' households. The rationale behind lending to poor people is that access to credit will lead to improvement in the performance of poorly performing MEs. Investment of microloans into MEs is expected to yield funds for loan repayment and for general welfare improvement of households. This is supposed to be mediated by improvement in profitability of MEs, self-employment income and ultimately household welfare (Morduch, 1999). For poor borrowers with urgent financial needs it is sometimes not possible to consider the possibility of failure in profits improvements, at the time of borrowing. The lack of anticipation for possibility of failure in improvement in the profits from MEs, has also been observed in several other studies (Banerjee et al., 2015; Crépon et al., 2015). Lack of improvement in profits of MEs, impedes the mediating roles of improved income for loan repayment and welfare improvement. The ensuing loan repayment burden may then 
negatively affect the much anticipated improvement in family welfare, manifested by reduction in the quality of the diets among borrowers' households.

The burden of loan repayment faced by women has been discussed by different authors (Brett, 2006; Namayengo et al., 2016). In these studies, women decry strict requirements of loan repayment that for the benefit of the lender leave no room for repayment default. Pressure from group members and from credit officers makes borrowers do whatever it takes to obtain funds for loan repayment. Common sources of funds for loan repayment, mentioned in our focus group discussions, included (1) Cash from the loan-funded microenterprises, trade and agricultural related microenterprises; (2) savings or use of funds from husbands, meant for household supplies; (3) begging from husbands, children and other relatives; (4) sale of any saleable agricultural produce, even from non-loan funded MEs (Brett, 2006; Namayengo et al., 2016).

Poverty. Poverty has been reported to affect economic decision making and behaviour. Shah et al. (2012) observed that financial scarcity tends to shift attention allocation from future to current needs. This has been exemplified with the tendency of the poor to borrow, even at high interest rates, with minimal regard to loan repayment burden that may ensue.

Farmers in rural areas usually have scanty savings and limited sources of income, leading to very few food reserves, thus causing food insecurity (FAO, 2000a). Under such circumstances, current consumption decisions are compromised because the strict and mandatory regime of BRAC and other MFIs loan repayments leave no room for loan repayment failure (Namayengo et al, 2016).

Loan use on non-production expenditures. A surprising observation from our study is the panel-study DID result of reduction in per-capita expenditure on education. This is contrary to the focus group result of borrowers indicating using part of loan funds for children education 
expenditures. We also found that about $10 \%$ of borrowed funds are used for education expenditures (Namayengo et al., 2016). Other potential negative effects of borrowing on education of children have been reported (Augsburg et al., 2015; Wydick, 1999).

Nutrition and food security knowledge. Partly due to lack of food and nutrition knowledge, women do not seem to prioritise food intake improvement when they borrow. Banerjee and Duflo (2007) also observed that, even if the poor could spend more on food, they usually do not.

In general, FGD participants commended BRAC as a steady and reliable source of short-term loans, to meet family needs, which they would otherwise not be able to access (Namayengo et al., 2016). Studies have observed improvement in household consumption with credit (Morris \& Barnes, 2005; Pitt \& Khandker, 1998). The loans provide an instrument for smoothing income and expenditure flows over time (Carlton et al., 2001). Because money is fungible, within these households, recipients seem to allocate part of the loans to other household needs and funds from other household sources into the business. This reduces the amount available for investment. The diversion of loan funds by poor borrowers from business to competing household needs has been discussed by Matin et al. (2002), and Rutherford (2011).

On the other hand, women's increased engagement in income-generating activities may give rise to nutritional problems if there is no alternative help and when there are no affordable foods on the market. Indeed, as Adams and Von Pischke (1992) indicated, women need more than credit to improve their welfare. Eradication of food insecurity will require improvement in agricultural production, improvement in quality of education and health as well as infrastructure improvement (FAO, 2000a).

Our results show that households of female agrarian borrowers seem to become more food insecure after borrowing. The trend is partly explained by an apparent shift to reliance on food 
purchase by households, which is not accompanied by an increase in income when women borrow. It is also explained by the burden of loan repayment, poverty, and lack of nutrition knowledge. This outcome of the microcredit intervention, which has so much potential, suggests that lenders may do more to ensure attainment of their social goals, especially with respect to food security.

Our finding is similar to Islam et al. (2016) who postulate that food security of households may become worse in the period after borrowing. Our result is also in line with Brett (2006), who observed that clients of microfinance ate less to meet the demands of loan repayment. However, our result contrasts those of others who showed improvement in food security after borrowing (Hazarika \& Guha-Khasnobis, 2008), including improvement in dietary diversity (Sraboni et al., 2014), and consumption of foods of animal origin (Colecraft et al., 2006). Still others have reported no change in food security (Angelucci et al., 2013). Many factors explain our observation some of which we theorised at the beginning of our study (See Figure 1.1 in Chapter 1). The reduction in the amount of consumed food from own production partly explains our result. Respondents depend more on food purchase, which may not provide adequate diets if there is no commensurate improvement in income from farm and non-farm MEs. In Chapter 4 we provide findings of reduction in agricultural production of households, indicated by a reduction in the monetary value of the harvest. We also observe a reduction in number of respondents keeping local chicken, goats and local cattle, as well as the monetary value of these animals. This may partly explain the reduction in animal-source food-intake scores of the households. In addition, we find that the contribution of others to household food provision reduces, after women start to borrow. 
As a conclusion, microcredit seems to negatively impact on food security of households. Microcredit interventions may need to address this by adjusting loan conditions to foster food production. They may also need to incorporate food security and nutrition education of borrowers, to protect the nutrition of vulnerable groups in households of borrowers. 


\section{Appendix 5.1}

Table A5.1. Differences between OB and NB food security parameters using Radius matching (RM) and Nearest Neighbour (NN) matching

\begin{tabular}{|c|c|c|c|c|c|c|}
\hline & & $\begin{array}{l}\text { OB } \\
\text { Mean }\end{array}$ & $\begin{array}{l}\text { NB } \\
\text { Mean }\end{array}$ & $\begin{array}{l}\text { Difference } \\
\text { (ATT) }\end{array}$ & SE & $t$ \\
\hline \multirow[t]{2}{*}{ Caloric intake } & RM & 2334.39 & 2367.05 & -32.66 & 69.96 & -0.47 \\
\hline & NN & 2334.00 & 2280.46 & 53.91 & 132.29 & -0.41 \\
\hline \multirow[t]{2}{*}{$\operatorname{HDDS}^{1}$} & RM & 4.89 & 5.40 & -0.51 & 0.13 & $-3.79 * *$ \\
\hline & $\mathrm{NN}$ & 4.89 & 5.36 & -0.47 & 0.20 & $-2.25 * *$ \\
\hline \multirow[t]{2}{*}{ HFIAS $^{2}$ score } & RM & 4.72 & 4.02 & 0.70 & 0.33 & $2.11 * *$ \\
\hline & $\mathrm{NN}$ & 4.71 & 4.55 & 0.45 & 0.55 & 0.30 \\
\hline \multirow[t]{2}{*}{ Proportion of energy from fat } & RM & 0.18 & 0.16 & 0.02 & 0.00 & $-2.82 * *$ \\
\hline & $\mathrm{NN}$ & 0.18 & 0.15 & 0.02 & 0.01 & $-2.25 * *$ \\
\hline \multirow{2}{*}{$\begin{array}{l}\text { Proportion of own-food } \\
\text { production }\end{array}$} & RM & 0.47 & 0.53 & -0.05 & 0.02 & $-2.90 * *$ \\
\hline & $\mathrm{NN}$ & 0.47 & 0.58 & -0.11 & 0.03 & $-3.27 * *$ \\
\hline \multirow[t]{2}{*}{ Seven-day fruit intake score } & RM & 0.59 & 0.70 & -0.11 & 0.03 & $-3.33 * *$ \\
\hline & NN & 0.59 & 0.72 & -0.12 & 0.06 & $-2.24 * *$ \\
\hline \multirow[t]{2}{*}{ Seven-day sugar intake score } & RM & 0.79 & 0.87 & -0.07 & 0.03 & $-2.71 * *$ \\
\hline & $\mathrm{NN}$ & 0.79 & 0.86 & -0.07 & 0.04 & $-1.64 *$ \\
\hline \multirow[t]{2}{*}{ Seven-day oil intake score } & $\mathrm{RM}$ & 0.67 & 0.75 & -0.08 & 0.03 & $-2.67 * *$ \\
\hline & NN & 0.67 & 0.72 & -0.06 & 0.05 & -1.09 \\
\hline \multirow{2}{*}{$\begin{array}{l}\text { Seven-day starchy food intake } \\
\text { score }\end{array}$} & $\mathrm{RM}$ & 1.37 & 1.47 & -0.10 & 0.04 & -2.29 \\
\hline & $\mathrm{NN}$ & 1.38 & 1.48 & -0.12 & 0.06 & -1.47 \\
\hline \multirow{2}{*}{$\begin{array}{l}\text { Seven-day per-capita expense } \\
\text { on food }\end{array}$} & $\mathrm{RM}$ & 8.45 & 8.34 & 0.10 & 0.05 & $1.97 * *$ \\
\hline & $\mathrm{NN}$ & 8.45 & 8.33 & 0.11 & 0.10 & 1.11 \\
\hline \multirow{2}{*}{$\begin{array}{l}\text { Monthly expenditure of others } \\
\text { on food }\end{array}$} & $\mathrm{RM}$ & 6.90 & 8.21 & -1.31 & 0.37 & $-3.52 * *$ \\
\hline & NN & 6.90 & 8.23 & -1.33 & 0.26 & $-2.21 * *$ \\
\hline
\end{tabular}

Figures in parentheses in column 1 are numbers of respondents in the common support region for NB and OB respectively. $* * p<0.05$

${ }^{1}$ Household dietary diversity score; ${ }^{2}$ 30-Day Household Food Insecurity Access Scale score 
Table A5.2. Sensitivity analysis and R-bounds for household dietary diversity and weekly household food expenditures

\begin{tabular}{lccccccc}
\hline Variable & $\begin{array}{c}\text { Critical } \\
\boldsymbol{\Gamma}\end{array}$ & Sig- & Sig+ & t-hat- & t-hat + & CI+ & CI- \\
\hline Log weekly household & 1 & 0 & 0 & 8.40 & 8.40 & 8.33 & 8.47 \\
food cost & 1.5 & 0 & 0 & 8.26 & 8.57 & 8.10 & 8.60 \\
& 2 & 0 & 0 & 8.1 & 8.6 & 8.07 & 8.7 \\
& 2.5 & 0 & 0 & 8.07 & 8.70 & 7.99 & 8.77 \\
Household dietary & 3 & 0 & 0 & 2 & 6.5 & 8.01 & 8.77 \\
diversity scores & 1 & 0 & 0 & 5.5 & 5.5 & 5 & 5.5 \\
& 1.5 & 0 & 0 & 5 & 5.5 & 5 & 5.5 \\
& 2 & 0 & 0 & 5 & 6 & 4.5 & 6 \\
& 2.5 & 0 & 0 & 4.5 & 6 & 4.5 & 6 \\
\hline
\end{tabular}

$\Gamma$ : Gamma-Log odds of different assignments due to unobserved factors

Sig-: Lower bound significance level

Sig+: Upper bound significance level

t-hat -: Lower bound Hodges-Lehman point estimate

t-hat +: Upper bound Hodges-Lehman point estimate

CI+: Upper bound confidence interval $(a=0.95)$.

CI-: Lower bound confidence interval $(a=0.95)$. 
Table A5.3. DID for result for disaggregated dietary diversity components for NB and CG groups

\begin{tabular}{|c|c|c|c|c|c|c|}
\hline & & $\mathbf{N}$ & $\mathbf{T}_{0}$ & $T_{1}$ & Diff-in- Diff & GLS (fe) \\
\hline \multirow[t]{2}{*}{ Animal-food intake } & $\mathrm{CG}$ & 382 & 0.94 & 0.82 & \multirow{2}{*}{$\begin{array}{l}-0.33 * * \\
(0.12)\end{array}$} & $-0.34 * * *$ \\
\hline & NB & 404 & 1.12 & 0.67 & & $(0.12)$ \\
\hline \multirow[t]{2}{*}{ Fruit intake } & $\mathrm{CG}$ & 380 & 0.70 & 0.593 & \multirow{2}{*}{$\begin{array}{l}-0.129 * \\
(0.068)\end{array}$} & $-0.13 * *$ \\
\hline & NB & 402 & 0.716 & 0.478 & & $(0.06)$ \\
\hline \multirow[t]{2}{*}{ Sugar-intake } & CG & 380 & 0.830 & 0.747 & \multirow{2}{*}{$\begin{array}{l}-0.131 * * \\
(0.059)\end{array}$} & $-0.20 * * *$ \\
\hline & NB & 402 & 0.856 & 0.642 & & $(0.05)$ \\
\hline \multirow{2}{*}{ Vegetable-intake } & CG & 380 & 0.793 & 0.693 & \multirow{2}{*}{$\begin{array}{l}-0.103 \\
(0.064)\end{array}$} & \multirow{2}{*}{$\begin{array}{l}-0.13 * * \\
(0.05)\end{array}$} \\
\hline & NB & 402 & 0.791 & 0.693 & & \\
\hline \multirow[t]{2}{*}{ Starchy intake } & CG & 380 & 1.438 & 1.254 & \multirow{2}{*}{$\begin{array}{l}-0.134 \\
(0.097)\end{array}$} & \multirow{2}{*}{$\begin{array}{l}-.24 * * \\
(0.09)\end{array}$} \\
\hline & NB & 402 & 1.473 & 1.154 & & \\
\hline \multirow[t]{2}{*}{ Oil intake score } & $\mathrm{CG}$ & 380 & 0.731 & 0.641 & \multirow{2}{*}{$\begin{array}{l}-0.069 \\
(0.066)\end{array}$} & \multirow{2}{*}{$\begin{array}{r}(-0.05) \\
(0.06)\end{array}$} \\
\hline & NB & 402 & 0.751 & 0.592 & & \\
\hline
\end{tabular}

Standard errors in parenthesis. $* * * p<0.10 * * p<0.05 * p<0.10$. Both difference-in-difference and GLS performed on the common support region using Kernel matching. GLS model also controls for time effects. 


\title{
Chapter 6
}

\author{
General discussion
}




\subsection{Introduction}

The contents of this dissertation are based on a quantitative and qualitative survey that was conducted to assess the contribution of microcredit access of women to production and household food security status, and the factors associated with enterprise performance and food security outcomes. In order to do so four main issues were addressed: (a) assessment of the borrowing context and the match or mismatch between lender and borrower goals and objectives; (b) the extent to which taking microcredit affected business input expenditures and performance of non-farm MEs; (c) the extent to which taking microcredit affected production input expenditures and outputs from farming activities; (d) the changes in household food security associated with microcredit.

The study utilised two alternative methods to evaluate differences in the dependent variables for borrowers and non-borrowers. The overall study design was a panel approach, involving two waves of data collection. In one analytical approach, baseline data for a group of existing borrowers of the BRAC microfinance program (Old borrowers=OB) and incoming borrowers (New borrowers=NB) before they received their first loan were used in a quasi-experimental cross-sectional design to determine the effect of borrowing as the difference between the two groups using propensity score matching (PSM).

In an alternative approach, two waves of data for the NB and a control group (CG) of women who never borrowed from BRAC or other MFI, were subjected to difference-in-difference analysis (DID), with Kernel matching, to assess differences between borrowers and nonborrowers.

Based on the premise that credit access avails producers with capital to finance inputs, labour and equipment for productive activities (Zeller \& Sharma, 2000), enables them to take up riskier 
but more profitable ventures (Guiso et al., 2004; Sen, 1999), helps them reach markets more effectively, leads to adoption of more efficient technologies (Feder et al., 1990; Zeller \& Sharma, 2000), and stabilises food consumption of households, MFIs target the rural poor especially women with microcredit.

The relevance of this study lies in the continuing debate about the impact of microcredit on poor households, with six recent randomised evaluations of microfinance programs (Banerjee et al., 2015) indicating that effects of borrowing may not be as large as once acclaimed, and that the previously reported negative effects of microcredit were not conclusive. Given the influence borrowers' context can impart on microfinance programs outcomes (Chliova et al., 2015; Coleman, 1999; Kabeer, 2005), we contribute to the current debate by conducting our evaluation in a rural agrarian setting of Uganda. Being a subsistence rural community, we assessed the effect of borrowing on the largely non-monetised income of women, from crop and animal production. The women's produce rarely reaches markets and yet contributes to food security attainment. Because of the importance of non-farm ME activity in rural communities, we also assessed ME profits. We also measured the effect of borrowing on monetary worth of MEs and recurrent business expenditures, which are intermediary business performance indicators that have not been subjects of much study. In addition we utilised a rich set of food security indicators and as mentioned before utilised two alternative analytical methods to assess if the results are robust across methods. 


\subsection{Summary of research findings}

\subsubsection{The context of borrowing}

The benefits of microfinance programs highly depend on their alignment to needs of the target population. In Chapter 2, we systematically assessed the objectives and design of the BRAC microfinance program with a view of assessing to what extent they matched the expectations, context and characteristics of the female borrowers. We observed that BRAC female borrowers were poor, sometimes ultra-poor in the context described by Hulme et al. (2011).

The main reason for joining the borrowing program was to obtain funds to meet lump-sum monetary needs they would otherwise not be able to meet. The other reason for borrowing was to invest in non-farm microenterprises. Women on average obtained loans of $\$ 278$, at the time of the study. We found that borrowers invested loan funds in subsistence level farming and in small low monetary worth non-farm MEs, with rather low levels of commercialisation and low returns. They also invested loans into consumption expenditures including education and house construction. Borrowers found borrowing costs high; these include the interest rates as well as the security deposit, which is retained by the lender at the time of loan disbursement and yet used in the calculation of repayment amounts. The borrowers reported experiencing high loan repayment pressure, because of weekly repayments, which started the week after borrowing and even when they invested funds into activities with no immediate returns. Many respondents diversified their livelihood sources by running both farm and non-farm MEs, in order to secure funds for loan repayment. Borrowers did whatever they could to obtain funds for loan repayment including keeping some loan funds for loan repayment, selling whatever is saleable including crop produce and small animals, as well as diverting household basic upkeep funds for loan 
repayment. As a result these efforts together with the VO joint liability for loan repayment requirement by BRAC, defaulting on loan repayment was quite low. Borrowers found the loan application procedure rigorous, especially for repeat borrowers. This was given as a reason for stopping to borrow after overcoming the need for which they took the loan. This made the dropout rate from the borrowing program quite high.

\subsubsection{Microcredit and performance of non-farm MEs}

Food access, a main pillar of food security, may be attained via income improvement of households. The latter is one of the expected outcomes of microcredit participation. Borrowing is expected to lead to higher involvement of women in non-farm ME activities and extra investment in non-farm MEs, as well as higher recurrent business expenditures, leading to improved performance of MEs. In Chapter 3 we assessed the contribution of microcredit access to performance of non-farm enterprises. Using a panel design, first-time borrowers (NB) were compared to the control group (CG) based on 2-year data. In an alternative approach the effect of borrowing was determined in a quasi-experimental comparison of $\mathrm{OB}$ and NB groups using PSM.

Panel data results revealed weakly significant effects of borrowing on the monetary worth of MEs. On the other hand the quasi-experimental approach revealed that borrowers' MEs had higher monetary worth, recurrent business input expenditures, and ME restocking expenditures than controls. However, we found no effect of borrowing on ME profits. We also found no effect of selected measures of women empowerment variables, i.e. decision making on loan allocation, and loan-taking initiative, on the profits from MEs. The general conclusion from this finding is that borrowing leads to extra investment into non-farm MEs, as evidenced by the increase in ME 
monetary value and in the recurrent business expenditures. This has a positive connotation to food security, as improved ME worth is a store of wealth that can be used for food and non-food consumption smoothing.

\subsubsection{Microcredit and agricultural production}

It has long been argued that lack of credit is one of the impediments to agricultural development in rural communities (FAO et al., 2015) and that access to credit will lead to extra investment in agriculture. In Chapter 4 we evaluated whether borrowing contributed to food production of households, by assessing changes in expenditure and output from farm MEs (both crop and animal), using PSM analysis of OB and NB cross-sectional data. In comparison to NBs, OBs spent more time on garden work, recorded lower recurrent crop production expenditures and monetary worth of harvested crops. Production of crops which are easily saleable but require purchased inputs (beans and maize) was also lower for OBs. In the case of animal production, ownership and monetary worth of some commonly kept animals was lower for OB than NB so were the numbers of different types of animals kept.

The main conclusion from Chapter 4 was that borrowing did not lead to extra recurrent crop and animal production expenditures. The prevailing subsistence nature of crop and animal production seems not to favour investment of borrowed funds into agriculture. Contrary to expectations, animal production expenditures, numbers of different types of animals kept by borrowers and monetary worth of some commonly kept animals, and non-cash income from crop production went down among borrowers. From the results of FGD on loan repayment, it seems plausible to attribute the lower animal production indicators among OBs to sale of animals for loan repayment, as discussed in Chapter 2 of this thesis. Food production, a main pillar of food 
security, was thus unlikely to improve on the account of these subsistence farmers accessing microcredit.

\subsubsection{Microcredit and food security}

Lack of access to credit may hamper rural livelihood diversification, exposing poor households to shocks and seasonality that lead to food deprivation and hunger. Access to microcredit provides households with capital for productive investment that could lead to improved household food security. In Chapter 5 we investigated the effects of microcredit on food security, using different measures of food security, including caloric availability, dietary diversity, and household food insecurity access scores, among others. We used both panel and quasiexperimental methods to assess changes in modes of food acquisition, caloric and protein intake, and qualitative food insecurity measures after borrowing. We found no difference in caloric and protein intake of households. However, we observed a decline in dietary quality as indicated by robustly lower household dietary diversity scores (HDDS) among OBs than NBs. The reduction was traced to reduction in animal-source food, fruits and sugar intake. These being foods which

are commonly purchased, pointed to decreased ability of households to purchase foods generally considered non-essential and reliance on monotonous low nutrient density starchy-root and tuber diets. It was also partly explained by a shift from reliance on own food production to food purchase when women access credit. Another explanation was a reduction in the contribution of other household members towards food expenditures of the household, when women borrowed. Generally, our result showed that, contrary to expectations, microcredit may be resulting in higher food insecurity among borrowers' households. 


\subsection{General synthesis and conclusion}

As a general objective we set out to identify the contribution of microcredit access by women to production and household food security, and the underlying mechanisms. In affirmation of Banerjee et al. (2015), our study results also indicate that the effect of borrowing on different anticipated outcome variables is not as high as expected. We also find that, in the population we studied, microcredit has some negative effects, as already noted.

We set out to answer different research questions as to whether borrowing led to a positive contribution to production and household food security, by exploring if there was an improvement in investment in trade, crop and animal production, and if this translated into improvement in performance for the respective activities. We also measured different food security parameters for borrowers and non-borrowers.

While borrowing led to extra investment in non-farm MEs, as evidenced by a high ME loaninvestment ratio, increase in monetary worth of non-farm MEs and increase in recurrent business expenditures, this was not the case for farm MEs. Borrowing did not lead to increase in recurrent farm expenditures or to increase in deployment of new technology in farm production. The increment in monetary worth of non-farm MEs signalled a potentially positive implication of borrowing on food security of households. Business stock may be a store of wealth, which can be used in food and non-food consumption smoothing. In addition, increased stocking levels may eventually lead to higher self-employment income. Sometimes stock may even be consumed directly.

In addition, borrowing seemed to fulfil other household needs including allocation of received loans in children's education. This constitutes a human capital investment, whose returns accrue later. Other contributions of microcredit included use of loans for investments like building. 
On the question as to whether borrowing led to increase in farm and non-farm ME income, the results for farm MEs differed from those for non-farm MEs. Although we found no change in non-farm ME profits, we found a decline in non-cash income from crop and animal production. These results did not offer support to the argument of microcredit leading to food security improvement within the timespan covered by this study.

Finally, we assessed changes in food security indicators after borrowing. Our earlier observations on investment and output from farm and non-farm MEs seemed to get augmented by results of higher food insecurity among microcredit recipients. The lack of improvement in cash income from non-farm MEs and a decline in non-cash income from agricultural production signalled a negative trend in food security of the borrowers' households. Although improvement in the monetary value of non-farm MEs had potential for household consumption smoothing, this was not observed in the current study. Instead we observed reduction in access to food from purchase, as indicated by reliance on low dietary diversity diet. Borrowers' households reduced the quantity of food consumed from own production, and relied more on food purchase, but limited the range of foods as reflected in the low household dietary diversity scores (HDDS) driven by low intake of foods of animal source, fruits and sugar. Low HDDS, an indicator of food insecurity due to poor access, increases the risk of vulnerable household members including children and pregnant women suffering from chronic malnutrition (Muhoozi et al., 2016). Chronic malnutrition affects long-term development of children and nations (World Bank, 2006). In another study in Uganda (Kikafunda, Agaba, \& Bambona, 2014), low dietary diversity scores were linked to poverty in households. We may not be able to conclude from our study that poverty among borrower households increased but our results show a decline in dietary diversity, a food insecurity indicator dependent on food access. Interventions aimed at improvement in 
incomes of women are associated with improved intake of animal source food (Colecraft et al., 2006) dietary diversity (Sraboni et al., 2014; Swindale \& Bilinsky, 2006b) and DDS has been shown to reduce rapidly when incomes of households are affected (Ashley, 2016). We may thus argue that the households of borrowers become more cash constrained after borrowing since the poor tend to spend most of their income on food.

Next we try to offer explanations for other factors that may have influenced study outcomes. Studies have shown that the local context the borrowers operated under (Chliova et al., 2015; Coleman, 1999; Kabeer, 2005), borrower needs (Mahajan \& Ramola, 1996) and characteristics, as well as the characteristics of their MEs (Asian Development Bank, 1997; Gladwin et al., 2001; Schreiner \& Woller, 2003), the loan terms and processes (Armendáriz \& Morduch, 2010; Meyer, 2013; Wright et al., 1998) influence the effect of borrowing on the food security of households.

We found that borrowers worked well within their VOs to ensure loan repayment. Similar results have been reported elsewhere (Ghatak, 1999; Ghatak \& Guinnane, 1999). However, the anticipated benefits of the gained social capital and networking from the village organisations (McKernan, 2002; Pitt et al., 1999), including adoption of agricultural technologies (van Rijn, Bulte, \& Adekunle, 2012), better ME financial outcomes and social marketing for improved nutrition, were not evident in this study. Women would possibly reap more benefits from the groups formed to satisfy the group lending model by collectively engaging in business activities such communal farming and agro-processing or even joint trading. These may lead to better business outcomes than the individual poorly resourced microenterprises.

Our findings augment outcomes of some studies (Goetz \& Gupta, 1996; Mayoux, 2001; Rahman, 1999b) throwing doubt on the beneficial effects of group lending to women empowerment. These studies reported over-indebtedness and borrower stress related to ME 
running and loan repayment. We also observed similar trends in the current study. In addition, unlike what others have reported about positive effects of borrowing on women empowerment (Armendáriz \& Morduch, 2010; Fofana et al., 2015), we observed low scores of women on the empowerment variables, i.e. loan taking initiative and decision making power.

The characteristics of the borrowers and the activities they engaged in also seemed to influence the food security outcomes of borrowing. The majority of the women were loweducated poor peasants as defined by Ellis (1993). This is evidenced by the type of activities they engaged in and based on their scores on the wealth and asset index. They set up self-employment activities, probably not because they are entrepreneurial but rather due to lack of alternatives. The enterprises set up by such a population tend to be poorly resourced, with poor human capital and operate in fragile business environments. These factors limit the productivity of the enterprises and hence their contribution to food security. The potential contribution of microcredit towards enhancing productivity of borrowers MEs seem to be limited by the loan conditions and the tendency of borrowers to divert part of the loans to consumption needs.

According to FAO (1998) and Banerjee (2013), risk aversion because of their impoverished state may explain the observed reliance of borrowers on low-risk, low-investment, low-return activities, rather than on riskier but potentially more productive activities. The risky nature of agricultural production (Morvant-Roux, 2011) may also have impeded extra investment in agriculture by borrowers with farm MEs. The respondents with farming MEs also remained more inclined towards less lucrative food crop production, probably as dictated by their culture (Ali et al., 2015.), and because these are rarely productive, they shift focus to non-farm MEs. Much as the non-farm MEs showed potential for improvement in household consumption smoothing, the 
reduction in non-cash income from farm MEs may have led to reduction of household food availability and access among borrowers.

The local conditions of borrowing may also explain some of our observations. The lack of the necessary infrastructure and socio-economic environment for their activities hindered borrowers to benefit from borrowing (Diagne \& Zeller, 2001). Local prices of commodities, as well as competition with other retailers because of homogeneous products as observed by Copestake et al. (2001) in Zambia, may offer little opportunity for ME expansion. This is typical of Uganda, which has been characterised as one of the poorest countries in the world by the World Bank (2016). Poor financial and commodity markets, low purchasing power and poor infrastructure have been named as some of the growth limitations of micro and small enterprises in Uganda (Ishengoma \& Kappel, 2008). Poor markets may also have impeded extra investment and output from borrower-run MEs. As argued by Morvant-Roux (2011), there is need for all key players in the agriculture and informal business industry, buyers, processors, suppliers, local governments and other key players, who all face the risks described above, to come together to address risks associated with rural farm and non-farm productivity.

\subsection{Policy implications of study}

Microfinance has much potential for improving food security of households of borrowers. For this objective to be achieved the lenders need to balance both the financial and social goals of lending.

From a policy perspective, our results generally bring out the need to revisit elements of the loan program if significant livelihood improvement among beneficiaries is to be attained. Firstly, since farming is a major source of livelihood and food, there seems to be a missed opportunity 
for microcredit to contribute to income, food production and food security. The time between loan disbursement, and loan repayment commencement, as well the borrowing costs need to be revisited, if microcredit is to contribute to income and food security via improved agricultural production. In addition, alternative interventions for agricultural production improvement, including direct provision of agricultural inputs, may be explored. Since women seem to borrow against meagre future earnings, the borrowing program should strengthen the savings components, both before and after borrowing, to enable women to benefit more from the borrowing programs. In addition, MFIs need to design products that minimise loan repayment pressure and drop-outs from the borrowing program. High drop-outs are a disadvantage to both borrowers and the MFIs.

Secondly, lending should be accompanied by interventions to increase financial and nonfinancial literacy of women for better decision making on income and expenditures, in line with household capital and consumption needs. Also, liaison is needed between government and MFIs to promote borrower education and protection. Much as MFIs operate in a liberalised financial economy the government needs to have systems of monitoring MFI operations and procedures to protect poor borrowers

Thirdly, since credit alone is insufficient to improve the income and non-income activities of women, the government needs to create an enabling environment for MEs to flourish. This will include rural infrastructure development to link rural farmers to produce and input markets. Programs for seed distribution and ease in access to agriculture inputs, as well as information dissemination on advantages of shifting from peasant to semi-commercial farming should be promoted. 
Finally the government and civil society both may need to work with MFIs for optimal lending rates and protocol not only for protection of the poor borrowers but to also enhance the social outcomes of borrowing, food security being one of them.

\subsection{Limitations of the study and suggestions for future research}

The findings presented in this dissertation contribute in many ways to the current debate on the effect of microcredit on household food security, through exploration of the effect of borrowing on household farm and non-farm productive activities. We did this by use of a quasiexperimental methodology that we combined with a panel study design. We used both quantitative and qualitative methods of data collection to obtain answers to our study questions. However, like many studies that attempt to measure the effect of interventions there may be many potential methodological limitations that could have influenced our results. We tried to overcome many of these by the use of different methods described below.

First and foremost, quasi-experimental designs and other non-experimental impact assessment methods face the possibility of selection bias into programs that may lead to differences between those who borrow and those who do not borrow, to the extent that comparison groups are different even at the beginning of the interventions (Armendáriz \& Morduch, 2010; Khandker et al., 2010). We addressed such bias designing the quasi-experimental comparison of old borrowers $(\mathrm{OB})$ to in-coming new borrowers $(\mathrm{NB})$ who had already self-selected to take credit. This comparison may have less self-selection issues as argued by Nelson et al. (2004). In addition, recognising that drop-outs in the cross-sectional study could have influenced results as argued by Karlan, (2001), we followed drop-outs from VOs of the OB group and included them in our analysis. This procedure and the use of a comparison group that had already self-selected 
to borrow are expected to have significantly reduced selection bias. Before matching, the two groups were similar on all control variables, except for age. The PSM methodology was then useful to make the groups even more comparable before assessment of effect size. One limitation of the PSM methodology is matching only based on characteristics that we measured. In the event that there are attributes we did not measure that would influence self-selection, this would bias our results. To check the effect of unobserved variables on our result, we conducted sensitivity analysis using Rosenbaum bounds as described by Rosenbaum (2010) and found that the effect of unobservables would have to be of very high magnitude to influence our result. However, there could still be limitations related to the methodology, for example, differences could arise because of differences among the VOs in the study.

Secondly, for the panel analysis we ensured high level of rigour by incorporating Kernel matching with DID analysis, as recommended by Khandker et al. (2010). Otherwise the DID analysis already took care of time invariant unobservables, which were differenced out in the DID analysis.

However, our result could have been limited by the relatively short time between the baseline and follow-up study. We only allowed one year between baseline and follow-up studies. This was to ensure traceability of study respondents, as some were not permanent residents in the area and could move away from the baseline locations, and also drop outs from the BRAC borrowing program. One year may not have been enough time to detect effects that take time, including changes in ME income, and education attainments, among others. We still had a number of dropouts especially from the NB group; some did not eventually take up the loans and some dropped out after one round of borrowing. We tried to overcome this by matching the NB and CG groups 
based on baseline characteristics. Further research may need to be done, with a longer time between baseline and follow-up study, to gain further insights into the issues.

Another limitation of the study could be measurement errors in non-farm ME profits based on self-reported amounts because of lack of records. The method we used was straightforward but could still have left some errors in the result. Further research could be conducted, with daily visits to respondents to keep track of business expenses and income.

Another limitation was in the estimations of amounts of food consumed that relied on recall and estimates by respondents. Finally many factors other than food production and income may influence food availability and access of households.

\subsection{Areas for further research}

In light of our observations, further research is needed to determine optimal lending rates, payment terms and even loan amounts that will reduce loan repayment burden and drop-out rates, and also enable MFIs to operate sustainably and yet attain desired social benefits for their recipients. Further research is needed to assess if loans for non-farm MEs indeed have better food security effects than for farm MEs. In addition, longer studies need to be conducted on the effect of borrowing on farm and non-farm MEs, as well as food security. It may also be good to follow up borrowers for longer periods to determine at which point effects of borrowing may be realised.

\subsection{Overall study conclusion}

Borrowing hardly improved the food security situation of the borrowers' households. Borrowers tended to shift attention from farm to non-farm activities and yet proceeds from non-farm 
activities were not adequate to ensure improved food access. This led to reliance on poorer and maybe cheaper diets, making households more food insecure. However, microcredit may have served to fulfil many other household needs like consumption smoothing as MEs with higher monetary worth could be used by households to meet consumption needs. In addition significant proportions of loans were invested in human capital improvement, usually children education. The most important determinants of the effect of microcredit as we envisaged at the beginning of the study were the context of borrowing, the loan terms and processes as well as the personality and socio-demographic characteristics of the women. Many contextual factors need to change before microcredit will have the desired effect. 


\section{References}

Abate, G.T., Rashid, S., Borzaga, C., \& Getnet, K. (2016). Rural finance and agricultural technology adoption in Ethiopia: Does the institutional design of lending organizations matter? World Development, 84, 235-253.

Adams, D.W., \& Von Pischke, J. (1992). Microenterprise credit programs: Deja vu. World Development, 20(10), 1463-1470.

Agarwal, B. (1997). "Bargaining" and gender relations: Within and beyond the household. Feminist economics, 3(1), 1-51.

Agier, I., \& Szafarz, A. (2013). Microfinance and gender: is there a glass ceiling on loan size? World Development, 42, 165-181.

Ahmed, S.M., Chowdhury, M., \& Bhuiya, A. (2001). Micro-credit and emotional well-being: experience of poor rural women from Matlab, Bangladesh. World Development, 29(11), 1957-1966.

Ali, D.A., Bowen, F.H., Deininger, K.W., \& Duponchel, M.F. (2015). Investigating the gender gap in agricultural productivity: evidence from Uganda. World Bank Group. Retrieved 212-2016, from http://documents.worldbank.org/curated/en/

AMFIU. (2011). The Uganda microfinance directory 2011/12 (5th Edition). Retrieved 18-032016, from http://www.amfiu.org.ug/

Angelucci, M., Karlan, D., \& Zinman, J. (2013). Win some lose some? Evidence from a randomized microcredit program placement experiment by Compartamos Banco. IZA Discussion Paper, No. 7439.

Arimond, M., \& Ruel, M.T. (2004). Dietary diversity is associated with child nutritional status: evidence from 11 demographic and health surveys. The Journal of Nutrition, 134(10), 2579-2585.

Armendáriz, B., \& Labie, M. (2011). Handbook of microfinance. New Jersey: World Scientific.

Armendáriz, B., \& Morduch, J. (2010). The economics of microfinance. Cambridge, MA: MIT Press.

Ashley, J.M. (2016). Food security in the developing world. Amsterdam: Academic Press.

Asian Development Bank. (1997). Microenterprise development. Not by credit alone. Retrieved 25-6-2014, from http://bdresearch.org.bd/

Attanasio, O., Augsburg, B., De Haas, R., Fitzsimons, E., \& Harmgart, H. (2015). The impacts of microfinance: Evidence from joint-liability lending in Mongolia. American Economic Journal: Applied Economics, 7(1), 90-122.

Augsburg, B., De Haas, R., Harmgart, H., \& Meghir, C. (2015). The Impacts of microcredit: Evidence from Bosnia and Herzegovina. American Economic Journal: Applied Economics, 7(1), 183-203.

Balatibat, E.M. (2004). The linkages between food and nutrition security in lowland and coastal villages in the Philippines. Retrieved 9-3-2016, from http://edepot.wur.nl/

Banerjee, A., Duflo, E., Glennerster, R., \& Kinnan, C. (2015). The miracle of microfinance? Evidence from a Randomized Evaluation. American Economic Journal: Applied Economics, 7(1), 22-53.

Banerjee, A., Karlan, D., \& Zinman, J. (2015). Six randomized evaluations of microcredit: Introduction and Further Steps. American Economic Journal: Applied Economics, 7(1), $1-21$.

Banerjee, A.V. (2013). Microcredit under the microscope: what have we learned in the past two decades, and what do we need to know? Annual Review of Economics, 5(1), 487-519. 
Banerjee, A.V., \& Duflo, E. (2007). The economic lives of the poor. The Journal of Economic Perspectives, 21(1), 141.

Barman, D., Mathur, H.P., \& Kalra, V. (2009). Role of microfinance interventions in financial inclusion: A comparative study of microfinance models. Vision: The Journal of Business Perspective, 13(3), 51-59.

Barnes, C., Keogh, E., \& Nemarundwe, N. (2001). Microfinance program clients and impact: An assessment of Zambuko Trust, Zimbabwe. Washington, DC: USAID.

Barnes, C., Morris, G., \& Gaile, G. (1999). An assessment of client of microfinance programs in Uganda. International Journal of Economic Development, 1(1), 80-121.

Barnes, C., \& Sebstad, J. (2000). Guidelines for microfinance impact assessments. Washington, DC: Assessing the Impact of Microenterprise Services, Management Systems International. Retrieved 3-6-2015, from http://scholar.google.nl.ezproxy.library.wur.nl/

Barrett, C.B. (2010). Measuring food insecurity. Science, 327(5967), 825-828.

Barrett, C.B., Reardon, T., \& Webb, P. (2001). Nonfarm income diversification and household livelihood strategies in rural Africa: concepts, dynamics, and policy implications. Food Policy, 26(4), 315-331.

Basargekar, P. (2008). Economic empowerment through microfinance: An assessment of CSR activity run by Forbes Marshall Ltd. International Journal of Business Insights \& Transformation, 2(1).

Bategeka, L., \& Okummu, L.J. (2010). Banking sector liberalisation in Uganda. Process, results and policy options. Amsterdam: SOMO.

Bates, T. (1990). Entrepreneur human capital inputs and small business longevity. The Review of Economics and Statistics, 72(4), 551-559.

Bauer, M., Chytilová, J., \& Morduch, J. (2012). Behavioral foundations of microcredit: Experimental and survey evidence from rural India. The American Economic Review, 102(2), 1118-1139.

Begley, T.M., \& Boyd, D.T. (1987). Psychological characteristics associated with performance in entrepreneurial firms and small business. Journal of Business Venturing, 2(1), 79.

Berger, M. (1989). Giving women credit: The strengths and limitations of credit as a tool for alleviating poverty. World Development, 17(7), 1017-1032.

Bigsten, A., \& Kayizzi-Mugerwa, S. (1995). Rural sector responses to economic crisis in Uganda. Journal of international Development, 7(2), 181-209.

Blais, A.R., \& Weber, E.U. (2006). A domain-specific risk-taking (DOSPERT) scale for adult populations. Judgment and Decision Making, 1(1), 33-47.

Blumberg, R.L. (1989). Making the case for the gender variable: Women and the wealth and well-being of nations (M.H.Clark Ed. Vol. 1). Washington: U.S. Agency for International Development.

Bornstein, D. (1997). The price of a dream: The story of the Grameen Bank. Chicago: University of Chicago Press.

Bouis, H.E., \& Novenario-Reese, M.J.G. (1997). The determinants of demand for micronutrients. Washington: International Food Policy Research Institute (IFPRI).

BRAC. (2008). Annual report. Empowering women and girls in Uganda. Kampala.

BRAC. (2013). Annual report 2013. Kampala.

Brett, J.A. (2006). "We sacrifice and eat less": the structural complexities of microfinance participation. Human Organization, 65(1), 8-19. 
Buckley, G. (1997). Microfinance in Africa: Is it either the problem or the solution? World Development, 25(7), 1081-1093.

Burchi, F., \& De Muro, P. (2016). From food availability to nutritional capabilities: Advancing food security analysis. Food Policy, 60, 10-19.

Buvinić, M. (1997). Women in poverty: A new global underclass. Foreign Policy(108), 38-53.

Carletto, C., Zezza, A., \& Banerjee, R. (2013). Towards better measurement of household food security: Harmonizing indicators and the role of household surveys. Global Food Security, 2(1), 30-40.

Carloni, A.S., \& Goddard, P.O. (1987). Women in development: A.I.D.'s experience, 1973 1985. Washington: A.I.D.

Carlton, A., Mandorf, H., Obara, A., Reichter, W., \& Ryne, E. (2001). Microfinance in Uganda. Vienna: Austrian Ministry of Foreign Affairs.

Chan, S.H., \& Ghani, M. A. (2011). The impact of microloans in vulnerable remote areas: evidence from Malaysia. Asia Pacific Business Review, 17(1), 45-66.

Chemin, M. (2008). The benefits and costs of microfinance: Evidence from Bangladesh. The Journal of Development Studies, 44(4), 463-484.

Chemin, M. (2012). Response to 'high noon for microfinance impact evaluations'. Journal of Development Studies, 48(12), 1881-1885.

Cheston, S., \& Kuhn, L. (2002). Empowering women through microfinance. Retrieved 4/7/2013, from http://storage.globalcitizen.net/

Chliova, M., Brinckmann, J., \& Rosenbusch, N. (2015). Is microcredit a blessing for the poor? A meta-analysis examining development outcomes and contextual considerations. Journal of Business Venturing, 30(3), 467-487.

Chua, E.Y., Zalilah, M. S., Chin, Y.S., \& Norhasmah, S. (2012). Dietary diversity is associated with nutritional status of Orang Asli children in Krau Wildlife Reserve, Pahang. Malaysian Journal of Nutrition, 18(1), 1-13.

Coates, J., Frongillo, E.A., Rogers, B.L., Webb, P., Wilde, P.E., \& Houser, R. (2006). Commonalities in the experience of household food insecurity across cultures: what are measures missing? The Journal of Nutrition, 136(5), 1438S-1448S.

Coates, J., Swindale, A., \& Bilinsky, P. (2007). Household food insecurity access scale (HFIAS) for measurement of food access: indicator guide. Washington, DC: Food and Nutrition Technical Assistance Project, Academy for Educational Development.

Coates, J., Webb, P., \& Houser, R. (2003). Measuring food insecurity: going beyond indicators of income and anthropometry: Food and Nutrition Technical Assistance Project, Academy for Educational Development.

Cohen, M., \& Snodgrass, D. (1997). Assessing the effects of program characteristics and program context on the impact of microenterprise services: A guide for practitioners. Washington.

Colecraft, E., Marquis, G.S., Aryeetey, R., Sakyi-Dawson, O., Lartey, A., Ahunu, B., \& Canacoo, E. (2006). Constraints on the use of animal source foods for young children in Ghana: A participatory rapid appraisal approach. Ecology of Food and Nutrition, 45(5), 351-377.

Coleman, B.E. (1999). The Impact of group lending in Northeast Thailand. Journal of Development Economics, 60, 105-141.

Copestake, J. (2007). Mainstreaming microfinance: social performance management or mission drift? World Development, 35(10), 1721-1738. 
Copestake, J., Bhalotra, S., \& Johnson, S. (2001). Assessing the impact of microcredit: A Zambian case study. Journal of Development Studies, 37(4), 81-100.

Crépon, B., Devoto, F., Duflo, E., \& Pariente, W. (2015). Estimating the impact of microcredit on those who take it up: Evidence from a randomized experiment in Morocco. American Economic Journal: Applied Economics, 7(1), 123-150.

Crook, T.R., Todd, S.Y., Combs, J. G., Woehr, D. J., \& Ketchen, D. (2011). Does human capital matter? A meta-analysis of the relationship between human capital and firm performance. Journal of Applied Psychology, 96(3), 443-456.

Daniels, L. (2001). Testing alternative measures of microenterprise profits and net worth. Journal of International Development, 13(5), 599-614.

De Mel, S., McKenzie, D., \& Woodruff, C. (2009). Are women more credit constrained? Experimental evidence on gender and microenterprise returns. American Economic Journal: Applied Economics, 1-32.

De Mel, S., McKenzie, D., \& Woodruff, C. (2009). Measuring microenterprise profits: Must we ask how the sausage is made? Journal of Development Economics, 88(1), 19-31.

Deininger, K. (2003). Does cost of schooling affect enrollment by the poor? Universal primary education in Uganda. Economics of Education Review, 22(3), 291-305.

den Hartog, A.P., van Staveren, W.A., \& Brouwer, I.D. (2006). Food habits and consumption in developing countries. Manual for field studies. Wageningen: Wageningen Publishers.

Develtere, P., \& Huybrechts, A. (2002). Evidence on the social and economic impact of Grameen Bank and BRAC on the poor in Bangladesh. Retrieved 7-01-2017, from http://www.microfinancegateway.org/

Diagne, A., \& Zeller, M. (2001). Access to credit and its impact on welfare in Malawi (Vol. 116). Washington: IFPRI.

DiPrete, T.A., \& Gangl, M. (2004). Assessing bias in the estimation of causal effects: Rosenbaum bounds on matching estimators and instrumental variables estimation with imperfect instruments. Sociological methodology, 34(1), 271-310.

Doocy, S., Teferra, S., Norell, D., \& Burnham, G. (2005). Credit program outcomes: coping capacity and nutritional status in the food insecure context of Ethiopia. Social Science \& Medicine, 60(10), 2371-2382.

Dowla, A.U. (2011). Higher education through microfinance: The case of Grameen Bank. In B. Armendariz \& M. Labie (Eds.), The handbook of microfinance (pp. 643-659). World Scientific.

Duflo, E., Glennerster, R., Kremer, M., Schultz, T.P., \& John, A.S. (2007). Using randomization in development economics research: A toolkit. In: Schultz, T. and Strauss, J. (Eds.), Handbook of Development Economics (Vol. 4, pp. 3895-3962). Amsterdam: Elsevier.

Economist (2010). Face value: BRAC in Business. Retrieved 14-05-2016, from http://www.economist.com.

Ehlers, T.B., \& Main, K. (1998). Women and the false promise of microenterprise. Gender \& Society, 12(4), 424-440.

Eijkel, R.V., Hermes, N., \& Lensink, B.W. (2011). Group lending and the role of the group leader. Small Business Economics, 36(3), 299-321.

Ellis, F. (1993). Peasant economics: Farm households and agrarian development. Cambridge: Cambridge University Press.

Ellis, F. (1998). Household strategies and rural livelihood diversification. The Journal of Development Studies, 35(1), 1-38. 
Esenu, B., Ossiya, S., Serunkuma, D., Oluka, J., Alin, D., Owesigire, B., Olokojo, B. (2005). Positioning agro-pastoral women in livestock production: the link between socioeconomic factors and improved household food security. Tropicultura, 23(I), 28.

Fafchamps, M. (2003). Rural poverty, risk and development. Cheltenham: Edward Elgar Publishing.

Fafchamps, M., McKenzie, D., Quinn, S. R., \& Woodruff, C. (2011). When is capital enough to get female microenterprises growing? Evidence from a randomized experiment in Ghana. Working paper 17207. Retrieved 25-10-2016, from http://www.nber.org/.

FANTA-2 (2010). The analysis of the nutrition situation in Uganda. Retrieved 17-12-2016, from http://www.fantaproject.org/.

FAO (1996). Rome declaration on world security and world food plan of action. World Food Summit 13-17th Nov. 1996. Retrieved from http://www.fao.org/docrep/003/.

FAO (1998). The state of food and agriculture: Rural non-farm income in developing countries. Retrieved from http://www.fao.org/.

FAO (2000a). The elimination of food insecurity in the Horn of Africa - FINAL REPORT. Rome: FAO. Retrieved from http://www.fao.org/.

FAO (2000b). The state of food insecurity in the world 2001. Retrieved from http://www.fao.org/.

FAO (2011). The state of agriculture and food (2010-2011). Closing the gender gap for development. Retrieved 20-10-2016, from http://www.fao.org/.

FAO (2016). The state of food and agriculture. Climate change, agriculture and food security. Rome: FAO. Retrieved from http://reliefweb.

FAO, IFAD, \& WFP (2015). The state of food insecurity in the world 2015. Meeting the 2015 international hunger targets: taking stock of uneven progress. Rome: FAO. Retrieved from http://www.fao.org/.

FAO, WFP, \& IFAD (2012). The state of food insecurity in the world 2012. Economic growth is necessary but not sufficient to accelerate reduction of hunger and malnutrition. Rome: FAO. Retrieved from http://www.fao.org/. Accessed 5-3-2015.

Feder, G., Lau, L.J., Lin, J.Y., \& Luo, X. (1990). The relationship between credit and productivity in Chinese agriculture: A microeconomic model of disequilibrium. American Journal of Agricultural Economics, 72(5), 1151-1157.

Feroze, S., Chauhan, A., \& Chakravarty, A. (2011). Microfinance and income from dairy in Haryana: An impact analysis. Indian Journal of Animal Sciences, 81(9), 971-976.

Field, E., Pande, R., Papp, J., \& Park, Y. J. (2012). Repayment flexibility can reduce financial stress: a randomized control trial with microfinance clients in India. Plos One, 7(9), e45679.

Fletschner, D. (2009). Rural women's access to credit: Market imperfections and intrahousehold dynamics. World Development, 37(3), 618-631.

Fletschner, D., Anderson, C.L., \& Cullen, A. (2010). Are women as likely to take risks and compete? Behavioural findings from Central Vietnam. The Journal of Development Studies, 46(8), 1459-1479.

Fletschner, D., \& Kenney, L. (2014). Rural women's access to financial services: Credit savings and insurance. In: A. R. Quisumbing, R. Meinzen-Dick, T. L. Raney, A. Croppenstedt, J. A. Behrman, \& A. Peterman (Eds.), Gender in Agriculture (pp. 187-208): Springer Netherlands. Retrieved from http://dx.doi.org/10.1007/978-94-017-8616-4_8. 
Fofana, N.B., Antonides, G., Niehof, A., \& van Ophem, J.A.C. (2015). How microfinance empowers women in Côte d'Ivoire. Review of Economics of the Household, 1-19.

Foltz, J.D. (2004). Credit market access and profitability in Tunisian agriculture. Agricultural Economics, 30(3), 229-240.

Frederick, S., Loewenstein, G., \& O'donoghue, T. (2002). Time discounting and time preference: A critical review. Journal of Economic Literature, 351-401.

Frongillo, E., Nanama, S., \& Wolfe, W. (2004). Technical guide to developing a direct, experience-based measurement tool for household food insecurity. Food and Nutrition Technical Assistance Project, Academy for Educational Development. Washington, DC. Retrieved 19-2-2016, from https://www.google.com/

Gaile, G.L., \& Foster, J. (1996). Review of methodological approaches to the study of the impact of the microenterprise credit programs. AIMS Publication. Retrieved 29-4-2015, from http://erepository.uonbi.ac.ke

Ganle, J.K., Afriyie, K., \& Segbefia, A.Y. (2015). Microcredit: Empowerment and disempowerment of rural women in Ghana. World Development, 66, 335-345.

Ghatak, M. (1999). Group lending, local information and peer selection. Journal of Development Economics, 60(1), 27-50.

Ghatak, M., \& Guinnane, T.W. (1999). The economics of lending with joint liability: theory and practice. Journal of Development Economics, 60(1), 195-228.

Ghosh, J. (2013). Microfinance and the challenge of financial inclusion for development. Cambridge Journal of Economics, 37(6), 1203-1219.

Gifford, J. (Ed.). (2004). Utilizing, accumulating, and protecting livelihood assets: The role of urban informal financial services in Kampala, Uganda. Delft: Eburon Academic Publishers.

Gladwin, C.H., Thomson, A.M., Peterson, J.S., \& Anderson, A.S. (2001). Addressing food security in Africa via multiple livelihood strategies of women farmers. Food Policy, 26(2), 177-207.

Glennerster, R., \& Takavarasha, K. (2013). Running randomized evaluations: A practical guide. Princeton: Princeton University Press.

Gobezie, G. (2004). Microfinance and development: Can impact on poverty and food in-security be improved upon? International Conference on Microfinance Development in Ethiopia. Retrieved 28-11-2016, from http://www.microfinancegateway.org/

Goetz, A.M., \& Gupta, R.S. (1996). Who takes the credit? Gender, power, and control over loan use in rural credit programs in Bangladesh. World Development, 24(1), 45-63.

GOU (2011). Uganda nutrition action plan of 2011-2016. Scaling up multisectoral efforts to establish a strong nutrition foundation in Uganda development. Kampala: GOU. Retrieved from http://www.fantaproject.org/

GOU (2016). Agriculture sector strategic direction 2015/16-2019/20. Kampala: MAAIF.

Grimpe, B. (2002). Rural microfinance clients in Uganda: FINCA client analysis. FSD series No.6. Financial System Development Project 2002. Retrieved 31-3-2015, from http://www.microfinancegateway.org/

Grown, C.A., \& Sebstad, J. (1989). Introduction: Toward a wider perspective on women's employment. World Development, 17(7), 937-952.

Guiso, L., Sapienza, P., \& Zingales, L. (2004). Does local financial development matter? The Quarterly Journal of Economics, 119(3), 929-969. 
Haggblade, S., Hazell, P.B., \& Reardon, T.A. (2002). Strategies for stimulating povertyalleviating growth in the rural nonfarm economy in developing countries. Retrieved 1311-2016, from http://xxpt.ynjgy.com/.

Haile, H.B., Bock, B., \& Folmer, H. (2012). Microfinance and female empowerment: Do institutions matter? Womens Studies International Forum, 35(4), 256-265.

Hamad, R., \& Fernald, L.C.H. (2015). Microcredit participation and women's health: Results from a cross-sectional study in Peru. International Journal for Equity in Health, 14.

Hashemi, S.M., Schuler, S.R., \& Riley, A.P. (1996). Rural credit programs and women's empowerment in Bangladesh. World Development, 24(4), 635-653.

Hazarika, G., \& Guha-Khasnobis, B. (2008). Household access to microcredit and children's food security in rural Malawi: A gender perspective. Retrieved 18-4-2016, from http://repec.iza.org/.

Hermes, N., \& Lensink, R. (2011). Microfinance: Its impact, outreach, and sustainability. World Development, 39(6), 875-881.

Hoddinott, J., \& Yohannes, Y. (2002). Dietary diversity as a food security indicator. Retrieved 22-4-2016, from http://scholar.google.nl.ezproxy.library.wur.nl/.

Hudon, M. (2011). Ethics in microfinance. In: B. Armendáriz de Aghion \& M. Labie (Eds.), The handbook of microfinance (pp. 123-138). London-Singapore: Scientific Work.

Hulme, D. (1990). Can the Grameen Bank be replicated? Recent experiments in Malaysia, Malawi and Sri Lanka. Development Policy Review, 8(3), 287-300.

Hulme, D. (2000a). Impact assessment methodologies for microfinance: Theory, experience and better practice. World Development, 28(1), 79-98.

Hulme, D. (2000b). Is microdebt good for poor people? A note on the dark side of microfinance. Small Enterprise Development, 11(1), 26-28.

Hulme, D., Moore, K., \& Seraj, K.F.B. (2011). Reaching the people whom microfinance cannot reach: Learning from BRAC's "Targeting the ultra poor" programme. In: B. Armendáriz \& M. Labie (Eds.), The handbook of microfinance (pp. 563-586): World Scientific.

Hulme, D., \& Mosley, P. (1996). Finance against poverty. Volume 1. London and New York: Routledge.

IFAD, \& UNEP (2013). Small holders, food security and the environment. Retrieved 16-5-2016, from http://www.unep.org/.

Imai, K.S., Arun, T., \& Annim, S.K. (2010). Microfinance and household poverty reduction: New evidence from India. World Development, 38(12), 1760-1774.

Imai, K.S., \& Azam, M.D.S. (2012). Does microfinance reduce poverty in Bangladesh? New evidence from household panel data. The Journal of Development Studies, 48(5), 633653.

Ishengoma, E.K., \& Kappel, R. (2008) : Business constraints and growth potential of micro and small manufacturing enterprises in Uganda, GIGA working papers, No. 78). Business constraints and growth potential of micro and small manufacturing enterprises in Uganda. GIGA working papers, Number 78. Retrieved 10-12-2016, from http://hdl.handle.net/.

Islam, A., Maitra, C., Pakrashi, D., \& Smyth, R. (2016). Microcredit programme participation and household food security in rural Bangladesh. Journal of Agricultural Economics, 67(2), 448-470.

Jiggins, J. (1989). How poor women earn income in sub-Saharan Africa and what works against them. World Development, 17(7), 953-963. 
Kabeer, N. (2001). Conflicts over credit: Re-evaluating the empowerment potential of loans to women in rural Bangladesh. World Development, 29(1), 63-84.

Kabeer, N. (2005). Is microfinance a 'magic bullet' for women's empowerment? Analysis of findings from South Asia. Economic and Political Weekly, 4709-4718.

Kaboski, J.P., \& Townsend, R.M. (2011). A structural evaluation of a large-scale quasiexperimental microfinance initiative. Econometrica, 79(5), 1357-1406.

Kaboski, J.P., \& Townsend, R.M. (2012). The impact of credit on village economies. American Economic Journal: Applied Economics, 4(2), 98-133.

Karlan, D. (2001). Microfinance impact asessments: The perils of using new members as a control group. Journal of Microfinance, 3(2), 75-85.

Karlan, D., \& Goldberg, N. (2011). Microfinance evaluation strategies. In: B. Armendáriz \& J. Morduch (Eds.), The handbook of microfinance (pp. 17-58). Singapore: World Scientific Publishing.

Karlan, D., \& Zinman, J. (2011). Microcredit in theory and practice: Using randomized credit scoring for impact evaluation. Science, 332(6035), 1278-1284.

Karuhanga, B. M. K. (2008). Living with AIDS in Uganda : impacts on banana-farming households in two districts. (PhD Thesis), Wageningen Academic Publishers, Wageningen University. Retrieved from http://edepot.wur.nl/ (29-2-2016).

Keinan, A., \& Kivetz, R. (2011). Productivity orientation and the consumption of collectable experiences. Journal of Consumer Research, 37(6), 935-950.

Kempson, E., Crame, M., \& Finney, A. (2007). Financial services provision and prevention of financial exclusion. Eurobarometer Report, University of Bristol. Retrieved 19-12-2016, from http://www.bristol.ac.uk/.

Kennedy, E., \& Peters, P. (1992). Household food security and child nutrition. The interaction of income and gender of household head. World Development, 20(8), 1077-1085.

Khandker, S.R. (2005). Microfinance and poverty: Evidence using panel data from Bangladesh. The World Bank Economic Review, 19(2), 263-286.

Khandker, S.R., \& Koolwal, G.B. (2016). How has microcredit supported agriculture? Evidence using panel data from Bangladesh. Agricultural Economics, 47(2), 157-168.

Khandker, S.R., Koolwal, G.B., \& Samad, H.A. (2010). Handbook on impact evaluation: quantitative methods and practices. Washington, DC: World Bank.

Kikafunda, J., Agaba, E., \& Bambona, A. (2014). Malnutrition amidst plenty: an assessment of factors responsible for persistent high levels of childhood stunting in food secure western Uganda. African Journal of Food, Agriculture, Nutrition and Development, 14(5), 20882113.

Lakwo, A. (2006). Microfinance, rural livelihoods, and women's empowerment in Uganda. (Ph.D Thesis), Radboud Universiteit, Nijmegen. (African Studies Centre Research report no 85.)

Ledgerwood, J. (1999). Microfinance handbook: An institutional and financial perspective. Washington: World Bank.

Ljungqvist, B. G., Mellander, O., \& Svanberg, U. S.-O. (1981). Dietary bulk as a limiting factor for nutrient intake in pre-school children. A problem description. Journal of Tropical Pediatrics.

Luellen, J.K., Shadish, W.R., \& Clark, M. (2005). Propensity scores. An introduction and experimental test. Evaluation Review, 29(6), 530-558. 
MacGuire, J.S., \& Popkin, B.M. (1990). Helping women improve nutrition in the developing world: beating the zero sum game. World Bank technical paper, no. 114. Retrieved 7-12017, from http://edepot.wur.nl/73935

Mahadevan, R., \& Hoang, V. (2016). Is there a link between poverty and food security? Social Indicators Research, 128(1), 179-199.

Mahajan, V., \& Ramola, B.G. (1996). Financial services for the rural poor and women in India: Access and sustainability. Journal of International Development, 8(2), 211-224.

Makokha, K.A. (2001). Structural adjustment participatory review initiative (SAPRI). Uganda country report: A synthesis of the Four SAPRI Studies. Retrieved 4-5-2016, from http://www.saprin.org/

Margolis, D.N. (2014). By choice and by necessity: Entrepreneurship and self-employment in the developing world. European Journal of Development Research, 26(4), 419-436.

Marquis, G.S., Colecraft, E.K., Sakyi-Dawson, O., Lartey, A., Ahunu, B., Birks, K.A., HuffLonergan, E. (2015). An integrated microcredit, entrepreneurial training, and nutrition education intervention is associated with better growth among preschool-aged children in rural Ghana. Journal of Nutrition, 145(2), 335-343.

Matin, I., Hulme, D., \& Rutherford, S. (2002). Finance for the poor: From microcredit to microfinancial services. Journal of international Development, 14(2), 273-294.

Maxwell, S. (1996). Food security: A post-modern perspective. Food Policy, 21(2), 155-170.

Maxwell, S., \& Frankenberger, T. R. (1995). Household food security: Concepts, indicators, measurements: A technical review. New York: UNICEF.

Mayoux, L. (2001). Tackling the down side: Social capital, women's empowerment and microfinance in Cameroon. Development and Change, 32(3), 435-464.

McKernan, S.M. (2002). The impact of microcredit programs on self-employment profits: Do noncredit program aspects matter? Review of Economics and Statistics, 84(1), 93-115.

Melgar-Quinonez, H.R., Zubieta, A.C., MkNelly, B., Nteziyaremye, A., Gerardo, M.F.D., \& Dunford, C. (2006). Household food insecurity and food expenditure in Bolivia, Burkina Faso, and the Philippines. The Journal of nutrition, 136(5), 1431S-1437S.

Mellor, J.W. (1983). Food prospects for the developing countries. The American Economic Review, 73(2), 239-243.

Meyer, R.L. (2013). Microcredit and agriculture: Challenges, successes and prospects. In: Gueyie, Jean-Pierre, R. Manos, \& J. Yaron (Eds.), Microfinance in developing countries: issues, policies and performance evaluation. Houndmills, Basingstoke, Hampshire: Palgrave Macmillan.

Microcredit Summit Campaign. (2015). The status of the campaign report 2015. Retrieved 8-12017, from https://stateofthecampaign.org/.

Misselhorn, A.A. (2005). What drives food insecurity in southern Africa? A meta-analysis of household economy studies. Global Environmental Change, 15(1), 33-43.

Mittal, A. (2009). The 2008 food price crisis: Rethinking food security policies. Retrieved from http://www19.iadb.org/.

MkNelly, B., \& Lippold, K. (1998). Practitioner-led impact assessment: A test in Mali. from http://www.microfinancegateway.org/.

MoFPED. (2014). Proverty status report 2014. Structural change and poverty reduction in Uganda. Retrieved 1-12-2016, from https://www.google.nl/.

Momsen, J.H. (2004). Gender and development. London: Routledge. 
Montgomery, R., Bhattacharya, D., \& Hulme, D. (1996). Credit for the poor in Bangladesh. The BRAC rural development programme and the government Thana resource development and employment programme. In: D. Hulme \& P. Mosley (Eds.), Finance against poverty: Volume 2. (pp. 94-176).

Morduch, J. (1995). Income smoothing and consumption smoothing. The Journal of Economic Perspectives, 9(3), 103-114.

Morduch, J. (1999). The microfinance promise. Journal of Economic Literature, 37(4), 15691614.

Morduch, J. (2000). The microfinance schism. World Development, 28(4), 617-629.

Morris, G., \& Barnes, C. (2005). An assessment of the impact of microfinance: a case study from Uganda. Journal of Microfinance/ESR Review, 7(1), 39-54.

Morvant-Roux, S. (2011). Is microfinance the adequate tool to finance agriculture? In: The handbook of microfinance. In B. Armendáriz \& M. Labie (Eds.), The handbook of microfinance (pp. 421-435). London: World Scientific.

Moseson, H., Hamad, R., \& Fernald, L. (2014). Microcredit participation and child health: results from a cross-sectional study in Peru. Journal of Epidemiology and Community Health, 68(12), 1175-1181.

Mosley, P., \& Hulme, D. (1998). Microenterprise finance: Is there a conflict between growth and poverty alleviation? World Development, 26(5), 783-790.

Moti, J., Berhanu, G., \& Hoekstra, D. (2009). Smallholder commercialization: Processes, determinants and impact. Improving Productivity and Market Success (IPMS) of Ethiopian Farmers Project. Discussion Paper No. 18. Retrieved from https://cgspace.cgiar.org/.

Muhoozi, G. K., Atukunda, P., Mwadime, R., Iversen, P. O., \& Westerberg, A. C. (2016). Nutritional and developmental status among 6-to 8-month-old children in southwestern Uganda: A cross-sectional study. Food Nutrition Research, 60.

Mukono District Local Government. (2010). Mukono 5- year district development plan (20102015). from http://npa.ug/wp-content/themes/npatheme/documents/.

Mutesasira, L., \& Kaffu, E. (2003). Competition working for customer: The evolution of the Ugandan microfinance sector: A longitudinal study from December 2001 to March 2003. Kampala: MicroSave-Market-led solutions for financial services, Nairobi, Kenya.

Namayengo, F.M.M., Antonides, G., \& van Ophem, J.A.C. (2016). Women and microcredit in rural agrarian households of Uganda: Match or mismatch between lender and borrower? Applied Studies in Agribusiness and Commerce-APSTRACT, 10(2-3), 77-88.

Nanayakkara, G., \& Stewart, J. (2015). Gender and other repayment determinants of microfinancing in Indonesia and Sri Lanka. International Journal of Social Economics, 42(4), 322-339.

Nelson, C., Mknelly, B., Garber, C., Edcomb, E., Horn, N., Gaile, G., \& Lippold, K. (2004). Learning from clients: assessment tools for microfinance practitioners. AIMS Publication. from http://pdf.usaid.gov/.

NEPAD. (2006). Championing agricutural success for Africa's future in support of CAADP: Synthesis report of a parliamentary dialogue. Somerset West, CapeTown.

Ngulube, T.J. (1989). The composition of foods commonly eaten in East Africa. Edited by C. E. West, F. Pepping and C.R. Temalilwa. Wageningen: Wageningen University.

Niehof, A. (2004a). A micro-ecological approach to home care for AIDS patients. Medische Antropologie, 16(2), 245-265. 
Niehof, A. (2004b). The significance of diversification for rural livelihood systems. Food Policy, 29(4), 321-338.

Niehof, A. (2015). Contours of matriarchy in care for people living with AIDS. In: M. Barnes, T. Brannelly, L. Ward, \& N. Ward (Eds.), Ethics of care: critical advances in international perspective (pp. 139-164). Bristol: Policy Press.

Niehof, A. (2016). Food and nutrition security as a gendered social practice. Applied Studies in Agribusiness and Commerce-APSTRACT, 10(2-3), 59-66.

Niels, H., \& Lensink, R. (2007). The empirics of microfinance: What do we know? The Economic Journal, 117(517), F1-F10.

NPA (2010). National development plan 2010/11-2014/15. GOU. Retrieved from http://npa.ug/development-plans/ndp-201011-201415/.

Østergaard, L. (1992). Gender and development: A practical guide: Routledge.

Panjaitan-Drioadisuryo, R.D., \& Cloud, K. (1999). Gender, self-employment and microcredit programs an Indonesian case study. The Quarterly Review of Economics and Finance, 39(5), 769-779.

Papanek, H.C.F. (1973). Purdah: Separate worlds and symbolic shelter. Comparative Studies in Society and History, 15(3), 289-325.

Parpart, J.L., \& Connelly, M.P. (2000). Theoretical perspectives on gender and development. Ottawa: International Development Research Centre.

Petrocelli, J.V. (2003). Factor validation of the consideration of future consequences scale: Evidence for a short version. Journal of Social Psychology, 143(4), 405-413.

Pitt, M.M., \& Khandker, S.R. (1998). The impact of group-based credit programs on poor households in Bangladesh: does the gender of participants matter? Journal of Political Economy, 106(5), 958-996.

Pitt, M.M., Khandker, S.R, \& Cartwright, J. (2006). Empowering women with micro finance: Evidence from Bangladesh. Economic Development and Cultural Change, 54(4), 791831.

Pitt, M.M., Khandker, S. R., Chowdhury, O.H., \& Millimet, D.L. (2003). Credit programs for the poor and the health status of children in rural Bangladesh. International Economic Review, 44(1), 87-118.

Pitt, M.M., Khandker, S.R., Chowdhury, O.H., \& Millimet, D.L. (2003). Credit programs for the poor and the health status of children in rural Bangladesh. International Economic Review, 44(1), 87-118.

Pitt, M.M., Khandker, S.R., McKernan, S.M., \& Latif, M.A. (1999). Credit programs for the poor and reproductive behavior in low-income countries: Are the reported causal relationships the result of heterogeneity bias? Demography, 36(1), 1-21.

Postelnicu, L., Hermes, N., \& Szafarz, A. (2014). Defining social collateral in microfinance group lending. In: R. Mersland \& R. Ø. Strøm (Eds.), Microfinance institutions: Financial and social performance (pp. 187-207). London: Palgrave Macmillan.

Quisumbing, A.R., Brown, L.R., Feldstein, H.S., Haddad, L., \& Peña, C. (1995). Women: The key to food security. Retrieved from https://core.ac.uk/.

Rahman, A. (1999a). Micro-credit initiatives for equitable and sustainable development: Who pays? World Development, 27(1), 67-82.

Rahman, A. (1999b). Women and microcredit in rural Bangladesh: Anthropological study of the rhetoric and realities of Grameen Bank Lending. Boulder: Westview Press. 
Rahman, P.M.M., Matsui, N., \& Ikemoto, Y. (2013). Poverty and food security. In P. M. M. Rahman, N. Matsui, \& Y. Ikemoto (Eds.), Dynamics of poverty in rural Bangladesh. Tokyo: Springer Japan.

Rakodi, C. (1999). A capital assets framework for analysing household livelihood strategies: implications for policy. Development Policy Review, 17(3), 315-342.

Rauch, A., \& Frese, M. (2000). Psychological approaches to entrepreneurial success: A general model and an overview of findings. International Review of Industrial and Organizational Psychology, 15, 101-142.

Ray, J.J. (1980). The comparative validity of Likert, projective, and forced-choice indices of achievement motivation. The Journal of Social Psychology, 111(1), 63-72.

Republic of Uganda. (2014a). The HIV and AIDS Uganda country progress report 2014. Kampala: UNAIDS. Retrieved 6-3-2016., from http://www.unaids.org/.

Republic of Uganda. (2014b). The state of the Uganda population report 2014. Harnessing Ugandas demographic dividend for socio-economic transformation. Kampala: UNFPA.

Rooks, G., Szirmai, A., \& Sserwanga, A. (2009). The interplay of human and social capital in entrepreneurship in developing countries. The case of Uganda. Research Paper: UNUWIDER, No. 2009.09.

Rosenbaum, P.R. (2010). Design of observational studies (2nd ed.). New York: Springer.

Rosenbaum, P.R., \& Rubin, D.B. (1983). The central role of the propensity score in observational studies for causal effects. Biometrika, 70(1), 41-55.

Roxin, H., \& Fiege, K. (2010). Economic empowerment of women through microcredit: The case of the "Microfinance investment and technical assistance facility" (MITAF) SLE publication series; S240. Retrieved from http://edoc.hu-berlin.de/.

Ruel, M.T., \& Alderman, H. (2013). Nutrition-sensitive interventions and programmes: How can they help to accelerate progress in improving maternal and child nutrition? The Lancet, 382(9891), 536-551.

Rutherford, S. (2000). The poor and their money. Oxford: Oxford University Press.

Rutherford, S. (2011). Boosting the poor's capacity to save. In: B. Armendariz \& M. Labie (Eds.), The handbook of microfinance (pp. 520). New Jersey: World Scientific.

Schreiner, M., \& Woller, G. (2003). Microenterprise development programs in the United States and in the developing world. World Development, 31(9), 1567-1580.

Schroeder, R.A. (1996). "Gone to their second husbands": Marital metaphors and conjugal contracts in the Gambia's female garden sector. Canadian Journal of African Studies / Revue Canadienne des Études Africaines, 30(1), 69-87.

Sebstad, J. (1998). Toward guidelines for lower-cost impact assessment methodologies for microenterprise programs. AIMS, Washington. Retrieved 3-6-2015, from http://pdf.usaid.gov/.

Sebstad, J., Neill, C., Barnes, C., \& Chen, G. (1995). Assessing the impacts of microenterprise intervention: A framework for analysis. USAID Managing for Results. Working Paper 7. Retrieved 15-3-2016, from http://pdf.usaid.gov/.

Sen, A. (1981). Poverty and famines: An essay on entitlement and deprivation. Oxford: Clarendon.

Sen, A. (1999). Development as freedom. New York: Knopf Publishers.

Sibhatu, K.T., Krishna, V.V., \& Qaim, M. (2015). Production diversity and dietary diversity in smallholder farm households. Proceedings of the National Academy of Sciences, 112(34), 10657-10662. 
Smith, D.R., Gordon, A., Meadows, K., \& Zwick, K. (2001). Livelihood diversification in Uganda: patterns and determinants of change across two rural districts. Food Policy, 26(4), 421-435.

Smith, L. C., El Obeid, A.E., \& Jensen, H.H. (2000). The geography and causes of food insecurity in developing countries. Agricultural Economics, 22(2), 199-215.

Smith, L.C., \& Subandoro, A. (2007). Measuring food security using household expenditure surveys. Food security in practice technical guide. Retrieved from http://www.ifpri.org/.

Snodgrass, D., \& Sebstad, J. (2002). Clients in context: The impacts of microfinance in three countries: Synthesis report. From https://www.researchgate.net/.

Sraboni, E., Malapit, H.J., Quisumbing, A. R., \& Ahmed, A.U. (2014). Women's empowerment in agriculture: What role for food security in Bangladesh? World Development, 61, 1152.

Stevens, G.A., Finucane, M.M., Paciorek, C.J., Flaxman, S.R., White, R.A., Donner, A.J. (2012). Trends in mild, moderate, and severe stunting and underweight, and progress towards MDG 1 in 141 developing countries: A systematic analysis of population representative data. Lancet, 380(9844), 824-834.

Stewart, R., van Rooyen, C., Dickson, K., Majoro, M., \& de Wet, T. (2010). What is the impact of microfinance on poor people? A systematic review of evidence from sub-Saharan Africa. Technical report. Retrieved Accessed 22-11-2016, from http://eprints.ioe.ac.uk/.

Swain, R.B., \& Wallentin, F.Y. (2009). Does microfinance empower women? Evidence from self-help groups in India. International Review of Applied Economics, 23(5), 541-556.

Swindale, A., \& Bilinsky, P. (2006a). Development of a universally applicable household food insecurity measurement tool: Process, current status, and outstanding issues. The Journal of Nutrition, 136(5), 1449S-1452S.

Swindale, A., \& Bilinsky, P. (2006b). Household dietary diversity score (HDDS) for measurement of household food access: Indicator guide. Retrieved from http://www.fantaproject.org/.

Tedeschi, G.A. (2008). Overcoming selection bias in microcredit impact assessments: A case study in Peru. The Journal of Development Studies, 44(4), 504-518.

Todd, P.E., Schultz, T.P., \& John, A.S. (2007). Evaluating social programs with endogenous program placement and selection of the treated. Handbook of Development Economics (Vol. 4, pp. 3847-3894). Amsterdam: Elsevier.

Torheim, L.E., Ouattara, F., Diarra, M. M., Thiam, F. D., Barikmo, I., Hatloy, A., \& Oshaug, A. (2004). Nutrient adequacy and dietary diversity in rural Mali: Association and determinants. European Journal of Clinical Nutrition, 58(4), 594-604.

UBOS (2006). Uganda national household survey 2005/2006. Report on the Socio-economic module. Kampala: UBOS Retrieved from http://www.ubos.org/.

UBOS (2010a). Report on the Census of Microfinance Institutions in Uganda. Kampala: Government of Uganda.

UBOS (2010b). Uganda National Household Survey 2009/2010. Socio-economic Module. Abridged Report. Kampala: UBOS. Retrieved from http://www.ubos.org/.

UBOS (2014). Uganda National Household Survey 2012/2013. Kampala Uganda Retrieved from http://www.ubos.org/.

UBOS (2016). National Population and Housing Census 2014. Main report. Kampala Uganda. Retrieved from http://www.ubos.org/. 
UBOS, \& ICF (2012). Uganda Demographic and Health Survey 2011. Kampala, Uganda:: UBOS and Calverton, Maryland: ICF International Inc. Retrieved from http://www.ubos.org/.

UBOS, \& MoFPED (2014). Report on census of microfinance institutions in Uganda. Kampala: UBOS Retrieved from https://searchworks.stanford.edu/.

UBOS, \& WFP (2013). Comprehensive food security and vulnerability analysis (CVSVA) 2013. Kampala. Retrieved from http://documents.wfp.org/.

Udry, C., Hoddinott, J., Alderman, H., \& Haddad, L. (1995). Gender differentials in farm productivity: implications for household efficiency and agricultural policy. Food Policy, 20(5), 407-423.

UNDP (1994). Human development report 1994: Oxford University Press.

UNDP (1996). 1995 Human Development Report (Vol. 4). New York.

UNDP (2003). Human Development Report 2003 Millenium Development Goals: A Compact among Nations to end Human Poverty. New York: Oxford University Press.

UNDP (2014). Human development report 2014 Sustaining human progress: Reducing vulnerabilities and building resilience. New York: Oxford University Press.

UNICEF (1990). Strategy for improved nutrition of women and children in developing countries. A UNICEF policy review. New York: UNICEF.

van Rijn, F., Bulte, E., \& Adekunle, A. (2012). Social capital and agricultural innovation in SubSaharan Africa. Agricultural Systems, 108, 112-122.

van Rooyen, C., Stewart, R., \& de Wet, T. (2012). The Impact of microfinance in Sub-Saharan Africa: A systematic review of the evidence. World Development, 40(11), 2249-2262.

Viswanathan, K. (2002). The informal sector and microfinance institutions in West Africa. Indian Journal of Agricultural Economics, 57(1), 126.

Von Braun, J., De Haen, H., \& Blanken, J. (1991). Commercialization of agriculture under population pressure: Effects on production, consumption, and nutrition in Rwanda (Vol. 85). Washington: IFPRI.

Wakoko, F. (2004). Microfinance and women's empowerment in Uganda: A socioeconomic approach. (PhD Thesis), Ohio State University.

Wärneryd, K. (1988). The psychology of innovative enterpreneurship. In: W. F. van Raaij, G. M. van Veldhoven, \& K. Warneryd (Eds.), Handbook of Economic Psychology. (ed., pp. 404-447). London: Kluwer Academic Publishers.

Webb, P., Coates, J., \& Houser, R. (2002). Allocative responses to scarcity: Self-reported assessments of hunger compared with conventional measures of poverty and malnutrition in Bangladesh. Food Policy and Applied Nutrition Program, Discussion paper. Retrieved 13, from http://citeseerx.ist.psu.edu/.

Weisfeld-Adams, E., \& Andrzejewski, A. (2008). Hunger and poverty: Definitions and distinctions. The Hunger Project.

Word Bank (2007). World development report 2008: Agriculture for development. Washington, DC: World Bank.

World Bank (2006). Repositioning nutrition as central to development: A strategy for large-scale action. from http://www.unhcr.org/45f6c4432.pdf:

World Bank (2007). Agriculture for development. World development report 2008. Retrieved from http://edepot.wur.nl/.

World Bank (2016a). Global monitoring report 2015/2016. Development goals in an era of demographic change. Retrieved from http://pubdocs.worldbank.org/. 
World Bank (2016b). The Uganda poverty assessment report 2016. Farms, cities and good fortune: Assessing poverty reduction in Uganda from 2006 to 2013. Retrieved from http://pubdocs.worldbank.org/.

Wright, G.A., Mutesasira, L., Sempangi, H., Hulme, D., \& Rutherford, S. (1998). Drop-outs Amongst Ugandan Microfinance Institutions. Retrieved 20-03-2016, from http://www.microsave.net/files/.

Wright, G.A., \& Rippey, P. (2003). The competitive environment in Uganda: Implications for microfinance institutions and their clients. Retrieved 8-5-2016., from http://www.microfinancegateway.org/.

Wydick, B. (1999). The effect of microenterprise lending on child schooling in Guatemala. Economic Development and Cultural Change, 47(4), 853-869.

Zeller, M., \& Sharma, M. (2000). Many borrow, more save, and all insure: implications for food and micro-finance policy. Food Policy, 25(2), 143-167. 


\section{Study Instruments}

\section{Survey questionnaire}

Dear respondent,

The current study on "Microcredit to women and its contribution to production and household food security" is an academic research project. The aim is to provide information on microfinance support of women, production and household food security.

We would like to ask you some questions on the loan that you have with BRAC, your production activities, and the food intake of your household. All information obtained will be treated with confidentiality. Do you object to using the questionnaire and other information from BRAC about the loan, for purposes of this study? Can we proceed? Thank you.

Name of interviewer...............................Cleaning status................................. Supervisor signature. 


\section{Section 0}

Interview Identification: Area Office: Mukono

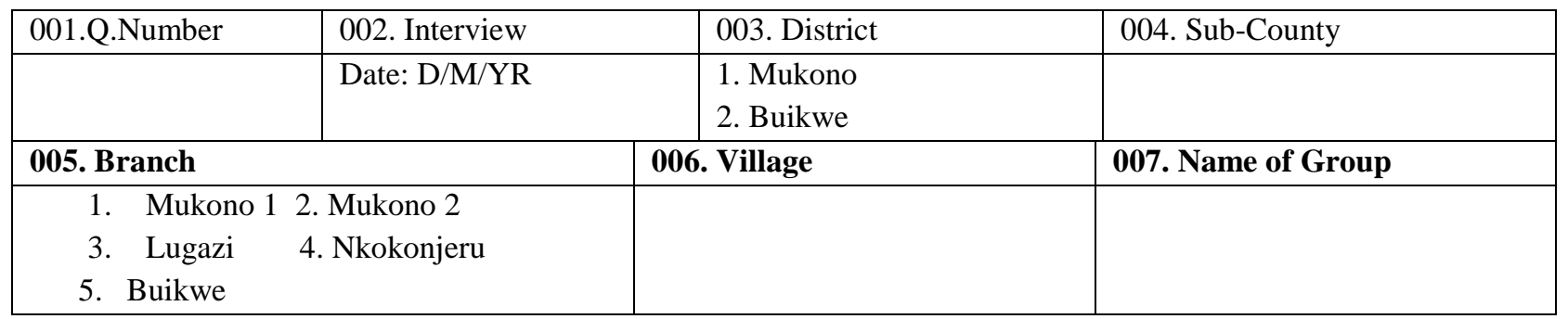

\section{RESPONDENT CATEGORISATION:}

Interviewer: Ask the respondent if she ever received a loan from BRAC or any other financial institution. Use table 008 to categorise the respondent.

Question: Did you ever take any loan with BRAC or other Organisation?

Categorise respondent into the following.

008. RESPONDENT CATEGORY

\begin{tabular}{|l|c|c|l|}
\hline \multicolumn{1}{|c|}{ 1. Old Borrower } & 2. Drop out & 3. New Borrower & Control \\
\hline $\begin{array}{l}\text { Ever taken BRAC loan } \\
\text { (still borrowing) }\end{array}$ & $\begin{array}{c}\text { Ever took BRAC Loan } \\
\text { (no longer borrowing) }\end{array}$ & $\begin{array}{l}\text { Applied for BRAC loan } \\
\text { (Not yet received loan) }\end{array}$ & $\begin{array}{l}\text { Has microenterprise but has } \\
\text { never taken loan }\end{array}$ \\
\hline
\end{tabular}

\section{Section 1A}

\begin{tabular}{|c|c|c|c|c|c|}
\hline $101 \mathrm{a}$ & Name & & & & \\
\hline $101 b$ & BRAC ID. NUMBER & & & & \\
\hline $101 \mathrm{c}$ & Phone Number & & & & \\
\hline 102 & Age & & & & \\
\hline 103 & Marital status & & & & \\
\hline 104 & Religion & & & & \\
\hline \multirow[t]{2}{*}{105} & Schooling Status & \multicolumn{4}{|c|}{ Highest level of education } \\
\hline & & $\begin{array}{l}\text { Primary (P.1- } \\
\text { P.7) }\end{array}$ & $\begin{array}{l}\text { Secondary } \\
\text { (S.1-S.6) }\end{array}$ & Tertiary education & None \\
\hline
\end{tabular}

Codes for 103: $1=$ Married, 2= Never married/single, 3=Co-habiting, 4= Widow, 5=Separated

Code for 104: $1=$ Roman Catholic, 2=Anglican, 3=Pentecostal, 4=SDA, 5=Orthodox, 6=Moslem, 7=Other (specify) 


\section{Section 1B: $\quad$ Socio demographic/household information}

(List all members of this household, starting with the household head)

A household is a group of people who routinely eat from the same pot and live on the same compound (or physical location); it is possible that they may live in different structures.

\begin{tabular}{|l|l|l|l|l|l|}
\hline ID & 110 & 111 & 112 & 113 & 114 \\
\hline & Name & Relationship to the & Sex & Age (completed & Schooling \\
& & respondent & years) & 1.Male school \\
& & 1.Husband & 2.Female & & 2. Not in school \\
& & 2. Son/ daughter & & \\
& & 3. Sister/brother & & \\
& & 4. Other adults & & & \\
\hline 1 & & & & & \\
\hline$\ldots$ & & & & & \\
\hline 10 & & & & & \\
\hline
\end{tabular}

Section 1C: $\quad$ Schooling status of household members

\begin{tabular}{|c|c|c|c|c|c|}
\hline ID & 115 & 116 & 117 & 118 & 119 \\
\hline & $\begin{array}{l}\text { If still in school, } \\
\text { which grade is } \\
\text { he/she currently } \\
\text { attending? }\end{array}$ & $\begin{array}{l}\text { If not in } \\
\text { school, why } \\
\text { not school? }\end{array}$ & $\begin{array}{l}\text { Highest grade } \\
\text { completed } \\
\text { (if no longer } \\
\text { in school) }\end{array}$ & $\begin{array}{l}\text { What is the status of the last } \\
\text { school? } \\
\text { 1.Government 2.Private } \\
\text { 3.NGO/ religious } \\
\text { 4.Other }\end{array}$ & $\begin{array}{l}\text { What type of } \\
\text { scholar is child } \\
\text { (last)? } \\
\text { 1. Day school } \\
\text { 2. Boarding school }\end{array}$ \\
\hline 1 & & & & & \\
\hline$\ldots$ & & & & & \\
\hline 10 & & & & & \\
\hline
\end{tabular}

\section{Code for reason (qn.116)}

1. Distance to school too far

5. Did not want to study
2.Household could not afford 6. Health condition (illness / disability)
3. Institution did not admit

7. Social/religious pressure
4. Had to work

8. Other(specify) 
Section 2: Microcredit information (Loan allocation)-New borrowers proceed to 202a. (Skip section for all controls)

I will now ask you questions about the microcredit from BRAC

\begin{tabular}{|c|c|c|c|c|c|c|c|}
\hline 200 & 201 & 202 & 203 & 204 & 205 & 206 & 207 \\
\hline $\begin{array}{l}\text { How many } \\
\text { times did } \\
\text { you take the } \\
\text { loan } \\
\text { since/when } \\
\text { you joined } \\
\text { the credit } \\
\text { group? } \\
\text { (put } \\
\text { number) }\end{array}$ & $\begin{array}{l}\text { When } \\
\text { (How } \\
\text { many } \\
\text { months } \\
\text { ago) did } \\
\text { you } \\
\text { receive } \\
\text { your first } \\
\text { loan? }\end{array}$ & $\begin{array}{l}\text { Amount } \\
\text { of first } \\
\text { loan } \\
\text { (UGX.) }\end{array}$ & $\begin{array}{l}\text { When (How } \\
\text { many } \\
\text { months ago) } \\
\text { did you } \\
\text { receive the } \\
\text { current/ last } \\
\text { loan? }\end{array}$ & $\begin{array}{l}\text { Amount of } \\
\text { current/ } \\
\text { last loan } \\
\text { (UGX.) }\end{array}$ & $\begin{array}{l}\text { What } \\
\text { was the } \\
\text { main } \\
\text { reason } \\
\text { for } \\
\text { borrowin } \\
\text { g your } \\
\text { current } \\
\text { /last } \\
\text { loan? }\end{array}$ & $\begin{array}{l}\text { What is the } \\
\text { Loan } \\
\text { period? } \\
1 . \\
40 \text { weeks } \\
2 . \\
20 \text { weeks }\end{array}$ & $\begin{array}{l}\text { Whose initiative } \\
\text { was it to take your } \\
\text { current/last loan? } \\
\text { 1. Self } \\
\text { 2. Spouse } \\
\text { 3.Self and spouse } \\
\text { 4. BRAC staff } \\
\text { 5. Group members } \\
\text { 6. Self and } \\
\text { other(specify) } \\
\text { 7. Other(specify) }\end{array}$ \\
\hline & & & & & & & \\
\hline
\end{tabular}

FILL FOR NEW BORROWERS.

\begin{tabular}{|c|c|c|c|c|c|c|c|}
\hline $200 a$ & $201 \mathrm{a}$ & $202 a$ & $203 a$ & $204 a$ & $205 a$ & $206 a$ & $207 a$ \\
\hline & & $\begin{array}{l}\text { Amount } \\
\text { of loan } \\
\text { (UGX.) }\end{array}$ & & & $\begin{array}{l}\text { What is } \\
\text { the main } \\
\text { reason } \\
\text { for } \\
\text { borrowing? }\end{array}$ & $\begin{array}{l}\text { What is the } \\
\text { loan } \\
\text { period? } \\
1 . \\
40 \text { weeks } \\
2 . \\
20 \text { weeks }\end{array}$ & $\begin{array}{l}\text { Whose initiative } \\
\text { was it to take the } \\
\text { loan? } \\
\text { 1. Self } \\
\text { 2. Spouse } \\
\text { 3.Self and spouse } \\
\text { 4. BRAC staff } \\
\text { 5. Group members } \\
\text { 6. Self and } \\
\text { other(specify) } \\
\text { 7. Other(specify) }\end{array}$ \\
\hline & & ….............. & & & & & \\
\hline
\end{tabular}

\section{Code for reason (205 and 205a)}

1.To buy land

2. To buy livestock

3. Recapitalize farming-related microenterprise

4.Recapitalize trade related microenterprise
5.

6.Buying building materials

7.Pay for education expenses

8.Pay for health expenses
9.Pay for ceremonial expenses

10. Pay for other consumption goods / services

11. Other (specify).

12. Begin new business

Microcredit information (loan repayment)

(For old borrowers) NEW BORROWERS GO TO 208a

\begin{tabular}{|l|l|l|}
\hline 208 & 209 & 210 \\
\hline Who is responsible to repay the & Did you ever face difficulties & What was the source of cash for the last \\
loan in your household? & with the weekly repayments & weekly repayment of your loan? \\
1. Self & of your loan? & 1. Loan funded enterprises \\
2. Spouse & 1. Yes & 2. Group members \\
3. Self and spouse & 2. No & 3. Loan from other MFI \\
4. Spouse and other(specify) & & 4. From spouse \\
\hline
\end{tabular}




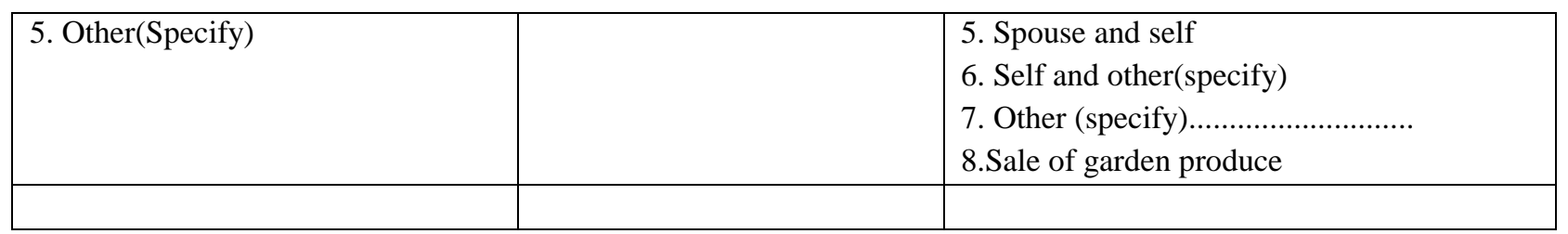

For New borrowers

\begin{tabular}{|l|l|l|}
\hline $208 \mathrm{a}$ & $209 \mathrm{a}$ & $210 \mathrm{a}$ \\
\hline Who will be responsible to repay & Do you think you might & What will be the source of cash for the loan \\
the loan in your household? & sometimes face difficulties & repayments? \\
1. Self & with the weekly repayments & 1. Loan funded enterprises \\
2. Spouse & of your loan? & 2. Group members \\
3. Self and spouse & 1. Yes & 3. Loan from other MFI \\
4. Spouse and other(specify) & 2. No & 4. From spouse \\
5. Other(Specify) & & 5. Spouse and self \\
& & 6. Self and other(specify) \\
& & 7. Other (specify)............................ \\
& & \\
\hline
\end{tabular}

Microcredit information (FOR OLD BORROWERS). NB GO TO 211a

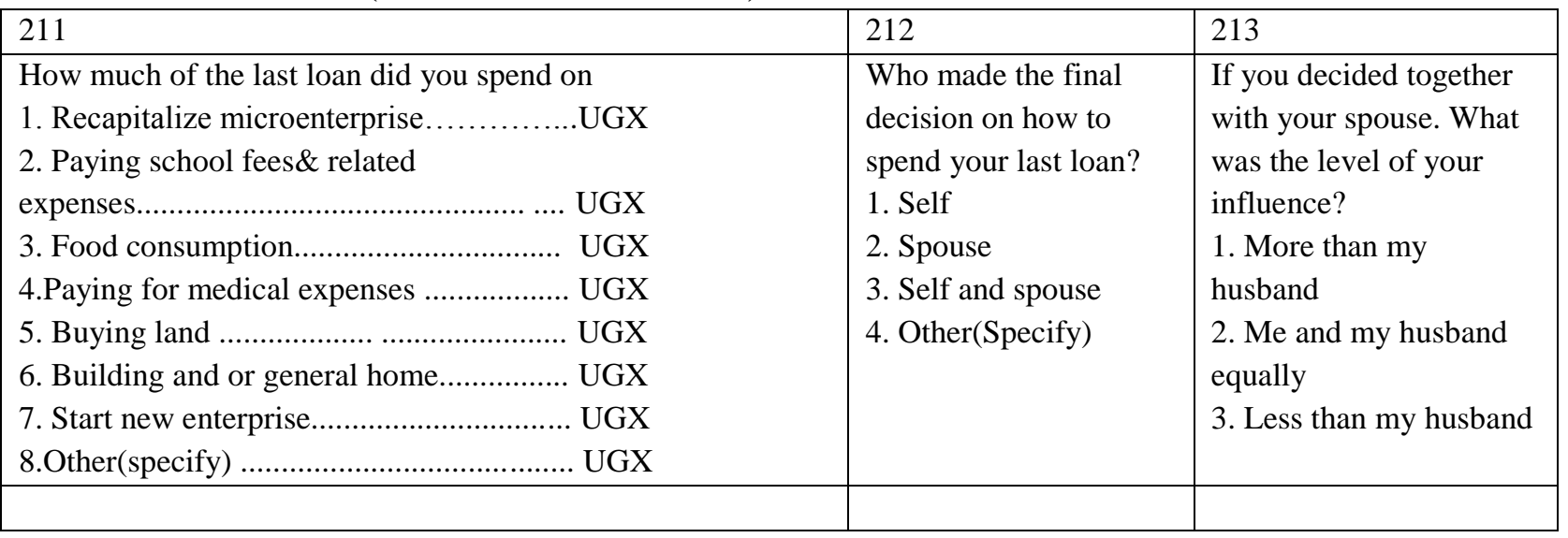


Microcredit information (continued)

\begin{tabular}{|c|c|c|c|}
\hline 214 & $214 b$ & $214 c$ & 215 \\
\hline 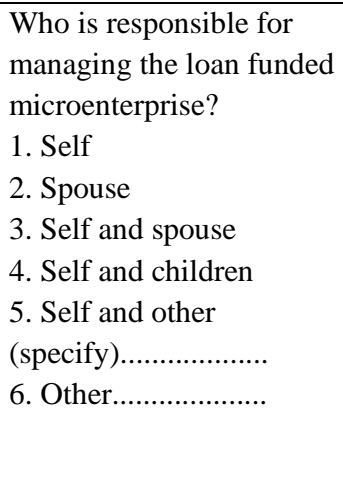 & $\begin{array}{l}\text { Do you have anyone } \\
\text { (Husband or other } \\
\text { relative), who makes } \\
\text { significant monetary } \\
\text { and non-monetary } \\
\text { contributions towards } \\
\text { your ME? } \\
\text { 1. Yes } \\
\text { 2. No }\end{array}$ & $\begin{array}{l}\text { If yes, what is the } \\
\text { nature of the } \\
\text { contribution? } \\
\text { 1. Provided start-up } \\
\text { capital } \\
\text { 2. Re-Injects funds } \\
\text { into ME } \\
\text { 3. Provides labour } \\
\text { and time }\end{array}$ & $\begin{array}{l}\text { For drop-outs and resting borrowers: why } \\
\text { did you stop/rest borrowing from BRAC? } \\
\text { 1- Difficulties with loan repayment } \\
\text { 2- Interest rate too high } \\
\text { 3- } \quad \text { Frequency of payment too high } \\
\text { 4- } \quad \text { Time for processing new loans and loan } \\
\text { renewals too long } \\
\text { 5- Loan renewal procedure too complicated } \\
6-\quad \text { Stopped the ME/ME closed } \\
\text { 7- } \quad \text { Illness } \\
\text { 8- } \quad \text { Pressure from husband to stop borrowing } \\
\text { 9- } \quad \text { Other (Specify) }\end{array}$ \\
\hline
\end{tabular}

Microcredit information (continued) (For new borrowers only)

\begin{tabular}{|c|c|c|}
\hline $211 a$ & $212 \mathrm{a}$ & $213 a$ \\
\hline $\begin{array}{l}\text { How much of the loan do you hope to spend on the } \\
\text { following: } \\
\text { 1. Recapitalize microenterprise...........UGX } \\
\text { 2. Paying school fees \& related expenses } \\
\text {.....................................UGX } \\
\text { 3. Food consumption...................UGX } \\
\text { 4.Paying for medical expenses ...........UGX } \\
\text { 5. Buying land ............................UGX } \\
\text { 6. Building and or general home........UGX } \\
\text { 7. Start new enterprise......................UGX } \\
\text { 8. Other (specify) ...............................UGX }\end{array}$ & $\begin{array}{l}\text { Who will make the final } \\
\text { decision on how to spend the } \\
\text { loan? } \\
\text { 1. Self } \\
\text { 2. Spouse } \\
\text { 3. Self and spouse } \\
\text { 4. Other(Specify) }\end{array}$ & $\begin{array}{l}\text { If you will decide with your } \\
\text { spouse, What will be the level of } \\
\text { your influence? } \\
\text { 1. More than my husband } \\
\text { 2. Me and my husband equally } \\
\text { 3. Less than my husband }\end{array}$ \\
\hline
\end{tabular}

Microcredit information (continued)

\begin{tabular}{|c|c|c|c|}
\hline $214 a$ & $214 a b$ & $214 \mathrm{ac}$ & 215 \\
\hline 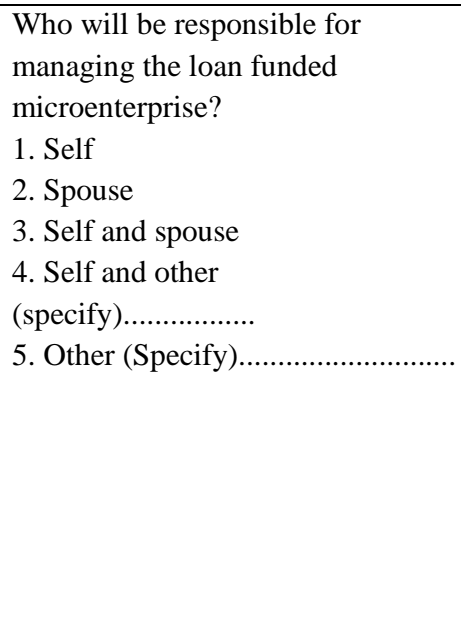 & $\begin{array}{l}\text { Do you have any } \\
\text { one (Husband or } \\
\text { other relative), who } \\
\text { makes significant } \\
\text { monetary and non- } \\
\text { monetary } \\
\text { contributions } \\
\text { towards your ME } 1 . \\
\text { Yes } \\
\text { 2.No }\end{array}$ & $\begin{array}{l}\text { If yes, what is the } \\
\text { nature of the } \\
\text { contribution? } \\
\text { 1. Provided start-up } \\
\text { capital } \\
\text { 2. Re-injects funds } \\
\text { into ME } \\
\text { 3. Provides labour } \\
\text { and time }\end{array}$ & 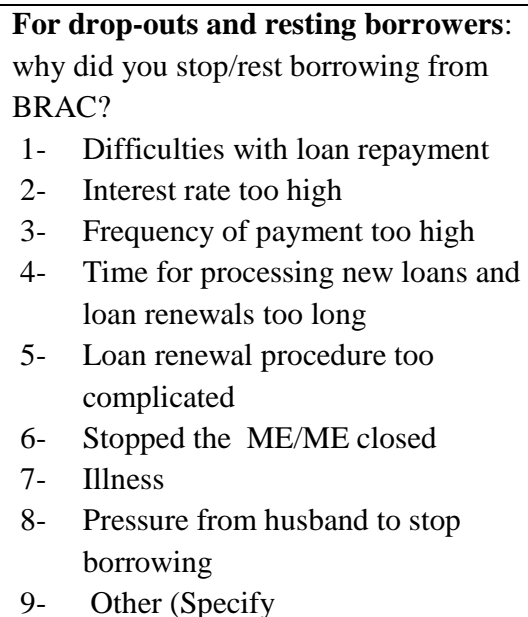 \\
\hline
\end{tabular}

Information from BRAC: (Loan history, amounts, dates, and how much they have to repay) 


\section{SECTION 3: INCOME AND INCOME SOURCES}

Loan-funded enterprises (type, ownership and labour allocation)

(Drop-outs with no running ME proceed to 336)

\begin{tabular}{|c|c|c|c|c|}
\hline 301(For OB and NB) & 302 & 303 (All MEs) & 304 & 305 \\
\hline $\begin{array}{l}\text { Did you ever engage in income } \\
\text { generating activities to earn } \\
\text { independent income? (before } \\
\text { joining BRAC) } \\
\text { 1. Yes } \\
\text { 2. No } \\
\text { For controls: Do you engage in } \\
\text { any Income generating } \\
\text { activities to earn income } \\
\text { 1. Yes } \\
\text { 2. No }\end{array}$ & $\begin{array}{l}\text { What type of } \\
\text { ME are you } \\
\text { running? }\end{array}$ & $\begin{array}{l}\text { How would you } \\
\text { describe the } \\
\text { ownership of the } \\
\text { ME? } \\
\text { 1. Exclusively mine } \\
\text { 2. Co-owned with } \\
\text { husband/family } \\
\text { member/friend (tick } \\
\text { where appropriate) }\end{array}$ & $\begin{array}{l}\text { Type of( loan } \\
\text { funded) agricultural } \\
\text { ME } \\
\text { 1. Crop } \\
\text { 2. Animal } \\
\text { If crop go to } 305 \\
\text { If animal go to } 315 \\
\text { If both answer } 305 \text { to } \\
321\end{array}$ & $\begin{array}{l}\text { How much area } \\
\text { did you have under } \\
\text { cultivation of the } \\
\text { following in the } \\
\text { previous season } \\
\text { (Acres) }\end{array}$ \\
\hline
\end{tabular}

Code 302

1- Agricultural related ME proceed to 304

2- Trade-related ME proceed to 325

3- None proceed to 336

4-Both (Answer all questions)

Code 305: $1 .<$ half acre2. Half acre

3.half-acre 4.one acre 5. More than an acre 


\section{A. AGRICULTURAL-RELATED ME}

306 Expenditure on crop-related agricultural ME

How much did you spend on the following in the last season/month?

\begin{tabular}{|c|c|c|c|c|c|c|c|c|}
\hline EC0 & $\mathrm{EC} 1$ & EC2 & EC3 & $\mathrm{EC} 4$ & EC5 & EC6 & EC7 & EC8 \\
\hline $\begin{array}{l}\text { Type } \\
\text { of } \\
\text { crops }\end{array}$ & $\begin{array}{l}\text { Number of } \\
\text { employees/ } \\
\text { labourers }\end{array}$ & $\begin{array}{l}\text { Cost of } \\
\text { labour for } \\
\text { weeding, } \\
\text { planting, } \\
\text { land clearing } \\
\text { (UGX) }\end{array}$ & $\begin{array}{l}\text { Transport, to } \\
\text { buy crop- } \\
\text { related } \\
\text { inputs }\end{array}$ & $\begin{array}{l}\text { Seeds } \\
\text { Purchase }\end{array}$ & $\begin{array}{l}\text { Value of } \\
\text { seeds } \\
\text { planted } \\
\text { not } \\
\text { bought }\end{array}$ & $\begin{array}{l}\text { Fertilizers } \\
\text { and } \\
\text { pesticides? }\end{array}$ & $\begin{array}{l}\text { Rent or } \\
\text { lease of } \\
\text { agricult } \\
\text { ural } \\
\text { land? }\end{array}$ & $\begin{array}{l}\text { Interest } \\
\text { on loan } \\
\text { invested } \\
\text { in the } \\
\text { ME? }\end{array}$ \\
\hline 1. & & & & & & & & \\
\hline 2. & & & & & & & & \\
\hline 3. & & & & & & & & \\
\hline 4. & & & & & & & & \\
\hline
\end{tabular}

307. Income from crop-related agricultural ME

How much cash and non-cash income did you get from the crops in the last season/month?

\begin{tabular}{|c|c|c|c|c|c|c|c|}
\hline IC 1 & IC 2 & IC 3 & IC 4 & IC 5 & IC 6 & IC 7 & IC8 \\
\hline $\begin{array}{l}\text { Type of } \\
\text { crops } \\
\text { cultivated }\end{array}$ & $\begin{array}{l}\text { What } \\
\text { quantity } \\
\text { did you } \\
\text { produce? }\end{array}$ & $\begin{array}{l}\text { Unit of } \\
\text { quantit } \\
\text { y } \\
\text { tins, } \\
\text { sacs or } \\
\text { litres) }\end{array}$ & $\begin{array}{l}\text { Quantity of } \\
\text { crops } \\
\text { consumed } \\
\text { From last } \\
\text { season }\end{array}$ & $\begin{array}{l}\text { Quantity sold } \\
\text { From last } \\
\text { season }\end{array}$ & Unit cost & $\begin{array}{l}\text { For seasonal } \\
\text { crops what } \\
\text { quantity of } \\
\text { produce do } \\
\text { you have } \\
\text { under } \\
\text { storage? }\end{array}$ & $\begin{array}{l}\text { For non- } \\
\text { seasonal } \\
\text { crops } \\
\text { indicate Qty } \\
\text { in garden } \\
\text { and in } \\
\text { storage? }\end{array}$ \\
\hline 1. & (Quantity) & (unit) & $\begin{array}{l}\text { Qty } \\
\text { Unit }\end{array}$ & Qty Unit & & Qty Unit & $\begin{array}{l}\text { Qty } \\
\text { Unit }\end{array}$ \\
\hline 2. & 1 & 1. & & & & 1. & \\
\hline 3. & 2 & 2. & & & & 2. & \\
\hline 4. & 3 & 3. & & & & 3. & \\
\hline 5. & & & & & & & \\
\hline & & & & & & & \\
\hline
\end{tabular}

Code 306:1. Maize, 2.Vegetable (tomatoes, eggplant,cabbage, dodo,nakati,sukuma wiki), 3. Cassava

4. Coffee, 5. Bananas, 6.Yams, 7.Beans, 8.Potatoes, 9. Other (specify)

308. Compare your current total area under cultivation to before you got the loan

1- Area is less than before I got the first loan 2- Area is the same as before I got the first loan

3- Area is more than before I got the first loan 
309. Expenses on animal-related agricultural ME

How much did you spend on the following in the previous month or season?

\begin{tabular}{|c|c|c|c|c|c|c|c|c|}
\hline EA0 & EA 1 & EA 2 & EA 3 & EA 4 & EA 5 & EA 6 & EA 7 & EA 8 \\
\hline $\begin{array}{l}\text { Type } \\
\text { Of } \\
\text { Animal }\end{array}$ & $\begin{array}{l}\text { Transport } \\
\text { (UGX) }\end{array}$ & $\begin{array}{l}\text { Veterinary } \\
\text { expenses } \\
\text { and food } \\
\text { supplements } \\
\text { (UGX) }\end{array}$ & $\begin{array}{l}\text { Animal } \\
\text { feed/ } \\
\text { fodder } \\
\text { (UGX) }\end{array}$ & $\begin{array}{l}\text { Fuel } \\
\text { (paraffin or } \\
\text { firewood) } \\
\text { (UGX) }\end{array}$ & $\begin{array}{l}\text { Labour } \\
\text { (UGX) }\end{array}$ & $\begin{array}{l}\text { Repairs \& } \\
\text { maintenanc } \\
\text { e } \\
\text { (UGX) }\end{array}$ & $\begin{array}{l}\text { Livestock } \\
\text { purchases } \\
\text { (UGX) }\end{array}$ & $\begin{array}{l}\text { Interest } \\
\text { on loan } \\
\text { invested } \\
\text { in ME } \\
\text { (UGX) }\end{array}$ \\
\hline & & & & & & & & \\
\hline & & & & & & & & \\
\hline
\end{tabular}

310. Income from animal-related agricultural $\mathrm{ME}$

\begin{tabular}{|c|c|c|c|c|c|c|c|c|}
\hline IA1 & IA2 & \multicolumn{2}{|l|}{ IA3 } & IA4 & IA5 & & IA6 & \\
\hline \multirow[t]{2}{*}{$\begin{array}{l}\text { What type of } \\
\text { animals do you } \\
\text { keep? }\end{array}$} & \multirow[t]{2}{*}{$\begin{array}{l}\text { How many } \\
\text { animals do } \\
\text { you have? } \\
\text { (Number) }\end{array}$} & \multicolumn{2}{|c|}{$\begin{array}{l}\text { In the last month, what } \\
\text { quantity of animal } \\
\text { products/young ones did } \\
\text { you produce? (trays, } \\
\text { litres or kgs/ number) }\end{array}$} & $\begin{array}{l}\text { Quantity of } \\
\text { product/ } \\
\text { animals } \\
\text { consumed } \\
\text { past } 1 \text { month }\end{array}$ & \multicolumn{2}{|c|}{$\begin{array}{l}\text { Qty of } \\
\text { product/animal } \\
\text { sold } \\
\text { past } 1 \text { month }\end{array}$} & \multicolumn{2}{|c|}{$\begin{array}{l}\text { Number and } \\
\text { price of animals } \\
\text { bought and } \\
\text { resold }\end{array}$} \\
\hline & & Item & Qty & & Qty & Price & No & Price \\
\hline 1. & 1. & 1. & & & & & & \\
\hline 2. & 2. & 2. & & & & & & \\
\hline 3. & 3. & 3. & & & & & & \\
\hline 4. & 4. & 4. & & & & & & \\
\hline 5. & 5. & 5. & & & & & & \\
\hline
\end{tabular}

Code 315
1. Local chicken
2. Pigs
3. Exotic chicken
4. Goats
9. Rabbits
5.Zero grazing cattle
6. Local cattle
7. Sheep
8. Ducks

General comments on agricultural-related microenterprises

\begin{tabular}{|c|c|c|}
\hline 311 & 312 & $\begin{array}{l}\text { 313(Skip for NB and } \\
\text { control) }\end{array}$ \\
\hline $\begin{array}{l}\text { What is the total value of sales from } \\
\text { agriculture? } \\
\text { From crops }=\ldots \ldots \ldots \ldots . . .(\text { last season) } \\
\text { From animals=.............. (last month) (per } \\
\text { month/year)(UGX) }\end{array}$ & $\begin{array}{l}\text { Do you think last season's level of } \\
\text { crop production was: } \\
\text { 1. Below normal } \\
\text { 2. Normal } \\
\text { 3. Above normal }\end{array}$ & $\begin{array}{l}\text { Compare your current level of } \\
\text { agricultural production to } \\
\text { what you produced before you } \\
\text { got the first loan? }\end{array}$ \\
\hline Tick appropriate time period) & & \\
\hline
\end{tabular}

Code 324: 1. Production is less than before I got the loan

2. Production is the same as before I got the loan

3. Production is more than before I got the loan 


\section{B. TRADE-RELATED MICROENTERPRISES}

314.What type of trade ME do you deal in? (List all MES)

Codes for 325: 1. Sale of small shop, 2. Stall in weekly markets, 3. Permanent stall in market, 4. Tailor, 5. Hair salon, 6. Brewing and or selling alcohol, 7. Runs small restaurant/cooked food business, 8 . Hawking, 9. Secretarial bureau, 10. Sell airtime and phone accessories, 11. Other

315. What is the monetary value of your business? (UGX)

316. How many people do you employ for micro enterprise activities?

317. Business expenses and business income

I would like you to tell me how much you spend and how much you earn for different aspects of your business per month/week/day.

A. Cost information (for All)

\begin{tabular}{|l|l|l|}
\hline Costs of doing business & $\begin{array}{l}\text { Time period per: 1.Day 2.Week } \\
\text { 3.Month 4.Year }\end{array}$ & Amount \\
\hline (a) Paid Labour/ salary (month) & & \\
\hline (b) Paid labour piece workers & & \\
\hline (c) Rent & & \\
\hline (d) Transport for inputs/ restocking & & \\
\hline (e) Transport for final product/ for sales & & \\
\hline (f) Electricity / paraffin(for business) & & \\
\hline (g) Water (for business) & & \\
\hline (h) Charcoal/firewood(for business) & & \\
\hline (i) Tax and license & & \\
\hline (j) Telephone costs (for business) & & \\
\hline (k) Repairs and service & & \\
\hline (l) Cost of credit (loan repayment) & & \\
\hline (m) Other & & \\
\hline (n) Other & & \\
\hline
\end{tabular}

B. Cost information for traders only (Non-traders skip to C)

i) Restocking days $=\ldots$ (days)

ii) In which time period? 1. Week 2. Month 3. Year(7 days a week means daily)

iii) How much do you usually spend to restock your business on restocking days? 
C. Cost information for non- traders (Manufacturer, repairs or service) if trader skip to D

\begin{tabular}{|l|l|l|l|l|l|}
\hline $\begin{array}{l}\text { Costs of different business } \\
\text { Inputs/ supplies e.g. Raw } \\
\text { materials and raw foods }\end{array}$ & $\begin{array}{l}\text { Time period } \\
\text { 1.Day 2.Week } \\
\text { 3.Month } \\
\text { 4.Year }\end{array}$ & Cost & $\begin{array}{l}\text { Costs of different } \\
\text { business } \\
\text { inputs/ supplies }\end{array}$ & $\begin{array}{l}\text { Time period } \\
\text { 1. Day 2.Week } \\
\text { 3.Month 4.Year }\end{array}$ & Cost \\
\hline A. & & & & & \\
\hline$\ldots$. & & & & & \\
\hline J. & & & & & \\
\hline
\end{tabular}

D. Income and sales information (For all)

\begin{tabular}{|l|l|l|}
\hline \multicolumn{2}{|l|}{} & Amount/ No of days \\
\hline Item & $\begin{array}{l}\text { Time Period } \\
\text { 1.Day 2.Week 3.Month 4.Year }\end{array}$ & \\
\hline Number of business days & & \\
\hline Number Of Months & & \\
\hline Value of sales on a typical day & & \\
\hline Value of stock at restocking day & & \\
\hline
\end{tabular}

\begin{tabular}{|l|l|}
\hline 318 & \\
\hline Compare your current level of trade today to before you got the first loan? & \\
\hline
\end{tabular}

Code 331: 1. trade is less than before I got the loan, 2. It is the same as before I got the loan,

3. It is more than before I got the loan

Income from trade-related microenterprise (continued)

319.(a) What is the money value of the stock items that you consume?

Time period 1. Day 2.Week 3.Month 4. Year

\begin{tabular}{|l|l|l|l|l|l|l|l|l|}
\hline Item & & & & & & & & \\
\hline Time Period & & & & & & & & \\
\hline Quantity & & & & & & & & \\
\hline Amount & & & & & & & & \\
\hline
\end{tabular}

319(b)(i). Do you use some of the money you get from this business for yourself, or for your household? If yes, How much money do you normally use for yourself or for your household?
(ii)Time period: 1. Day
2. Week
3.Month
4.Year

UGX

(This Qn is similar to similar to 335. Check them against each other).

319(c).(i)After making purchases for the business, (after the weekly loan payment)and after using some money for yourself, or your household, is there usually any money left?

(After paying off the weekly loan payment)-on a typical restocking day 1.Yes 2. No
(ii)Time period: 1 . Day
2. Week
3.Month
4.Year (Put Zero if no money is left)

(ii) If yes how much money do you usually have left after purchases for the business and using some of the money for yourself or your household? UGX

\section{GO TO 333}

Time allocation (food production versus ME) $\mathbf{3 3 3}$

How much time do you spend on the following on a typical day?

334 (skip for new borrowers and controls, proceed to 335)

Compare the amount of time you spend on the following these days and before you got the loan. 


\begin{tabular}{|c|c|c|c|}
\hline & & \multicolumn{2}{|c|}{ 1. I spend less time, 2. I spend same time,3. I spend more time } \\
\hline ME (days/wk) & (days) & ME & 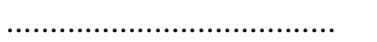 \\
\hline ME (hrs/working day) & (hrs) & Garden work & 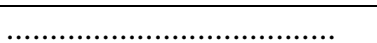 \\
\hline Garden work (ME Day) & (hrs) & $\begin{array}{l}\text { Domestic work (excluded from } \\
\text { ME time) }\end{array}$ & …....................... \\
\hline Garden work (Non-ME day) & & & \\
\hline Domestic work (ME day) & (hrs) & & \\
\hline Domestic work (Non ME day) & & & \\
\hline
\end{tabular}

\section{Use of (loan)-funded enterprise income}

335a. How much of ME income do you use each day/week for the following (please list according to priorities)

\begin{tabular}{|l|l|l|l|l|l|}
\hline Period /Item & $\begin{array}{l}\text { 1.Food } \\
\text { expenditures }\end{array}$ & $\begin{array}{l}\text { 2.Education } \\
\text { expenditures }\end{array}$ & $\begin{array}{l}\text { 3.Health } \\
\text { expenditures }\end{array}$ & $\begin{array}{l}\text { 4.Other } \\
\text { household } \\
\text { expenditures }\end{array}$ & $\begin{array}{l}\text { 5.Improvement } \\
\text { Build new house }\end{array}$ \\
\hline Day & & & & & \\
\hline Week & & & & & \\
\hline Month & & & & & \\
\hline Term/Semester & & & & & \\
\hline
\end{tabular}

335b. Did you ever buy land from your ME Income? 1. Yes, 2. No

336. Other income sources (FOR ALL)

\begin{tabular}{|c|c|c|c|c|}
\hline \multirow{6}{*}{$\begin{array}{l}\text { How much income do } \\
\text { you, your husband and } \\
\text { other income earners in } \\
\text { the home get from } \\
\text { other activities? (Not } \\
\text { the ones discussed } \\
\text { above) }\end{array}$} & \multirow{2}{*}{$\begin{array}{l}\text { Main non-loan related income sources: (circle all } \\
\text { income sources mentioned by household }\end{array}$} & \multicolumn{3}{|c|}{ Income per month/season } \\
\hline & & Woman & Husband & Other \\
\hline & $1=$ Food crop production (e.g cereals, tubers) & & & \\
\hline & $\begin{array}{l}2=\text { Growing non-food cash crops (e.g. coffee } \\
\text { growers) }\end{array}$ & & & \\
\hline & $3=$ Livestock production (e.g. animal husbandry) & & & \\
\hline & 4= Selling animal products (e.g. eggs and milk) & & & \\
\hline \multirow{4}{*}{$\begin{array}{l}\text { (Use code } 999 \text { for I } \\
\text { don't know) }\end{array}$} & $5=$ Trading in Food Crop or Non Food crops. & & & \\
\hline & $6=$ Seller, commercial activity/petty trade & & & \\
\hline & $7=$ Bodaboda or special-hire driver & & & \\
\hline & $8=$ Unskilled wage labour & & & \\
\hline \multirow{10}{*}{$\begin{array}{l}\text { What is your husband's } \\
\text { main occupation? (use } \\
\text { codes in the table) }\end{array}$} & $9=$ Agricultural labour & & & \\
\hline & $10=$ Handicrafts and hair dressing & & & \\
\hline & $11=$ Brewing and sale of local brew & & & \\
\hline & $12=$ Sale of Natural Resources (firewood, charcoal) & & & \\
\hline & 13= Remittance/ Kinship/relatives/neighbours & & & \\
\hline & 14= Salaries, wages, (employees) private/Govt & & & \\
\hline & $15=$ Rental of property like buildings and land & & & \\
\hline & $16=$ pension & & & \\
\hline & 17=Others (specify) & & & \\
\hline & TOTAL & & & \\
\hline
\end{tabular}

337. Are there other household members who contribute towards food expenditure?

1. Yes 2. No

If Yes, how much funds are provided by the different income earners for household food expenditures? 


\begin{tabular}{|c|c|c|c|c|}
\hline \multirow[t]{2}{*}{ Name of Income earner } & \multirow[t]{2}{*}{ Relationship } & \multicolumn{3}{|c|}{ Expenditure on food } \\
\hline & & Per day & Per week & Per month \\
\hline 1 & & & & \\
\hline 2 & & & & \\
\hline 3 & & & & \\
\hline
\end{tabular}

338. Levels of non-loan related/Non business-related agricultural production: Apart from the ME/ loan-funded agricultural ME, estimate the food produced by the household (the recipient and other $\mathrm{HH}$ members) from other sources

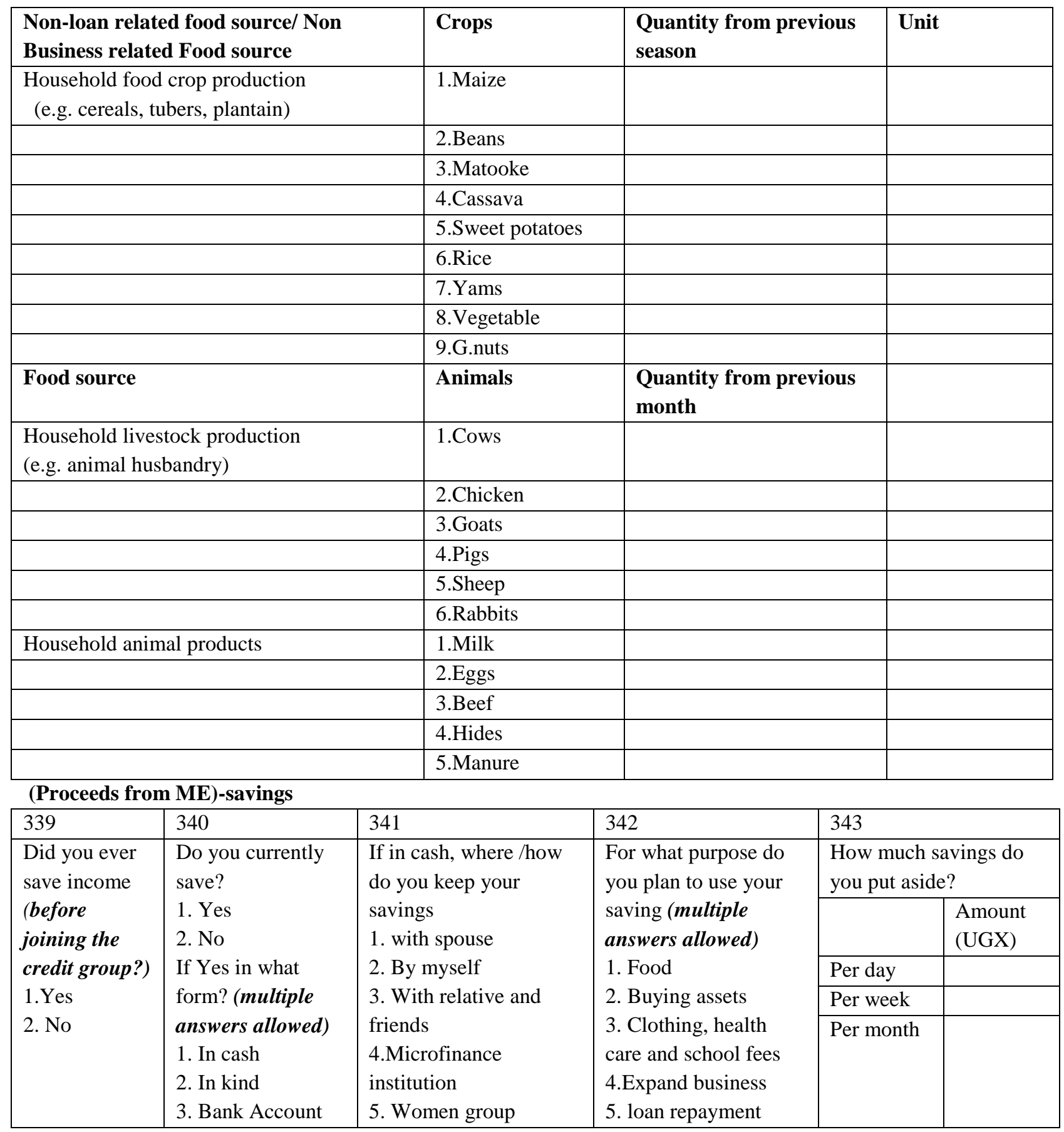




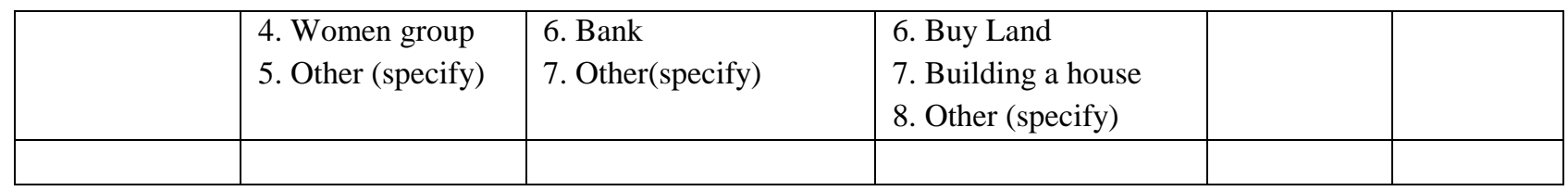

Section 4: Household consumption expenditures

401. Expenditure on non-durable goods and frequently purchased services (by woman and other income earners)

\begin{tabular}{|c|c|c|c|}
\hline Item description & $\begin{array}{l}\text { Expenditure } \\
\text { (UGX) }\end{array}$ & Item description & $\begin{array}{l}\text { Expenditure } \\
\text { (UGX) }\end{array}$ \\
\hline 1.Rent of house & & 10.Medical care expenses & \\
\hline 2. Rent of land & & 11.House help & \\
\hline 3.Electricity & & 12.Air time and phone charging & \\
\hline 4.Charcoal /firewood & & 13.Entertainment (music shows etc) & \\
\hline 5. Petrol, diesel & & 14.Water & \\
\hline 6. Cosmetics & & 15. Paraffin & \\
\hline 7.Soap, tooth paste & & 16. Repairs and spare parts & \\
\hline $\begin{array}{l}\text { 8. Hair salon and hair } \\
\text { dressing, barber }\end{array}$ & & 17.Other household utensils & \\
\hline \multirow[t]{2}{*}{ 9.Salt } & & 18. Match boxes & \\
\hline & & 19. Education expenditures/term/semester & \\
\hline
\end{tabular}

402. To what extent do you contribute towards the household expenditures? (tick one)

\begin{tabular}{|l|l|}
\hline 1. I pay for all & \\
\hline 2. I contribute more than half & \\
\hline 3. Other household members and me spend almost equal amounts & \\
\hline 4. I contribute less than half & \\
\hline 5. I do not contribute anything & \\
\hline
\end{tabular}




\section{Dietary diversity and household caloric supply}

I would like to ask you a few questions about different foods that you have eaten in the last seven days 403. Could you please tell me how many days in the past one week (seven days) your household has eaten the following foods and what was the main source?

(Use codes on the right, write 0 for the items not eaten over the last 7 days).

Respondent (Ask if any member of $\mathrm{HH}$ ate the food item the previous day)

(Ask line by line for each item both questions)

\begin{tabular}{|c|c|c|c|c|c|c|c|c|c|c|}
\hline & & Food Item & $\begin{array}{l}\text { Amount } \\
\text { consumed } \\
\text { (Qty) }\end{array}$ & Unit & $\begin{array}{l}\text { Main } \\
\text { sources }\end{array}$ & $\begin{array}{l}\text { Total } \\
\text { consumed } \\
\text { from own } \\
\text { produce }\end{array}$ & $\begin{array}{l}\text { Qty } \\
\text { purchased }\end{array}$ & $\begin{array}{l}\text { Total } \\
\text { cost }\end{array}$ & $\begin{array}{l}\text { No of days } \\
\text { eaten in the } \\
\text { last } 7 \text { days }\end{array}$ & $\begin{array}{l}\text { Eaten } \\
\text { Y.day } \\
\text { 1=Yes } \\
\text { 0=No }\end{array}$ \\
\hline 1 & \multirow{5}{*}{ 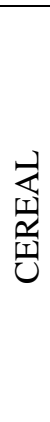 } & $\begin{array}{l}\text { Maize } \\
\text { (Posho/ } \\
\text { Porridge/Fre } \\
\text { sh/hard } \\
\text { corn) } \\
\end{array}$ & & & & & & & & \\
\hline 2 & & Rice & & & & & & & & \\
\hline 3 & & Bread & & & & & & & & \\
\hline 4 & & Mandaazi & & & & & & & & \\
\hline 5 & & Chapatti & & & & & & & & \\
\hline 6 & \multirow{3}{*}{$\begin{array}{l}5 \\
0 \\
0 \\
\simeq\end{array}$} & Cassava & & & & & & & & \\
\hline 7 & & Potatoes & & & & & & & & \\
\hline 8 & & Yams & & & & & & & & \\
\hline 9 & & Matooke & & & & & & & & \\
\hline 10 & \multirow{4}{*}{ 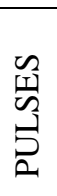 } & Beans & & & & & & & & \\
\hline 11 & & Cow peas & & & & & & & & \\
\hline 12 & & Simsim & & & & & & & & \\
\hline 13 & & Ground nuts & & & & & & & & \\
\hline 14 & \multirow[b]{2}{*}{ D্ } & $\begin{array}{l}\text { Fruit } \\
\text { vegetables }\end{array}$ & & & & & & & & \\
\hline 15 & & $\begin{array}{l}\text { Leafy } \\
\text { vegetables }\end{array}$ & & & & & & & & \\
\hline 16 & \multirow{2}{*}{$\frac{\sqrt{\Omega}}{\tilde{I}}$} & Silver fish & & & & & & & & \\
\hline 17 & & Fish & & & & & & & & \\
\hline 18 & \multirow{5}{*}{ 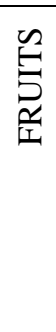 } & Pawpaw & & & & & & & & \\
\hline 19 & & Avocado & & & & & & & & \\
\hline 20 & & Jack fruit & & & & & & & & \\
\hline 21 & & $\begin{array}{l}\text { Sweet } \\
\text { bananas }\end{array}$ & & & & & & & & \\
\hline 22 & & $\begin{array}{l}\text { Pine apple } \\
\text { /mangoes }\end{array}$ & & & & & & & & \\
\hline 23 & \multirow{3}{*}{ 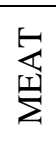 } & Chicken & & & & & & & & \\
\hline 24 & & Beef & & & & & & & & \\
\hline 25 & & Pork & & & & & & & & \\
\hline 26 & ত্工 & Eggs & & & & & & & & \\
\hline
\end{tabular}




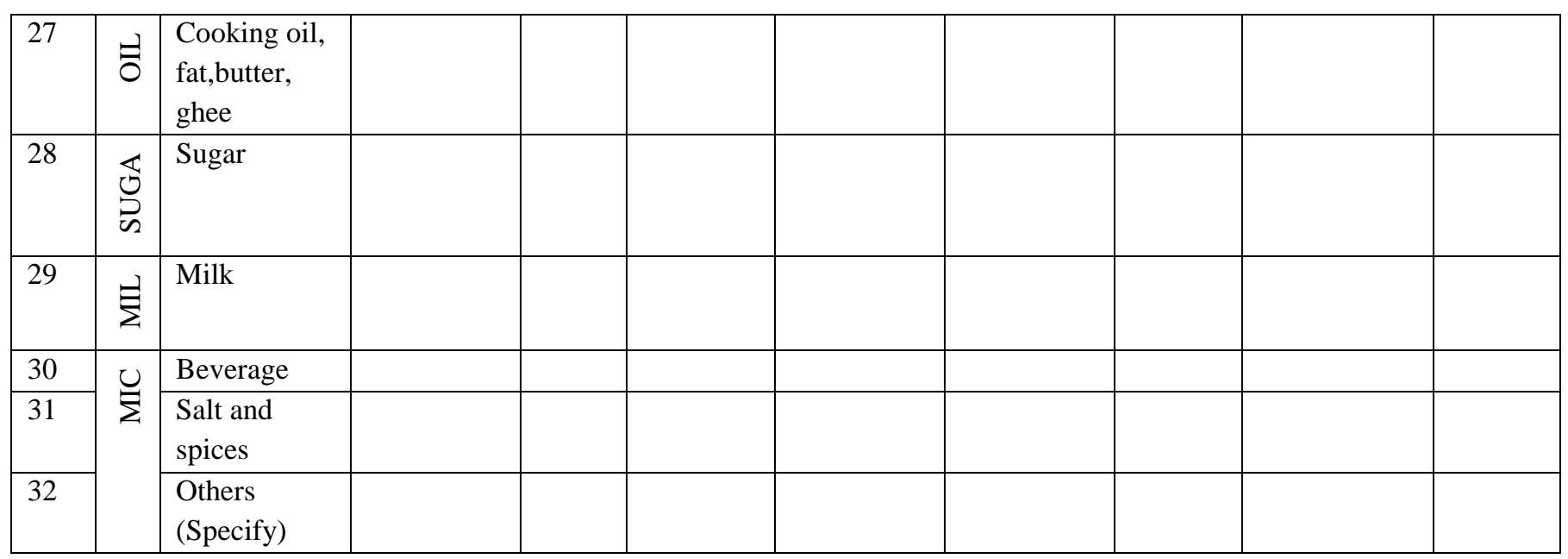

1=Own production (crops , animals), direct or indirect sale or exchange, $2=$ Purchased, $3=$ Hunting, fishing, gathering, 4=Exchange labour /items for food, 5=Borrowed, 6= Gift (food) from family/ relatives, 7= Sale of household non-productive item, $8=$ Sale of household productive item

\begin{tabular}{|l|l|l|}
\hline $403 a$ & $\begin{array}{l}\text { Did last week (the last seven days) have any celebration or a feast day } \\
\text { where you ate unusual foods? }\end{array}$ & $\begin{array}{l}\text { Number of cselebration or feast } \\
\text { days }\end{array}$ \\
\cline { 2 - 3 } & 1.Yes 2.No
\end{tabular}

403b. Did you/any other household member eat anything meal/snack outside the home last week/in the last seven days? $\quad$ 2.Yes

\begin{tabular}{|l|l|l|l|l|}
\hline Name & Sex & Age & No. of days missed & $\begin{array}{l}\text { No./Type of meals } \\
\text { missed }\end{array}$ \\
\hline & & & & \\
\hline & & & & \\
\hline
\end{tabular}


403 c. Dietary diversity (foods categorisations).

\begin{tabular}{|l|l|l|l|}
\hline $\begin{array}{l}\text { Question } \\
\text { Number }\end{array}$ & Food Group & Examples & Yes/No \\
\hline & Cereal and cereal products & Maize, rice,bread, mandazi and chapati, & \\
\hline & Roots, tubers or their products & Cassava, potatoes, yams, Irish potatoes, bucopa/koona & \\
& Vegetables & $\begin{array}{l}\text { Cabbage, doodo, nakati, buga, sukumawiiki, Jobyo, } \\
\text { ntula and biringanya }\end{array}$ & \\
\hline & Fruits & $\begin{array}{l}\text { Pawpaws, avocado, Jackfruits, bananas, pine aple, } \\
\text { mango, guava, }\end{array}$ & \\
\hline & Meat, poultry/offals & Beef, chicken, pork, offals, & \\
\hline & Eggs & Eggs & \\
\hline & Fish and sea food & mukene, tilapia, Nile-perch & \\
\hline & Pulses, legumes andnNuts & Beans, peas, ground nuts, simsim & \\
\hline & Milk and milk products & Milk, yoghurt, Ice cream & \\
\hline & Oils or fats & Cooking oil or ghee & \\
\hline & Sugar or honey & Sugar and honey, sugar cane & \\
\hline & Miscellaneous & Condiments and spices & \\
\hline
\end{tabular}

404. Qualitative measurements of household food security (household food Insecurity access scale)

\begin{tabular}{|c|c|c|}
\hline $\begin{array}{l}\text { Question: In the past month or in the past } 4 \\
\text { weeks: }\end{array}$ & & Code \\
\hline $\begin{array}{l}\text { 1. Did you worry that your household would } \\
\text { not have enough to eat? }\end{array}$ & $\begin{array}{l}0=\text { No }(\text { Skip to Q2) } \\
1=\text { Yes }\end{array}$ & \\
\hline 1.a If yes, how often? & $\begin{array}{l}\text { 1.Rarely (once or twice in the past four weeks) } \\
\text { 2.Sometimes (three to ten times in the past four weeks } \\
\text { 3.Often (more than ten times in the past four weeks) }\end{array}$ & \\
\hline $\begin{array}{l}\text { 2. Were you or any household member not } \\
\text { able to eat the kinds of foods you preferred to } \\
\text { eat because of lack of resources }\end{array}$ & $\begin{array}{l}0=\text { No }(\text { Skip to Q3) } \\
1=\text { Yes }\end{array}$ & \\
\hline 2.a If yes, how often? & $\begin{array}{l}\text { 1.Rarely (once or twice in the past four weeks) } \\
\text { 2.Sometimes (three to ten times in the past four weeks } \\
\text { 3.Often (more than ten times in the past four weeks) }\end{array}$ & \\
\hline $\begin{array}{l}\text { 3. Did you or any other household member eat } \\
\text { just a few kinds of food day after day due to } \\
\text { lack of resources? }\end{array}$ & $\begin{array}{l}0=\text { No }(\text { Skip to } Q 4) \\
1=\text { Yes }\end{array}$ & \\
\hline 3.a. If yes, how often? & $\begin{array}{l}\text { 1.Rarely (once or twice in the past four weeks) } \\
\text { 2.Sometimes (three to ten times in the past four weeks } \\
\text { 3.Often (more than ten times in the past four weeks) }\end{array}$ & \\
\hline $\begin{array}{l}\text { 4. Did you or any household member eat food } \\
\text { that you did not want to eat because of lack of } \\
\text { resources to obtain other foods? }\end{array}$ & $\begin{array}{l}0=\text { No }(\text { Skip to Q5) } \\
1=\text { Yes }\end{array}$ & \\
\hline 4.a. If yes, how often? & $\begin{array}{l}\text { 1.Rarely (once or twice in the past four weeks) } \\
\text { 2.Sometimes (three to ten times in the past four weeks } \\
\text { 3.Often (more than ten times in the past four weeks) }\end{array}$ & \\
\hline $\begin{array}{l}\text { 5. Did you or any other household member eat } \\
\text { a smaller meal than you felt you needed } \\
\text { because there was not enough food? }\end{array}$ & $\begin{array}{l}0=\text { No }(\text { Skip to Q6) } \\
1=\text { Yes }\end{array}$ & \\
\hline
\end{tabular}




\begin{tabular}{|c|c|}
\hline 5.a. If yes how often? & $\begin{array}{l}\text { 1.Rarely (once or twice in the past four weeks) } \\
\text { 2.Sometimes (three to ten times in the past four weeks } \\
\text { 3.Often (more than ten times in the past four weeks) }\end{array}$ \\
\hline $\begin{array}{l}\text { 6. Did you or any household member eat fewer } \\
\text { meals in a day because there was not enough } \\
\text { food? }\end{array}$ & $\begin{array}{l}0=\text { No }(\text { Skip to Q7) } \\
1=\text { Yes }\end{array}$ \\
\hline 6.a. If yes how often? & $\begin{array}{l}\text { 1.Rarely (once or twice in the past four weeks) } \\
\text { 2.Sometimes (three to ten times in the past four weeks } \\
\text { 3.Often (more than ten times in the past four weeks) }\end{array}$ \\
\hline $\begin{array}{l}\text { 7. Was there ever no food at all in the } \\
\text { household because there were no resources to } \\
\text { get more? }\end{array}$ & $\begin{array}{l}0=\text { No }(\text { Skip to Q8) } \\
1=\text { Yes }\end{array}$ \\
\hline 7.a. If yes how often? & $\begin{array}{l}\text { 1.Rarely (once or twice in the past four weeks) } \\
\text { 2.Sometimes (three to ten times in the past four weeks } \\
\text { 3.Often (more than ten times in the past four weeks) }\end{array}$ \\
\hline $\begin{array}{l}\text { 8. Did any household member go to sleep at } \\
\text { night hungry because there was not enough } \\
\text { food? }\end{array}$ & $\begin{array}{l}0=\text { No }(\text { Skip to Q9) } \\
1=\text { Yes }\end{array}$ \\
\hline 8.a. If yes how often? & $\begin{array}{l}\text { 1.Rarely (once or twice in the past four weeks) } \\
\text { 2.Sometimes (three to ten times in the past four weeks } \\
\text { 3.Often (more than ten times in the past four weeks) }\end{array}$ \\
\hline $\begin{array}{l}\text { 9. Did any household member go a whole day } \\
\text { without eating anything because there was not } \\
\text { enough food? }\end{array}$ & $\begin{array}{l}0=\text { No } \\
1=\text { Yes }\end{array}$ \\
\hline 9.a. If yes how often? & $\begin{array}{l}\text { 1.Rarely (once or twice in the past four weeks) } \\
\text { 2.Sometimes (three to ten times in the past four weeks } \\
\text { 3.Often (more than ten times in the past four weeks) }\end{array}$ \\
\hline
\end{tabular}

\begin{tabular}{|l|l|l|}
\hline $\begin{array}{l}\text { 405. Now I would like to ask you about your household's food supply during different } \\
\text { months of the year. In the past } 12 \text { months, were there months in which you did not have } \\
\text { enough food to meet your family's needs? }\end{array}$ & 1-Yes \\
\hline $\begin{array}{l}\text { Which were the months in the past } 12 \text { months in which you did not have enough food to } \\
\text { meet your family needs? }\end{array}$ & January & February \\
(Do not read the list of months. Mark with a check-mark those that respondent mentions) & March \\
& April \\
& May \\
& June \\
& July \\
August \\
\end{tabular}

\section{Household wealth and asset-ownership}

\begin{tabular}{|l|l|l|l|l|l|l|}
\hline 412 & & Item & Number & & Item & Number \\
\hline Does anyone in your household own & 1 & Bed & & 11 & Motor -boat & \\
\cline { 2 - 7 } $\begin{array}{l}\text { any of the following assets? If yes, } \\
\text { how many of each asset does the }\end{array}$ & 2 & Table & & 12 & Canoe & \\
\cline { 2 - 7 } $\begin{array}{l}\text { household own? } \\
\text { (While asking, also observe) }\end{array}$ & 3 & Chairs & & 13 & Fishing nets & \\
\cline { 2 - 7 } & 4 & Mattress & & 14 & Hoe & \\
\cline { 2 - 7 } & 5 & Generator & & 15 & Ox-plough & \\
\hline
\end{tabular}




\begin{tabular}{|l|l|l|l|l|l|l|}
\hline & 6 & Radio/tape & & 16 & Motorcycle & \\
\cline { 2 - 7 } & 7 & Cell phone & & 17 & Television & \\
\cline { 2 - 7 } & 8 & $\begin{array}{l}\text { Sewing } \\
\text { machines }\end{array}$ & & 18 & Tractor & \\
\cline { 2 - 7 } & 9 & Bicycle & & 19 & Solar panel & \\
\cline { 2 - 6 } & 10 & Car & & 20 & & \\
\hline
\end{tabular}

\begin{tabular}{|c|c|c|c|c|c|}
\hline $\begin{array}{l}\text { 412a. Number of } \\
\text { rooms on house } \\
\text { 1.One-roomed } \\
\text { 2.Two-roomed } \\
\text { 3.More than two } \\
\text { rooms }\end{array}$ & $\begin{array}{l}\text { 412b. House } \\
\text { ownership } \\
\text { 1.Owned } \\
\text { 2.Rented }\end{array}$ & $\begin{array}{l}\text { 412c. Electricity } \\
\text { 1.Present } \\
\text { 2.Not present }\end{array}$ & $\begin{array}{l}\text { 412d. Are walls } \\
\text { made of concrete? } \\
\text { 1.Yes } \\
\text { 2. No } \\
\text { 412e. What are the } \\
\text { wall made of? } \\
\text { 1.Burnt bricks } \\
\text { 2.Unburnt bricks } \\
\text { 3.Mud walls } \\
\text { 4.Concrete blocks }\end{array}$ & $\begin{array}{l}412 \mathrm{f} \text {. Floor } \\
\text { is finished } \\
\text { with } \\
\text { cement? } \\
1 . \text { Yes } \\
2 \text {. No }\end{array}$ & $\begin{array}{l}412 \mathrm{~g} \text {. Type of } \\
\text { roof } \\
\text { 1.Iron sheets } \\
\text { 2.Tiles } \\
\text { 3. Grass }\end{array}$ \\
\hline & & & & & \\
\hline
\end{tabular}

413.(512) In general, how happy would you say you are?
1. Very happy
2. Pretty happy
3. Not too Happy

\section{Section 5: $\quad$ MF recipient personality characteristics}

\section{Time preference}

Could you please tell me whether you agree or disagree that these statements describe you personally

\begin{tabular}{|c|c|c|}
\hline 501 & 502 & 503 \\
\hline $\begin{array}{l}\text { I only focus on the short term. } \\
\begin{aligned} \text { 1. } & \text { Agree } \\
\text { 2. } & \text { Disagree }\end{aligned}\end{array}$ & $\begin{array}{l}\text { I live more for the present day than for } \\
\text { tomorrow } \\
\text { 1. Agree } \\
\text { 2. Disagree }\end{array}$ & $\begin{array}{l}\text { The future will take care of itself } \\
\text { 1. Agree } \\
\text { 2. Disagree }\end{array}$ \\
\hline $\begin{array}{l}\text { Do you agree/disagree with this } \\
\text { statement strongly or to some extent? } \\
\text { 1. Strongly } \\
\text { 2. To some extent }\end{array}$ & $\begin{array}{l}\text { Do you agree/disagree with this } \\
\text { statement strongly or to some extent? } \\
\text { 1. Strongly } \\
\text { 2. To some extent }\end{array}$ & $\begin{array}{l}\text { Do you agree/disagree with this } \\
\text { statement strongly or to some } \\
\text { extent? } \\
\text { 1. Strongly } \\
\text { 2. To some extent }\end{array}$ \\
\hline
\end{tabular}

\section{Need for achievement motivation}

For each of the following statements, indicate whether the statement is a true reflection of yourself.

\begin{tabular}{|l|l|l|l|}
\hline 504 & 505 & 506 & 507 \\
\hline $\begin{array}{l}\text { I get restless /annoyed } \\
\text { when I feel am wasting } \\
\text { time }\end{array}$ & $\begin{array}{l}\text { I have always worked hard } \\
\text { in order to be among the } \\
\text { best in my village } \\
\text { 2.Disagree }\end{array}$ & $\begin{array}{l}\text { I am an ambitious person } \\
\text { 1.Agree } \\
\text { 2.Disagree }\end{array}$ & $\begin{array}{l}\text { Improving my life is } \\
\text { important to me. } \\
\text { 2.Disagree } \\
\text { 2.Disagree }\end{array}$ \\
\hline $\begin{array}{l}\text { Do you agree/disagree } \\
\text { with this statement }\end{array}$ & $\begin{array}{l}\text { Do you agree/disagree } \\
\text { with this statement }\end{array}$ & $\begin{array}{l}\text { Do you agree/disagree } \\
\text { with this statement }\end{array}$ & $\begin{array}{l}\text { Do you agree/disagree } \\
\text { with this statement }\end{array}$ \\
\hline
\end{tabular}




\begin{tabular}{|c|c|c|c|}
\hline $\begin{array}{c}\text { strongly or to some extent? } \\
\text { 1. Strongly } \\
\text { 2. To some extent }\end{array}$ & $\begin{array}{c}\text { strongly or to some extent? } \\
\text { 1. Strongly } \\
\text { 2. To some extent }\end{array}$ & $\begin{array}{c}\text { strongly or to some extent? } \\
\text { 1. Strongly } \\
\text { 2. To some extent }\end{array}$ & $\begin{array}{c}\text { strongly or to some extent? } \\
\text { 1. Strongly } \\
\text { 2. To some extent }\end{array}$ \\
\hline
\end{tabular}

\section{Risk preference}

In life, we may have to take decisions to participate in activities that have uncertain outcomes. One example is investment of funds into activities even when we are not sure of the outcomes. The outcomes may be good and we make profit. The outcomes may be bad and we lose all funds invested.

Another example of an uncertain outcome is also given here: An individual asks you for your chair, hoe, spraying pump and promises to return it the next day with a one hundred thousand shilling. If he brings it back with the money, you stand to gain. However he may not and you lose your items. In situations like these different people decide differently.

The next questions assess how you deal with situations like these in life; that have uncertain outcomes.

\begin{tabular}{|c|c|c|c|}
\hline 508 & 509 & 510 & 511 \\
\hline $\begin{array}{l}\text { I enjoy taking part in } \\
\text { decisions with uncertain } \\
\text { outcomes } \\
\text { 1.Agree } \\
\text { 2.Disagree }\end{array}$ & $\begin{array}{l}\text { I avoid activities whose results } \\
\text { depend on chance or whose } \\
\text { outcomes are uncertain } \\
\text { 1.Agree } \\
\text { 2.Disagree }\end{array}$ & $\begin{array}{l}\text { To gain high profits in } \\
\text { business one should take } \\
\text { decisions even when uncertain } \\
\text { of the outcomes. } \\
\text { 1.Agree } \\
\text { 2.Disagree }\end{array}$ & $\begin{array}{l}\text { Would you invest } \\
\text { all of monthly } \\
\text { profit in a new } \\
\text { business venture } \\
\begin{array}{ll}\text { 1. Yes } \quad \text { 2. Not } \\
\text { sure } \\
\text { 3. No }\end{array}\end{array}$ \\
\hline $\begin{array}{l}\text { Do you agree/disagree } \\
\text { with this statement } \\
\text { strongly or to some } \\
\text { extent? } \\
\text { 1. Strongly } \\
\text { 2. To some extent }\end{array}$ & $\begin{array}{l}\text { Do you agree/disagree with } \\
\text { this statement strongly or to } \\
\text { some extent? } \\
\begin{aligned} 1 . & \text { Strongly } \\
2 . & \text { To some extent }\end{aligned}\end{array}$ & $\begin{array}{l}\text { Do you agree/disagree with } \\
\text { this statement strongly or to } \\
\text { some extent? } \\
\begin{aligned} & \text { 1. Strongly } \\
& 2 . \text { To some extent }\end{aligned}\end{array}$ & $\begin{array}{l}\text { Do you } \\
\text { agree/disagree with } \\
\text { this statement } \\
\text { strongly or to some } \\
\text { extent? } \\
\text { 1.Strongly } \\
\text { 2.To some extent }\end{array}$ \\
\hline
\end{tabular}




\section{Focus group discussion guide}

- Number of the village organisation:.

- Date:

- Length (Time spent):
Number of members:

Location/Village.

\section{Introduction:}

Dear respondents

The current study on "Microcredit to women and its contribution to production and household food security" is an academic research project. The aim is to provide information on the microcredit loans that you obtained and their effect on production and food security of your households. We would like to ask you some questions on the loans that you obtained from BRAC, your farm and non-farm MEs, and also about the food intake of your household. All information obtained will be treated with confidentiality. We would like to record your responses on paper and also make audio-recordings of our discussion with you, for purposes of this study only? Can we proceed? Thank you.

1. Why do women access microcredit from BRAC? What are the objectives of borrowing?

2. Explain to what extent the need for improvement of the quality and quantity of food intake motivates women in this area to borrow.

3. What are the main ways in which women spend funds borrowed from BRAC?

4. What is the level of involvement of husbands in the decision to take credit, in loan use and in the running of the MEs?

5. In what farm or non-farm businesses do women invest funds borrowed from BRAC?

6. What changes do borrowers register in their farm and non-farm ME as result of borrowing?

7. What are the sources of funds for loan repayment? How is the involvement of husbands, other family members and VO members in loan repayment?

8. What challenges if any do borrowers face in repayments loans taken from BRAC and how these resolved?

9. How common is loan defaulting and how are defaults handled by the village organisations?

10. What changes have generally taken place in your lives after you joined the borrowing programme?

11. Why and when do women stop borrowing from BRAC?

12. What other challenges do you face with respect to loans taken from BRAC and what changes in the program do you propose?

Thank you so much. I will now share with you some information about how to feed our families. This is not part of the study. It is for your own personal development.

NB: This instrument was adopted for the NB focus group discussions. 


\section{Summary}

The general objective of this study was to assess the contribution of microcredit to women in Uganda to production and household food security and to determine the factors that enhance or limit food security outcomes.

Food insecurity as indicated by levels of food availability, food access and nutritional status remain a big challenge in Uganda. While the majority of the population rely on subsistence agricultural production as a source of food and livelihoods, food availability is hampered by among others unpredictable weather patterns, depleted soils, and limited use of agricultural inputs, that all impair optimal agricultural production. Food access on the other hand is hampered by high food prices, and high levels of poverty. As a method of survival, people in rural areas supplement agricultural activities with non-farm self-employment activities. Despite many societal, cultural and economic limitations they face, women play key roles in household food security and livelihood maintenance. They have thus attracted the attention of many government and non-government partners, who aim at improving the welfare of the poor. With the majority of the rural poor being unbanked, lack of credit is commonly cited as a hindrance to development of agricultural and non-farm activities. Provision of microcredit to women in agrarian communities is promoted as a means to transform rural livelihoods, leading to income and food security. However, despite all the enthusiasm about the potential benefits of microcredit, evidence for its beneficial effects remains mixed. Observed effects are context-specific, with indications that microcredit may not be a silver bullet to transform the lives of the rural poor, and may not be as beneficial as previously thought. The purpose of this study was to contribute to the on-going debate by evaluating the contribution of microcredit to agricultural production, microenterprise performance, food security, and the factors associated with recorded outcomes. 
The study was conducted among female microcredit recipients of BRAC, one of the largest micro lenders in Uganda, with operations in rural areas. To the best of our knowledge no such study had been conducted among female agrarian borrowers in Uganda before. The study is unique in its focus on rural agrarian female borrowers. Most studies on microcredit have been done in Asia, where the microfinance movement started. The study entailed two alternative methods of evaluating outcomes of microcredit. The overall study design was a panel approach, involving two waves of data collection. In one analytical approach, baseline data for a group of existing borrowers (Old borrowers=OB) and incoming borrowers $($ New borrowers=NB) before they received their first loan, was used in a quasi-experimental cross-sectional design to assess the effect of borrowing as the difference between the two groups using propensity score matching.

In an alternative approach, two waves of data for the NB and a control group (CG) of women who never borrowed from BRAC or other MFI, was subjected to difference-in-difference analysis (DID), with Kernel matching, to assess differences between borrowers and nonborrowers.

In Chapter 2 we investigate the extent to which the objectives and design of the BRAC microfinance program match the expectations, context and characteristics of female borrowers. We found that BRAC uses a modified 'Grameen-like' group-lending model to provide small, high-interest rate production loans, and follows a rigorous loan processing and recovery procedure. BRAC microfinance clients are mainly poor subsistence farmers who derive income from diverse farming and non-farm activities. The major objective to borrow is to meet lumpsum monetary needs usually for school fees and building expenses, and for investment in informal small non-farm businesses. Many borrowers use diverse sources of funds to meet 
repayment obligations. Although defaulting on loans is quite rare, stress caused by weekly loan repayment and resolution of lump-sum cash needs were identified as reasons for women to stop borrowing. Limited loan amounts, the diversion of loans to non-production activities, the size of the businesses, and the weekly recovery program without a grace period were identified as constraints which may diminish the contribution of microcredit to ME expansion and income increase.

Chapter 3 provides results of our investigation of the effects of microcredit on the performance of non-farm microenterprises (MEs) run by small-holder female farmers. We did this for respondents with non-farm MEs. We compared parameters for new borrowers (NB), before and after they received their first loan, and a control group (CG) of women who never received credit. In an alternative approach, baseline data from current borrowers (OB) was compared to NB data. Differences between OB to NB parameters were obtained using propensity score matching (PSM). PSM revealed positive effects of microcredit on funds used to restock businesses, and on the monetary value of the MEs. Furthermore, we found older, unmarried, and risk-averse females to obtain relatively low profits from their MEs. No evidence of improvement of profits from MEs, which is needed for food security improvement of households, was recorded. This is probably due to the short time period of analysis.

In chapter 4 we assessed changes in expenditure and outputs for agricultural production (crop and animal production) when women access microcredit. We used a quasi-experimental design with both quantitative and qualitative survey methods to obtain socio-demographic, personality and microenterprise (ME) characteristics of existing borrowers (OB) and incoming borrowers (NB) before they received their first loan. To assess the effect of microcredit, we measured production input expenditures for crop and animal production, crop harvests in the season before 
the study, and the animal wealth for the respondents. We used propensity score matching to assess differences between OB and NB groups. While the lack of credit is widely considered a constraint to agricultural production for resource-constrained female farmers, PSM results revealed lower recurrent crop production input expenditures for current borrowers than incoming borrowers. Current borrowers also spent more time on garden work and yet had lower monetary value of harvested crops than in-coming borrowers. Likewise, we found no evidence of increase in input expenditures for animal production after borrowing. The numbers of borrowers that kept most of the common animal types was lower than that for non-borrowers. Monetary worth of some commonly kept animals was also lower for borrowers. The subsistence nature of female crop and animal production does not seem to have room for extra investment and commercialisation. The nature of production, coupled with the risky nature of agricultural enterprises, could be a discouraging investment of microloans in farming activities. The need for weekly loan repayment may promote engagement in non-farm activities, at the expense of crop production, leading to lower harvests among borrowers. The negative trend in animal production was also probably for the same reasons. In addition, the sale of animals to obtain funds for loan repayments may explain the depletion of animal stocks.

In chapter 5 we investigate the effects of participation of women in a microcredit program on household food security parameters of female borrowers. We explore the modes of food acquisition, dietary diversity, calorie and protein intake, and qualitative food insecurity measures for different categories of respondents. Results revealed a decline in food security following the uptake of microcredit. In particular, the analysis reveals robustly lower dietary diversity among long-time borrowers than among new borrowers, and larger reductions in dietary diversity scores among new borrowers, after one year, compared to controls. The reduction in dietary diversity 
was traced to a reduction in animal-source food, fruit and sugar intake. This may be partly explained by an apparent shift from own production to reliance on food purchase by households, which is not accompanied by substantial increase in income. The burden of loan repayment and other household members relegating the burden of food provision to women after borrowing may further explain the observed result.

In chapter 6 we discuss the key findings of the study. While we find increase in monetary value of borrowers non-farm MEs, investment in farming MEs and other ME performance indicators did not improve. Overall, we find that taking microcredit did not lead to improved farm and non-farm income or food security among the rural women borrowers studied. This may be because of extreme poverty among borrowers and the loan conditions which are not conducive for investment in agriculture. The periods covered by the analysis is relatively short (1 year for the DID analysis and average of 97 weeks for PSM). Studies over longer periods are recommended to establish long term outcomes of microcredit in similar resource-constrained settings. 


\section{Acknowledgements}

I am highly indebted to the Netherlands government, under the Nuffic Programme, for funding my $\mathrm{PhD}$ project and the SEPON Foundation for providing supplementary funding. I sincerely thank Kyambogo University for granting me study leave to undertake the PhD project.

I thank my promotor Prof. Gerrit Antonides for taking me under his wing and guiding me on the project. I appreciate all the support accorded to me in the different stages of the project; from the time I applied for the PhD grant, to my promotion ceremony. I appreciate your dedication to the advancement of my work, the timely and quality comments you always gave me, the continuous guidance and the mentoring that enabled me to improve my scholarly, analytical and writing skills. Your expertise, kindness and gentle demeanor were invaluable to successful completion of my PhD.

I also acknowledge the support and contribution of my co-promotor Dr. Johan van Ophem. Your valuable inputs in the many brainstorming; data analysis and drafts review sessions of my work, greatly enriched this thesis. In addition, you and your family extended a hand of friendship to me at the time when I needed it most. In this regard, I extend my heartfelt thanks to you, madam Roelien Timmerman and Julia, for the kind hospitality, love and sharing that enriched my experience of the Netherlands' unique culture, including its special water management systems.

Members of the committee, Prof. Dr Niehof, Prof. Dr Bulte, Prof. Dr Heijman and Prof. Dr de Graaf, thank you for accepting to be part of the thesis reading committee and the public defence.

I am also grateful to the research office of BRAC Uganda whose desire to improve the lives of the poor women they serve, permitted me to work with their microcredit clients. Special 
thanks go to Ricardo and Munshi and the loan officers of the Mukono 1 and Mukono 2, Nkokonjeru, Buikwe, Kasawo and Lugazi, who linked us to the study respondents. I am very grateful to the study respondents; who patiently sat through the long questionnaire interviews and provided the data for the study.

Special thanks go our team of research assistants who braved the tropical weather and terrain in search of study participants. The resilience of Seera, Namasaba, Afra, Enoch and Lwanga Ausi, enabled us to obtain quality data. I also thank Hong, for her quality input in data analysis.

I am deeply indebted to the administrative team of the Economics of Consumers and Households chair group; Karen, Dineke, Gre and Betty, for the enduring and warm welcome each time I approached you. I greatly appreciate the support you accorded me on this project. I also thank other colleagues in the friendly chair group of Economics of Consumers and Households; Michelle, Pierre, Jannette and Anouk for the special and ever friendly chair group support. Special thanks go to my office mates Muriel, Ernst-Jan, Jiaqi, and Lieke for making the office a conducive place to work. Manon, I treasured the times we shared the office and our out office interactions. Thank you for the friendship and the sharing. I would like to thank Corry for support with End-note and Jack Peerlings for his support under the PhD mentoring program. Special thanks go to Francesco, for the insightful discussions and contributions that enriched the microfinance debate in the thesis and for his input in panel data analysis and the food security chapter. I am also grateful to Muriel and Nico who reviewed my chapter drafts and provided invaluable comments and suggestions. I thank Marion for the support with illustrations of my work, Billy and Gerald for designing the thesis cover page. 
Valerie, Aisha and Agbeko, I will always treasure your special and warm comradeship, fellowship and support. Thanks to Prossy, John, Okello, TauB, Stella, Christina, Onzima, Zacharia, Maria, Margaret, Dawitt, Florence, Leah, Daniel, Nsibo and Nsubuga for the support and encouragement. Special thanks go to my bible study friends; Tabby, Nowella, Jaap, Doortje, Felicidade, Chris and Tilly. Tabby and Ernst-Jan thanks for accepting to be my paranymphs.

I am ever grateful to my late father Charles Mayanja for believing in me. It hurts that you did not live to see me graduate. Thanks go to my Kooki and Bulucheke families; Maria, Clet and Sylivia, my mother, mother-in-law and father-in-law, and siblings. I also thank Immaculate, Aida, Mujuzi, Lwanga, Kissa, Wambede, other members of the Cornerstone family and colleagues at Kyambogo University for keeping the work we do together going in my absence. Special thanks go to my friend and neighbour Allen for the unwavering motherly support to my children. I also thank Shiwuma, Mercy, Otim and Florence for the support to my son Samwiri, during my absence.

Last but not least I would like to thank my Khafu-Muyonga family for standing with me on this journey. My children Atiila, Aliinda and Muyonga Samwiri, stood with me and kept me in their thoughts and prayers, as they tried to make sense of my long absences because of my scholarly pursuits. Having watched at close range my aspirations, struggles and achievements leave me no doubt that you will emulate and strive for greater heights. The two Nakuya's, thank you for keeping-fort and taking care of my children, during my absence. In a special way, I would like to express my profound and sincere gratitude to my husband John Muyonga. Thank you for being a single-father to our children during my absence. Thank you for the emotional support and mentoring during my study. You encouraged me, motivated me, rebuked me, and yet held my hand from the beginning to the end of this journey. 


\section{About the author}

Faith MM Namayengo was born in Masaka, Uganda. She attended Luwero Girls Primary School, (Luwero) and St. John Bosco Katende Primary School, (Mpigi). She attained Uganda Certificate of Education (UCE) and Uganda Advanced Certificate of Education (UACE) from Kings College Budo, from where she enrolled into Makerere University and pursued BSc Food Science and Technology. Upon graduation, she started her working life as Fisheries Officer in the Ministry of Agriculture, Animal Industry and Fisheries, in which she worked as a Fisheries Inspector, before settling down to an academic career as a lecturer, Department of Human Nutrition, Kyambogo University.

In 1994, Faith graduated with a post graduate Diploma (Distinction), in Maternal and Child Nutrition: The Prevention of the Main Nutrition Disorders in the World. This was supported by the Netherlands Fellowship Program. In 1997, she was awarded UNU scholarship to pursue MSc Applied Human Nutrition, University of Nairobi Kenya. Her M.Sc. research was entitled "Substitution of milk with lactic-fermented maize and beans, in the diet for severely malnourished children (6-59 months)." In 2004, under the Fulbright Fellowship Program, Faith took post graduate Nutrition Science courses at the University of Alabama, Birmingham. In 2012, Faith enrolled as a PhD candidate in Wageningen University. She currently stays in Kampala, Uganda with her family. 


\section{Completed Training and Supervision Plan}

Wageningen School of Social Sciences (WASS)

M. Mayanja Faith Namayengo

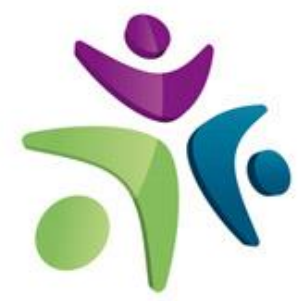

Wageningen School

of Social Sciences

\section{Name of the learning activity \\ A) Project related competences}

\section{Department/Institute}

Year

ECTS*

Quantitative Research Methods and

WUR

2013

6

Statistics, MAT 22306

Qualitative Data Analysis, YRM 60806

WUR

2013

6

Summer school: Experiments in

University of Groningen

developing countries

\section{B) General research related competences}

WASS

2012

1

Influence of microcredit on farming and

WASS PhD Day conference

2015

1

non-farming enterprises in rural agrarian and

communities'

Food in the bio-based economy,

Sustainable Provision and Access,

Wageningen

Working with EndnoteX5

WUR Library

2012

Research Design and Research methods, WUR

2012

6

YRM 20806

Research Methodology Course: Topic to

WASS

2012

4

proposal

Information Literacy for PhD including WUR Library

2013

0.6

Endnote

Writing PhD Research Proposal

WUR

2012/2013 


\section{C) Career related competences/personal development}

Techniques of Writing and Presenting a WGS

Scientific paper

Project and Time management

Scientific Publishing

MCB/ECH/RME PhD Colloquia

Economics cluster seminar series
WGS

WGS

WUR

Economics
2012

2012

1.5

2016

0.3

Total

37.6

* One credit according to ECTS is on average equivalent to 28 hours of study load 


\section{Funding}

The research described in this thesis as well as printing and other associated costs was financially supported by the Nuffic Netherlands Fellowship Program.

Financial support from the SEPON Foundation for longitudinal data collection is also acknowledged. 